\title{
The effect of driving conditions and ambient temperature on energy flow and gaseous emissions from light-duty gasoline-electric hybrid vehicles
}

By

Aaron Loiselle, B. Eng.

A thesis submitted to the Faculty of Graduate Studies and Research in partial fulfillment of the requirements for the degree of

Master of Applied Science

Ottawa-Carleton Institute of Environmental Engineering

Carleton University

Ottawa, Ontario

May, 2008

Copyright $(\mathcal{C}$ 


$\begin{array}{ll}\text { Library and } & \text { Bibliothèque et } \\ \text { Archives Canada } & \text { Archives Canada } \\ \begin{array}{l}\text { Published Heritage } \\ \text { Branch }\end{array} & \begin{array}{l}\text { Direction du } \\ \text { Patrimoine de l'édition }\end{array} \\ \begin{array}{l}\text { 395 Wellington Street } \\ \text { Ottawa ON K1A ON4 } \\ \text { Canada }\end{array} & \begin{array}{l}\text { 395, rue Wellington } \\ \text { Ottawa ON K1A ON4 }\end{array} \\ \end{array}$

Your file Votre référence ISBN: 978-0-494-44050-6

Our file Notre référence

ISBN: 978-0-494-44050-6

NOTICE:

The author has granted a nonexclusive license allowing Library and Archives Canada to reproduce, publish, archive, preserve, conserve, communicate to the public by telecommunication or on the Internet, loan, distribute and sell theses worldwide, for commercial or noncommercial purposes, in microform, paper, electronic and/or any other formats.

The author retains copyright ownership and moral rights in this thesis. Neither the thesis nor substantial extracts from it may be printed or otherwise reproduced without the author's permission.
AVIS:

L'auteur a accordé une licence non exclusive permettant à la Bibliothèque et Archives Canada de reproduire, publier, archiver, sauvegarder, conserver, transmettre au public par télécommunication ou par l'Internet, prêter, distribuer et vendre des thèses partout dans le monde, à des fins commerciales ou autres, sur support microforme, papier, électronique et/ou autres formats.

L'auteur conserve la propriété du droit d'auteur et des droits moraux qui protège cette thèse. $\mathrm{Ni}$ la thèse ni des extraits substantiels de celle-ci ne doivent être imprimés ou autrement reproduits sans son autorisation.
In compliance with the Canadian

Privacy Act some supporting forms may have been removed from this thesis.

While these forms may be included in the document page count, their removal does not represent any loss of content from the thesis.
Conformément à la loi canadienne sur la protection de la vie privée, quelques formulaires secondaires ont été enlevés de cette thèse.

Bien que ces formulaires aient inclus dans la pagination, il n'y aura aucun contenu manquant.

\section{Canadä}


The undersigned hereby recommend to the Faculty of Graduate Studies and Research acceptance of the thesis

\title{
The effect of driving conditions and ambient temperature on energy flow and gaseous emissions from light-duty gasoline-electric hybrid vehicles
}

\author{
Submitted by \\ Aaron Loiselle \\ Student \#: 100301104 \\ in partial fulfillment \\ of the requirements for the degree of
}

Master of Applied Science

Thesis Supervisor

Thesis Supervisor (print)

Chair

Chair (print)

Date

Carleton University

Ottawa, Ontario, Canada

May 15, 2008

ii 


\section{Abstract}

The effects of five transient drive cycles (LA4, LA92, US06, HWFET, NYCC), and two steady speeds ( 40 and $80 \mathrm{~km} / \mathrm{hr}$ ), at two ambient temperatures, on emissions of $\mathrm{CO}, \mathrm{NMOG}, \mathrm{NO}_{x}, \mathrm{CO}_{2}, \mathrm{CH}_{4}$ and $\mathrm{N}_{2} \mathrm{O}$ were analyzed for four gasoline-electric hybrid vehicles and one spark-ignition vehicle operated on chassis dynamometers. Battery and braking energy values, the cumulative time the engine was off during a drive cycle, and the number of engine restarts per drive cycle were also estimated. Pollutant emissions were below detection limits in many cases and elevated but below regulated limits during coldstart and aggressive cycles. Testing at $-18^{\circ} \mathrm{C}$ increased pollutant emissions by up to 65 times and greenhouse gas emissions by up to 23 times relative to $20^{\circ} \mathrm{C}$ tests. Hybrid vehicle engine off time was proportional to pollutant emission rates of $\mathrm{CO}, \mathrm{HC}$ and $\mathrm{NO}_{x}$. The effects of augmented braking and battery net energy change are also discussed.

iii 


\section{Acknowledgements}

My co-supervisor Lisa Graham started this project at Environment Canada and allowed me to join during the tail end of testing. She readily provided logistical assistance, information and insight into subjects with which I was unfamiliar.

My co-supervisor, Professor Deniz Karman at the Civil and Environment Engineering Department at Carleton University, took me on as a graduate student and I am grateful for it. During all parts of my thesis he provided guidance and information.

Martha Christenson, a former Carleton University graduate student, not only made a significant number of data files for this project, but also assisted me in becoming acquainted with the project material and procedures.

My thanks to the staff, at the Emissions Research and Measurement Division of Environment Canada, who carried out all the testing and emission speciation for this project. The drivers, chemical technologists and technicians were patient and helpful with all of my questions.

I would like to also thank my wife, Kristin Loiselle-Lapointe for providing support and periodic reality checks.

iv 


\section{Table of Contents}

Abstract iii

Acknowledgments iv

List of Tables $\quad x$

List of Figures $\quad$ xii

List of Symbols $\quad$ xvii

1 Introduction 1

1.1 Objectives and Contributions .................. 4

2 Literature Review of Hybrid Electric Vehicles and Gaseous Emissions from Internal Combustion Engines $\quad 6$

2.1 Gaseous Emissions from Internal Combustion Engines . . . . . . . 7

2.1.1 Air-Fuel Ratio and Gaseous Emissions . . . . . . . . . . 10

2.1.2 Formation of Carbon Monoxide and Hydrocarbons . . . . . . 12

2.1.3 Formation of Carbonyl Compounds . . . . . . . . . . . . . . . 14

2.1 .4 Oxides of Nitrogen Formation . . . . . . . . . . . . . . 16

2.1.5 Greenhouse Gas Emissions . . . . . . . . . . . . . . . . . . . 17

2.2 Vehicle Emission Control Technology . . . . . . . . . . . . . . . . . . 20

V 
2.3 Types of Hybrid Electric Vehicles . . . . . . . . . . . . . . . . . 21

2.3 .1 Series . . . . . . . . . . . . . . . . . 22



2.3.3 Combined . . . . . . . . . . . . . . . . . . . 24

2.4 Braking Strategies . . . . . . . . . . . . 26

2.4.1 Series Regenerative Braking . . . . . . . . . . . 26

2.4.2 Parallel Regenerative Braking . . . . . . . . . . . . 28

2.5 Energy Consumption and Recuperation . . . . . . . . . 30

2.5 .1 Braking Energy Losses . . . . . . . . . . . . . . 31

2.5.2 Typical Braking and Traction Energy Values . . . . . . . . 33

2.6 Unique Chassis Dynamometer Test Procedures . . . . . . . . . . . 34

3 Chassis Dynamometer Operation $\quad 37$

3.1 The Chassis Dynamometer . . . . . . . . . . . . . . . 38

3.2 Dynamometer Computer Calculations . . . . . . . . . . . . . 39

3.2 .1 Distance . . . . . . . . . . . . . . . . . . . . . . 39

3.2.2 Speed and Acceleration . . . . . . . . . . . . 40

3.2.3 Torque . . . . . . . . . . . . . . . . . . . . . 40

3.2.4 Motor Simulation Force $\ldots \ldots \ldots \ldots$. . . . . . . 41

3.2 .5 Friction Force . . . . . . . . . . . . . . . . . 41

3.2.6 Roller Force . . . . . . . . . . . . . . . . . . . . . . 41

3.3 Road Load Force . . . . . . . . . . . . . . . . . . . . . 42

3.4 Inertial Masses . . . . . . . . . . . . . . . . . . 45

3.5 Augmented Braking $\ldots \ldots \ldots \ldots \ldots \ldots \ldots$

4 Experimental Procedure $\quad 48$

4.1 Driving Cycles . . . . . . . . . . . . . . . . 50

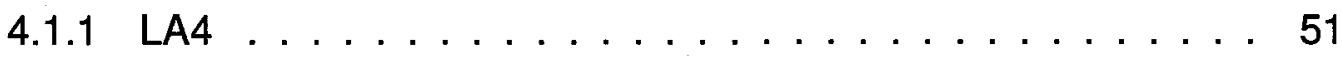

vi 
4.1 .2 LA92 . . . . . . . . . . . . . . . . . . . . . . 52

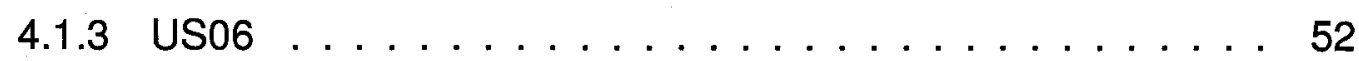

4.1 .4 HWFET $\ldots \ldots \ldots \ldots \ldots \ldots \ldots \ldots \ldots$

4.1 .5 NYCC . . . . . . . . . . . . . . 54

4.1 .6 Steady State . . . . . . . . . . . . . . 55

4.2 Vehicles Studied . . . . . . . . . . . . . . . . 55

4.2 .12000 Honda Insight $\ldots \ldots \ldots \ldots$

4.2.2 2002 Cabriole SmartCar . . . . . . . . . . . . . . . . 58

4.2 .32003 Honda Civic Hybrid . . . . . . . . . . . . . . . 58

4.2 .42004 Toyota Prius . . . . . . . . . . . . . . . . . . 58

4.2 .52005 Ford Escape Hybrid . . . . . . . . . . . . . . 59

4.3 Vehicle Condition and Mileage . . . . . . . . . . . . . 59

4.4 Vehicle Preconditioning and Fuel Properties . . . . . . . . . 60

4.5 Chassis Dynamometer Calibration and Operation . . . . . . . . . 61

4.6 Sampling Methodology . . . . . . . . . . . . . . . 63

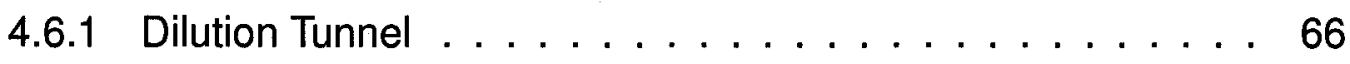

4.6.2 Detection Limits of Measured Gaseous Emissions . . . . . 66

4.6.3 Cycle and Modal Gaseous Emissions Collection and Measurement . . . . . . . . . . . . . . 6 67

4.6.4 Collection and Speciation of Carbonyl Compounds and Nitrous Oxide . . . . . . . . . . . . . . 70



4.6.6 Test and Sample Validation . . . . . . . . . . . 76

5 Data Analysis $\quad 77$

5.1 Dilution Factor $\ldots \ldots \ldots \ldots \ldots \ldots$

vii 
5.2 Emission Factors of Carbon Dioxide, Carbon Monoxide, Hydrocarbon and Oxides of Nitrogen . . . . . . . . . . . . . . 79

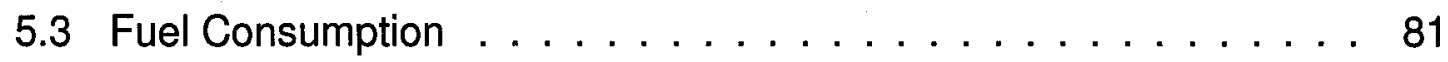

5.4 Unregulated Emission Factors $\ldots \ldots \ldots$. . . . . . . . . 82

5.4.1 Carbonyl Compounds . . . . . . . . . . . . . . 82

5.4 .2 Nitrous Oxide . . . . . . . . . . . . . . . . . 83

5.5 Battery Change in State of Charge . . . . . . . . . . . . 83

5.6 Net Energy Change . . . . . . . . . . . . . . . . . . . . . . 85

5.7 Energy Consumption and Recuperation . . . . . . . . 86

5.7 .1 Assumptions . . . . . . . . . . . . . 86

5.7.2 Battery Energy Calculations . . . . . . . . . . . . . . 87

5.7.3 Chassis Dynamometer Roller Energy Calculations . . . . . 89

5.8 Engine-Off Time and Number of Engine Restarts . . . . . . . . 90

5.9 Vehicle Specific Power . . . . . . . . . . . . . . . . . . . . . . 92

5.9.1 Modal Speed Data: Time Synchronization . . . . . . . . . . 93

6 Results 96

6.1 Battery and Braking Energies . . . . . . . . . . . 97

6.1 .1 Battery Activity . . . . . . . . . . . . . 97

6.1 .2 Battery Energies . . . . . . . . . . . . . . . . . . 98

6.1.3 Vehicle Energy Comparisons . . . . . . . . . . . . 105

6.1 .4 Braking Energies . . . . . . . . . . . . . . . . . 109

6.2 Greenhouse Gas and Regulated Emissions . . . . . . . . . . . 110

6.2.1 Battery Net Energy Change and Emissions . . . . . . . 111

6.2.2 Effect of Drive Cycle and Operating Temperature on Gaseous Emissions . . . . . . . . . . . . . . . . . 114

viii 
6.3 Internal Combustion Engine Restarts, Engine-Off Time and Gaseous Emissions . . . . . . . . . . . . . . . . . . . 125

6.4 Carbonyl Compound Emissions . . . . . . . . . . . . . . . . . 132

6.5 Documentation of Data . . . . . . . . . . . . . . 135

7 Discussion $\quad 137$

7.1 Battery and Braking Energies . . . . . . . . . . . . 138

7.1 .1 Energy Values . . . . . . . . . . . . . . . . . . . 141

7.1.2 Drive Cycles and Battery Energies . . . . . . . . . . 143

7.1.3 Battery Energies and Emissions . . . . . . . . . . 145

7.1.4 Battery Activity and Operating Temperature . . . . . . 146

7.1.5 Augmented Braking . . . . . . . . . . . . . . . 147

7.2 Integrated Gaseous Emissions ．. . . . . . . . . . . . . 148

7.2.1 Drive Cycle and Emission Factors . . . . . . . . . . . 149

7.2.2 Ambient Temperature and Emission Factors . . . . . . . . . 151

7.2.3 Battery Net Energy Change and Emission Factors . . . . . 154

7.2.4 Carbonyl Compound Emission Factors . . . . . . . . . 157

7.3 Effect of Engine Off Time and Number of Engine Restarts on Gaseous Emission Rates . . . . . . . . . . . . . . . . . 158

8 Conclusions and Recommendations 162 Appendix: DVD Containing All Data 


\section{List of Tables}

2.1 United States Environmental Protection Agency Emission Factors for selected vehicles driven over the FTP drive cycle $\ldots \ldots \ldots$

2.2 U.S. EPA, CARB and EURO emission standards . . . . . . . . . 9

2.3 Emission factors of selected carbonyl species from different studies 15

2.4 Greenhouse gases and their global warming potentials . . . . . . 18

2.5 Simulated braking and total cycle energy values for electric vehicles from two studies . . . . . . . . . . . . . . . . 33

4.1 Transient drive cycles and their specifications . . . . . . . . 51

4.2 Test Vehicle Specifications . . . . . . . . . . . . . . . 56

4.3 Test vehicle mileages at the end of testing . . . . . . . . . 60

4.4 Test fuel specifications . . . . . . . . . . . . . . . . . 61

4.5 Pollutant detection limits in $\mathrm{g} / \mathrm{km} \ldots \ldots \ldots 7$

4.6 Carbonyl compound detection limits in $\mathrm{g} / \mathrm{km} \ldots \ldots . \ldots 68$

6.1 Average battery activities of the Escape Hybrid and Prius transient drive cycle tests at $-18^{\circ} \mathrm{C}$ and $20^{\circ} \mathrm{C} \ldots \ldots \ldots \ldots$

6.2 Escape Hybrid: Braking energy distribution between regenerative braking (reg), friction brakes and augmented braking (aug) . . . 110

6.3 Prius: Braking energy distribution between regenerative braking (reg), friction brakes and augmented braking (aug) . . . . . . 110 $x$ 
6.4 Tests with $N E C$ greater than $1 \%$ for the Prius, Escape Hybrid, Civic Hybrid and Insight at $20^{\circ} \mathrm{C}$ and $-18^{\circ} \mathrm{C} \ldots \ldots \ldots \ldots$

$6.5-18^{\circ} \mathrm{C} \mathrm{NO}_{x}$ emission factor fraction of $20^{\circ} \mathrm{C} \mathrm{NO} \mathrm{NO}_{x}$ emission factor . . 119

6.6 Average ICE off times as a percentage of drive cycle duration for all transient drive cycles . . . . . . . . . . . . . . . . . . . 125

6.7 Average number of ICE restarts for all transient drive cycles . . . . 126

7.1 Transient drive cycle cumulative acceleration and deceleration times 144

7.2 Number of tests conducted that included carbonyl speciation . . . 158 


\section{List of Figures}

2.1 Empirical relationship between the $\mathrm{A} / \mathrm{F}$ ratio and $\mathrm{HC}, \mathrm{CO}$ and $\mathrm{NO}_{x}$ concentrations for internal combustion . . . . . . . . . . . 11

2.2 Formation of 2-butanone from 2-butanol . . . . . . . . . . . . 14

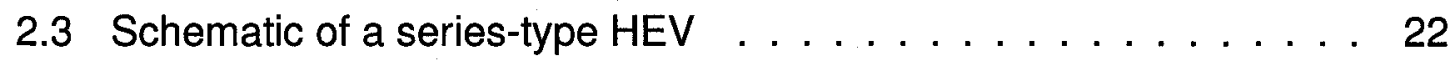

2.4 Schematic of a parallel-type HEV . . . . . . . . . . . . 23

2.5 Schematic of a combined-type HEV . . . . . . . . . . 25

2.6 Series regenerative braking system . . . . . . . . . . . . . 27

2.7 Braking forces for a parallel regenerative braking system . . . . . . 29

3.1 Twin-roller chassis dynamometer schematic . . . . . . . . . . . 38

3.2 Chassis dynamometer friction force and roller speed . . . . . . . 42

3.3 Relationship between road load force and vehicle speed; Escape Hybrid NYCC test . . . . . . . . . . . . . . . . 46 46

4.1 The LA4 speed-time trace . . . . . . . . . . . . . . . . . . 52

4.2 The LA92 speed-time trace . . . . . . . . . . . . . . . . . . . 53

4.3 The US06 speed-time trace . . . . . . . . . . . . . . . 53

4.4 The HWFET speed-time trace . . . . . . . . . . . . . . . . . 54

4.5 The NYCC speed-time trace $\ldots \ldots \ldots \ldots \ldots \ldots$

4.6 The Honda integrated motor assist system . . . . . . . . . . 57

4.7 Toyota's second generation Hybrid Synergy Drive . . . . . . . . . . 59 xii 
4.8 The SmartCar on a chassis dynamometer . . . . . . . . . . . . 63

4.9 Constant volume sampler schematic . . . . . . . . . . . . 64

4.10 Test vehicle schematic . . . . . . . . . . . . . . . . . . . 65

4.11 ERMD regulated emission bags (a) and real-time gaseous bench (b) 69

4.12 Schematic of the chassis dynamometer gas analyzer bench . . . . 70

4.13 ERMD sample train for unregulated emissions . . . . . . . . . . 71

4.14 MKS Instruments Inc. mass flow controller (5000 SCCM) . . . . 73

4.15 ERMD unregulated emission sample train - carbonyl sampling . . 74

4.16 AEMC Instruments MD510 Series Ammeter (a) and Wavetek Meterman Multimeter $(b) \ldots \ldots \ldots \ldots$. . . . . . . . . . . . . . . .

5.1 Battery Related Energies . . . . . . . . . . . . . . . 88

5.2 Difference in speed decrease to $\mathrm{CO}_{2}$ emission rate decrease during a NYCC test of the Prius . . . . . . . . . . . . . . . . . 91

5.3 Schematic of a typical $\mathrm{CO}_{2}$ declination curve over time $\ldots \ldots . .91$

5.4 Vehicle specific power and $\mathrm{CO}_{2}$ emission rate before the VSP was

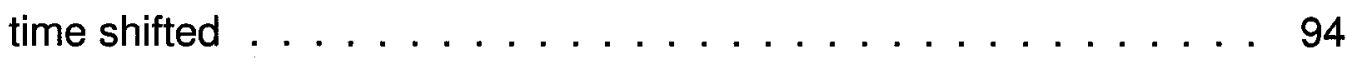

5.5 Vehicle specific power and $\mathrm{CO}_{2}$ emission rate after the speed was time shifted . . . . . . . . . . . . . . . . . . . . . . . . . . 94

6.1 Battery energy distribution for the Escape Hybrid at $-18^{\circ} \mathrm{C}$; averages of multiple tests . . . . . . . . . . . . . . . . . . . 99

6.2 Battery energy distribution for the Escape Hybrid at $20^{\circ} \mathrm{C}$; averages of multiple tests . . . . . . . . . . . . . . . 100

6.3 Battery energy distribution for the Prius at $-18^{\circ} \mathrm{C}$; averages of multiple tests . . . . . . . . . . . . . 100

6.4 Battery energy distribution for the Prius at $20^{\circ} \mathrm{C}$; averages of multiple tests . . . . . . . . . . . . . . . . . . . . 101

xiii 
6.5 Average regenerative braking energy to total cycle energy ratios and average emission factors . . . . . . . . . . . . . . . 102

6.6 Average battery energies to average $T C E$ ratios for Escape Hybrid tests at $-18^{\circ} \mathrm{C} \ldots \ldots \ldots \ldots$. . . . . . . . . . . 102

6.7 Average battery energies to average TCE ratios for Escape Hybrid

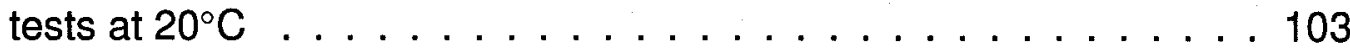

6.8 Average battery energies to average $T C E$ ratios for the Prius tests at $-18^{\circ} \mathrm{C} \ldots \ldots \ldots \ldots \ldots \ldots \ldots$

6.9 Average battery energies to average $T C E$ ratios for the Prius tests



6.10 Regenerative braking energies of the Prius and Escape Hybrid at $-18^{\circ} \mathrm{C}$; average of multiple tests $\ldots \ldots \ldots \ldots \ldots$

6.11 Regenerative braking energies of the Escape Hybrid, with and without (NO aug) augmented braking, and of the Prius at $20^{\circ} \mathrm{C}$; average of multiple tests . . . . . . . . . . . . . 107

6.12 Internal combustion engine battery charging energy of the Prius and Escape Hybrid at $-18^{\circ} \mathrm{C}$; average of multiple tests . . . . . . . 107

6.13 Internal combustion engine battery charging energy of the Prius and Escape Hybrid at $20^{\circ} \mathrm{C}$; average of multiple tests . . . . . . 108

6.14 Battery discharging energy of the Prius and Escape Hybrid at $20^{\circ} \mathrm{C}$; average of multiple tests . . . . . . . . . . . . . 108

6.15 Battery discharging energy of the Prius and Escape Hybrid at $-18^{\circ} \mathrm{C}$; average of multiple tests . . . . . . . . . . . . . 109

6.16 Example of the Prius $\mathrm{CO}_{2}$ emission factor correction for the $2 \mathrm{XNYCC}$ cycle at $-18^{\circ} \mathrm{C}$ based on $N E C \ldots \ldots \ldots \ldots \ldots$

6.17 Example of the Civic Hybrid $\mathrm{CO}_{2}$ emissions and $\mathrm{NEC}$ for the HWFET, $2 \times N Y C C$ and $2 x U S 06$ drive cycles at $20^{\circ} \mathrm{C} \ldots \ldots 112$ xiv 
6.18 CO emission factors averaged over multiple tests for the SmartCar,

Prius, Escape Hybrid, Civic Hybrid and Insight at $20^{\circ} \mathrm{C} \ldots \ldots \ldots$

6.19 CO emission factors averaged over multiple tests for the SmartCar,

Prius, Escape Hybrid, Civic Hybrid and Insight at $-18^{\circ} \mathrm{C} \ldots \ldots .116$

6.20 $\mathrm{NO}_{x}$ emission factors averaged over multiple tests for the SmartCar,

Prius, Escape Hybrid, Civic Hybrid and Insight at $20^{\circ} \mathrm{C} \ldots \ldots \ldots 116$

6.21 $\mathrm{NO}_{x}$ emission factors averaged over multiple tests for the SmartCar,

Prius, Escape Hybrid, Civic Hybrid and Insight at $-18^{\circ} \mathrm{C} \ldots \ldots$

6.22 NMOG emission factors averaged over multiple tests for the Smart-

Car, Prius, Escape Hybrid, Civic Hybrid and Insight at $20^{\circ} \mathrm{C} \ldots \ldots 117$

6.23 NMOG emission factors averaged over multiple tests for the Smart-

Car, Prius, Escape Hybrid, Civic Hybrid and Insight at $-18^{\circ} \mathrm{C} \ldots \ldots 118$

$6.24 \mathrm{CO}_{2}$ emission factors averaged over multiple tests for the SmartCar,

Prius, Escape Hybrid, Civic Hybrid and Insight at $20^{\circ} \mathrm{C}$. . . . . . . 120

$6.25 \mathrm{CO}_{2}$ emission factors averaged over multiple tests for the SmartCar,

Prius, Escape Hybrid, Civic Hybrid and Insight at $-18^{\circ} \mathrm{C} \ldots \ldots$

6.26 $\mathrm{CH}_{4}$ emission factors averaged over multiple tests for the SmartCar,

Prius, Escape Hybrid, Civic Hybrid and Insight at $20^{\circ} \mathrm{C} \ldots \ldots$.

6.27 $\mathrm{CH}_{4}$ emission factors averaged over multiple tests for the SmartCar,

Prius, Escape Hybrid, Civic Hybrid and Insight at $-18^{\circ} \mathrm{C} \ldots \ldots$

$6.28 \mathrm{~N}_{2} \mathrm{O}$ emission factors averaged over multiple tests for the SmartCar,

Prius, Escape Hybrid, Civic Hybrid and Insight at $20^{\circ} \mathrm{C}$. . . . . . 122

$6.29 \mathrm{~N}_{2} \mathrm{O}$ emission factors averaged over multiple tests for the SmartCar, Prius, Escape Hybrid, Civic Hybrid and Insight at $-18^{\circ} \mathrm{C} \ldots \ldots$

6.30 Average ICE off time compared to average ICE restart count for all transient drive cycle tests at $20^{\circ} \mathrm{C} \ldots \ldots \ldots \ldots \ldots \ldots$ 
6.31 Prius emissions and ICE off times from all transient drive cycles at $20^{\circ} \mathrm{C}$

6.32 Example of Prius real-time emissions during a $2 \times N Y C C$ at $20^{\circ} \mathrm{C}$ with ICE restart locations numbered in sequence . . . . . . . . . . 128

6.33 Example of the real-time emissions of the SmartCar during a

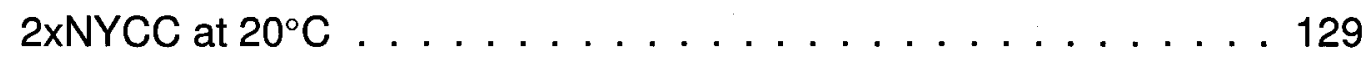

6.34 Example of Civic real-time emissions during the first 400 seconds of the $2 \times N Y C C$ at $20^{\circ} \mathrm{C}$ with ICE restart locations numbed in sequence 131

6.35 Example of SmartCar real-time emission rates during the first 400 seconds of the $2 \times N Y C C$ at $20^{\circ} \mathrm{C} \ldots \ldots \ldots \ldots \ldots 131$

6.36 Example of Civic Hybrid real-time emission rates during the SS80 at

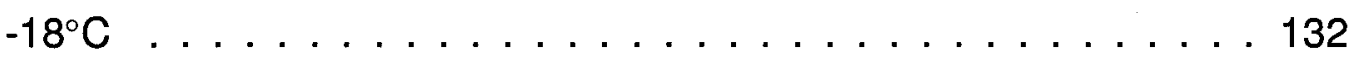

6.37 Carbonyl compound emission factors averaged over multiple tests for the $2 \times L A 4$ drive cycle at $20^{\circ} \mathrm{C} \ldots \ldots \ldots \ldots$

6.38 Carbonyl compound emission factors averaged over multiple tests for the $2 x L A 4$ drive cycle at $-18^{\circ} \mathrm{C} \ldots \ldots \ldots \ldots$

6.39 Carbonyl compound emission factors averaged over multiple tests for the $2 x \mathrm{LA92}$ drive cycle at $20^{\circ} \mathrm{C} \ldots \ldots \ldots \ldots$

6.40 Carbonyl compound emission factors averaged over multiple tests for the $2 x \mathrm{LA92}$ drive cycle at $-18^{\circ} \mathrm{C} \ldots \ldots \ldots \ldots \ldots \ldots$ 


\section{List of Symbols}

\section{Symbols}

$a_{g}\left(\mathrm{~m} / \mathrm{s}^{2}\right)$

$a_{i}\left(\mathrm{~m} / \mathrm{s}^{2}\right)$

$a_{m p s}\left(\mathrm{~m} / \mathrm{s}^{2}\right)$

$A(\mathrm{~m})$

$A_{\text {dyno }}(\mathrm{kg})$

$A_{f}\left(\mathrm{~m}^{2}\right)$

$A_{R L F}(\mathrm{~N})$

$B(\mathrm{~m})$

$B_{\text {dyno }}\left(\mathrm{kg} \cdot \frac{\mathrm{hr}}{\mathrm{km}}\right)$

$B_{R L F}(\mathrm{~kg} / \mathrm{s})$

battery capacity (Ah)
Acceleration due to the force of gravity; $-9.81 \mathrm{~m} / \mathrm{s}^{2}$

Average translational acceleration of the chassis dynamometer roller surface at time interval $i$

Acceleration of vehicle

Distance from the center of gravity of the vehicle to the front wheel axle

First of three chassis dynamometer road load coefficients for a vehicle

Area of the front cross-section of the vehicle

First of three road load force coefficients

Distance from the center of gravity of the vehicle to the rear wheel axle

Second of three chassis dynamometer road load coefficients for a vehicle

Second of three road load force coefficients

The rated hybrid battery capacity for a specific hybrid vehicle 
$C(\mathrm{~m}) \quad$ Circumference of the chassis dynamometer electric motor shaft

$C_{1_{g a s}}, \quad C_{2_{g a s}}, \quad$ Gas analyzer curve coefficients for pollutant gas

$C_{3 g a s}, C_{4 g a s}$

$C_{d}$

Aerodynamic drag coefficient

$C_{\text {dilute }}$

Ratio of the moles of carbon to moles of dilute exhaust

$C_{d y n o}\left(\mathrm{~kg} \cdot\left(\frac{\mathrm{hr}}{\mathrm{km}}\right)^{2}\right) \quad$ Third of three chassis dynamometer road load coefficients for a vehicle

$C_{\text {raw }}$

Ratio of the moles of carbon to moles of raw exhaust

$C_{R L F}(\mathrm{~kg} / \mathrm{m}) \quad$ Third of three road load force coefficients

$C W F$

Mass of carbon in fuel divided by the mass of the fuel

$D_{i-1}$ and $D_{i}(\mathrm{~m})$ Cumulative translational distance that the test vehicle has traversed on the chassis dynamometer at time measurement number $i-1$ and $i$, respectively

DF $\quad$ Factor by which the raw exhaust is diluted, using filtered ambient air

distance $(\mathrm{km}) \quad$ Equivalent translational distance travelled by a test vehicle on a chassis dynamometer

$E_{\text {discharge }}(\mathrm{kWh}) \quad$ Battery discharge energy

$E_{i}(\mathrm{~W} \cdot \mathrm{s}) \quad$ Electrical energy of the hybrid battery at time measurement number $i$

$E_{I C E c h a r g i n g} \quad$ Battery charging energy derived from the internal combustion (kWh) engine

$E_{\text {mode }_{i}}(\mathrm{~W} \cdot \mathrm{s}) \quad$ Braking energy mode (either friction or augmented braking) at time measurement number $i$

$E_{\text {regen }}(\mathrm{kWh}) \quad$ Regenerative braking energy

xviii 
$f_{d a}$

$F_{\text {aero }}(\mathrm{N})$

$F_{b f}(\mathrm{~N})$

$F_{b r}(\mathrm{~N})$

$F_{\text {flex }}(\mathrm{N})$

$F_{\text {friction }}(\mathrm{N})$

$F_{\text {grad }}(\mathrm{N})$

$F_{\text {mode }_{i}}(\mathrm{~N})$

$F_{\text {motor }}(\mathrm{N})$

$F_{\text {motor } r}(\mathrm{~N})$

$F_{m s}(\mathrm{~N})$

$F_{r f}$ and $F_{r r}(\mathrm{~N})$

$F_{\text {roll }}(\mathrm{N})$

$F_{\text {trans }, I}(\mathrm{~N})$

$F_{w / t, I}(\mathrm{~N})$

$F C(\mathrm{~L} / 100 \mathrm{~km})$

grade
Amount of braking that occurs on the drive axle divided by the total braking force

Force required by the vehicle to overcome aerodynamic resistance; a part of the road load force

Braking force on the front wheel assembly

Braking force on the rear wheel assembly

Force required by the vehicle to overcome tire flex; a part of the road load force

Force of friction created by the chassis dynamometer parasitic losses

Force that opposes forward motion of a vehicle up a gradient due to a component of gravity; a part of the road load force Force of braking (either friction braking or augmented braking) at time measurement number $i$

Chassis dynamometer electric motor force

Chassis dynamometer electric motor force at the roller surface The simulated force created by the chassis dynamometer electric motor

Tire friction force on the front and rear wheels of a vehicle, respectively; a part of the road load force

Sum of roller inertia, flywheel and electric motor generated force acting at the surface of the roller

Translational inertial force due to the motion of the vehicle mass

Inertial force of the wheel and tire assembly

Fuel consumption of the test vehicle for a drive cycle test

The road incline; set to zero

xix 


\begin{tabular}{|c|c|}
\hline$H_{v}(\mathrm{~m})$ & Height of the vehicle \\
\hline$I_{\text {ave }}(\mathrm{amp})$ & Average current \\
\hline$I_{i}(\mathrm{amp})$ & Current at measurement reading number $i$ \\
\hline$L(\mathrm{~m})$ & $\begin{array}{l}\text { The distance between the front and rear wheel axles of a } \\
\text { vehicle }\end{array}$ \\
\hline$m_{\text {fuel }}(\mathrm{kg})$ & Mass of fuel used in a drive cycle test \\
\hline$m_{i}(\mathrm{~kg})$ & $\begin{array}{l}\text { Inertial mass of the rotating components of a chassis } \\
\text { dynamometer }\end{array}$ \\
\hline$m_{v}(\mathrm{~kg})$ & Mass of vehicle \\
\hline$M R_{a m b_{g a s}}$ & $\begin{array}{l}\text { Gas analyzer ambient air concentration meter reading for } \\
\text { pollutant gas }\end{array}$ \\
\hline$M R_{d_{g a s}}$ & $\begin{array}{l}\text { Gas analyzer dilute exhaust concentration meter reading for } \\
\text { pollutant gas }\end{array}$ \\
\hline$n$ & Number of current readings \\
\hline$N$ & Number of pulses from the optical sensor \\
\hline$N_{R}$ & $\begin{array}{l}\text { Number of pulses per revolution of the chassis dynamometer } \\
\text { electric motor shaft }\end{array}$ \\
\hline $\begin{array}{l}N E C \quad \text { and } \\
N E C_{i} \quad(\mathrm{kWh} \text { or } \\
\%)\end{array}$ & $\begin{array}{l}\text { Net energy change of the hybrid battery from start to end of a } \\
\text { test or phase } i\end{array}$ \\
\hline$N H V(\mathrm{BTU} / \mathrm{lb})$ & Net heating value of fuel \\
\hline$N H V_{g}(\mathrm{BTU} / \mathrm{g})$ & $\begin{array}{l}\text { Net heating value of fuel in units applicable to find the total } \\
\text { cycle energy }\end{array}$ \\
\hline$P_{b r a k e, i n}(\mathrm{~kW})$ & $\begin{array}{l}\text { The braking power input; maximum potential power for } \\
\text { regenerative braking }\end{array}$ \\
\hline$P_{w / t, i n}(\mathrm{~kW})$ & $\begin{array}{l}\text { Power input to the wheel/tire assembly required to stop the } \\
\text { vehicle } \\
\text { xx }\end{array}$ \\
\hline
\end{tabular}


$r_{a r m}(m)$

$r_{\text {roller }}(\mathrm{m})$

$R(\mathrm{~N})$

$R L F(\mathrm{~N})$

$S$

$S G_{\text {fuel }}$

$S L P M(\mathrm{~L} / \mathrm{min})$
Length of torque arm

Radius of the chassis dynamometer roller(s)

Rolling resistance coefficient for a vehicle

Total force equivalent to all the resistant forces opposing forward motion of a vehicle on a flat road; the road load force +1 and -1 for wind direction oriented in the same and opposite direction of the vehicle trajectory, respectively

Specific gravity of fuel

Flow rate of ambient air and dilute exhaust through 2,4Dinitrophenylhydrazine cartridges

SOC (\%) State of charge of the battery

$t_{i}$ and $t_{i-1}(\mathrm{~s}) \quad$ Time at measurement number $i$ and $i-1$, respectively

$T_{\text {motor }}(\mathrm{N} \cdot \mathrm{m}) \quad$ Chassis dynamometer electric motor torque

$T C E$ and $T C E_{i}$ Total energy consumed by a test vehicle during a drive cycle test or drive cycle phase number $i$

$T F E(\mathrm{kWh})$ Total fuel energy consumed by a test vehicle during a drive cycle test

time amb (min) Test time for which ambient air sample was collected; first two or second two phases of a 4-phase test

time $_{\text {phase }}$ (min) Test time of one phase of a test, in minutes unless specified otherwise

$V(\mathrm{~km} / \mathrm{hr}) \quad$ Vehicle speed parallel to wind vector

$V_{\text {air }}(\mathrm{km} / \mathrm{hr}) \quad$ Wind speed parallel to vehicle trajectory

$V_{e x}(\mathrm{~mL}) \quad$ Volume of dilute exhaust or ambient air in the carbonyl cartridge extract

$v_{i-1}$ and $v_{i}(\mathrm{~m} / \mathrm{s})$ Translational equivalent average speed of the chassis dynamometer roller at time interval $i$ and $i-1$ XXi 


\begin{tabular}{|c|c|}
\hline$V_{k p h}(\mathrm{~km} / \mathrm{hr})$ & Vehicle speed, in kilometers per hour \\
\hline$V_{m p s}(\mathrm{~m} / \mathrm{s})$ & Vehicle speed, in meters per second \\
\hline$V_{N}$ (volt) & The rated hybrid battery voltage for a specific hybrid vehicle \\
\hline$V_{x}(\mathrm{~km} / \mathrm{hr})$ & Wind speed parallel to trajectory of vehicle \\
\hline$V_{y}(\mathrm{~km} / \mathrm{hr})$ & Wind component perpendicular to trajectory of vehicle \\
\hline$V o l_{\text {phase }}\left(\mathrm{ft}^{3}\right)$ & $\begin{array}{l}\text { Volume of dilute exhaust that flows through the dilution tunnel } \\
\text { during the phase }\end{array}$ \\
\hline $\begin{array}{l}V S P \\
\text { (kW/tonne) }\end{array}$ & Vehicle specific power \\
\hline$W_{v}(\mathrm{~m})$ & Width of the vehicle \\
\hline$x$ & Number of carbon atoms in fuel \\
\hline$y$ & Number of hydrogen atoms in fuel \\
\hline Greek & Number of oxygen atoms in fuel \\
\hline Symbols & \\
\hline$\triangle S O C(\mathrm{Ah})$ & $\begin{array}{l}\text { Change in battery state of charge from start to end of a drive } \\
\text { cycle test }\end{array}$ \\
\hline$\epsilon_{i}$ & $\begin{array}{l}\text { Mass factor coefficient; converts the rotating components' } \\
\text { inertias into translational mass }\end{array}$ \\
\hline$\theta$ (degrees) & Road grade \\
\hline$\lambda$ & $\begin{array}{l}\text { The actual air-fuel ratio divided by the stoichiometric air-fuel } \\
\text { ratio, } 14.7\end{array}$ \\
\hline$\mu_{\text {flex }}$ & Vehicle tire flex coefficient \\
\hline$\mu_{\text {road }}$ & Road adhesion coefficient \\
\hline$\rho_{\text {air }}\left(\mathrm{kg} / \mathrm{m}^{3}\right)$ & Density of air \\
\hline
\end{tabular}


$\rho_{\text {gas }}\left(\mathrm{g} / \mathrm{ft}^{3}\right) \quad$ Density of a gas

$\rho_{\text {fuel }}(\mathrm{kg} / \mathrm{L}) \quad$ Density of fuel

Concentration

Symbols

$[\text { carbonyl }]_{a m b} \quad$ Concentration of a carbonyl compound in ambient air

$(\mathrm{mg} / \mathrm{L})$

$[\text { carbonyl }]_{a m b_{e x}} \quad$ Concentration of a carbonyl compound extract from ambient $(\mu \mathrm{g} / \mathrm{L}) \quad$ air

$[\text { carbonyl }]_{d} \quad$ Concentration of a carbonyl compound in dilute exhaust

$(\mathrm{mg} / \mathrm{L})$

$[\text { carbonyl }]_{d_{e x}} \quad$ Concentration of a carbonyl compound extract from dilute $(\mu \mathrm{g} / \mathrm{L}) \quad$ exhaust

$[\text { carbonyl }]_{e f} \quad$ Emission factor of a carbonyl

(mg/mile)

$[\text { carbonyl }]_{e m} \quad$ Emission mass of a carbonyl

(mg/phase)

$[C O]_{d}(\mathrm{ppm}) \quad$ Dilute exhaust concentration of carbon monoxide from vehicle tailpipe

$[C O]_{e f}(\mathrm{~g} / \mathrm{mile}) \quad$ Emission factor of carbon monoxide

$\left[\mathrm{CO}_{2}\right]_{d}(\%) \quad$ Dilute exhaust concentration of carbon dioxide from vehicle tailpipe

$\left[\mathrm{CO}_{2}\right]_{e f}(\mathrm{~g} / \mathrm{mile}) \quad$ Emission factor of carbon dioxide

$[\text { gas }]_{a m b}$ (ppm or The ambient air concentration of a pollutant gas

$\%)$

xxiii 
$[g a s]_{d}$ (ppm or The dilute exhaust concentration of a pollutant gas

\%)

$[\mathrm{gas}]_{\text {ef }}(\mathrm{g} / \mathrm{mile}) \quad$ Emission factor of a gas

$[\mathrm{gas}]_{e m} \quad$ Emission mass of gas

(g/phase)

$[H C]_{d}(\mathrm{ppm}) \quad$ Dilute exhaust concentration of total hydrocarbons from vehicle tailpipe

$[H C]_{e f}(\mathrm{~g} / \mathrm{mile})$ Emission factor of total hydrocarbons

$\left[\mathrm{N}_{2} \mathrm{O}\right]_{a m b}$ (ppb) The ambient air concentration of nitrous oxide

$\left[\mathrm{N}_{2} \mathrm{O}\right]_{d}(\mathrm{ppb}) \quad$ The dilute exhaust concentration of nitrous oxide

$\left[\mathrm{N}_{2} \mathrm{O}\right]_{e f}(\mathrm{~g} / \mathrm{mile}) \quad$ Emission factor of nitrous oxide

$\left[\mathrm{N}_{2} \mathrm{O}\right]_{e m} \quad$ Emission mass of nitrous oxide

(g/phase)

\section{Chemicals}

$\begin{array}{ll}\text { 2,4-DNPH } & \text { 2,4-Dinitrophenylhydrazine } \\ \mathrm{CH}_{4} & \text { Methane } \\ \mathrm{CO} & \text { Carbon monoxide } \\ \mathrm{CO}_{2} & \text { Carbon dioxide } \\ \mathrm{CO}_{2 e q} & \text { The equivalent mass of carbon dioxide of a greenhouse gas, } \\ & \text { based on its global warming potential } \\ \mathrm{H} \cdot & \text { Hydrogen radical } \\ \mathrm{H}_{2} \mathrm{O} & \text { Water molecule } \\ \mathrm{HC} & \text { Hydrocarbon } \\ \mathrm{N} \cdot & \text { Nitrogen radical } \\ \mathrm{N} & \text { Nitrogen gas }\end{array}$


NMHC

NMOG

NO

$\mathrm{NO}_{2}$

$\mathrm{NO}_{x}$

$\mathrm{N}_{2} \mathrm{O}$

$\mathrm{O}_{2}$

\section{Acronyms}

2xLA4

2xLA92

2xNYCC

2xUS06

A/F

ABS

AC

APT

AT-PZEV

AWD

CAI

CARB

CFR

CPC

CPT
Non-methane hydrocarbon

Non-methane organic gas

Nitric oxide

Nitrogen dioxide

Oxides of nitrogen

Nitrous oxide

Oxygen gas
Two LA4 drive cycles, one driven as a coldstart and another driven 20 minutes later, as a hotstart Two LA92 drive cycles, one driven as a coldstart and another driven 20 minutes later, as a hotstart Two NYCC tests, driven back to back Two US06 tests, driven back to back

Air-fuel

Anti-lock braking system

Alternating current

Auxiliary power-train

Advanced technology partial zero emission vehicle

All-wheel drive

California Analytical Instruments

California Air Resource Board

Code of Federal Regulations

Condensation particle counter

$\underset{\mathrm{XxV}}{\text { Conventional power-train }}$ 
Dilution factor

EBS

Electronic braking system

ECE

Economic Commission for Europe Test Cycle

ECVT

Electric continuously variable transmission

EGR

Exhaust gas recirculation

ELPI

Electrical low pressure impactor

EPA

Environmental Protection Agency

ERMD

Emissions Research and Measurement Division

ETC

Environmental Technology Center

EUDC

Extra Urban Driving Cycle

FTP

Federal Test Procedure

FWD

Front-wheel drive

GC

Gas chromatography

GC-ECD

Gas chromatography by electron capture detection

GHG

Greenhouse gas

GWP

Global warming potential

HCLD

Heated chemiluminescence detector

HFID

Heated flame ionization detector

HEPA

High efficiency particle air

HEV

Hybrid electric vehicle

HPLC

High performance liquid chromatography

HS

Hotstart

HSD II

Second generation Hybrid Synergy Drive

HWFET

Highway Fuel Economy Test 
Los Angeles route 4 drive cycle

LA4CS

The LA4, driven as a coldstart

LA4HS

The LA4, driven as a hotstart

LA92

Los Angeles route 92 drive cycle

LA92CS

The LA92, driven as a coldstart

LA92HS

The LA92, driven as a hotstart

LDV

Light-duty vehicle

LDT

Light-duty truck

LEV

Low-emission vehicle

$\mathrm{LHC}$

Light hydrocarbon

MFC

Mass flow controller

MPFI

Multi-port fuel injection

NC

No engine crank

NDIR

Non-dispersive infrared

NEC

Net energy change

NHV

Net heating value

NRCAN

Natural Resources Canada

NYCC

New York City Cycle

OBD

On-board Diagnostics

PM

Particulate matter

QFF

Quartz fiber filter

RBS

Regenerative braking system

RLF

Road load force

RP-HPLC

Reverse phase high performance liquid chromatography

SAE xxvii 
$\mathrm{SOC}$

State of charge

SOPS

Standard operating procedures

SS

Steady state

SULEV

Super-ultra low emission vehicle

TBE

Total braking energy

TCE

Total cycle energy

TFE

Total fuel energy

TMF

Teflon membrane filter

TWC

Three-way catalytic converter

ULEV

Ultra low-emission vehicle

US06

Supplemental drive cycle to the FTP

UV

Ultraviolet

VOC

Volatile organic compound

VSP

Vehicle specific power 


\section{Chapter 1}

\section{Introduction}

Energy consumption and air pollution are serious issues that influence government politics and affect public health and the environment. Vehicles continue to cumulatively emit massive amounts of pollutants and greenhouse gases into the atmosphere while depleting limited natural resources. Six major air pollutants that are emitted from vehicles are carbon monoxide $(\mathrm{CO})$, hydrocarbons $(\mathrm{HC})$, oxides of nitrogen $\left(\mathrm{NO}_{x}\right)$, particulate matter $(\mathrm{PM})$, carbonyl compounds and volatile organic compounds (VOCs), which includes HC species and carbonyl compounds. Organic gases contain carbon atoms; thus, VOCs are organic gases. Non-methane organic gases (NMOG) excludes methane $\left(\mathrm{CH}_{4}\right)$ because it is a relatively benign chemical in terms of human health impact and ground level ozone formation, and is therefore of little interest in the study of pollution. Emissions of $\mathrm{CO}, \mathrm{NO}_{x}$ and NMOG, among others, are regulated in the United States and Canada. These three emissions are therefore referred to as regulated emissions, while other emissions, such as carbonyl compounds, are referred to as unregulated emissions. 
The major greenhouse gases (GHGs) emitted by vehicles include carbon dioxide $\left(\mathrm{CO}_{2}\right), \mathrm{CH}_{4}$ and nitrous oxide $\left(\mathrm{N}_{2} \mathrm{O}\right)$. In this study, $\mathrm{CO}, \mathrm{HC}, \mathrm{NO}_{x}$, carbonyl compounds and the above three GHGs were measured. A companion study has quantified and characterized PM emissions from the same experimental program as this study [1].

Exposure to $\mathrm{CO}$ results in acute and chronic health effects, varying from headaches, to angina, to death [2]. Exposure to nitrogen dioxide $\left(\mathrm{NO}_{2}\right)$ and nitric oxide (NO), both constituents of $\mathrm{NO}_{x}$, has been correlated with respiratory tract irritation, asthma, and at high concentrations, death [2]. VOCs and carbonyl compounds can cause chest tightness and respiratory symptoms [3]. Some VOCs are also carcinogens, such as benzene; or probable carcinogens, such as formaldehyde and 1,3-butadiene [4]. VOCs and $\mathrm{NO}_{x}$ act together with sunlight to create ground level ozone, a secondary gaseous pollutant that greatly compromises human health.

Not only do these air pollutants affect human health, but some have deleterious effects on the environment. For instance, gaseous $\mathrm{NO}$ and $\mathrm{NO}_{2}$ are precursors to $\mathrm{O}_{3}$ as well as acid precipitation. GHGs do not locally damage the environment, but contribute to the greenhouse effect, altering the Earth's average global temperature and thereby inducing environmental changes on a global scale.

Alternative vehicle technologies exist to replace conventional spark-ignition (SI) vehicle technology that reduce pollutant emission rates and energy consumption. One such alternative is the gasoline-electric hybrid vehicle (HEV). More than 20 HEVs, ranging from light-duty vehicles (LDVs) to sports utility vehicles (SUVs), have become commercially available since 1999 , when the Honda Insight was in- 
troduced to North America. HEVs make use of a secondary power source, namely the hybrid battery pack, to provide supplementary power during accelerations, at low speeds or during idle. Some HEVs can be powered completely by the hybrid battery pack during low speeds or at idle. The presence of this secondary power source allows the use of a smaller internal combustion engine (ICE) in the HEV, compared to conventional SI vehicles. A smaller ICE consumes less fuel and emits fewer pollutants. The emissions of $\mathrm{CO}, \mathrm{HC}, \mathrm{NO}_{x}$ and $\mathrm{CO}_{2}$ from $\mathrm{HEVs}$ have been quantified for all HEVs commercially sold in the U.S., but only under two specific driving patterns at $20^{\circ} \mathrm{C}$. To the author's knowledge, no study has been published that quantifies the emissions from HEVs over seven driving patterns and at cold temperatures. Such research is important to establish a clear understanding of the impact that driving an HEV has on the environment and on human health. The energy flow through an HEV is also of interest because it has not been published and its effect on emissions have not been characterized in published literature todate.

This thesis quantifies $\mathrm{CO}, \mathrm{NMOG}, \mathrm{NO}_{x}$, carbonyl compounds, $\mathrm{CO}_{2}, \mathrm{CH}_{4}$ and $\mathrm{N}_{2} \mathrm{O}$ emissions from the 2005 Ford Escape Hybrid, 2004 Toyota Prius, 2003 Honda Civic Hybrid, 2002 SmartCar and 2000 Honda Insight. This study also quantifies estimates of the battery energies of the Escape Hybrid and Prius for seven different drive cycles and two temperatures. This study was completed in conjunction with a project initiated by the Emissions Research and Measurement Division (ERMD) of Environment Canada. The project was undertaken to test advanced vehicle propulsion systems in order to quantify their GHG emissions, and was funded by the Climate Change Technology and Innovation program. The five vehicles were tested on a chassis dynamometer over five transient drive cycles (two of which were multi-phase) and two steady state (SS) drive cycles. These tests were 
conducted at both $20^{\circ} \mathrm{C}$ and $-18^{\circ} \mathrm{C}$. During each test real-time battery current or state of charge (SOC), vehicle speed, acceleration, chassis dynamometer forces, and cycle emissions of $\mathrm{CO}, \mathrm{CO}_{2}, \mathrm{CH}_{4}, \mathrm{~N}_{2} \mathrm{O}, \mathrm{HC}, \mathrm{NO}_{x}$, and carbonyl compounds (for selected multi-phase tests) were measured. Real-time emissions of $\mathrm{CO}, \mathrm{CO}_{2}$, $\mathrm{NO}_{x}$ and $\mathrm{HC}$ were also measured during each test.

\subsection{Objectives and Contributions}

This study focuses on quantitatively answering the following questions:

- How does energy consumption and recuperation contribute to vehicle energy and overall battery activity? What is the contribution of regenerative braking energy and battery discharge energy to the total cycle energy, and how do these energies vary with driving patterns and ambient temperature? What is the relation of battery energies to gaseous emissions of $\mathrm{CO}, \mathrm{NMOG}, \mathrm{NO}_{x}$ and $\mathrm{CO}_{2}$ ?

- What is the magnitude of $\mathrm{CO}, \mathrm{NMOG}, \mathrm{NO}_{x}$, carbonyl compounds, $\mathrm{CO}_{2}, \mathrm{CH}_{4}$ and $\mathrm{N}_{2} \mathrm{O}$ emissions from HEVs during different drive cycles, and how are these emissions affected by ambient temperature and driving patterns?

- What impact does ICE off time and the number of ICE restarts have on emissions from HEVs?

In answering the above questions, the following contributions to current academic knowledge will be made:

- Estimated HEV battery energy values.

- Emission factors for four different HEVs, two temperatures and seven drive cycles. 
- Relation between ICE restart count and ICE off time on emissions from HEVs.

- List of recommendations for future HEV testing procedures, and subjects benefiting from more research.

Chapter 2 provides a review of the literature on the formation of $\mathrm{CO}, \mathrm{HC}, \mathrm{NO}_{x}$, carbonyl compounds $\mathrm{CO}_{2}, \mathrm{CH}_{4}$ and $\mathrm{N}_{2} \mathrm{O}$ in ICEs and compares $\mathrm{HEV}$ and $\mathrm{SI}$ vehicle emission factors. Chapter 2 also describes the types of HEVs, braking designs, and HEV operation modes, which includes energy values from literature. Chapter 3 provides an explanation of the fundamental principles of chassis dynamometer operation to provide context for calculations made in Chapter 5 . Chapter 4 describes the experimental procedure used for testing the HEVs and SI vehicle on the chassis dynamometer. Chapter 5 presents the equations and methods used to analyze the data. The results are presented in Chapter 6 and the discussion on those results is provided in Chapter 7 . The findings of this study are summarized in Chapter 8. 


\section{Chapter 2}

\section{Literature Review of Hybrid Electric}

\section{Vehicles and Gaseous Emissions}

\section{from Internal Combustion Engines}

In this chapter, the design and operation of the HEV is reviewed. Furthermore, seven gaseous emissions from ICEs, specifically those of conventional SI vehicles and HEVs, are discussed.

HEVs combine a conventional power train (CPT), an ICE, with an auxiliary power train (APT), the hybrid battery pack. HEVs are usually constructed using one of three main designs: series, parallel or combined. Each design arranges the main components of an HEV differently, and each design has specific advantages and disadvantages.

The combination of two power sources, namely the CPT and APT, results in a higher fuel economy than SI vehicles and subsequently fewer gaseous emissions. Although the architecture of SI vehicles and HEVs are very different, the emissions 
from both are created by the combustion of fuel in the ICE. The mechanisms of pollutant formation in each type of vehicle are thus the same.

Where an SI vehicle draws energy solely from the fuel for power, an HEV may draw energy from the CPT, or energy stored in the APT. Furthermore, the APT may supplement or, in some designs, fully power the vehicle, and has the ability to recuperate energy. Thus, the HEV operates with a higher energy efficiency than an SI vehicle. The difference in architecture and components of SI vehicles and HEVs highlights the need for different test procedures regarding fuel economy and regulatory emission testing.

In the following sections, the mechanisms of gaseous emission formation in the ICE of HEVs and SI vehicles are discussed for $\mathrm{CO}, \mathrm{HC}$, carbonyl compounds, $\mathrm{NO}_{x}, \mathrm{CO}_{2}, \mathrm{CH}_{4}$ and $\mathrm{N}_{2} \mathrm{O}$. Also, the designs, braking strategies, and recuperation and consumption of energy of HEVs are outlined. Finally, the Society of Automotive Engineers (SAE) recommended chassis dynamometer testing procedure for HEVs is provided.

\subsection{Gaseous Emissions from Internal Combustion Engines}

Theoretically, combustion of an oxygenated hydrocarbon fuel may be expressed by the general reaction in equation 2.1. Here, the stoichiometric air and oxygenated fuel mixture, seen on the left side of the equation, combust to produce energy in the form of heat and the listed byproducts, seen on the right side of the equation.

$$
\mathrm{C}_{x} \mathrm{H}_{\mathrm{y}} \mathrm{O}_{z}+\left(\mathrm{x}+\frac{\mathrm{y}}{4}-\frac{\mathrm{z}}{2}\right)\left(\mathrm{O}_{2}+3.76 \mathrm{~N}_{2}\right) \rightarrow x \mathrm{CO}_{2}+\frac{\mathrm{y}}{2} \mathrm{H}_{2} \mathrm{O}+3.76\left(\mathrm{x}+\frac{\mathrm{y}}{4}-\frac{\mathrm{z}}{2}\right) \mathrm{N}_{2}
$$


The terms $x, y$ and $z$ in equation 2.1 refer to the number of carbon (C), hydrogen $(\mathrm{H})$ and oxygen $(\mathrm{O})$ atoms in the fuel, respectively, and the number of moles of reactants and products. Air, defined in this equation as a composition of oxygen gas $\left(\mathrm{O}_{2}\right)$ and nitrogen gas $\left(\mathrm{N}_{2}\right)$, burns with the oxygenated fuel $\left(\mathrm{C}_{x} \mathrm{H}_{y} \mathrm{O}_{z}\right)$ to produce $\mathrm{CO}_{2}$, water $\left(\mathrm{H}_{2} \mathrm{O}\right)$ and $\mathrm{N}_{2}$. This reaction goes to completion only if $\mathrm{N}_{2}$ is inert, the air and fuel are perfectly mixed at the stoichiometric air-fuel (A/F) ratio (mass of air divided by mass of fuel in equation 2.1), heat is not lost to the surroundings and the reactants are provided infinite time to react. Even if these conditions are met, equation 2.1 occurs in two steps: first $\mathrm{CO}$ is formed and then it is converted to $\mathrm{CO}_{2}$ in a reversible reaction. Thus, in addition to the conditions above, the equilibrium constant for the $\mathrm{CO}-\mathrm{CO}_{2}$ reaction must be infinite. However, in an ICE, these conditions are not present and so equation 2.1 does not explain most of the exhaust products in actual combustion.

The formation of the major gasoline ICE pollutants, $\mathrm{CO}, \mathrm{HC}$, and $\mathrm{NO}_{x}$, is important to understand because it provides researchers the knowledge to reduce these emissions from vehicle exhaust. The release of these pollutants into the air is detrimental to human health, agriculture and the environment so any reduction in their emissions has positive consequences.

Although SI vehicles and HEVs both employ ICEs, HEVs also employ an APT, so the gaseous emission rates of these two types of vehicles will be different. A table of $\mathrm{CO}, \mathrm{HC}, \mathrm{NO}_{x}$ and $\mathrm{CO}_{2}$ emissions is shown in Table 2.1 to provide a comparison between SI vehicles and their HEV versions. Note that all vehicles, except the Toyotas, were tested using the FTP drive cycle (see Section 4.1.1). 
Table 2.1: United States Environmental Protection Agency Emission Factors for selected vehicles driven over the FTP drive cycle [5]

\begin{tabular}{|l|c|c|c|c|}
\hline \multirow{2}{*}{ Vehicle } & \multicolumn{4}{|c|}{ Emission Factor (g/mile) } \\
\cline { 2 - 5 } & $\mathrm{HC}$ & $\mathrm{CO}$ & $\mathrm{CO}_{2}$ & $\mathrm{NO}_{x}$ \\
\hline 2005 Ford Escape & 0.012 & 0.09 & 229 & 0.01 \\
2005 Ford Escape Hybrid & 0.002 & 0.01 & 140 & 0.01 \\
\hline 2004 Toyota Corolla & 0.014 & 0.119 & 148 & 0.04 \\
2004 Toyota Prius & 0.005 & 0.013 & 81.9 & 0.006 \\
\hline 2003 Honda Civic & 0.013 & 0.081 & 143 & 0.063 \\
2003 Honda Civic Hybrid & 0.008 & 0.144 & 103 & 0.06 \\
\hline 2000 Honda Insight & 0.026 & 0.227 & 133 & 0.06 \\
\hline
\end{tabular}

To provide a context for the emission values in Table 2.1, North American and European emissions standards are provided in Table 2.2. The European emission standard provided in Table 2.2 applies to the 2002 SmartCar that was tested in this study.

Table 2.2: U.S. EPA, CARB and EURO emission standards (Adapted from [6])

\begin{tabular}{|l|c|c|c|c|c|}
\hline \multirow{2}{*}{ Standard } & \multirow{2}{*}{ Kilometers Travelled } & \multirow{2}{*}{ Model Year } & \multicolumn{3}{|c|}{ Emission Factors $(\mathrm{g} / \mathrm{km})$} \\
\cline { 4 - 6 } & & & & & \\
& & & & & \\
\hline EPA & & & & \\
Tier 1 & $\leq 100000$ or 10 years & $1994-2003$ & $0.19^{1}$ & 2.6 & 0.38 \\
Tier 2 Bin 1 & $\leq 192000$ or 10 years & $\geq 2004$ & 0 & 0 & 0 \\
Tier 2 Bin 2 & $\leq 192000$ or 10 years & $\geq 2004$ & 0.01 & 1.3 & 0.01 \\
Tier 2 Bin 3 & $\leq 192000$ or 10 years & $\geq 2004$ & 0.03 & 1.3 & 0.02 \\
Tier 2 Bin 4 & $\leq 192000$ or 10 years & $\geq 2004$ & 0.04 & 1.3 & 0.03 \\
CARB LEV II & & & & & \\
SULEV & $\leq 192000$ or 11 years & $\geq 2004$ & 0.01 & 0.6 & 0.01 \\
ULEV & $\leq 192000$ or 11 years & $\geq 2004$ & 0.03 & 1.3 & 0.04 \\
LEV & $\leq 192000$ or 11 years & $\geq 2004$ & 0.06 & 2.6 & 0.04 \\
\hline EURO III & $\leq 80000$ or 5 years & $\geq 2000$ & $0.2^{3}$ & 2.3 & 0.15 \\
\hline
\end{tabular}

The U.S. Environmental Protection Agency (EPA) standards are similar to the California Air Resource Board (CARB) standards. The terms LEV, ULEV and

\footnotetext{
${ }^{1} \mathrm{NMHC}$

${ }^{2}$ Vehicles tested using themodified ECE and EUDC drive cycles

${ }^{3} \mathrm{HC}$
} 
SULEV refer to low-emission vehicle, ultra low-emission vehicle and super ultra low-emission vehicle, respectively. The vehicle mileage or age for which these standards apply are shown to indicate that different standards expect vehicles to perform at the level of standard for varying times and distances.

In the following sections, the relation between the $A / F$ ratio and pollutant concentrations is discussed, and the formation of $\mathrm{CO}, \mathrm{HC}, \mathrm{NO}_{x}$, carbonyl compounds, $\mathrm{CO}_{2}, \mathrm{~N}_{2} \mathrm{O}$ and $\mathrm{CH}_{4}$ are described.

\subsubsection{Air-Fuel Ratio and Gaseous Emissions}

In the past, vehicle ICEs were not able to maintain a stoichiometric A/F ratio (14.7 for gasoline) during all transient conditions. In modern vehicles, an $\mathrm{O}_{2}$ sensor in the exhaust, and fuel control upstream provides a closed-loop feedback system so that the A/F ratio may be maintained at 14.7 [7], except during large accelerations, where the $A / F$ is essentially not controlled. Figure 2.1 shows the relation between the $\mathrm{A} / \mathrm{F}$ ratio and $\mathrm{HC}, \mathrm{NO}_{x}$ and $\mathrm{CO}$ concentrations. The normalized $\mathrm{A} / \mathrm{F}$ ratio, $\lambda$, is the ratio of actual $A / F$ ratio to the stoichiometric $A / F$ ratio. Large $\lambda$ refer to an $A / F$ mixture with excess air (lean $A / F)$, and small $\lambda$ refer to an $A / F$ mixture with excess fuel (rich A/F).

Emission rates of $\mathrm{CO}$ are very low at large $\lambda$ because there is more $\mathrm{O}_{2}$ available to react with $\mathrm{CO}$ and form $\mathrm{CO}_{2}$. $\mathrm{NO}_{x}$ emission rates are also very low because the peak flame temperatures attained inside the combustion chamber are lower for large $\lambda$, and as discussed in Section 2.1.4, $\mathrm{NO}_{x}$ concentrations are higher for higher flame temperatures. Peak temperatures are lower for large $\lambda$ because the heat produced in combustion is partially used to heat up the excess air that does 
not contribute to combustion (heat) [8]. HC concentrations can increase at very large $\lambda$ due to incomplete combustion of the fuel.

As $\lambda$ decreases to the left of Figure 2.1, less $\mathrm{O}_{2}$ is available to form $\mathrm{NO}_{x}$ and oxidize $\mathrm{CO}$ to $\mathrm{CO}_{2}$. The lower $\mathrm{O}_{2}$ content results in incomplete combustion, thus increasing $\mathrm{HC}$ emissions.

Figure 2.1: Empirical relationship between the $\mathrm{A} / \mathrm{F}$ ratio and $\mathrm{HC}, \mathrm{CO}$ and $\mathrm{NO}_{x}$ concentrations for internal combustion (Adapted from [9])

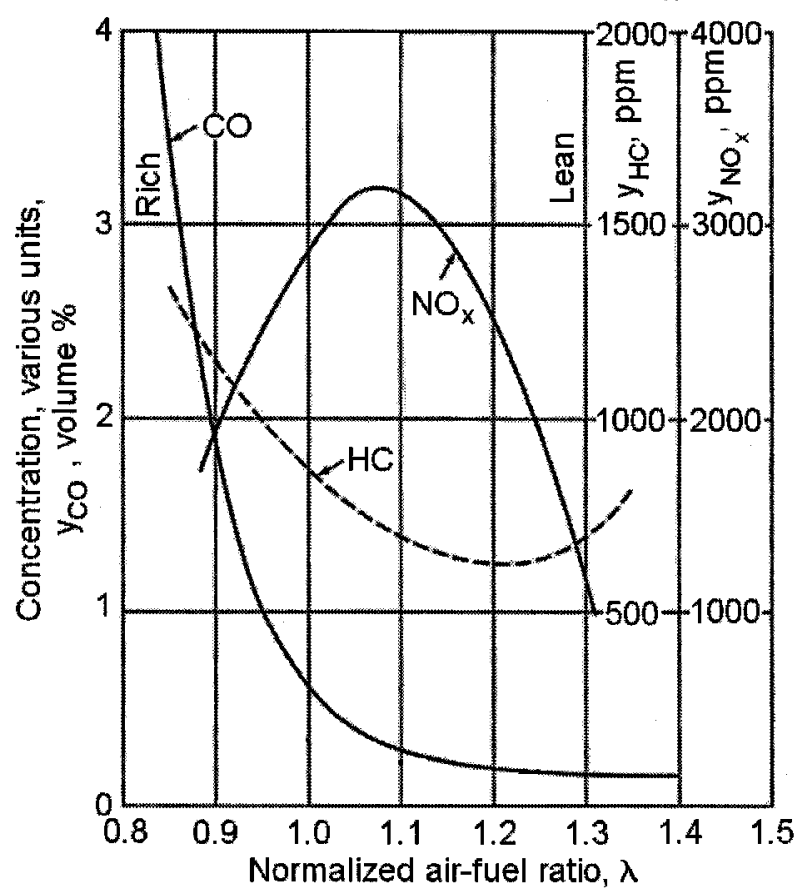

When $\lambda$ is slightly lean ( $>1)$, the emissions of $\mathrm{HC}$ and $\mathrm{CO}$ are low, while those of $\mathrm{NO}_{x}$ are at a maximum. $\mathrm{NO}_{x}$ emissions are largest at a $\lambda$ slightly greater than one because peak flame temperatures are high and $\mathrm{O}_{2}$ is available (Section 2.1.4). $\mathrm{HC}$ and $\mathrm{CO}$ emissions are low for a $\lambda$ slightly greater than one for this same reason. High combustion temperatures and the high availability of $\mathrm{O}_{2}$ in the A/F mixture ensures that the combustion of the fuel molecules is more complete than is possible with other $A / F$ ratios. 


\subsubsection{Formation of Carbon Monoxide and Hydrocarbons}

The formation of $\mathrm{CO}_{2}$ during the combustion of fuel and air is actually a result of two reactions. Firstly, the carbon in the fuel is oxidized to form $\mathrm{CO}$ and other products. $\mathrm{CO}$ will then be oxidized to $\mathrm{CO}_{2}$ by oxygen and hydrogen radicals $\left(\mathrm{H}^{\cdot}\right)$ $[8,9]$. However, CO still exists in significant concentrations in the exhaust of ICEs. At high temperatures, these oxidation reactions occur quickly, so equilibrium is established, which includes high concentrations of $\mathrm{CO}[8,9]$. At low temperatures, these oxidation reactions occur slowly, and equilibrium (i.e. virtually no $\mathrm{CO}$ ) is not established $[8,9]$. As the combustion ends and the gas expands, it cools and equilibrium favours the production of $\mathrm{CO}_{2}$. Most of the $\mathrm{CO}$ is oxidized to $\mathrm{CO}_{2}$ during this cooling, but not all of it, because of the short time this gas spends in the combustion chamber and exhaust stream. If not enough $\mathrm{O}_{2}$ is present in the A/F mixture, fewer oxidizing reactions will take place and more $\mathrm{CO}$ will be present in the exhaust (see Figure 2.1).

The formation of $\mathrm{HC}$ is attributed to non-stoichiometric $A / F$ ratio, poor $A / F$ mixing, physical conditions in the engine and low temperatures. The relation between HC concentration and the $A / F$ ratio is discussed in Section 2.1.1. If the air and fuel are poorly mixed, some fuel molecules $(\mathrm{HC})$ will not combust. These $\mathrm{HC}$ are emitted unburned from the combustion chamber. Air and fuel may not properly mix if the fuel is not broken into small droplets or if it does not evaporate within the injection system [7].

Even if the air and fuel are well mixed, some HC may not fully burn or burn at all. This may be attributed to conditions in the combustion chamber. Crevices in the combustion chamber are "regions of high enough surface-to-volume ratio to 
prevent flame propagation" [10]. Crevices are therefore rich in air and fuel that remain unburned during combustion. During expansion, when the exhaust valve is opened, some of this unburned $A / F$ mixture may exit the crevices and partially oxidize in the exhaust gas [10]. Crevices are located in the thread of a spark plug, between the piston ring pack and along the valve seats and gasket joints [8]. To facilitate the motion of the piston in the cylinder, lubricating oil lines the cylinder walls. Some fuel is absorbed in this oil layer before the flame propagates to the cylinder walls. After the A/F mixture has burned, the fuel in the oil layer is desorbed into the hot exhaust $[8,10]$.

Deposits in the combustion chamber are carbon-rich and form by fuel condensation and oxidation [10]. These deposits may absorb and desorb fuel in a manner similar to that of the oil layer, thereby contributing to more unburned and partially oxidized $\mathrm{HC}$ [8]. In engines that are poorly maintained, the exhaust valve may not close properly and fuel may escape, unburned, through this opening [8].

Temperatures in the combustion chamber also influence $\mathrm{HC}$ emissions. At the cylinder walls, the temperature is cold relative to the center of the cylinder. The flame may not propagate to these cold regions, in which case they are referred to as quench layers [10]. In this region, fuel does not combust, and only after combustion, when this fuel is enveloped in hot exhaust, does it partially oxidize [10].

Although these physical conditions are present in ICEs of both HEVs and SI vehicles, the $\mathrm{CO}$ and $\mathrm{HC}$ emissions of HEVs are lower than those of $\mathrm{SI}$ vehicles (Table 2.1). The differences in emissions between HEVs and conventional SI vehicles is partially due to the use of a smaller, more efficient ICE in HEVs. This efficient ICE is operated less frequently because of the energy provided by the 
battery. When it is operated, the battery can supplement some of the power in order to optimize the speed-torque output of the ICE. Thus, the ICE may be shut off and restarted while driving. Literature in the area of HEV ICE shut-off and restart impact on emissions, could not be found.

\subsubsection{Formation of Carbonyl Compounds}

Carbonyl compounds play a role in ground level ozone formation and many have deleterious human health effects. Carbonyl compounds are aldehyde and ketone molecules, which have a double bond between a $\mathrm{C}$ and $\mathrm{O}$ atom. Aldehydes are compounds that contain the carbonyl functional group $(\mathrm{C}=0)$ and an alkyl group (radical HC), and ketones contain two alkyl groups and one carbonyl group [11].

Carbonyl compounds will form under conditions similar for $\mathrm{HC}$ formation, discussed in Section 2.1.2. Carbonyl compounds are formed because some of the larger constituent oxygenates and $\mathrm{HC}$ of the fuel are partially oxidized. For instance, formaldehyde is created from the oxidation of ethyl alcohol, and methyl ethyl ketone (2-butanone) is formed from the oxidation of 2-butanol [11], a common gasoline oxygenate and alcohol [12]. Oxidizing an alcohol yields a carbonyl compound. Figure 2.2 shows the creation of 2-butanone from half an oxygen molecule and 2-butanol.

Figure 2.2: Formation of 2-butanone from 2-butanol<smiles>CC(O)CCCOCCC(=O)CC=O</smiles>

Several studies have shown that when testing a vehicle equipped with a threeway catalytic converter (Section 2.2), the aldehyde and ketone carbonyl species 
with the largest emission factors are formaldehyde, benzaldehyde, acetaldehyde, m\&p-tolualdeyhyde and acetone [13-15]. Table 2.3 provides the emission factors of selected carbonyl compounds speciated from these studies. These particular carbonyl compounds were speciated for this study, as well. The difference in emission factors between studies is partially as a result of differences in measurement conditions. Note that carbonyl compounds for which no emission factor is entered were not speciated in the respective study.

Table 2.3: Emission factors of selected carbonyl species from different studies

\begin{tabular}{|l|l|l|l|}
\hline \multirow{2}{*}{ Carbonyl Compound } & \multicolumn{3}{|c|}{ Study Results (mg/km) } \\
\cline { 2 - 4 } & $\begin{array}{l}\text { LDV Tunnel } \\
\text { Study [14] }\end{array}$ & $\begin{array}{l}\text { Tunnel } \\
\text { Study [15] }\end{array}$ & $\begin{array}{l}\text { LDV and } \\
\text { LDT }^{2} \text { FTP } \\
\text { CS }^{3} \text { [13] }\end{array}$ \\
\hline Formaldehyde & 5.41 & 4.9 & 8.69 \\
Acetaldehyde & 2.19 & 1.4 & 3.94 \\
Acrolein & 0.41 & & 0.06 \\
Acetone & 2.14 & 1.5 & 1.19 \\
Propionaldehyde & & & 0.37 \\
Crotonaldehyde & 0.61 & 0.04 & 1.76 \\
Methacrolein & 0.43 & $-0.2^{4}$ & 0.3 \\
2-Butanone & 0.46 & & 0.47 \\
Isobutyraldehyde \& & & & \\
Butyraldehyde & & 1.8 & 1.27 \\
Benzaldehyde & 0.44 & & 0.25 \\
Isovaleraldehyde & 0.059 & & 0.49 \\
Valeraldehyde & 0.35 & 0.56 & 0.39 \\
o-Tolualdehyde & 0.19 & 1.6 & 1.34 \\
m-Tolualdehyde \& p- & 0.87 & & \\
Tolualdehyde & & 0.44 & 0.3 \\
Hexanaldehyde & 0.21 & & 0.24 \\
2,5- & 0.34 & & \\
Dimethylbenzaldehyde & & & \\
\hline
\end{tabular}

Tests conducted by Graham included the 2000 Toyota Prius, but only formaldehyde and acetaldehyde were speciated [16]. No other studies could be found that measured carbonyl emissions from HEVs.

\footnotetext{
${ }^{1}$ Light-duty vehicle

${ }^{2}$ Light-duty truck

${ }^{3}$ Coldstart

${ }^{4}$ From a sample with a high standard deviation
} 


\subsubsection{Oxides of Nitrogen Formation}

$\mathrm{NO}_{x}$ emissions from ICEs are mostly a result of the interaction between $\mathrm{O}_{2}$ and $\mathrm{N}_{2}$ at high temperatures [10]. This type of $\mathrm{NO}_{x}$ is referred to as thermal $\mathrm{NO}_{x}$. At lower temperatures, other types of $\mathrm{NO}_{x}$ (prompt and fuel) contribute more to the overall $\mathrm{NO}_{x}$ concentration. These will be discussed shortly.

Thermal $\mathrm{NO}_{x}$ is actually $\mathrm{NO}$, and is predicted to form through a series of elementary reactions called the Zeldovich Mechanism. At low temperatures, the equilibrium concentration of $\mathrm{NO}$ is relatively low compared to its equilibrium concentration at high temperatures. Also, at low temperatures, equilibrium is reached slowly in comparison to high temperatures. In an ICE, the flame temperature is dependent on the completeness of combustion. In turn, complete combustion is dependent on the $A / F$ ratio. At near stoichiometric $A / F$ ratio, the flame temperature is the highest and therefore $\mathrm{NO}_{x}$ concentrations are maximum (Figure 2.1). However, the temperature in the combustion chamber of an ICE decreases rapidly as the exhaust stroke occurs and the gas expands. Theoretically, NO concentrations should decrease, but because this cooling happens rapidly and the destruction of NO at low temperatures is a slow reaction, the concentration does not decrease [9].

Prompt $\mathrm{NO}_{x}$ is created within low temperature flame fronts $[9,10]$. HC radicals react with $\mathrm{N}_{2}$ to produce a nitrogen-hydrocarbon $(\mathrm{HCN})$ species and a nitrogen radical $(\mathrm{N} \cdot)$. These then react with $\mathrm{O}_{2}$ to produce $\mathrm{NO}[9]$. Fuel $\mathrm{NO}_{x}$ is created when fuel containing $\mathrm{N}$ combusts. $\mathrm{N}$ is released from the fuel molecule as $\mathrm{N} \cdot$ and reacts with $\mathrm{HC}$ radicals [9] to produce $\mathrm{HCN}$. These newly formed $\mathrm{HCN}$ species react to produce $\mathrm{NO}, \mathrm{N}_{2}$ and water [9]. 
The more complete the combustion, the higher the flame temperature, and assuming a constant residence time, it is expected that $\mathrm{NO}_{x}$ emissions will be higher. Since the ICEs in HEVs operate more efficiently than SI vehicles (as a result of the ICE operating in a more ideal speed-torque range - see Section 2.3.1), it is expected that their $\mathrm{NO}_{x}$ emissions will be higher. As Table 2.1 shows, this is not necessarily the case. One explanation is that HEVs consume less fuel, so less $\mathrm{N}_{2}$, $\mathrm{O}_{2}$ and fuel combust. Another possible reason is that the HEVs, shown in Table 2.1, employ more emission technology than the conventional SI vehicles.

\subsubsection{Greenhouse Gas Emissions}

In this section, the definition and importance of GHGs is outlined. Also, the formation of $\mathrm{CO}_{2}, \mathrm{CH}_{4}$ and $\mathrm{N}_{2} \mathrm{O}$ in $\mathrm{HEVs}$ and $\mathrm{SI}$ vehicles is discussed.

Heat coming from the sun passes through the atmosphere (containing GHGs) and strikes the surface of the Earth. However, once the sunlight strikes the Earth and is absorbed, the radiated heat has a different wavelength, which cannot effectively pass back through the GHGs in the atmosphere. The consequence of this greenhouse effect is an increase in the average global temperature. The ability of a GHG to contribute to global warming is quantified using the so-called global warming potential (GWP). This is "the change in radiative forcing due to the instantaneous release of $1 \mathrm{~kg}$ of the GHG expressed relative to the radiate forcing from the release of $1 \mathrm{~kg}$ of $\mathrm{CO}_{2}$ " [17]. Radiative forcing is a change in net energy flux through a climate system, in this case the Earth. 
The three GHGs released from ICEs, in larger than trace quantities, are $\mathrm{CO}_{2}, \mathrm{~N}_{2} \mathrm{O}$ and $\mathrm{CH}_{4}$. The GWPs of these three GHGs are shown in Table 2.4. The GWPs are expressed for time periods of 25,50 or 100 years because the GHG degrades in the atmosphere over time so its ability to induce radiative forcing diminishes. Thus it is important to indicate the time frame associated with a GWP value. Table 2.4 reports the GWPs for 100 years.

Table 2.4: Greenhouse gases and their global warming potentials [18]

\begin{tabular}{|c|c|}
\hline Greenhouse Gas & GWP \\
\hline $\mathrm{N}_{2} \mathrm{O}$ & 298 \\
$\mathrm{CH}_{4}$ & 25 \\
$\mathrm{CO}_{2}$ & 1 \\
\hline
\end{tabular}

As shown in Table $2.4,1 \mathrm{~kg}$ of $\mathrm{N}_{2} \mathrm{O}$ is equivalent to $298 \mathrm{~kg} \mathrm{CO}_{2}$ in terms of its global warming potential. ICEs emit relatively large masses of $\mathrm{CO}_{2}$ and relatively far less $\mathrm{N}_{2} \mathrm{O}$ and $\mathrm{CH}_{4}$ masses. However, their impact on climate change is not as low as this comparison of emission mass suggests, because of the difference in GWPs between the GHGs.

$\mathrm{CO}_{2}$ is produced in an ICE in both HEVs and SI vehicles according to the general reaction in equation 2.1. The number of moles of $\mathrm{CO}_{2}$ produced is dependent on the number of carbon atoms in the molecular structure of the fuel and the amount of fuel burned. For instance, vehicle fuel economy defines the volume of fuel consumed per distance travelled. Lave and MacLean compared the fuel economy and gaseous emissions of the Toyota Prius and Toyota Corolla, as reported by the U.S. EPA [19]. The fuel economy of the Prius was $14 \mathrm{mpg}$ higher than that of the Corolla and the $\mathrm{CO}_{2}$ emission factor was 83 grams/mile less. Thus, vehicles with higher fuel economies emit fewer $\mathrm{CO}_{2}$ emissions. After-treatment devices also 
influence the emission mass of $\mathrm{CO}_{2}$, to a much lesser degree. After-treatment devices, such as the TWC, reduce and oxidize pollutants by converting them into $\mathrm{CO}_{2}, \mathrm{H}_{2} \mathrm{O}$ and $\mathrm{N}_{2}$. The U.S. EPA test results for $\mathrm{CO}_{2}$ emissions of several vehicles is shown in Table 2.1. Although the $\mathrm{CO}_{2}$ emission factors of all commercially available vehicles in North America are readily obtainable from [5], these values are for the HWFET and FTP drive cycles at $20^{\circ} \mathrm{C}$, only. Data for other drive cycles at different temperatures has not been found.

Unlike $\mathrm{CO}_{2}, \mathrm{CH}_{4}$ is a byproduct of incomplete combustion. The mass of $\mathrm{CH}_{4}$ released by a vehicle is dependent on the ICE design, emission technology used, fuel used and the vehicle age [20]. $\mathrm{CH}_{4}$ is one of many $\mathrm{HC}$ species created by the mechanisms discussed in Section 2.1.2. Like other $\mathrm{HC}$ species, $\mathrm{CH}_{4}$ may be oxidized by the TWC to produce $\mathrm{CO}_{2}$ and $\mathrm{H}_{2} \mathrm{O}$. However, $\mathrm{CH}_{4}$ is more resistant to oxidation by the TWC than other $\mathrm{HC}$ species. Thus, it is not as effectively removed from the exhaust of an ICE [20,21]. As reported in Canada's 2005 Greenhouse Gas Inventory, emission factors of $\mathrm{CH}_{4}$ from diesel-powered vehicles are less than those from gasoline-powered vehicles [17], because of the constituents of the fuels and the combustion processes. Older vehicles operate with less efficient components and less (effective) after-treatment devices, so their $\mathrm{CH}_{4}$ emission factors will be larger.

$\mathrm{N}_{2} \mathrm{O}$ is different from both $\mathrm{CH}_{4}$ and $\mathrm{CO}_{2}$ in that it is not a product of combustion. Although $\mathrm{N}_{2} \mathrm{O}$ can be an intermediate species in the formation of $\mathrm{NO}$ [22], the concentrations measured at the tailpipe of a non-catalyst vehicle are virtually zero [20]. Instead, $\mathrm{N}_{2} \mathrm{O}$ is formed in TWCs [23]. TWCs reduce $\mathrm{NO}$ and $\mathrm{NO}_{2}$ into $\mathrm{N}_{2}, \mathrm{CO}_{2}$ and water, where the carbon atoms in $\mathrm{CO}_{2}$ are derived from oxidized $\mathrm{HC}$ and $\mathrm{CO}$. If $\mathrm{NO}$ and $\mathrm{NO}_{2}$ are not completely reduced, $\mathrm{N}_{2} \mathrm{O}$ forms [20]. Huai et. al., 
among others, found that TWCs operating at higher temperatures produced less $\mathrm{N}_{2} \mathrm{O}$ than those operating at lower temperatures [24-28]. It has also been found that as the TWC ages, $\mathrm{N}_{2} \mathrm{O}$ emissions increase dramatically [29]. Other factors of $\mathrm{N}_{2} \mathrm{O}$ tailpipe concentrations include the sulfur content in the fuel [25], and the type of the TWC [26].

In general, the mass of $\mathrm{N}_{2} \mathrm{O}$ emitted from an ICE vehicle is much less than that of $\mathrm{CO}_{2}$. Becker, et. al., found that $\mathrm{N}_{2} \mathrm{O}$ contributed $4.5 \times 10^{-5}$ grams of exhaust for every gram of $\mathrm{CO}_{2}$ [30]. Although it is a small contributor to overall GHG mass emitted from an ICE vehicle, $\mathrm{N}_{2} \mathrm{O}$ has a significantly higher GWP than $\mathrm{CO}_{2}$ and therefore accounts for $1-3 \%$ of the total global warming impact from SI vehicle exhaust [30]. $\mathrm{N}_{2} \mathrm{O}$ and $\mathrm{CH}_{4}$ emissions from $\mathrm{HEVs}$ are not widely available in literature, but Beer has reported that $\mathrm{N}_{2} \mathrm{O}$ emissions from HEVs account for approximately $0.13 \%$ of the total global warming impact of GHGs [31].

\subsection{Vehicle Emission Control Technology}

Vehicles are now designed to operate within the stoichiometric $A / F$ ratio for most driving conditions, thus reducing pollutant emissions. However, to reduce the pollutant emissions of $\mathrm{CO}, \mathrm{HC}$ and $\mathrm{NO}_{x}$ to the levels seen in Table 2.1, the exhaust must be treated by emission control technologies after it is ejected from the engine. In this section, two specific technologies are described: TWCs and $\mathrm{NO}_{x}$ adsorbers.

A TWC destroys $\mathrm{HC}, \mathrm{CO}$ and $\mathrm{NO}_{x}$ by reduction and oxidation processes. $\mathrm{NO}_{x}$ is reduced to $\mathrm{N}_{2}$, CO is oxidized to $\mathrm{CO}_{2}$ and $\mathrm{HC}$ is oxidized to $\mathrm{CO}_{2}$ and water. The TWC destroys these three pollutants most effectively when the A/F ratio is stoichiometric. Lean $\mathrm{A} / \mathrm{F}$ ratios result in excess $\mathrm{O}_{2}$ in the exhaust that oxidizes $\mathrm{CO}$ 
and $\mathrm{HC}$, thus resulting in $\mathrm{NO}_{x}$ not being reduced. Rich $\mathrm{A} / \mathrm{F}$ ratios result in more $\mathrm{NO}_{x}$ being reduced to $\mathrm{N}_{2}$, but less $\mathrm{CO}$ and $\mathrm{HC}$ oxidation because of the lack of available $\mathrm{O}_{2}$. The TWC is encased in insulation, with a metal mesh connecting the wall of the TWC to the monoliths, which are metal or ceramic honeycomb structures coated with a catalyst material [7]. The exhaust passes through this catalyst-coated honeycomb structure and reacts with constituents in the exhaust to destroy $\mathrm{CO}, \mathrm{HC}$ and $\mathrm{NO}_{x}$. The performance of the TWC is dependant on its operating temperature. High exhaust temperatures result in more of the pollutants being destroyed. As the catalyst ages, its ability to destroy pollutants diminishes; a durable TWC has a life of about 80000 kilometers [7].

A NO${ }_{x}$ adsorber (or $\mathrm{NO}_{x}$ trap catalyst) is a TWC combined with a $\mathrm{NO}_{x}$ adsorbing material and is used in lean-burning vehicles [7]. When the ICE is running lean, most NO is adsorbed onto the honeycomb structure by chemically reacting with an adsorbing metal, such as barium carbonate [7], while some $\mathrm{NO}_{x}$ is reduced, and virtually all $\mathrm{HC}$ and $\mathrm{CO}$ are oxidized by the excess $\mathrm{O}_{2}$ in the exhaust stream [32]. A rich $\mathrm{A} / \mathrm{F}$ mixture is required periodically in order for the $\mathrm{CO}$ and $\mathrm{HC}$ to regenerate the adsorbing metal [7]. The $\mathrm{NO}_{x}$ released during this regeneration is reduced by the catalyst and the constituents in the rich exhaust stream [32].

\subsection{Types of Hybrid Electric Vehicles}

The emissions of HEVs are lower than those of SI vehicles because of the use of a smaller ICE, and a secondary power source, namely the battery. Here, the three different arrangements of the battery, ICE and other main components of an HEV are described. 
The main components of an HEV include the generator, motor, rectifier, inverter, ICE, transmission, battery and wheels. The generator converts the mechanical energy of the ICE and wheels into electrical energy that can be stored in the battery. The generator output, alternating current $(A C)$, is converted to direct current (DC) using a rectifier [33]. The electric motor converts electric energy into mechanical energy. The inverter converts direct current (DC) into variablefrequency alternating current $(\mathrm{AC})$ to allow the $\mathrm{HEV}$ computer to control the electric motor [34]. These main components may be arranged in such a way that the HEV has a series, parallel or combined design. In the following sections, these three designs are described.

\subsubsection{Series}

A series-type HEV is arranged in the general schematic shown in Figure 2.3.

Figure 2.3: Schematic of a series-type HEV (Adapted from [35])

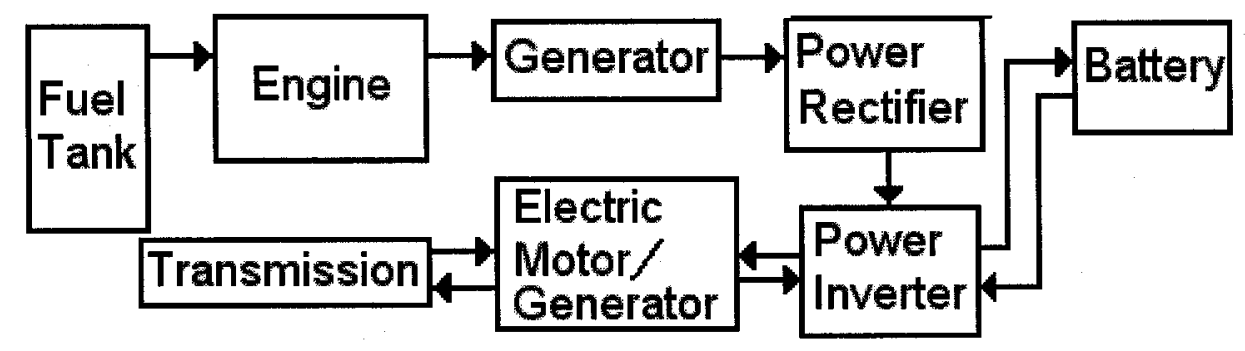

Fuel energy is converted to mechanical energy by combustion in the ICE. This design requires that the mechanical energy of the crankshaft is converted into electrical energy by the generator. This electrical energy is used to run the electric motor, and thus the wheels, at a variable speed. The battery may be used to power the HEV in tandem with the ICE, or alone. Regenerative braking energy from the wheels may also be captured by the HEV and stored in the battery. The energy from the ICE may be used to charge the battery as well, while driving the wheels 
or while at a stop.

One of the benefits of the series configuration is that the ICE may be operated solely within its most efficient speed-torque range, because it is decoupled from the wheels and the power is delivered electrically [36]. As well, the use of an electric motor removes the need for a multi-gear transmission because an electric motor has excellent speed-torque characteristics [36]. In a series configuration, the HEV may be powered solely by the battery, thereby allowing the ICE to shut off during idle or at low speeds. Thus, series HEVs operate very efficiently during city driving. However, a series configuration negatively affects energy efficiency of an HEV because the fuel energy is converted three times (chemical to mechanical, mechanical to electrical and electrical to mechanical), each with an efficiency less than $100 \%$. In addition, the components in Figure 2.3 increase the vehicle weight and cost. The electric motor needs to be large in order to meet the maximum speed-torque requirements, because it alone drives the HEV [37].

\subsubsection{Parallel}

A parallel-configured HEV is arranged according to the general schematic seen in Figure 2.4.

Figure 2.4: Schematic of a parallel type HEV (Adapted from [36])

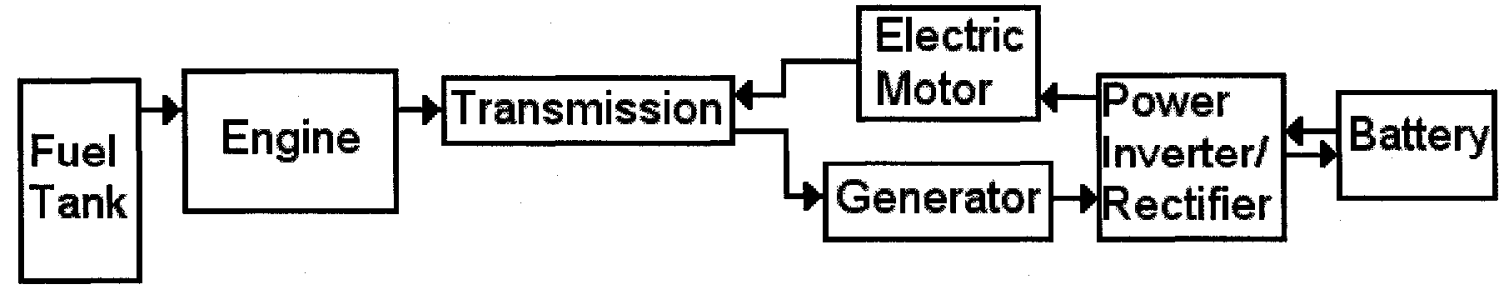

A parallel HEV has three optional power delivery methods. The fuel may be converted into mechanical energy via the ICE and delivered to the wheels by the 
transmission, the battery energy may be translated into mechanical energy through the electric motor, or both these power sources may be used simultaneously. The power flow for the parallel HEV is similar to that of a series-configured HEV, but differs in that the ICE and electric motor are connected to the transmission independently in a parallel HEV.

Unlike the series-configured HEV, the mechanical energy of the ICE in a parallel HEV may be used directly to power the vehicle wheels. As well, parallel HEVs do not require as much additional weight as a series HEV because the electric motor does not need to be sized to meet the maximum speed-torque demand possible from the ICE. Parallel HEVs are thus suited for LDVs. Although the electric motor does not need to be oversized, as is the case for series HEVs, the ICE does not operate at its ideal speed and torque, because the mechanical energy of the ICE is not converted to electrical energy. Thus, the torque and speed cannot be fine-tuned. Parallel HEVs are not as suited to city stop-and-go driving as series HEVs, but they function more efficiently on highways because a parallel HEV only converts the energy once from fuel energy to power the wheels.

\subsubsection{Combined}

A combined HEV may function as a series or parallel HEV, interchangeably. This combination of HEV configurations optimizes the efficiency of the HEV. A combined HEV functions well in both stop-and-go traffic and at high constant speeds. Figure 2.5 illustrates the configuration of the HEV components in a combined hybrid. 
Figure 2.5: Schematic of a combined-type HEV (Adapted from [35])

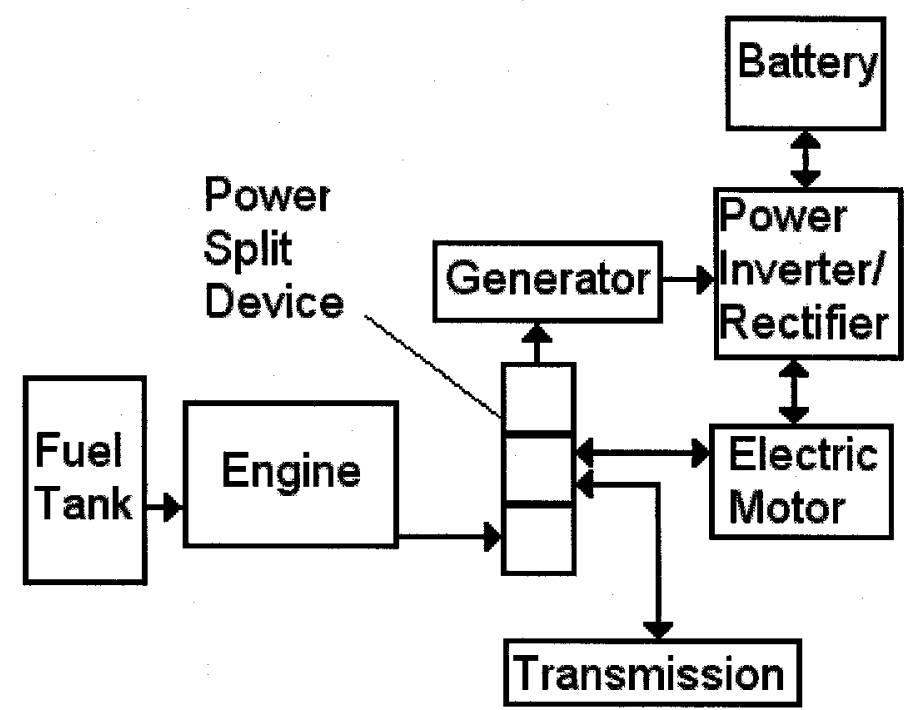

Several routes exist for power to travel in a combined HEV. Power may flow from the ICE, through the power-split device, to the wheels only, or some of this power may be directed to the generator to recharge the battery. Alternatively, both the electric motor, powered by the battery, and the ICE may power the wheels in order to run the ICE at an ideal speed and torque. During low speeds or idle, the battery may power the vehicle by the use of the electric motor. When the vehicle is coasting or slowing down, regenerative energy may be captured from the wheels by the generator. Finally, the ICE may use the fuel energy to charge the battery alone.

Combined HEVs offer the benefit of increased fuel economy, but the drive-train is complicated because of the added electric machine and power-split device [38]. This combined type of HEV has been seen in the light-duty commercial market, most notably in the Toyota Prius and Ford Escape Hybrid. 


\subsection{Braking Strategies}

Conventional mechanical brakes convert all kinetic energy of the wheels into friction energy and are therefore referred to as friction brakes. Regenerative brakes capture a portion, or all, of the kinetic energy of the wheels by connecting the generator (see Section 2.3) to the wheels. The generator resists the rotation of the wheels, and as a result, simultaneously decreases wheel speed and recuperates energy.

Any vehicular braking system has two goals: bring the vehicle to a stop as quickly as possible during emergency braking and bring the vehicle to a stop without losing longitudinal or lateral control [36]. In conventional SI vehicles, braking computers include emergency control systems, such as anti-lock braking systems (ABS). HEVs require more complex computers because regenerative braking is included as an additional braking function. This electronic braking system (EBS) dictates the contribution of regenerative braking for any given braking command. The type of regenerative braking system (RBS) employed will affect the energy recuperated for a given braking command. Two RBSs are discussed in the next two sections: the series and parallel RBS.

\subsubsection{Series Regenerative Braking}

The regenerative braking force in a series RBS is solely used to retard the vehicle motion up to a specific braking effort, as seen in Figure 2.6. At the bottom of Figure 2.6, a constant braking force, entitled compression braking, is shown. Compression braking is inherent to any braking effort, and provides a mild constant deceleration [35]. 
Figure 2.6: Series regenerative braking system (Adapted from [35, 39])

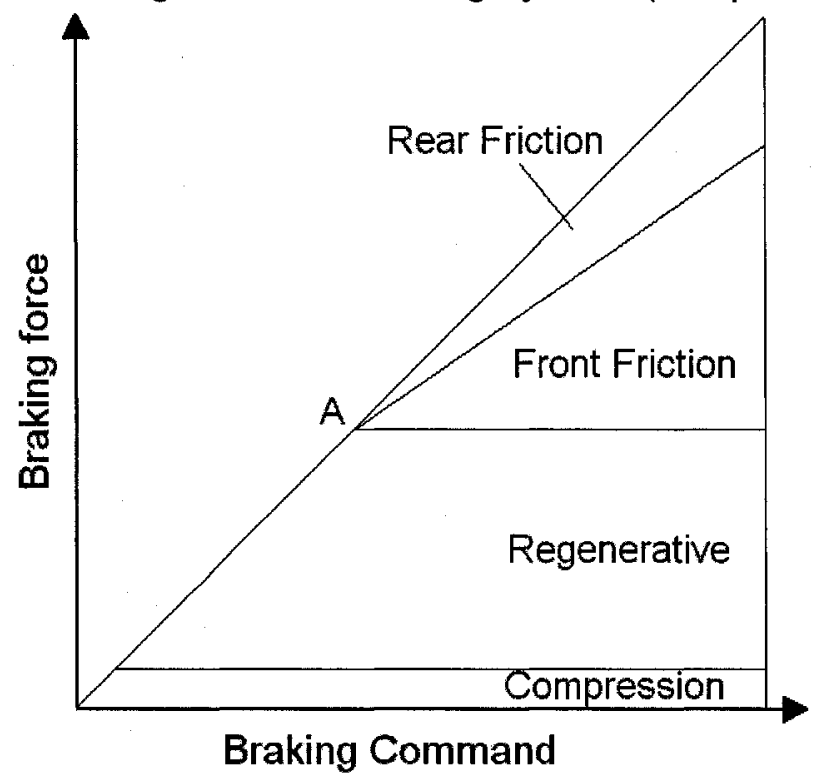

The regenerative brakes, applied by the generator unit, are used alone until some fixed braking command (point $A$ in Figure 2.6), at which point the friction brakes must be incorporated into the braking effort. Although Figure 2.6 implies a linear relationship between the regenerative braking effort and the braking command, this is not entirely true $[35,36]$. As the vehicle speed decreases, the efficiency of the generator decreases so the level of regenerative braking decreases and the friction brakes supplement this loss in braking force. Although not shown in Figure 2.6, at a specific low generator efficiency, the RBS is shut off and the friction brakes account for the total braking effort [35]. Two options for series RBS exist: optimal feel and optimal energy recovery [36].

According to Ehsani, optimal feel series RBS minimizes the stopping distance while optimizing the driver's feel of the braking [36]. If $a_{m p s}>\left(0.2 \times a_{g}\right)$, where $a_{m p s}$ is the acceleration of a vehicle and $a_{g}$ is the acceleration due to gravity $\left(-9.81 \mathrm{~m} / \mathrm{s}^{2}\right)$, then RBS alone is used to retard vehicle motion. Assuming a front wheel drive (FWD) vehicle, when $a_{m p s}<\left(0.2 \times a_{g}\right)$, the braking force is distributed between the front 
and rear brakes, where the front brakes are divided into regenerative and friction brakes, and the rear brakes are friction brakes only.

Ehsani states that series RBS for optimal energy recovery attempts to use regenerative braking as much as is safely possible to retard vehicle motion [36]. Maximum regenerative braking is based on the road adhesion value, $\mu_{\text {road }}$. Equation 2.2 is provided by [36]. When this equation is satisfied, the braking efforts of the front and rear wheels may be varied within a specified range [36].

$$
\frac{a_{m p s}}{a_{g}}<\mu_{\text {road }}, \quad \quad F_{b f}+F_{b r}=m_{v} \cdot a_{m p s}
$$

The terms $F_{b f}$ and $F_{b r}$ refer to front and rear wheel axle braking forces, respectively, and $m_{v}$ refers to the vehicle mass. If the braking command is too large for the regenerative brakes alone, the friction brakes will be applied either in the front, rear or both sets of wheels.

\subsubsection{Parallel Regenerative Braking}

Parallel RBS uses both regenerative and friction brakes to slow the vehicle, for any given braking command. Figure 2.7 provides an example of braking deceleration rates and braking forces for the front, rear and regenerative brakes. The regenerative braking force increases as a function of vehicle deceleration, up to a finite force (shown as point $A$ in Figure 2.7). Thus, complex electrical control over the parallel RBS is not required because a pressure sensor will detect the braking force command and immediately distribute the braking force between the front friction, front regenerative and rear friction brakes [36]. At large braking commands $\left(\frac{a_{m p s}}{a_{g}}>0.9\right)$ the regenerative braking force is designed to be zero so that the braking balance between the front and rear wheels may be maintained [36] 
(Figure 2.7). Similar to series braking, compression braking is present and constant for any level of braking command in parallel RBS.

Figure 2.7: Braking forces for a parallel regenerative braking system (Adapted from [36])

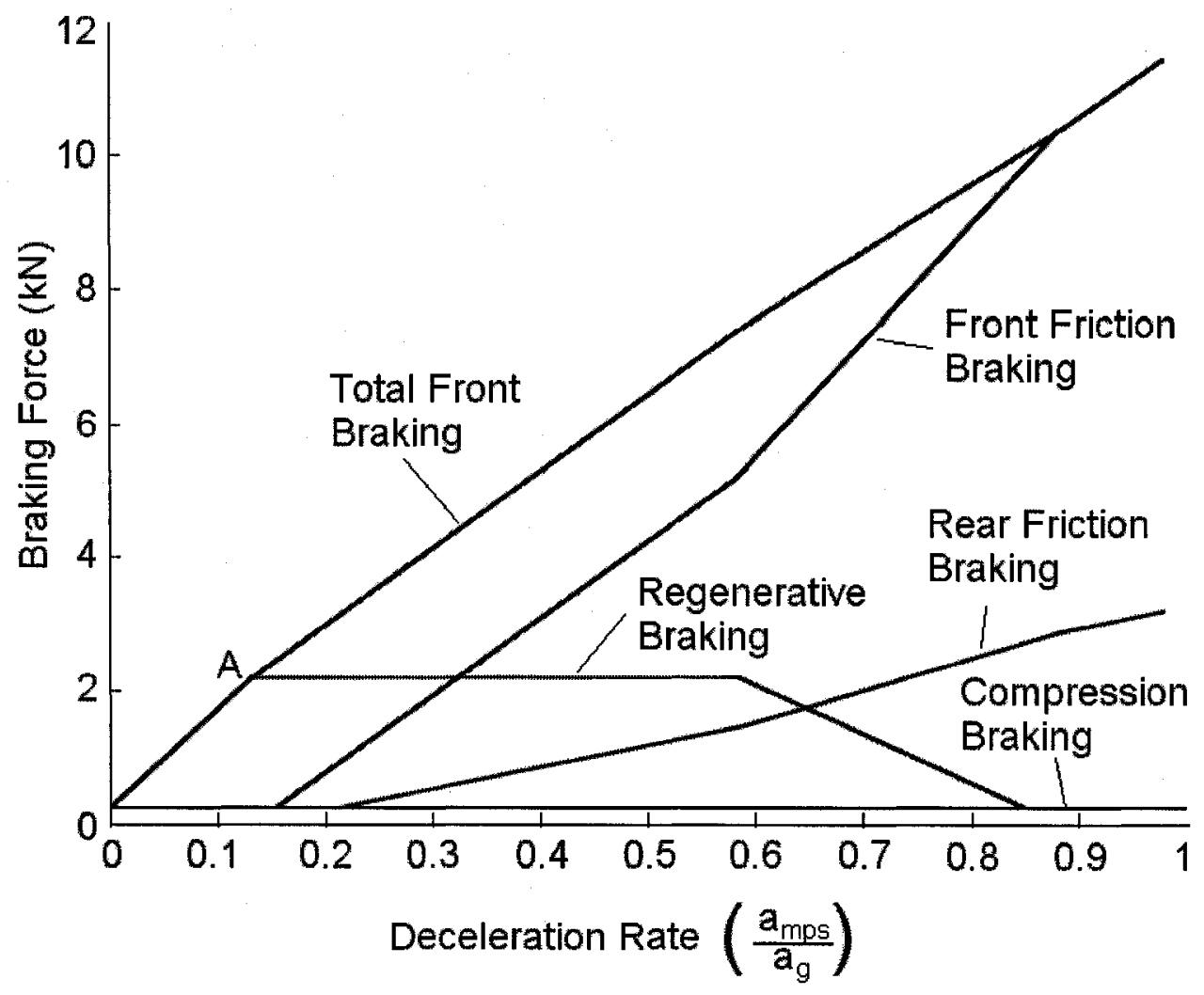

The parallel RBS is easier to implement than the series RBS because the ratio between the front and rear friction brakes is always constant [36]. Conversely, because friction brakes are always contributing to the braking force, parallel RBS does not offer as much energy recuperation potential as series RBS [35]. Regenerative braking is just one example of the routes available for energy to flow through an HEV. Other routes, or operation modes, are discussed in the next section. 


\subsection{Energy Consumption and Recuperation}

HEVs consume (energy sink) and gain (energy source) electrical energy and chemical energy. The ICE and associated components are an energy sink. The battery and fuel tank are energy storage units, while the electric motor is another energy sink, drawing energy from the fuel tank via the ICE or through the battery. Regenerative braking and fuel are energy sources.

The use of an auxillary power source (the battery) in HEVs complicates the flow of energy through the vehicle because it is no longer unidirectional. Sections 2.3.1 to 2.3.3 listed two specific hybrid designs. Below is a list of all the possible operation modes for an HEV, which involves the conventional power train (CPT) and the auxiliary power train (APT) (taken from [36]).

1. CPT alone delivers power to the load.

2. APT alone delivers power to the load.

3. CPT and APT deliver power to load at the same time.

4. APT obtains power from load (regenerative braking).

5. APT obtains power from CPT.

6. APT obtains power from CPT and load at the same time.

7. CPT delivers power to load and APT at the same time.

8. CPT delivers power to ATP, and ATP delivers power to load.

When the CPT delivers power to the load and no other power transfer is made, fuel energy is being converted into mechanical energy (1). This mode of operation is suitable for situations where the use of the APT is not beneficial to fuel economy. At 
low speeds or idling, the APT is able to power the vehicle alone (2). During large accelerations, the CPT may require, or benefit from, the added torque provided by the electric motor, assuming that the battery has a $S O C$ above its minimum charge (3). As the HEV decelerates, regenerative braking can salvage some of the otherwise wasted friction energy and transfer it to the battery (4). For the purposes of this study, regenerative braking energy is considered an energy gain, despite it having originated from the fuel source. If the battery's $S O C$ is very low, it will not be able to supplement the fuel energy, and the CPT will use all of its power during idle to power the battery (5). This energy recuperation may be enhanced during a braking period, when both the CPT and the regenerative brakes can recharge the battery (6). During constant moderate to high speeds, when the battery charge is not full, the ICE may use some of its excess power to recharge the battery (7). It may be advantageous to use the CPT to power the APT and then use the APT to power the load, for instance, to maintain the ICE's speed and torque within the ideal range for optimal efficiency (8). The rate at which the vehicle consumes energy is based upon its operation mode.

The energy sinks listed in this section do not include energy losses. Energy loss is an energy sink, but is described alone in the next section.

\subsubsection{Braking Energy Losses}

Regenerative braking energy increases as the braking demand increases. When other loads act to decrease the vehicle speed, the potential for regenerative braking decreases as well. These loads include aerodynamic drag (Section 3.3), tire flex (Section 3.3), compression braking (Section 2.4.1) and friction braking (see equation 2.3). The load on the friction brakes is often quite large, reducing 
the potential regenerative braking energy significantly. For instance, one study developed favourable braking conditions by selecting a very heavy vehicle and a driving schedule conducive to regenerative braking [40]. The result was that $59 \%$ of the braking power was supplemented by the friction brakes.

Many HEVs are FWD and thus the rear wheels cannot contribute to regenerative braking energy. Instead, this braking energy is lost as frictional heat from the friction brakes. Section 3.3 describes the relationship between the front and rear normal forces as a function of the center of gravity. These normal forces determine the maximum frictional force between the wheel and the road surface and this dictates the braking force per wheel. The brake force distribution between the front and rear wheels may vary within a limited range, so long as the frictional force is greater than the braking force, in order to maintain vehicle stability. Lee and Nelson estimated the power required to stop a vehicle, using equation 2.3 [41].

$$
P_{w / t, i n}=V\left(F_{\text {aero }}+F_{r r}+F_{r f}+F_{\text {trans,I }}\right)
$$

The term, $P_{w / t, i n}$ refers to the power input to the wheel/tire assembly required to stop the vehicle. The aerodynamic force $\left(F_{\text {aero }}\right)$, rear rolling resistance force $\left(F_{r r}\right)$ and front rolling resistance force $\left(F_{r f}\right)$ are described in Section 3.3. The translational inertial force, $F_{\text {trans,I }}$, is that created by the mass of the vehicle in motion and $V$ refers to the vehicle speed. The power input of the wheel/tire assembly is divided between the four wheel assemblies according to the normal force distribution. The braking power input, $P_{b r a k e, i n}$, is the maximum potential power for regenerative braking. Lee and Nelson estimated this parameter by summing the inertial force of the wheel and tire assemblies, $F_{w / t, I}$, and $P_{w / t, i n}$, as seen in equation 2.4 [41].

$$
P_{b r a k e, i n}=f_{d a}\left(P_{w / t, i n}+F_{w / t, I} V\right)
$$


The fraction of braking that occurs on the drive axle, $f_{d a}$, may be 0.7 or more for FWD vehicles [35].

\subsubsection{Typical Braking and Traction Energy Values}

Some studies have been conducted that investigate the energy required to propel and stop an electric vehicle for various driving cycles. As well, regenerative braking energy and front and rear friction braking energy have been estimated by these studies. The results are listed in Table 2.5.

Table 2.5: Simulated braking and total cycle energy values for electric vehicles from two studies

\begin{tabular}{|c|c|c|c|c|c|}
\hline \multirow{2}{*}{ Energy (kJ) } & \multicolumn{5}{|c|}{ Drive Cycle and Study } \\
\hline & NYCC $^{1}[42]$ & FTP [42] & FTP [41] & HWFET [41] & $\mathrm{US}^{2} \mathrm{6}^{2}[41]$ \\
\hline $\begin{array}{l}\text { Regenerative } \\
\text { Braking }\end{array}$ & 864 & 1934 & 1228.1 & 240.0 & 954.8 \\
\hline Total Braking & 878 & 1934 & 3501.7 & 696.0 & 2466.4 \\
\hline $\begin{array}{l}\text { Front Friction } \\
\text { Braking }\end{array}$ & 0 & 0 & N/A & $N / A$ & $N / A$ \\
\hline $\begin{array}{l}\text { Rear Friction } \\
\text { Braking }\end{array}$ & 14 & 0 & $N / A$ & $N / A$ & $N / A$ \\
\hline $\begin{array}{l}\text { Total cycle } \\
\text { energy }\end{array}$ & 998 & 4000 & 14677.6 & 12394.1 & 15294.1 \\
\hline
\end{tabular}

The energy values from [41] are for a FWD electric vehicle with unspecified braking strategy (but $50 \%$ regenerative braking fraction of total vehicle braking energy) and the energy values from [42] are for an electric vehicle with a series, optimal energy recovery braking strategy, with unknown drive system. The regenerative braking energy estimates of [42] are quite large, while those of [41] represent a smaller proportion of the total braking energy. A regenerative braking energy that is comparable in magnitude to the total traction energy indicates a driving cycle

\footnotetext{
${ }^{1}$ New York City Cycle - see Section 4.1.5

${ }^{2}$ Supplemental FTP drive cycle - see Section 4.1.3
} 
for which an electric vehicle or HEV will benefit most from regenerative braking. The total traction energy for an HEV will primarily be derived from the fuel energy. The values reported in Table 2.5 are for modelled vehicles. No real-world battery discharging energy, ICE battery recharging energy, regenerative braking energy or total friction braking energy values for HEVs have been published, to the author's knowledge.

\subsection{Unique Chassis Dynamometer Test Procedures}

Both HEVs and conventional SI vehicles must be tested to ensure emission factors meet regulatory standards. Many of the procedures to test HEVs are similar to those for conventional SI vehicles. However, some characteristics of HEVs require additional consideration when using test procedures for conventional vehicles. These include the use of two-wheel over four-wheel dynamometers, augmented braking, and the state of charge of the hybrid battery. These are discussed below.

The HEV battery can store and/or provide energy, the net effect being reflected in the battery's state of charge (SOC). From test to test, the $S O C$ may change by several percent. In order to standardize each test, a procedure has been suggested by the SAE for charge-sustaining HEVs [43]. A charge-sustaining HEV maintains the battery $S O C$ within a specific range so that, ideally, a net zero change in battery energy results from test to test. However, in actual practice, the battery may contribute or subtract from overall cycle energy. Standardizing regulatory emission compliance tests for SI vehicles and HEVs requires that the net energy change (NEC) of the battery of an HEV be zero. By setting $N E C=0 \%$, the total cycle energy (TCE) for the HEV is comparable to that of the SI vehicle. TCE is the amount of fuel and battery energy consumed throughout a drive cycle. Battery 
$N E C$ is quantitatively defined in Section 5.6. It is the product of the change in $S O C$ throughout the drive cycle $(\triangle S O C)$ and the rated voltage of the HEV battery $\left(V_{N}\right)$.

In order to identify the contribution of $N E C$ to the TCE of a drive cycle, SAE recommends that HEV battery current is continuously measured throughout the duration of a drive cycle test, at 0.05 second intervals. From the current, time and $V_{N}$, the $\triangle S O C$ is found for the drive cycle [44]. The $N E C$ is then calculated and then divided by the TCE. If the ratio between the $N E C$ and the $T C E$ is less than $1 \%$, the test results may be used without any alterations. If, however, this ratio is between $1-5 \%$, the fuel economy and emissions need to be corrected [43]. SAE recommends conducting three repeat tests so that at least three $N E C$ values may be calculated [43]. Then, the $N E C$ and emission factors for each test may be plotted on a graph so that the zero $N E C$ emissions can be linearly interpolated. SAE further recommends that the $\mathrm{R}^{2}$ value for this linear relationship is greater than or equal to 0.8 [43]. If the $N E C-T C E$ ratio is greater than $5 \%$, the results should be voided and the test re-conducted.

It is also recommended that the test be representative of the regenerative braking energy that would be captured on a real road [43]. The front wheels (on a FWD HEV) absorb all of the braking force during a drive cycle on a chassis dynamometer, and the rear wheels contribute no force to braking, thus overstating the effects of regenerative braking. Although [43] does not suggest the use of a four-wheel chassis dynamometer over two-wheel chassis dynamometer, Duoba et. al. recognized that by testing an HEV on a two-wheel chassis dynamometer, all of the braking effort was assigned to the front axle [39]. An HEV decelerating on a road incorporates rear and front axle brakes, so a two-wheel chassis dynamometer 
may overstate the regenerative braking contribution. Duoba et. al. found that "no consistent or significant bias beyond levels of confidence for any typical dynamometer test result" could be found between the two types of dynamometers [39]. Thus, two-wheel chassis dynamometers are sufficient for testing HEVs.

The SAE recommended procedures recognize that, when testing a vehicle on a chassis dynamometer, the tires of a vehicle may slip on the roller(s) [43]. An HEV is affected more than a conventional SI vehicle by this tire slippage because it detracts from the overall potential regenerative braking energy available to the HEV. No provisions have been recommended to avoid this problem.

A standard operating procedure in testing conventional $\mathrm{SI}$ vehicles is the use of augmented braking during testing (see Section 3.5) to facilitate the vehicle in reducing speed. Brake energy does not affect fuel economy or exhaust emissions in $\mathrm{SI}$ vehicles and is therefore not a variable in test procedures. However, HEVs do rely on braking energy to provide regenerative braking energy. Therefore, augmented braking may detract from the regenerative braking energy recovered by HEVs, because the dynamometer motor is removing energy that may otherwise have been recuperated by the HEV RBS. A report by the FreedomCAR \& Vehicle Technologies Program found that augmented braking does not influence the fuel economy of HEVs [45]. The report did not address the loss of regenerative braking energy as a result of augmented braking, nor have any other studies been found that investigate the effect of augmented braking on fuel economy, emissions and regenerative braking energy.

The principles of chassis dynamometer operation and force calculations related to HEVs are addressed in more detail in the next chapter. 


\section{Chapter 3}

\section{Chassis Dynamometer Operation}

This chapter aims to describe the theory of dynamometer operation to provide a background for the calculations in Sections 5.7 .3 and 5.9 as well as context for discussions about augmented braking and regenerative braking energy.

An electrohydraulic chassis dynamometer is a testing apparatus used to simulate on-road vehicle behaviour in a controlled environment. Each chassis dynamometer may test vehicles within a certain vehicle mass range. These mass ranges vary between different chassis dynamometers.

The performance of a vehicle may be characterized by its emissions from the tailpipe, engine parameters, and the forces imposed on the vehicle during the drive cycle test. These forces are measured and recorded in a file, named the Dyno File, that includes real-time measurements of the following parameters: cumulative translational equivalent distance, speed and acceleration of the roller(s), motor simulation force, dynamometer friction force, roller force, road load force, augmented braking forces, and the torque of the dynamometer. This information can be used to determine the energy used for vehicle braking and accelerations. These 
parameters are described and algebraically defined in the following sections.

\subsection{The Chassis Dynamometer}

Figure 3.1 illustrates the basic features of the twin-roller chassis dynamometer used in this study. The two front (or rear) vehicle wheels rest in between the two rollers (4).

Figure 3.1: Twin-roller chassis dynamometer schematic: 1 - electric motor, 2 torque sensor, 3 - speed detector, 4 - roller, 5 - inertia weight, 6 - motor axle (Adapted from [46])

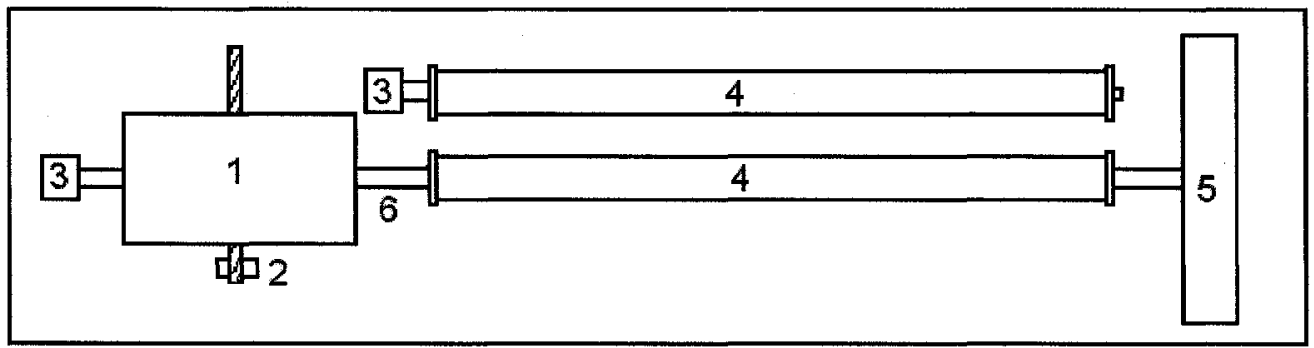

The electric motor (1) produces a variable load to compensate for any difference between the inertial weight of the chassis dynamometer and the vehicle. This compensation is applied during braking routines, to reduce the load on the vehicle, and during transient load routines, such as hill climbing. A torque sensor (2) measures the electric motor torque and relays this reading to the dynamometer computer. A speed sensor (3), in this case an optical sensor, measures the speed of the roller(s) (i.e. vehicle), and relays this information to the driver's aid monitor (see Section 4.5) and dynamometer computer. The dynamometer computer controls the electric motor to provide the correct load on the vehicle. Each of the twin rollers (4) have separate speed sensors because they are not connected, making it possible for them to have different speeds. The roller that is driven by the motor axle (6) is also connected to an inertia weight (5), in this case 
a flywheel. The roller that is not connected to the motor axle is free to rotate.

\subsection{Dynamometer Computer Calculations}

At the time a test begins, the dynamometer computer opens a .txt extension file and begins placing calculated parameters in this file. The computer is able to make these calculations using real-time data and predetermined parameters that are specific to the vehicle and to the chassis dynamometer. The real-time speed is measured at a frequency of $10 \mathrm{~Hz}$ by an optical sensor located at the end of the motor shaft (see Figure 3.1). This sensor measures the number of pulses between each time interval (i.e. 100 milliseconds); while in the case of [46], 1200 pulses represent one rotation of the motor axle, in this study, 5000 pulses represent one rotation. Torque is related to the armature current and speed [46]. Vehicle-specific parameters include vehicle mass and the predetermined road load dynamometer coefficients (Section 3.3). The dynamometer friction force, motor torque and inertial mass are specific to each chassis dynamometer.

\subsubsection{Distance}

An optical sensor pulsates a pre-set number of times per revolution of the motor axle. By dividing the number of pulses at every time interval, $N$, by the number of pulses per revolution of the motor shaft $\left(N_{R}\right)$, and multiplying this fraction with the circumference of the motor shaft $(C)$, the translational equivalent distance traversed by the vehicle is calculated. This parameter is reported at each time interval as the cumulative distance traversed $\left(D_{i}\right)$. Equation 3.1 is used to calculate this cumulative distance. The previous time interval cumulative translational equivalent distance traversed by the vehicle $\left(D_{i-1}\right)$ is added to the 
distance traversed in the present time interval, $i$, to arrive at $D_{i}$.

$$
D_{i}=D_{i-1}+C \cdot \frac{N}{N_{R}}
$$

\subsubsection{Speed and Acceleration}

The translational equivalent average roller surface speed $\left(v_{i}\right)$ at time measurement number $i$, is found as the division of $D_{i}-D_{i-1}$ by the time interval between measurements, which is 0.1 seconds. This expression is shown in equation 3.2.

$$
v_{i}=\frac{D_{i}-D_{i-1}}{0.1 \sec }
$$

The average acceleration of the surface of the chassis dynamometer roller, $a_{i}$, can similarly be found using the speed and time data from two time intervals, namely $t_{i}$ and $t_{i-1}$.

$$
a_{i}=\frac{v_{i}-v_{i-1}}{t_{i}-t_{i-1}}
$$

\subsubsection{Torque}

The torque is the moment that the dynamometer electric motor creates in order to simulate a force for the vehicle. This simulated force includes the motor simulation force and the friction force. The torque can be found by relating the armature current of the electric motor to its rotational speed [46]. It may also be measured by connecting a torque arm to the motor axle such that it strikes a force sensor as it rotates. Using the known length of the torque arm, the motor torque can be found from equation 3.4 , where the torque of the motor $\left(T_{\text {motor }}\right)$ is found as the product of the force of the torque arm on the force sensor, $F_{\text {motor }}$, and the torque arm length, $r_{\text {arm }}$.

$$
T_{\text {motor }}=F_{\text {motor }} \cdot r_{\text {arm }}
$$


The motor force felt at the roller surface, $F_{\text {motor } r}$, can then be calculated as the division of $T_{\text {motor }}$ by the dynamometer roller radius, $r_{\text {roller }}$.

\subsubsection{Motor Simulation Force}

The motor simulation force, $F_{m s}$, mentioned in Section 3.2.3, is created by the dynamometer electric motor. It has a magnitude related to the motor force at the roller surface, as shown in equation 3.5.

$$
F_{m s}=-\left(F_{\text {motor } r}-F_{\text {friction }}\right)
$$

$F_{m s}$ is the subtraction of the dynamometer friction force, $F_{\text {friction }}$, from $F_{\text {motor } r}$. It is the force that the dynamometer motor is simulating at the roller surface. A negative sign precedes the terms on the right side of equation 3.5. This negative sign exists because if the dynamometer motor creates a positive $F_{\text {motor } r}$, it is assisting the vehicle in slowing down, and therefore decreasing the load experienced by the vehicle wheels. Thus a positive $F_{\text {motor } r}$ creates a negative $F_{m s}$.

\subsubsection{Friction Force}

$F_{\text {friction }}$ is the resistant force that the dynamometer experiences as a result of bearing and windage parasitic losses. These losses are correlated to the dynamometer rotational speed (see Figure 3.2). $F_{\text {motor } r}$ is created to simulate real road conditions and is decreased by $F_{\text {friction }}$.

\subsubsection{Roller Force}

The roller force, $F_{\text {roll }}$, is the force that the surface of the roller experiences as a result of the $F_{m s}$ and the acceleration of the dynamometer inertial mass, $m_{i}$. This 
Figure 3.2: Chassis dynamometer friction force and roller speed

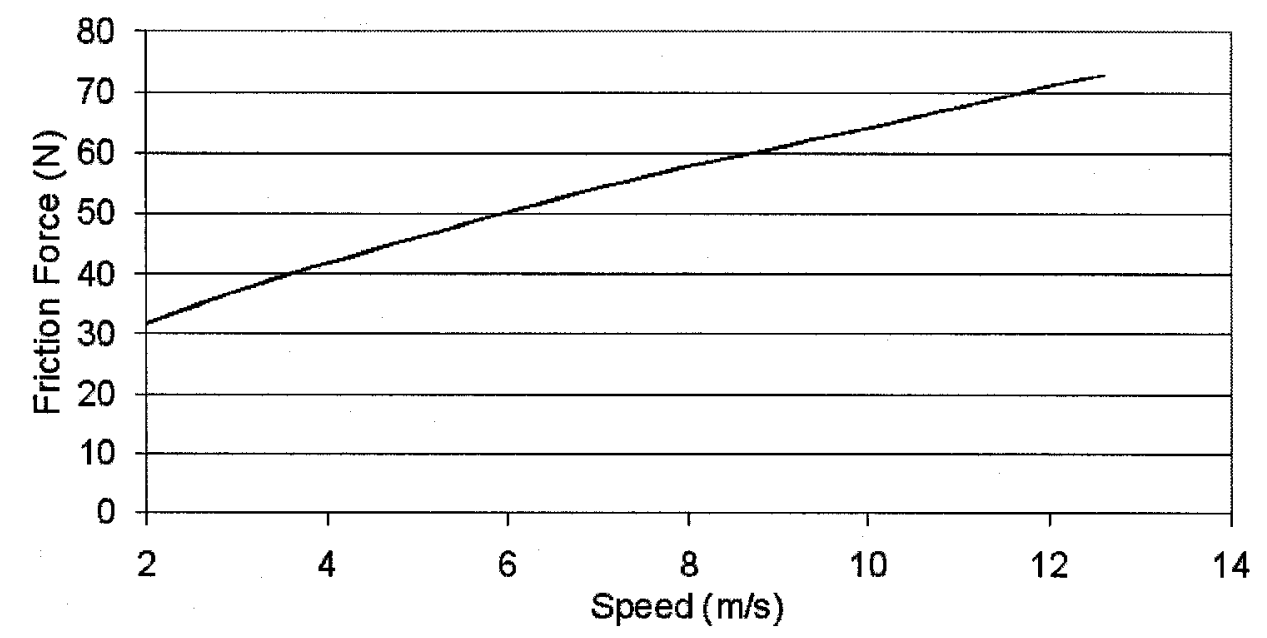

is the force that the vehicle wheels experience.

$$
F_{\text {roll }}=m_{i} \cdot a_{i}+F_{m s}
$$

As described in Section 3.2.4, if a positive force is supplied by the electric motor, then it represents a negative simulated motor force. This is subtracted from the inertial force $\left(a_{i} \cdot m_{i}\right)$ to represent an increase in resistance of the rotation of the vehicle wheels.

When the vehicle brakes are depressed, the roller force will become negative as a result of its negative acceleration. This negative roller force represents the braking force of the vehicle on the chassis dynamometer.

\subsection{Road Load Force}

The road load force (RLF) is the force that the vehicle ICE must exert on the wheels to overcome the sum of the power losses that the vehicle experiences on a real road. On a chassis dynamometer, the $R L F$ is simulated by the electric motor (i.e. 
$\left.F_{m s}\right)$. Every vehicle has a unique $R L F$ correlation to vehicle speed, expressed as a second degree polynomial. This polynomial is empirically determined by running coastdown tests on a real road. The dynamometer electric motor is then calibrated so that it recreates the on-road $R L F$ curve. The forces contributing to the $R L F$ are described here.

The $R L F$ includes all the forces that oppose forward motion of the vehicle: aerodynamic resistance force $\left(F_{\text {aero }}\right)$, rolling resistance force on the front wheels $\left(F_{r f}\right)$, rolling resistance force on the rear wheels $\left(F_{r r}\right)$, the force component of gravity on a gradient opposing forward motion $\left(F_{\text {grad }}\right)$ and the force due to tire flex $\left(F_{f l e x}\right)$. Miller represents the $R L F$ as equation $3.7[35,47]$.

$$
R L F=F_{\text {aero }}+F_{r f}+F_{r r}+F_{\text {grad }}+F_{\text {flex }}
$$

$F_{\text {aero }}$ is the force required to overcome aerodynamic drag and is calculated by equation 3.8 [35], where $C_{d}$ is the vehicle drag coefficient, $A_{f}$ is the frontal area of the vehicle in $\mathrm{m}^{2}$, and $V_{\text {air }}$ is the wind speed parallel to the trajectory of the vehicle.

$$
F_{\text {aero }}=0.5 \cdot \rho_{\text {air }} \cdot C_{d} \cdot A_{f} \cdot\left(V-V_{\text {air }}\right)^{2}
$$

Equation 3.9, provided by [48], does not assume that the wind vector is parallel to the trajectory of the vehicle, thus making this equation more robust. $S$ is assigned a value of +1 when the wind vector is opposing vehicle motion and -1 when it is facing the vehicle trajectory. The density of air is represented by $\rho_{a i r}$, and $V_{x}$ and $V_{y}$ are the wind vectors parallel and perpendicular to the vehicle trajectory, respectively.

$$
F_{\text {aero }}=0.5 \cdot \rho_{\text {air }} \cdot C_{d} \cdot A_{f} \cdot\left[\left(V+S \cdot V_{x}\right)^{2}+V_{y}^{2}\right]
$$

$A_{f}$ was estimated by [48] as,

$$
A_{f}=W_{v} \cdot H_{v} \cdot 0.8
$$


The factor 0.8 approximates that the vehicle clearance from the ground accounts for $20 \%$ of the total frontal area from the ground to the vehicle roof. $W_{v}$ and $H_{v}$ are the width and height of the vehicle in meters, respectively.

The tire friction forces are determined separately for the rear and front wheels. This is because the normal forces on the rear and front wheels are not equal, especially during accelerations or decelerations. Miller provides the equations for these forces, shown below [35]. The term $A$ refers to the distance from the center of gravity of the vehicle to the front wheel axle, while $B$ refers to the distance from the center of gravity of the vehicle to the rear wheel axle. The sum of $A$ and $B$ yields the distance between the front and rear wheel axles. The gradient term, $\cos \theta$ refers to the angle at which the road is inclined. It, and any other gradient terms, are not discussed because all tests in this study were simulated for a zero-gradient road.

$$
\begin{aligned}
& F_{r f}=R\left(\frac{B}{L}\right) m_{v} \cdot g \cdot \cos \theta \\
& F_{r r}=R\left(\frac{A}{L}\right) m_{v} \cdot g \cdot \cos \theta
\end{aligned}
$$

The ratios of $A$ and $B$ over $L$ distributes the total normal force between the front and rear wheels. The friction coefficient, $R$, is the rolling resistance coefficient. This rolling resistance, if unknown, may be estimated by equation 3.13 [36]. This equation is accurate for speeds less than $128 \mathrm{~km} / \mathrm{hr}$ [36].

$$
R=0.01 \cdot\left(1+\frac{V}{100}\right)
$$

The last term in equation $3.7, F_{f l e x}$, is the parasitic loss due to tire flex as the vehicle travels over a road [47]. It may be calculated from equation 3.14 [47]. The tire flex coefficient is represented by $\mu_{\text {flex }}$.

$$
F_{f l e x}=\mu_{f l e x} \cdot m_{v} \cdot g
$$


After the above parameters for the $R L F$ have been quantified, the $R L F$ can be calculated for any vehicle speed between 0 and $128 \mathrm{~km} / \mathrm{hr}$ (assuming the use of equation 3.13). Substituting equations 3.8 to 3.14 into equation 3.7 , the polynomial in equation 3.15 is formed.

$$
R L F=A_{R L F}+B_{R L F} \cdot V_{m p s}+C_{R L F} \cdot\left(V_{m p s}\right)^{2}
$$

The terms $A_{R L F}, B_{R L F}$ and $C_{R L F}$ refer to the RLF coefficients. These are derived from the force equations discussed above.

The SAE requires that the coefficients in equation 3.15 are empirically found by running coastdown tests [48]. This involves accelerating a vehicle on a flat straight road to a speed of $110 \mathrm{~km} / \mathrm{hr}$ and then releasing the accelerator and coasting until the vehicle stops. Some atmospheric parameters need to be accounted for, and the specific procedure for conducting this test is described in $[48,49]$. Once the coefficients of this quadratic equation have been solved for a specific vehicle, the dynamometer computer may be calibrated so that coastdown tests on the dynamometer simulate the real road coastdown tests. An example of an $R L F$ relationship to speed for a NYCC test of the Escape Hybrid is shown in Figure 3.3.

\subsection{Inertial Masses}

Inertial mass refers to the mass of the rotating components of the dynamometer. This mass is found by applying a known force to the rotating components, measuring the resultant acceleration and calculating the mass from $F=m_{i} a$. Some chassis dynamometers have variable inertial masses, controlled by the use of multiple energy storing devices, such as flywheels. By using multiple energy storing devices, the chassis dynamometer becomes more robust because vehicles 
Figure 3.3: Relationship between road load force and vehicle speed; Escape Hybrid NYCC test

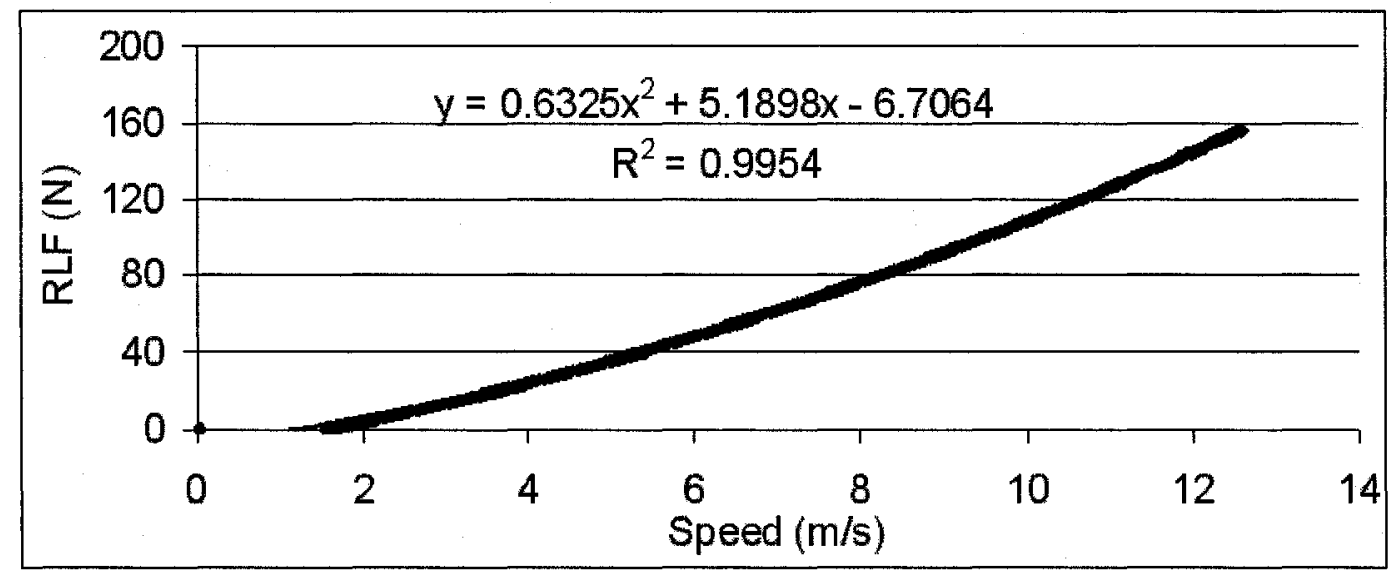

with various masses may be tested. The chassis dynamometer used in this study included a flywheel to increase the inertial mass of the dynamometer, but it was not variable (i.e. there was no gear system to control the flywheel inertial mass).

\subsection{Augmented Braking}

Augmented braking is an optional chassis dynamometer operation that supplements a vehicle's deceleration by providing a retarding force on the dynamometer roller(s). This operation was developed to reduce the amount of particulate matter released from vehicle brake pads, in a test cell, in consideration of the vehicle test driver's health. The retarding force is created by a negative torque applied to the roller shaft by the electric motor.

The chassis dynamometer, in test cell 1 in the ERMD facility, used the following pseudo-code to apply augmented braking. 
aug_braking_force_factor $=0.4$

aug_braking_on_point $=-0.25 \mathrm{~m} / \mathrm{s}^{2}$

If speed $>0 \mathrm{~m} / \mathrm{s}$ and ave_acc $<$ aug_braking_on_point then

Start a delay of $0.2 \mathrm{sec}$

If ave_acc $<-0.25 \mathrm{~m} / \mathrm{s}^{2}$ then

Find new_acc $=$-ave_acc $-(2 \times$ aug_braking_on_point $)$

If new_acc $>1.7 \mathrm{~m} / \mathrm{s}^{2}$ then

new_acc $=1.7 \mathrm{~m} / \mathrm{s}^{2}$

aug_brake_force $=$ aug_braking_force_factor $\times$ new_acc $\times m_{v}$

The augmented braking algorithm is started at any average acceleration measurement (ave_acc) that is less than $-0.25 \mathrm{~m} / \mathrm{s}^{2}$. As well, the augmented braking portion of the braking force applied to the roller (aug_braking_force_factor) is set at $40 \%$ of the total force applied by the vehicle wheels. The computer then ensures that the vehicle speed (speed) is greater than zero, and that its average acceleration is less than the minimum deceleration for augmented braking activation (aug_braking_on_point), $-0.25 \mathrm{~m} / \mathrm{s}^{2}$. If these conditions are met, then the computer waits for 0.2 seconds before rechecking that the average acceleration is less than $-0.25 \mathrm{~m} / \mathrm{s}^{2}$. If this is so, the computer assigns a new acceleration value (new_acc) defined as the sum of $0.5 \mathrm{~m} / \mathrm{s}^{2}$ and the negative of the average acceleration. If this acceleration is greater than $1.7 \mathrm{~m} / \mathrm{s}^{2}$, the computer assigns $1.7 \mathrm{~m} / \mathrm{s}^{2}$ as the new acceleration value. The augmented braking force (aug_braking_force) applied to the roller is then defined as the product of the augmented braking proportion (0.4), the new acceleration and the vehicle mass. 


\section{Chapter 4}

\section{Experimental Procedure}

All testing was conducted at Environment Canada's Emissions Research and Measurement Division, a part of the Environmental Technology Center (ETC) at 335 River Road, Ottawa, Ontario. These tests were conducted on a chassis dynamometer within a controlled environment test cell. Other vehicle testing methods exist, such as remote sensing, tunnel studies and on-board measurement systems, which measure real-world driving emissions. However they do not provide standardized test conditions. The advantage of the chassis dynamometer is that it controls extraneous variables. As well, chassis dynamometer testing is the accepted regulatory procedure used to report vehicle fuel economy and to test for emissions compliance in the United States and Canada. The regulatory framework for vehicle testing in these countries was developed by the U.S. EPA and is titled the Code of Federal Regulations (CFR) Title 40, subchapter C, Part 86 [50].

The 2005 Ford Escape Hybrid, 2004 Toyota Prius, 2003 Honda Civic Hybrid, 2002 SmartCar and 2000 Honda Insight were driven on a chassis dynamometer, over seven different driving cycles, and two different temperatures $\left(20^{\circ} \mathrm{C}\right.$ and $\left.-18^{\circ} \mathrm{C}\right)$, in order to simulate the range of conditions and vehicle responses experienced on- 
road. These temperatures were chosen to represent the ambient temperatures in Canada during summer and winter. Each test, specific to the vehicle, temperature and driving cycle, was repeated at least once.

During each test, the exhaust from the test vehicle was collected, diluted and then analyzed for gaseous emission masses, and particle concentration and number by using several measuring devices. Emissions were continuously collected and measured on a second-by-second basis (real-time emissions) throughout the test. Total test or phase emissions were calculated by analyzing the dilute exhaust captured in inert polymer bags. A phase is part of a multi-phase drive cycle defined by its time span (Figures 4.1 and 4.2). A test is the entire duration of the drive cycle. In this study, the LA4 (and LA92) drive cycle (Sections 4.1.1 and 4.1.2) was run twice, with a 20 minute rest period (soak) in between tests, thus making it a 4-phase drive cycle. The terms 2xLA4 and 2xLA92 will refer to these 4-phase drive cycles. The test emissions of the 2xLA4 (and 2xLA92) drive cycle refer to the composite emissions of the four phases that make up two repeats of a test. Coldstart (CS) and hotstart (HS) emission factors are often used in discussions of ambient temperature effects on emissions. CS and HS emission factors are those of the first test of an LA4 or LA92 (LA4CS or LA92CS), and those of the repeat test of an LA4 or LA92 (LA4HS or LA92HS), respectively. In some instances, CS will refer to only the first or third phase of the $2 x \mathrm{LA} 4$ or $2 x \mathrm{LA92}$. These emission factors will be identified as CS, or HS, phase emissions instead of simply CS or HS emissions.

The gaseous emissions that were collected and analyzed in real-time include $\mathrm{CO}, \mathrm{CO}_{2}, \mathrm{NO}_{x}$, $\mathrm{NO}$ (NO was collected for tests conducted in Test Cell 1) and $\mathrm{HC}$. As well, real-time particulate number and size distributions were calculated 
and reported in a companion study by Christenson [1]. For each test, the realtime dynamometer roller force, augmented braking force, distance, speed and acceleration were measured. The hybrid battery SOC was measured on a secondby-second basis for the Civic Hybrid and the Insight. Hybrid battery electric current was measured for the Prius and Escape Hybrid.

The gaseous cycle emissions that were collected and analyzed include $\mathrm{CO}, \mathrm{CO}_{2}$, $\mathrm{NO}_{x}, \mathrm{HC}$ and $\mathrm{N}_{2} \mathrm{O} . \mathrm{CH}_{4}$ was speciated from the total $\mathrm{HC}$ sample. In this study, the $\mathrm{HC}$ are presented as NMOG, which is the sum of $\mathrm{HC}$, oxygenates and carbonyl compounds subtracted by $\mathrm{CH}_{4}$. For most tests, oxygenates and carbonyl compounds were not speciated, so NMOG is equivalent to NMHC. Particulate matter of size $2.5 \mu \mathrm{m}$ or less, elemental and organic carbon, and sulphate emissions were also analyzed for each test in a parallel study by Christenson [1]. For some of the 4-phase drive cycle tests, carbonyl compounds were speciated.

In the following sections, the seven drive cycles used to test the vehicles on the chassis dynamometer are described. The specifications, condition, and emission technology of the five vehicles are listed, and the fuel properties and vehicle preconditioning procedures are provided. The operation of the chassis dynamometer and the sampling methodology are then outlined.

\subsection{Driving Cycles}

Test vehicles were driven over five transient and two steady state drive cycles. Each drive cycle was characterized by its idling time, accelerations, average speed, duration and length, which are listed in Table 4.1. Each vehicle was driven on all seven drive cycles at ambient temperatures of $-18^{\circ} \mathrm{C}$ and $20^{\circ} \mathrm{C}$. Each vehicle was 
driven over the first two phases of the 4-phase drive cycles and then the last two phases, after a hot soak. A hot soak is a period of time when the vehicle is at rest and the engine is off and warm from its last use.

Table 4.1: Transient drive cycles and their specifications

\begin{tabular}{|l|c|c|c|c|c|}
\hline Parameter & \multicolumn{5}{|c|}{ Driving Cycle } \\
\hline Drive Cycle & LA4 & LA92 & US06 & HWFET & NYCC \\
\hline Maximum Speed $(\mathrm{km} / \mathrm{hr})$ & 91.2 & 107 & 129.2 & 96.4 & 44.6 \\
Average Speed $(\mathrm{km} / \mathrm{hr})$ & 31.5 & 39.6 & 77.9 & 77.8 & 11.4 \\
Maximum Acceleration $(\mathrm{km} / \mathrm{hr} / \mathrm{s})$ & 5.3 & 11.1 & 13.5 & 5.1 & 14.5 \\
Maximum Deceleration $(\mathrm{km} / \mathrm{hr} / \mathrm{s})$ & 5.3 & 14.1 & 11.1 & 5.3 & 18.3 \\
Idling $(\%$ of test time) & 19 & 16 & 7 & 1 & 34 \\
Cycle Length $(\mathrm{km})$ & 12.1 & 15.8 & 12.8 & 16.4 & 1.9 \\
Cycle Time $(\mathrm{sec})$ & 1368 & 1434 & 600 & 762 & 600 \\
Test Type & CS/HS & CS/HS & HS & NC & HS \\
\hline
\end{tabular}

CS refers to a drive cycle driven after an extended time of engine-off, such that the ICE is no longer warm from a previous use. HS tests are any drive cycles driven when the engine is warmed up. Some tests involve no engine crank (NC), such as the HWFET (Section 4.1.4), phases 2 and 4 of the 2xLA4 and 2xLA92 (Sections 4.1.1 and 4.1.2), and the SS tests (Section 4.1.6). Sampling for these tests begins directly after a warm-up drive. Table 4.1 lists the characteristics for the five transient drive cycles: LA4, LA92, US06, HWFET and NYCC. Each of these drive cycles, and the steady state cycles, are described in the following sections.

\subsubsection{LA4}

The LA4 refers to the Los Angeles Route 4 road. This road was used to develop a driving schedule that simulated normal driving routes in an urban setting [51]. The LA4 cycle is composed of two phases, which are identified in Figure 4.1. The LA4 was used to develop the Federal Test Procedure (FTP), also known as the FTP-75 cycle and the Urban Dynamometer Driving Schedule (UDDS) [51]. The FTP has 
the first two phases of the LA4 followed by a repeat of the first phase of the LA4. In this study, a CS LA4 (LA4CS) was run, followed by a twenty minute soak and a HS LA4 (LA4HS). Thus, in this study the 2xLA4, 4-phase drive cycle, was used. The accelerations and speeds of the LA4 are relatively moderate in comparison to other drive cycles. Figure 4.1 shows the speed-time trace of the LA4.

Figure 4.1: The LA4 speed-time trace

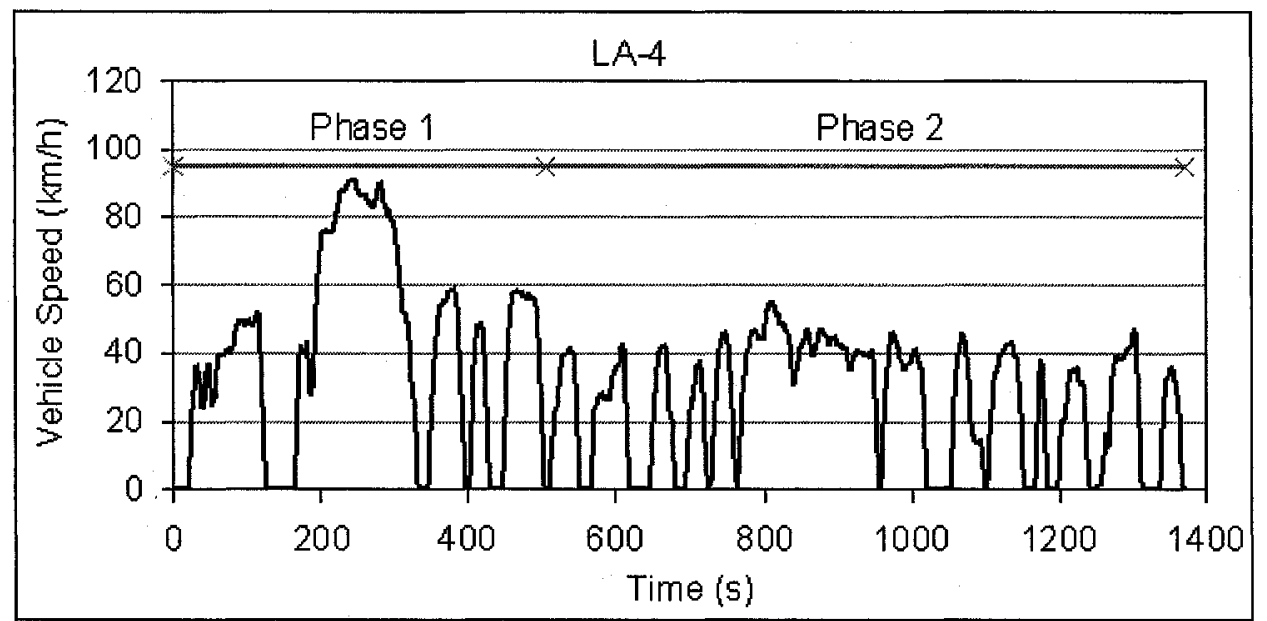

\subsubsection{LA92}

The LA92 drive cycle (Unified Cycle) was developed because U.S. EPA staff members did not believe that the LA4 drive cycle represented modern driving patterns [51]. Figure 4.2 illustrates that the LA92 is a more aggressive cycle than the LA4, characterized by the higher speeds and larger accelerations. Like the LA4, the LA92 was run twice, with a 20 minute soak between the CS and HS.

\subsubsection{US06}

The US06 is one of two supplemental driving cycles for the FTP, developed to more accurately represent real-world driving patterns. This cycle is the most aggressive 
Figure 4.2: The LA92 speed-time trace

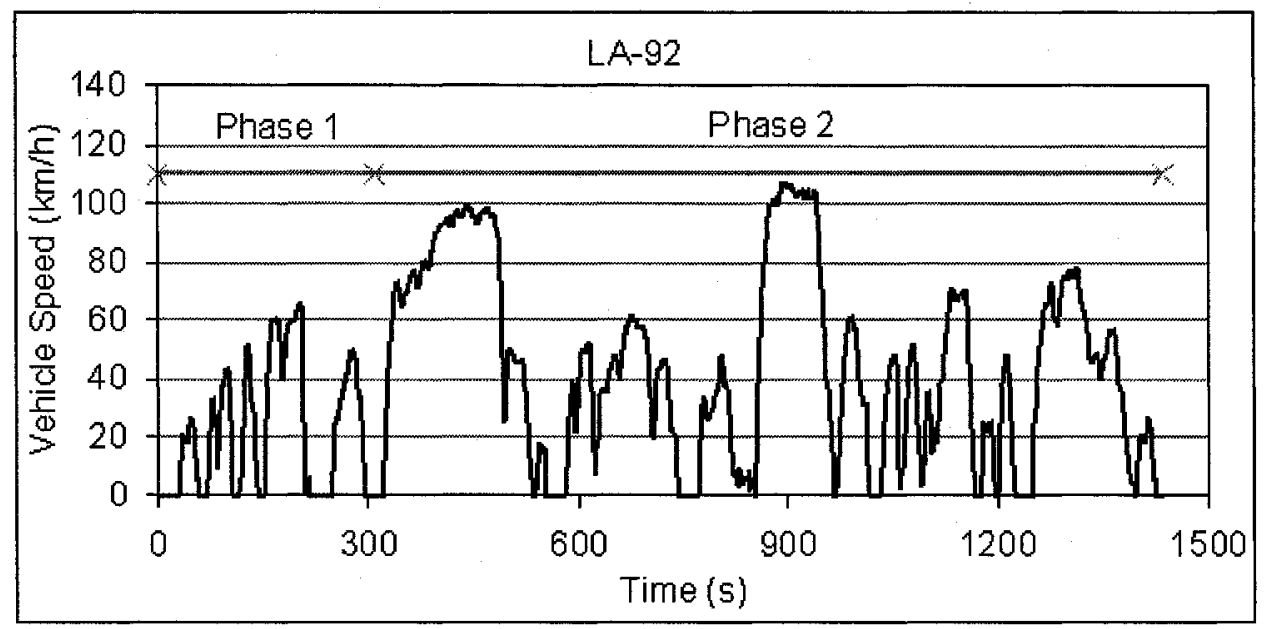

used in this study. As Figure 4.3 shows, the maximum speeds are in excess of $100 \mathrm{~km} / \mathrm{hr}$ and there are many large accelerations. The US06 is originally 600 seconds long, but in this study the US06 was run twice, back-to-back (2xUS06), without an hot soak, so that the HEV's computer could properly regulate the $S O C$ (Section 2.6).

Figure 4.3: The US06 speed-time trace






\subsubsection{HWFET}

The highway fuel economy test (HWFET) was designed to simulate highway driving. Similar to the FTP, the HWFET is used to calculate vehicle fuel economy. This cycle was run once, as a warm-up without measurements, and again immediately after with measurements, without shutting off and restarting the engine. Notice that there are only four large decelerations and accelerations in this cycle; otherwise the speed is relatively constant (see Figure 4.4).

Figure 4.4: The HWFET speed-time trace

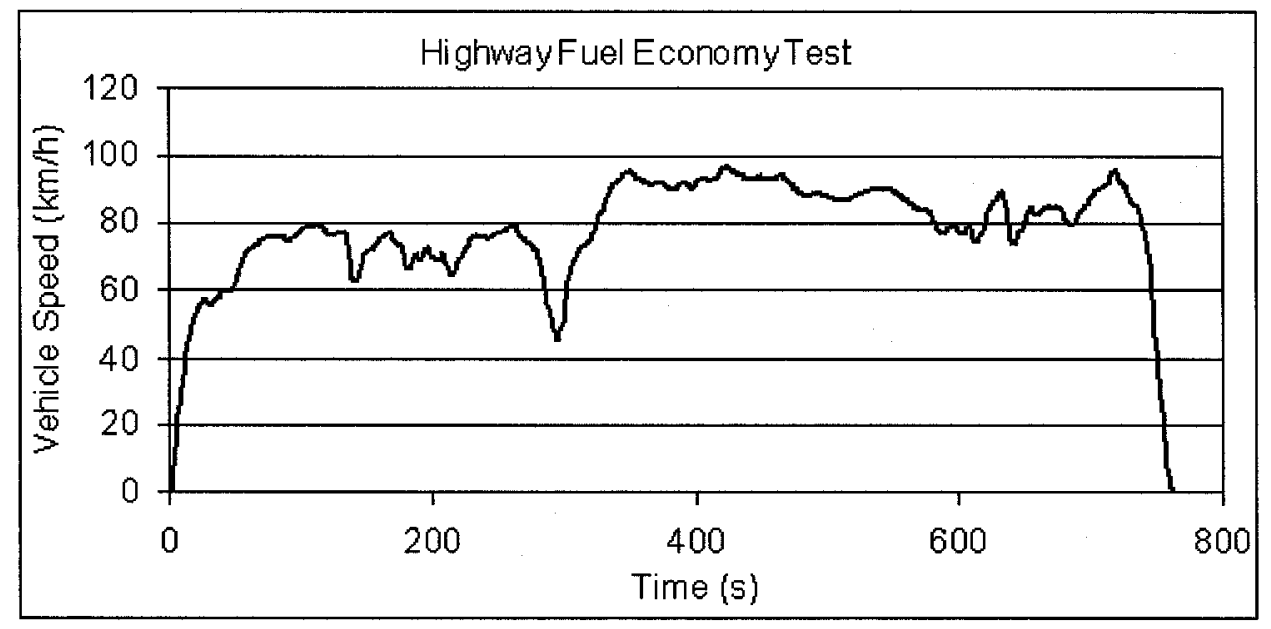

\subsubsection{NYCC}

The New York City Cycle (NYCC) is a drive cycle designed to represent the driving conditions in heavily congested urban centers. Like the US06, this cycle was run twice, back-to-back (2xNYCC), without an hot soak. This cycle contains long idling periods with large accelerations and low speeds (see Figure 4.5). 
Figure 4.5: The NYCC speed-time trace

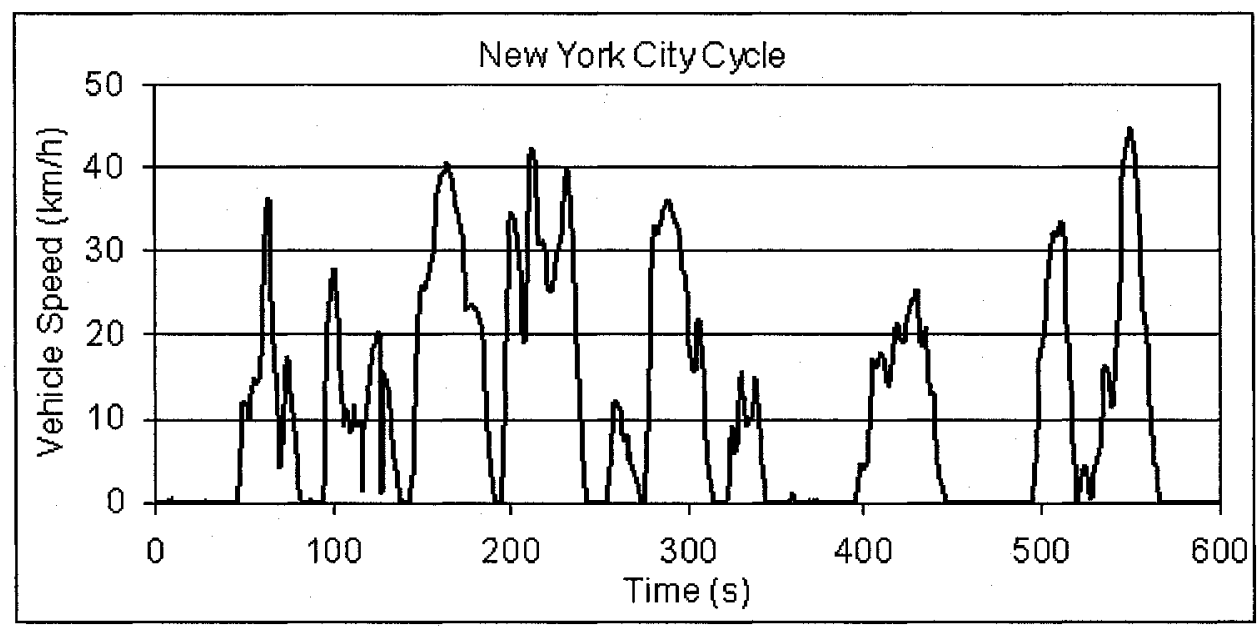

\subsubsection{Steady State}

The steady state drive cycle is unlike the above drive cycles because it is not transient. The vehicle was brought to a speed of either 40 or $80 \mathrm{~km} / \mathrm{hr}$ and driven for 20 minutes as a warm-up. Immediately following the 20 minute mark, the test cycle began, and measuring instruments were initiated until the end of the cycle (20 minutes later). This drive cycle captured the fuel economy of the HEVs without the use of the battery as an APT (see Chapter 2).

\subsection{Vehicles Studied}

The HEVs that were tested in this study include the 2000 Honda Insight, 2003 Honda Civic Hybrid, 2004 Toyota Prius and the 2005 Ford Escape Hybrid. The 2002 gasoline Cabriole SmartCar was tested alongside the hybrids, as a comparative conventional SI vehicle, with a similarly sized ICE. All of the HEVs have at least one catalytic converter, to reduce tailpipe emissions. The properties of each vehicle are listed in Table 4.2. 
Table 4.2: Test Vehicle Specifications (Transport Canada, 2005, as cited by [1])

\begin{tabular}{|c|c|c|c|c|c|}
\hline Test Vehicle & $\begin{array}{ll}\text { Honda } & \text { Insight } \\
(2000) & \end{array}$ & $\begin{array}{l}\text { Cabriole Smart- } \\
\text { Car (2002) }\end{array}$ & $\begin{array}{l}\text { Honda Civic Hy- } \\
\text { brid (2003) }\end{array}$ & \begin{tabular}{ll|} 
Toyota & Prius \\
(2004) & \\
\end{tabular} & $\begin{array}{l}\text { Ford Escape } \\
\text { Hybrid (2005) }\end{array}$ \\
\hline Hybrid Design & Parallel & $\mathrm{NA}$ & Parallel & Combined & Combined \\
\hline Curb Weight $(\mathrm{kg})$ & 996 & 730 & 1245 & 1313 & 1720 \\
\hline Transmission Type & 5-speed manual & $\begin{array}{l}\text { 6-speed } \\
\text { automatic }\end{array}$ & $\begin{array}{l}\text { Electric contin- } \\
\text { uously variable } \\
\text { (ECVT) }\end{array}$ & $\begin{array}{l}\text { Electric contin- } \\
\text { uously variable } \\
\text { (ECVT) }\end{array}$ & $\begin{array}{l}\text { Electric contin- } \\
\text { uously variable } \\
\text { (ECVT) }\end{array}$ \\
\hline Engine & Inline 3-cylinder & $\begin{array}{l}\text { Inline 3-cylinder } \\
\text { turbocharged } \\
\text { multi-port fuel } \\
\text { injection (MPFI) }\end{array}$ & $\begin{array}{l}\text { Inline 4-cylinder } \\
\text { multi-port fuel } \\
\text { injection (MPFI) }\end{array}$ & $\begin{array}{l}\text { Inline 4-cylinder } \\
\text { multi-port fuel } \\
\text { injection (MPFI) }\end{array}$ & $\begin{array}{l}\text { Inline 4-cylinder } \\
\text { multi-port fuel } \\
\text { injection (MPFI) }\end{array}$ \\
\hline $\begin{array}{l}\text { Cylinder } \\
\text { Displacement } \\
\left(\mathrm{cm}^{3}\right)\end{array}$ & $995^{1}$ & 599 & 1339 & 1497 & 2300 \\
\hline $\begin{array}{l}\text { Maximum Power - } \\
\text { no motor assist (kW } \\
@ \text { rpm) }\end{array}$ & $51 @ 5700^{1}$ & $40 @$ unknown & $63 @ 5700^{2}$ & $57 @ 5000^{3}$ & $99 @ 6000$ \\
\hline $\begin{array}{l}\text { Torque - no motor } \\
\text { assist (N.m @ rpm) }\end{array}$ & $91 @ 4800^{1}$ & $\begin{array}{l}80 @ 2000- \\
4500\end{array}$ & $119 @ 3300^{2}$ & $115 @ 4200^{3}$ & $168 @ 4250$ \\
\hline Electric Motor & $\begin{array}{l}\text { Permanent } \\
\text { Magnet AC }\end{array}$ & NA & $\begin{array}{l}\text { Permanent } \\
\text { Magnet AC }\end{array}$ & $\begin{array}{l}\text { Permanent } \\
\text { Magnet AC }\end{array}$ & $\begin{array}{l}\text { Permanent } \\
\text { Magnet AC }\end{array}$ \\
\hline $\begin{array}{l}\text { Maximum } \\
(\mathrm{kW} @ \text { rpm) }\end{array}$ & $10 @ 5700$ & NA & $10 @ 0-5700$ & $\begin{array}{l}50 @ 1250- \\
1540^{3}\end{array}$ & $\begin{array}{l}70 @ 3000- \\
5000\end{array}$ \\
\hline $\begin{array}{l}\text { Maximum Torque } \\
\text { (N.m @ rpm) }\end{array}$ & $34 @$ unknown & NA & $62 @ 0-1000$ & $400 @ 0-1000^{3}$ & Not available \\
\hline Hybrid Battery Type & $\begin{array}{l}\text { NiMH (Nickel } \\
\text { Metal Hydride) }\end{array}$ & $\mathrm{N} / \mathrm{A}$ & $\begin{array}{l}\text { NiMH (Nickel } \\
\text { Metal Hydride) }\end{array}$ & $\begin{array}{l}\text { NiMH (Nickel } \\
\text { Metal Hydride) }\end{array}$ & $\begin{array}{l}\text { NiMH (Nickel } \\
\text { Metal Hydride) }\end{array}$ \\
\hline Battery Voltage (V) & 144 & $N / A$ & 144 & 201.6 & 330 \\
\hline $\begin{array}{l}\text { Battery Capacity } \\
\text { (Ah) }\end{array}$ & 6 & $N / A$ & 6 & 6.5 & 6 \\
\hline Number of Cells & $120^{1}$ & N/A & Not available & $168^{3}$ & Not available \\
\hline Fuel Economy & & & & & \\
\hline $\begin{array}{l}\text { NRCAN (City/Hwy) } \\
(\mathrm{L} / 100 \mathrm{~km})\end{array}$ & $3.9 / 3.2$ & $4.8 / 3.8$ & $4.9 / 4.6$ & $4.0 / 4.2$ & $6.6 / 7.0$ \\
\hline $\begin{array}{l}\text { NRCAN } \\
\text { Conventional } \\
\text { Equivalent } \\
\text { (City/Hwy) } \\
(\mathrm{L} 100 \mathrm{~km}) \\
\end{array}$ & N/A & $N / A$ & $\begin{array}{l}2003 \text { Honda } \\
\text { Civic } 7.5 / 5.7\end{array}$ & $\begin{array}{ll}2004 & \text { Toyota } \\
\text { Corolla } 7.1 / 5.3\end{array}$ & $\begin{array}{l}2005 \text { Ford Es- } \\
\text { cape } 9.7 / 7.3\end{array}$ \\
\hline $\begin{array}{ll}\text { CARB } & \text { Emission } \\
\text { Rating } & \\
\end{array}$ & ULEV & $\mathrm{N} / \mathrm{A}$ & $\begin{array}{l}\text { SULEV } \\
\text { PZEV }^{4} \\
\end{array}$ & $\begin{array}{l}\text { SULEV } \\
\text { PZEV } \\
\end{array}$ & $\begin{array}{l}\text { SULEV } \\
\text { PZEV } \\
\end{array}$ \\
\hline
\end{tabular}




\subsubsection{Honda Insight}

The Insight was the first commercially sold HEV in North America. This vehicle employs a technology called the integrated motor assist (IMA) drive [32]. The IMA is composed of a gasoline engine, standard 12 Volt starter, electric motor-generator unit, inverter, transmission and the hybrid battery. These components are related as shown in Figure 4.6 for a FWD vehicle.

Figure 4.6: The Honda integrated motor assist system (Adapted from [54])



The Insight uses a parallel architecture and a series braking strategy. The manual transmission model, used in this study, does not recuperate as much regenerative braking energy as the ECVT, because the clutch must be engaged in order to capture regenerative braking energy. Thus, engine friction decreases the vehicle speed in conjunction with the regenerative brakes [39].

The Insight's emission reducing technologies include an integrated exhaust manifold and cylinder head, a NO${ }_{x}$ adsorption reaction catalyst, and a TWC at the rear of the ICE [32]. Furthermore, the Insight has an idle-stop feature that allows the ICE to shut off while the battery provides power during idling. If the ICE is off and the accelerator is depressed, the electric motor cranks the engine up to $600 \mathrm{rpm}$ before ignition [32]. The injection nozzles are swirled and the cylinder volume is minimized so that the air and fuel are more mixed [32]. As well, the ICE uses a lean burn to ensure a more complete combustion [32]. 


\subsubsection{Cabriole SmartCar}

Although the gasoline version of the Cabriole SmartCar was used in this study, it is not commercially available in North America. The SmartCar's engine size is similar to that of the HEVs used in this study, allowing a comparison between the two types of vehicles. This vehicle was designed to meet EURO III emission standards (Section 2.1) and is equipped with a TWC (Transport Canada, 2005, as cited by [1]).

\subsubsection{Honda Civic Hybrid}

The Civic Hybrid, like the Insight, employs the IMA drive and a parallel hybrid design. It has a TWC and a $\mathrm{NO}_{x}$ adsorption reaction catalyst placed underfloor, similar to the Insight [52]. As well, it is equipped with a 6-hole multi-hole injector, for improved $A / F$ mixing, and an electric exhaust gas recirculation (EGR) valve, for precise control of gas flow [52]. The Civic Hybrid also has a quick warm-up system, and a lean burn control at low temperature starts [52]. Like the Insight, the Civic Hybrid has an idle stop feature, except that the electric motor cranks the ICE up to 400 rpm before ignition [52].

\subsubsection{Toyota Prius}

The Toyota Prius is the best selling HEV in North America, to date [55]. It uses Toyota's patented second generation Hybrid Synergy Drive II (HSD II) to control vehicle power. This system employs a power-split device (planetary gear set) that allows the Prius to run as a parallel, series or combined HEV [53] (see Figure 4.7). The size of the components in the HSD II allows the ICE to shut off while the vehicle accelerates, at low vehicle speeds and while the vehicle is idling. 
Figure 4.7: Toyota's second generation Hybrid Synergy Drive II (Adapted from [54])

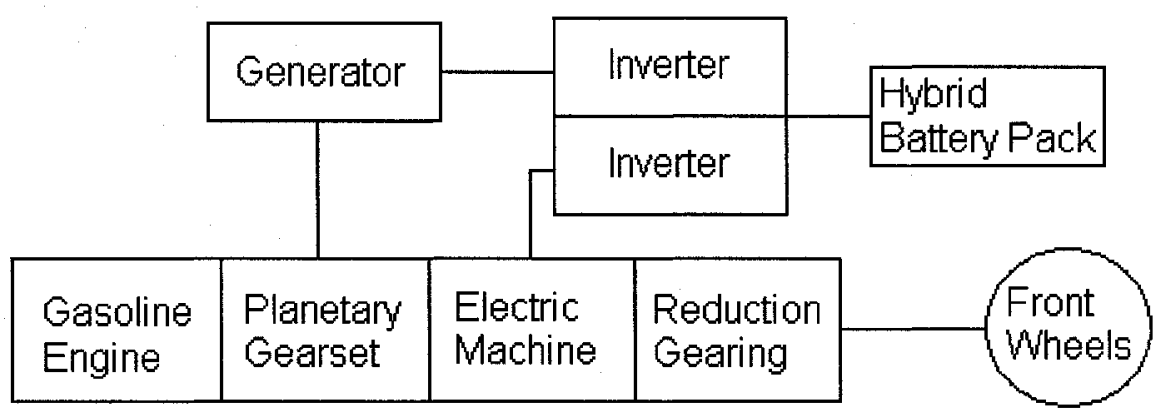

According to Muta et. al., the Prius is equipped with a vapour reduction tank, to reduce evaporative emissions, and a starter TWC mounted near the exhaust manifold. The Prius has a front A/F ratio sensor and a rear oxygen sensor to regulate the A/F ratio and determine TWC efficiency. This HEV has a second TWC (underfloor), a coolant heat storage system, and a quick catalyst warm-up, created by a retarded ignition timing and a stoichiometrically maintained $A / F$ ratio [53].

\subsubsection{Ford Escape Hybrid}

The Escape Hybrid is the first SUV HEV to be commercially produced in North America [56]. Like the Prius, the Escape Hybrid uses the patented HSD II to power the vehicle (see Figure 4.7) and it is equipped with a TWC (Transport Canada, 2005 , as cited by [1]).

\subsection{Vehicle Condition and Mileage}

On the day of the test, the tire pressure of each vehicle was measured and set to $40 \mathrm{psi}$, for those being tested on the twin-roller dynamometer, or to the manufacturer recommended pressure, for those tested on the single roll chassis dynamometer. The lubricants used were those recommended by the manufacturer 
of the vehicle, and no defeat devices were used to inhibit vehicle operations. All vehicle components were aged with the vehicle, and regenerative braking was enabled for all tests. For the cold temperature tests, augmented braking (see Section 3.5) on the dynamometer was enabled. Augmented braking was not used for the Prius tests conducted at $20^{\circ} \mathrm{C}$. At the end of this study the vehicles had accumulated the mileage shown in Table 4.3.

Table 4.3: Test vehicle mileages at the end of testing

\begin{tabular}{|l|l|l|l|l|l|}
\hline Vehicle & $\begin{array}{l}\text { Ford } \\
\text { Escape } \\
\text { Hybrid }\end{array}$ & $\begin{array}{l}\text { Toyota } \\
\text { Prius }\end{array}$ & $\begin{array}{l}\text { Honda } \\
\text { Civic } \\
\text { Hybrid }\end{array}$ & $\begin{array}{l}\text { Cabriole } \\
\text { SmartCar }\end{array}$ & $\begin{array}{l}\text { Honda In- } \\
\text { sight }\end{array}$ \\
\hline Mileage $(\mathrm{km})$ & 8977 & 5564 & 8670 & 16300 & 23348 \\
\hline
\end{tabular}

\subsection{Vehicle Preconditioning and Fuel Properties}

Before a vehicle was tested on the chassis dynamometer, specific pre-test procedures were carried out. These procedures are outlined here. Further details are available from the CFR Title 40, Part 86.131-132 [50]. The properties of the fuels used in this study are also provided in this section.

Before a vehicle was tested it was pushed onto the dynamometer and a certified test driver drove the vehicle over a preconditioning cycle (either the LA4 or LA92 drive cycle). The exhaust was captured by the sampling measurement devices, but it was not analyzed at any point. The vehicle was then soaked in the test cell, for a period ranging between 12 and 36 hours, at a temperature of either $-18^{\circ} \mathrm{C}$ or $20^{\circ} \mathrm{C}$, depending on the temperature of the scheduled tests. This preconditioning cycle needed to be driven only once if repeat tests were conducted at the same 
temperature. If the vehicle needed refueling, it was soaked afterward for a period of at least one hour. When required, vehicle fuel was exchanged by completely draining the fuel tank, refilling it with the new test fuel, running the vehicle at idle for one minute, and again draining and refilling the fuel tank.

Two different fuels were used for testing the vehicles: California Phase II Reformulated fuel for $20^{\circ} \mathrm{C}$ tests and Canadian commercial winter grade fuel for $-18^{\circ} \mathrm{C}$ tests. The properties of these fuels are listed in Table 4.4 .

Table 4.4: Test fuel specifications

\begin{tabular}{|l|l|l|l|l|l|}
\hline Fuel & $\begin{array}{l}\text { Carbon } \\
\text { Fraction }\end{array}$ & $\begin{array}{l}\text { Oxygen } \\
\text { Fraction }\end{array}$ & $\begin{array}{l}\text { Sulfur } \\
\text { (ppm) }\end{array}$ & kJ/kg & $\begin{array}{l}\text { Specific } \\
\text { Gravity }\end{array}$ \\
\hline $\begin{array}{l}\text { California } \\
\begin{array}{l}\text { Phase II } \\
\text { Reformulated } \\
\text { Canadian Win- } \\
\text { ter Grade }\end{array}\end{array}$ & 0.843 & 0.0178 & 37 & 42175 & 0.743 \\
\hline
\end{tabular}

\subsection{Chassis Dynamometer Calibration and Opera- tion}

Each chassis dynamometer was calibrated to the specifications of CFR Title 40, Part 86.118. The dynamometer was calibrated at least once a month, and its performance verified at least once a week. Calibration of the dynamometer involved determining the frictional power absorption by rotating the rollers up to $50 \mathrm{mph}$, disengaging the drive motor and allowing the rollers to coastdown. The weekly performance verification was done by conducting a dynamometer coastdown, and comparing the coastdown time to previous calibration coastdown 
times. If the coastdown time deviated by more than one second, a calibration of the dynamometer was required.

The operation of chassis dynamometers is described in Chapter 3. This study used two different dynamometers. All $-18^{\circ} \mathrm{C}$ tests and some $20^{\circ} \mathrm{C}$ tests were run on the 8.65 inch diameter twin-roller dynamometer. Other $20^{\circ} \mathrm{C}$ tests were run on the 48 inch diameter single-roller dynamometer. Each dynamometer had a different test cell, with its own dedicated computer system that controlled the ambient environment, dynamometer operation, and the gas analyzer bench.

The test vehicles, provided by Transport Canada, came with specification sheets listing their empirical road load coefficients. Each vehicle was driven on a coastdown test on both dynamometers. This was done to match the two sets of dynamometer road load coefficients to the empirical coefficients, and was accomplished by varying the dynamometer load (see Section 3.3). Every morning, before testing began, the dynamometer was warmed up. The vehicle was restrained from lateral or longitudinal displacement by cables that were hooked into reinforced concrete poles, shown in Figure 4.8.

The vehicle hood was opened and a fixed speed fan (maximum of $15000 \mathrm{ft}^{3} / \mathrm{min}$ flow rate) was placed 12 inches away from the hood, in order to cool the engine during testing. At the start of a test, the driver cranked the engine, and an analyst initiated sampling at the same time. The speed-time trace of the drive cycle appeared on a monitor above the dashboard. The dynamometer computer relayed a linear translation of the rotational roller speed to this monitor so that the driver could accurately follow the trace. At the end of the drive cycle test, the driver and analyst synchronized the end of the drive cycle trace with the end of sampling. 
Figure 4.8: The SmartCar on a chassis dynamometer (Taken from [1])

Dynamometer Rollers

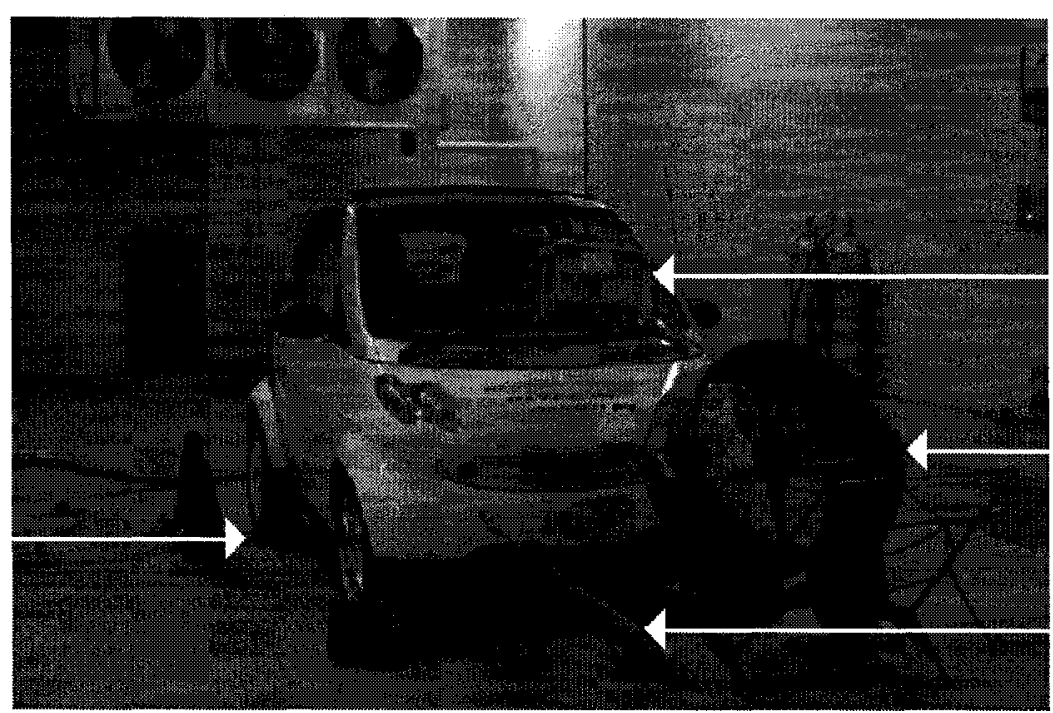

Monitor for

Trace Speed

Fixed Speed

Fan

Restraining Cables

\subsection{Sampling Methodology}

The constant volume sampler (CVS) schematic, illustrated in Figure 4.9, shows the main parts and devices connected to the dilution tunnel and sampling lines. The exhaust travelled from the tailpipe, through the exhaust tunnel (3) and mixed with dilution air. The dilution air was pumped from outside and passed through a series of five filters (1): a pleated dust filter and a pocket dust filter, an activated carbon filter, another pleated filter and a high efficiency particle air (HEPA) filter. The exhaust and air mixed in a portion of the dilution tunnel (6) within the test cell (5).

This segment of the dilution tunnel was insulated with a heated blanket (4) to prevent the dilute exhaust from condensing or chemically reacting. The dilute exhaust then entered a length of the CVS where multiple sample lines withdrew some of the diluted exhaust into the following measuring instruments. The ejector diluter (7) further diluted a portion of the dilute exhaust for analysis by the electrical 
low pressure impactor (ELPI) (8), and by the condensation particle counter (CPC) (9). Dilute exhaust was pumped to the test cell emission bags (10) for determination of $\mathrm{HC}, \mathrm{NO}_{x}, \mathrm{CO}$ and $\mathrm{CO}_{2}$ concentrations by the gas analyzer bench (11).

Figure 4.9: Constant volume sampler schematic: 1 - Filters for dilution air, 2 Dilution air filter packs, one containing a TMF and QFF, one containing only a QFF, 3 - Exhaust tunnel, 4 - Heated blanket, 5 - Test cell boundary, 6 - CVS dilution tunnel, 7 - Ejector diluter, 8 - ELPI, 9 - CPC, 10 - Test cell bags for integrated emissions, 11 - Gas analyzer bench, 12 - Sample cart for unregulated emissions, 13 - Sample filter packs and cyclones, one containing a TMF and QFF, one containing a QFF only, 14 - Choked flow venturi (Adapted from [1])

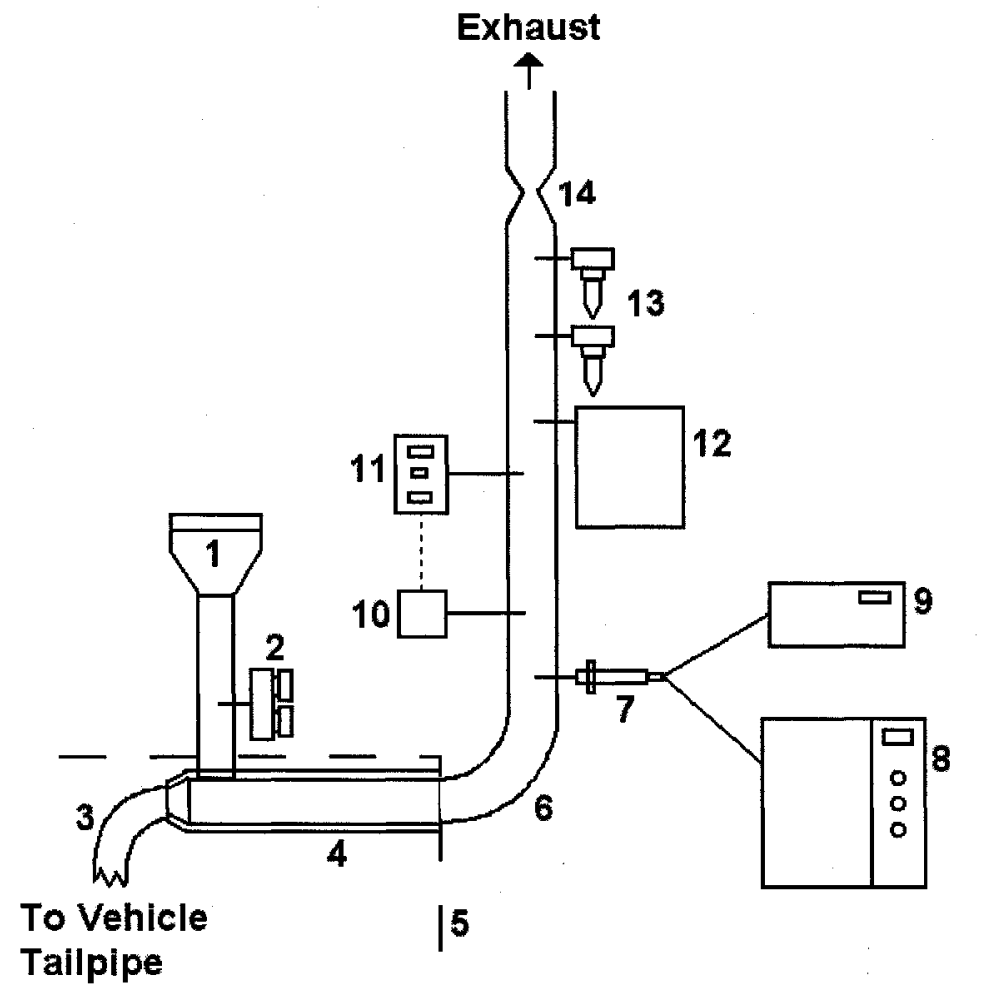

The gas analyzer bench also collected dilute exhaust from the dilution tunnel to measure real-time emission rates of the above gaseous emissions. The sample cart (12) collected dilute exhaust in 2,4-DNPH coated cartridges for carbonyl speciation, and in sample bags for light hydrocarbon (LHC) and $\mathrm{N}_{2} \mathrm{O}$ speciation. The dilution air filter packs (2) included one containing a teflon membrane filter (TMF) and quartz filter (QFF), and another containing QFF only. The sample filter 
packs and cyclones (13) also contained these filters. These two devices were used to measure PM mass concentrations, which were analyzed in a companion study [1]. A choked flow venturi (14) that maintained constant gas flow was downstream from the sampling ports. The remaining dilute exhaust, not sampled by the measuring devices, was ejected outside of the facility.

Figure 4.10 is a schematic of a test vehicle in the test cell. The vehicle (1) rests on the twin-rollers of the dynamometer (2), and the fixed speed fan (3) faces the front of the vehicle. Depending on the vehicle tested, either the on-board diagnostics (OBD) II monitor (4), or the amp probe and multimeter (5), are used to measure the battery $S O C$ (see Section 4.6.5). The exhaust of the vehicle travels through its exhaust pipe and exits the tailpipe (6) into the exhaust tunnel.

Figure 4.10: Test vehicle schematic: 1 - hybrid test vehicle, 2 - twin-rollers of the dynamometer, 3 - fixed speed fan, 4 - OBD II monitor, 5 - amp probe and multimeter, 6 - tailpipe

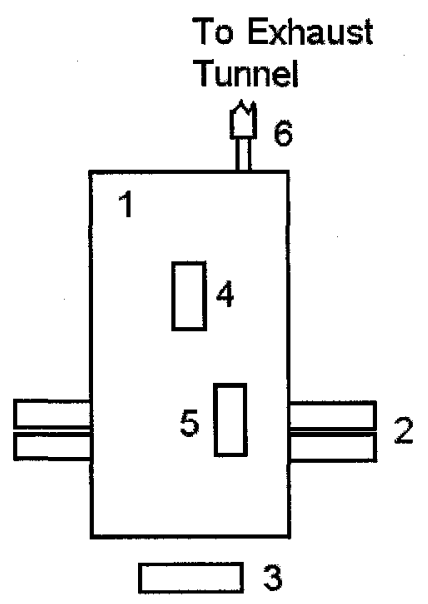

The following sections describe operation of the dilution tunnel, the collection and speciation of $\mathrm{CO}, \mathrm{HC}, \mathrm{CO}_{2}$ and $\mathrm{NO}_{x}$, the collection and speciation of carbonyl compounds and $\mathrm{N}_{2} \mathrm{O}$, the estimation of battery $S O C$, and the procedures to validate each test. 


\subsubsection{Dilution Tunnel}

The dilution tunnel mixed dilution air and raw exhaust, and channeled the flow of the resulting dilute exhaust so that sample extractions could be made by the instruments listed in Section 4.6.

Before each test, dilution air was pre-heated to $20^{\circ} \mathrm{C}$, regardless of the operating temperature. The temperature gradient between the dilute exhaust and the tunnel walls could reach up to $38^{\circ} \mathrm{C}$ when testing at $-18^{\circ} \mathrm{C}$. Thus, it was possible for gaseous emissions to condense and change chemical composition. To inhibit these changes, the portion of the dilution tunnel exposed to the test cell was insulated (see Section 4.6). Also, before each test, dilution air was pumped through the tunnel for approximately five minutes, to purge the tunnel walls of any particulate matter of gaseous emissions that were adsorbed from previous tests.

The flow of the dilute exhaust was maintained at a constant flow rate of approximately $330 \mathrm{ft}^{3} / \mathrm{min}$ with the choked flow venturi. At high engine speeds the exhaust flow rate increased and the dilute air flow rate decreased. At low engine speeds the exhaust flow rate decreased and the dilution air flow rate increased. The ratio of dilution air to raw exhaust volume is the so-called dilution factor. In this study, the

dilution factor ranged approximately between 6 to 43 . Aggressive tests driven by large vehicles have low dilution factors, while steady state tests driven by smaller vehicles have high dilution factors.

\subsubsection{Detection Limits of Measured Gaseous Emissions}

The detection limits of $\mathrm{CO}, \mathrm{CO}_{2}, \mathrm{HC}$ and $\mathrm{NO}_{x}$ for each transient drive cycle and steady state cycle are shown in Table 4.5. $\mathrm{N}_{2} \mathrm{O}$ detection limits varied between 5 
to $10 \mathrm{ppb}$; however concentrations of $\mathrm{N}_{2} \mathrm{O}$ in ambient air are between 300 to 400 $\mathrm{ppb}$, so this detection limit is never approached.

The detection limits of the carbonyl compounds speciated in this study are shown in Table 4.6. These detection limits applied to the extract concentration on the 2,4DNPH cartridges (see Section 4.6.4).

Table 4.5: Pollutant detection limits in $\mathrm{g} / \mathrm{km}[57]$

\begin{tabular}{|c|c|c|c|c|c|}
\hline \multirow{2}{*}{ Cycle } & \multicolumn{5}{|c|}{ Detection Limit $(\mathrm{g} / \mathrm{km})$} \\
\cline { 2 - 6 } & $\mathrm{CO}$ & $\mathrm{CO}_{2}$ & $\mathrm{NO}_{x}$ & $\mathrm{HC}$ & $\mathrm{CH}_{4}$ \\
\hline LA4 Phases 1\&3 & 0.002 & 7.5 & 0.007 & 0.0008 & 0.0001 \\
LA4 Phases 2\&4 & 0.003 & 12 & 0.01 & 0.001 & 0.0002 \\
LA92 Phases 1\&3 & 0.003 & 14 & 0.01 & 0.001 & 0.0003 \\
LA92 Phases 2\&4 & 0.001 & 6.8 & 0.006 & 0.0007 & 0.0001 \\
HWFET & 0.0008 & 3.9 & 0.003 & 0.0004 & 0.00007 \\
NYCC & 0.006 & 27 & 0.02 & 0.003 & 0.0005 \\
US06 & 0.0008 & 3.9 & 0.003 & 0.0004 & 0.00007 \\
SS40 & 0.002 & 7.7 & 0.007 & 0.0008 & 0.0001 \\
SS80 & 0.0008 & 3.8 & 0.004 & 0.0004 & 0.00007 \\
\hline
\end{tabular}

\subsubsection{Cycle and Modal Gaseous Emissions Collection and Measurement}

The gaseous emissions of $\mathrm{CO}, \mathrm{HC}, \mathrm{NO}_{x}, \mathrm{NO}$ (in Test Cell 1) and $\mathrm{CO}_{2}$ were analyzed from Tedlar ${ }^{\circledR}$ bags for every test. Tedlar ${ }^{\circledR}$ is an inert, impermeable polymer that inhibits chemical reactions between the bag walls and the sample. Teflon ${ }^{\circledR}$ tubing connected the CVS to the $\operatorname{Tedlar}^{\circledR}$ bags on the regulated emissions train (see Figure 4.12(a)). As shown in Figure 4.12(a), six $\operatorname{Tedlar}^{\circledR}$ bags were used to collect ambient dilution air and dilute exhaust samples from up to three phases of an uninterrupted test (i.e. without soak). Once the test was 
Table 4.6: Carbonyl compound detection limits in $\mathrm{g} / \mathrm{km}$

\begin{tabular}{|c|c|}
\hline Compound & Detection Limit (ng/L) \\
\hline Formaldehyde & 0.0045 \\
Acetaldehyde & 0.0004 \\
Acrolein & 0.0004 \\
Acetone & 0.0005 \\
Propionaldehyde & 0.0004 \\
Crotonaldehyde & 0.0006 \\
Methacrolein & 0.0004 \\
2-Butanone & 0.0005 \\
Benzaldehyde & 0.0004 \\
Isobutyraldehyde \& Butyraldehyde & 0.0004 \\
Isovaleraldehyde & 0.0004 \\
Valeraldehyde & 0.0006 \\
o-Tolualdehyde & 0.0005 \\
m-Tolualdehyde \& p-Tolualdehyde & 0.0008 \\
Hexanaldehyde & 0.0005 \\
2,5-Dimethylbenzaldehyde & 0.0006 \\
\hline
\end{tabular}

finished, the gas analyzer bench computer electronically released the valves for these bags, for each phase, sequentially (Figure 4.12). The gases from the ambient and sample bags were sent to the $\mathrm{NO}_{x}, \mathrm{HC}, \mathrm{CO}, \mathrm{NO}$ and $\mathrm{CO}_{2}$ gas analyzers (see Figure 4.12(b)).

Modal emissions were collected for all tests. Pump 1, labelled as 1 in Figure 4.12, was activated at the test start time. Valves along the pipe network were electronically opened by the gas analyzer computer, to allow the gas analyzers to measure the emission rate of $\mathrm{CO}, \mathrm{HC}, \mathrm{NO}_{x}, \mathrm{NO}$, or $\mathrm{CO}_{2}$. All gas analyzers output a current that was processed by a circuit board. This current was used to calculate the mass, in grams, of the gases, and reported the values to the computer. Although only shown for the $\mathrm{HC}$ gas analyzer (Figure 4.12), all gas analyzers were connected to span and zero gas canisters. These canisters were filled with high precision ppm concentrations of the gas measured by each analyzer. The canisters were used to 
Figure 4.11: ERMD regulated emission bags (a) and real-time gaseous bench (b)

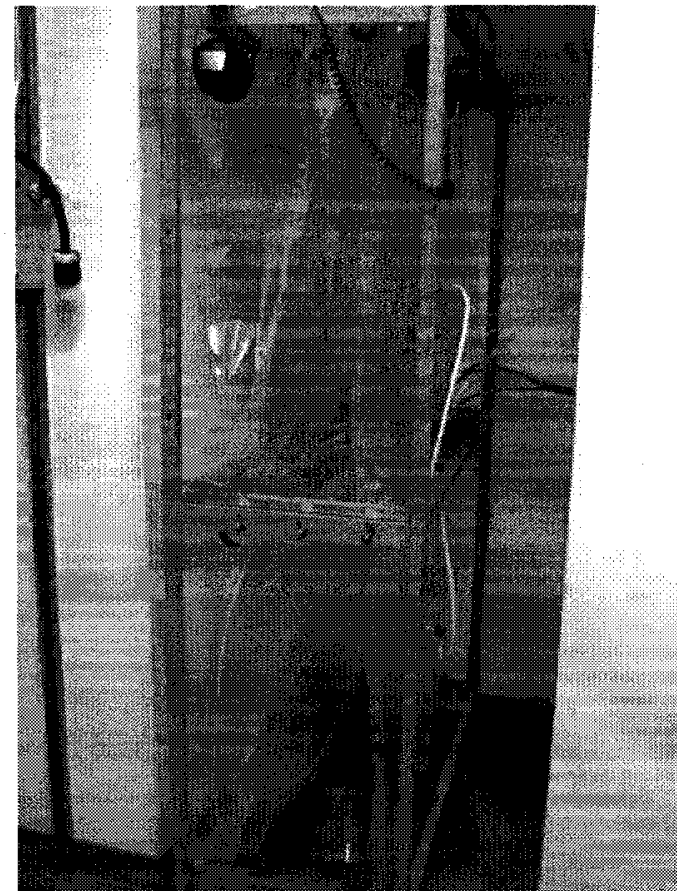

(a)

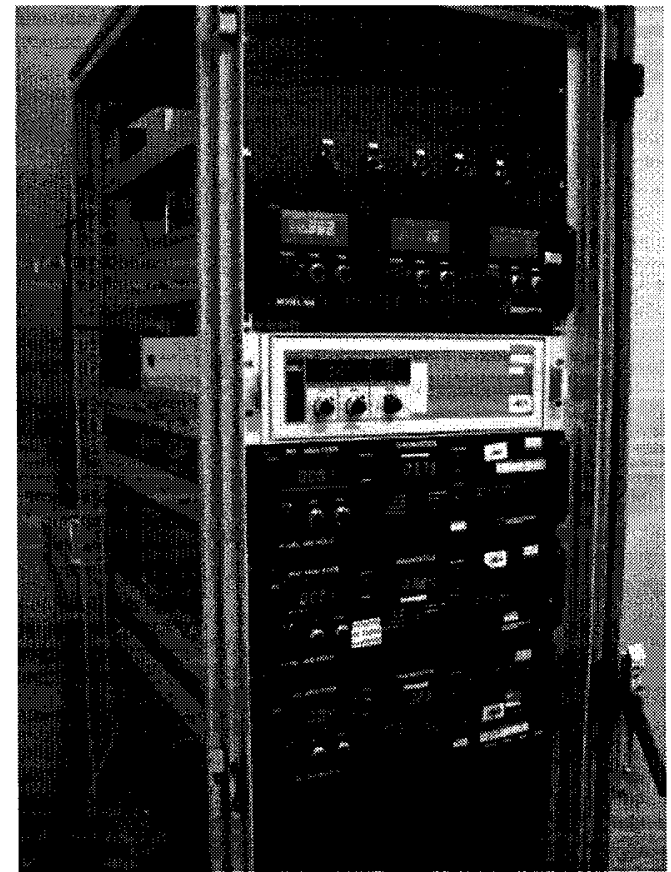

(b)

calibrate each gas analyzer.

Pump 2 was activated for the entire duration of the test, so that the bags were filled with dilute exhaust and ambient dilution air, representative of the entire cycle. Each gas analyzer used a different technique to measure the emission rate of each gas. These techniques and the gas analyzers are listed below. The gas analyzer operating principles and specifications can be obtained from [58].

$\mathrm{CO}_{2}$ and $\mathrm{CO}$ were measured by the California Analytical Instruments (CAI) Model 300 analyzer. This machine used non-dispersive infrared detection (NDIR). NO and $\mathrm{NO}_{x}$ were measured by the CAI Model 400 analyzer, a heated chemiluminescence detector (HCLD). HCs were measured by the CAI Model 300 analyzer. This device employed a heated flame ionization detector (HFID). After the bags of exhaust were analyzed with the gas analyzer bench, they were taken to the chemistry laboratory 
Figure 4.12: Schematic of the chassis dynamometer gas analyzer bench

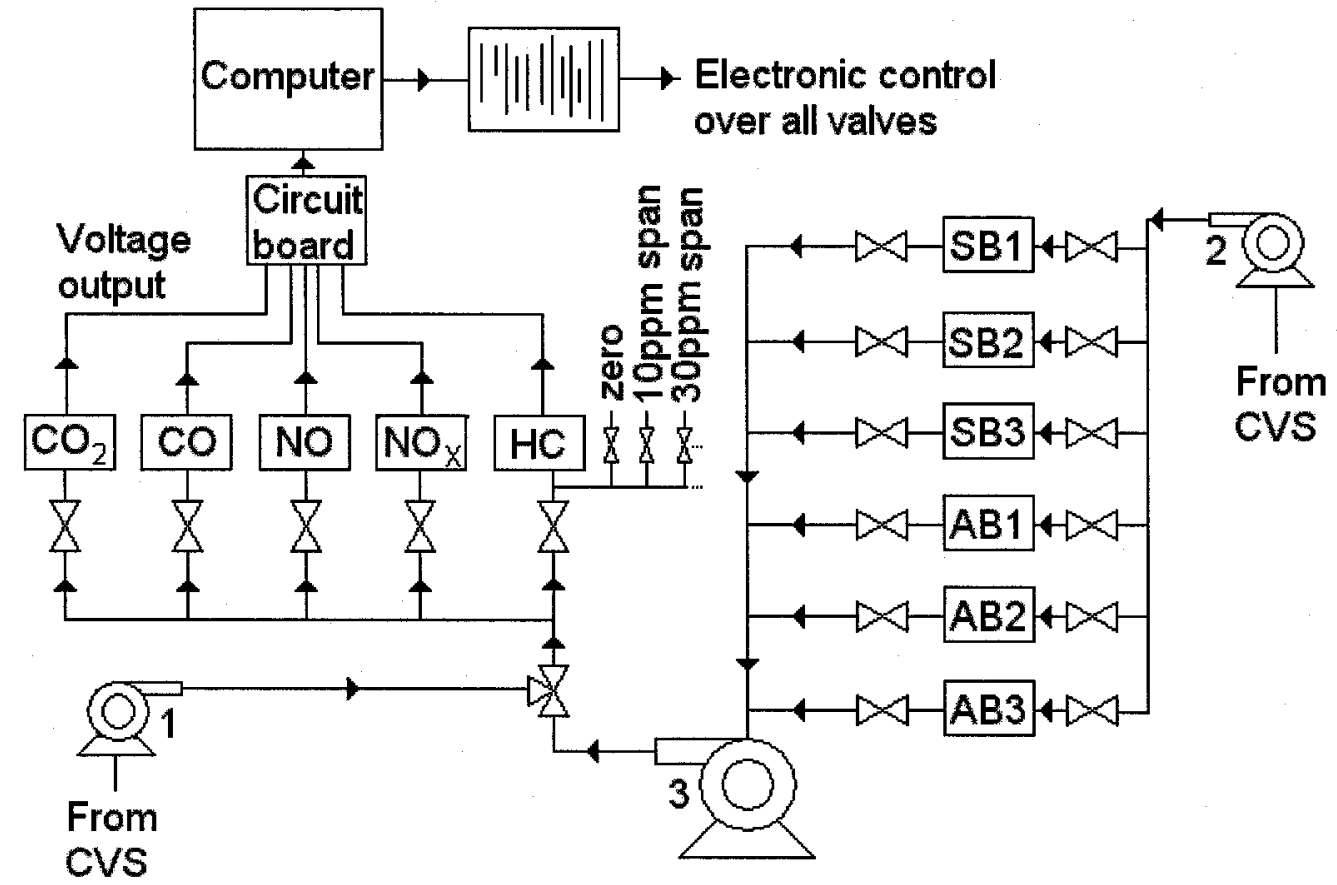

where the integrated emission rate of $\mathrm{CH}_{4}$ was measured. $\mathrm{CH}_{4}$ was measured using gas chromatography FID. This emission rate of $\mathrm{CH}_{4}$ was subtracted from total $\mathrm{HC}$ to arrive at the NMHC emission rate, and in most cases the NMOG emission rate.

\subsubsection{Collection and Speciation of Carbonyl Compounds and Nitrous Oxide}

A sample train collected dilute exhaust and sample dilution air for carbonyl compound, $\mathrm{N}_{2} \mathrm{O}$ and LHC speciation. Figure 4.13 shows the locations of the main components of the sample train. When a test was started, an Amphenol ${ }^{\circledR}$ connector, linked between the dynamometer computer and the sample train, automatically initiated sample collection. The main power and toggle switch board were activated and warmed up at least 30 minutes prior to testing. The 
dilute exhaust gas was collected via the Teflon ${ }^{\circledR}$ tubing, shown on the left side of Figure 4.13. Dilute exhaust and ambient air were drawn through these Teflon ${ }^{\circledR}$ tubes from the CVS and dilution air tunnel, respectively, for both carbonyl compound, and $\mathrm{LHC}$ and $\mathrm{N}_{2} \mathrm{O}$ collection. Swagelok ${ }^{\circledR}$ connectors attached the Teflon ${ }^{\circledR}$ tubing to the stainless steel pipe system of the sample train.

$\mathrm{N}_{2} \mathrm{O}$ emissions were collected and analyzed differently than carbonyl compounds. $\mathrm{N}_{2} \mathrm{O}$ was collected in tandem with LHC. The stainless steel pipes, shown in Figure 4.13, distributed the $\mathrm{N}_{2} \mathrm{O}$ sample lines throughout the sample train.

Figure 4.13: ERMD sample train for unregulated emissions

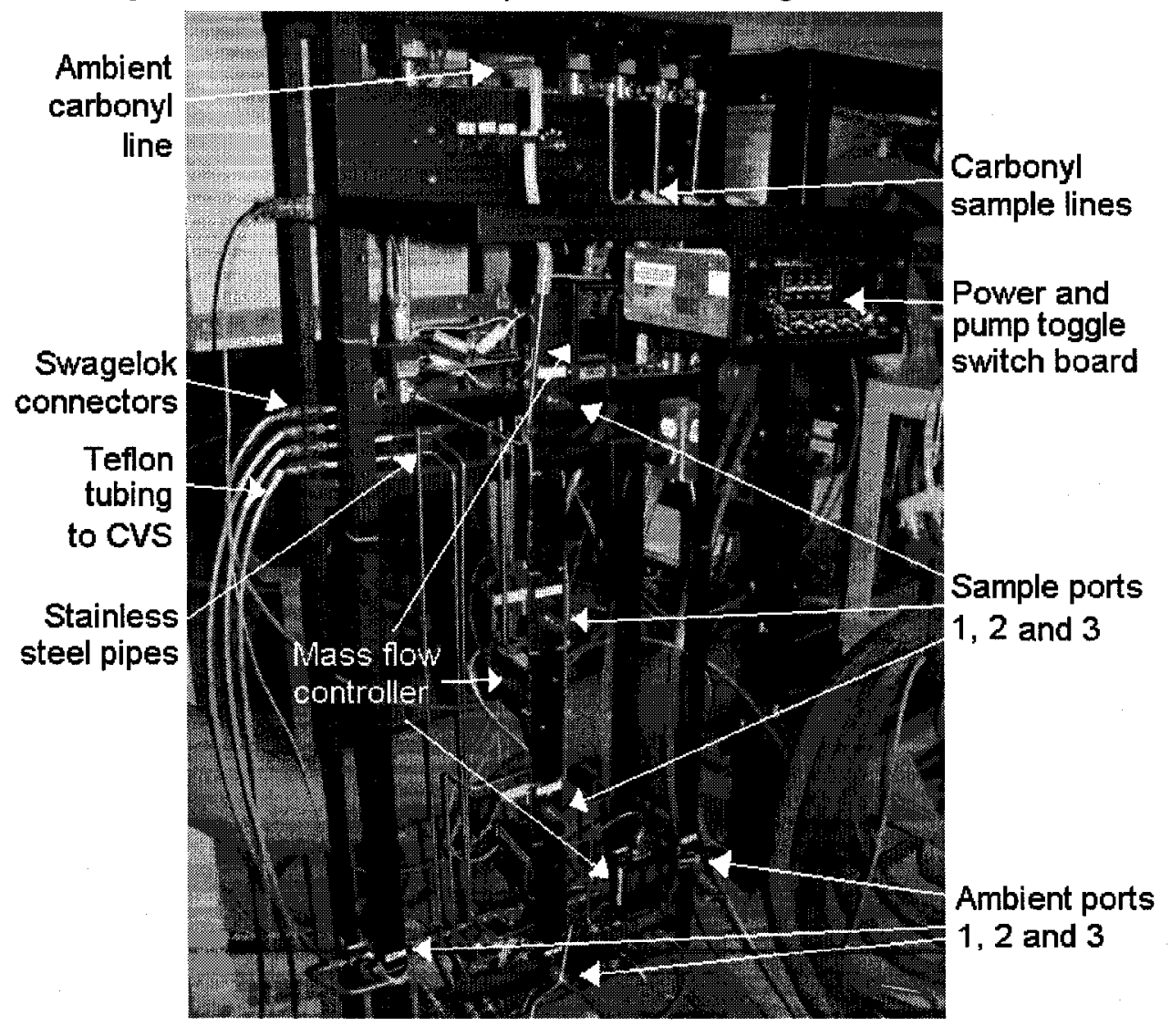

Dilute exhaust and ambient air were directed to the Swagelok ${ }^{\circledR}$ dilute exhaust sample ports 1,2 and 3, and ambient air ports 1,2 and 3, shown in Figure 4.13. 
Three dilute exhaust and three ambient ports allowed a maximum of three consecutive phases of exhaust to be collected and analyzed for each test. Although not shown in Figure 4.13, six pumps, one for each $\mathrm{N}_{2} \mathrm{O}$ sample line, drew the dilute exhaust from the CVS and dilution tunnel. These pumps were located at the bottom of the sample train. The flow rate of the gases, through the $\mathrm{N}_{2} \mathrm{O}$ sample lines, was regulated by two mass flow controllers (MFC), one for the dilute exhaust flow, and another for the ambient air flow. Both of these flows were regulated at $0.4 \mathrm{~L} / \mathrm{min}$ by the use of a Drycal ${ }^{\circledR}$ mass flow meter. The MFC reported flow rates at standard conditions $(T=273.15 \mathrm{~K}, \mathrm{P}=1 \mathrm{~atm})$, whereas the Drycal ${ }^{\circledR}$ mass flow meter measured the flow rate at actual pressure and temperature. The MFC and Drycal ${ }^{\circledR}$ readings were compared to ensure that the two flow rates were within $\pm 5 \%$ of each other. When a test ended, the bags were taken to the chemistry laboratory where they were analyzed for $\mathrm{N}_{2} \mathrm{O}$ and $\mathrm{LHC}$ concentrations by the use of gas chromatography with electron capture detection (GC-ECD). At all times, the samples were protected from exposure to direct sunlight. They were also analyzed on the same day they were collected. These precautions ensured that the sample would represent the original exhaust composition.

Dilute exhaust and ambient air, used to speciate carbonyl compounds, were collected on Sep-Pak silica cartridges coated with 2,4-dinitrophenylhydrazine (2,4DNPH). ERMD standard operating procedures (SOPs) outline the steps to make these cartridges. Each cartridge was capped with a luer plug at all times, except during testing. Once prepared, the cartridges were taken to the sample train and placed inline with the carbonyl sample lines. Silicone rubber tubing was used to connect the Teflon ${ }^{\circledR}$ tubes to the cartridges. Four Teflon ${ }^{\circledR}$ tubes were dedicated to collecting ambient air and exhaust for carbonyl compound speciation: one for ambient air and three for dilute exhaust. This dilute exhaust and ambient air 
travelled through the Teflon ${ }^{\circledR}$ tubes, labelled on the left side of Figure 4.13, at a flow rate of $1 \mathrm{~L} / \mathrm{min}$. The flow rate was regulated by the MFC, shown in Figure 4.14.

Figure 4.14: MKS Instruments Inc. mass flow controller (5000 SCCM)

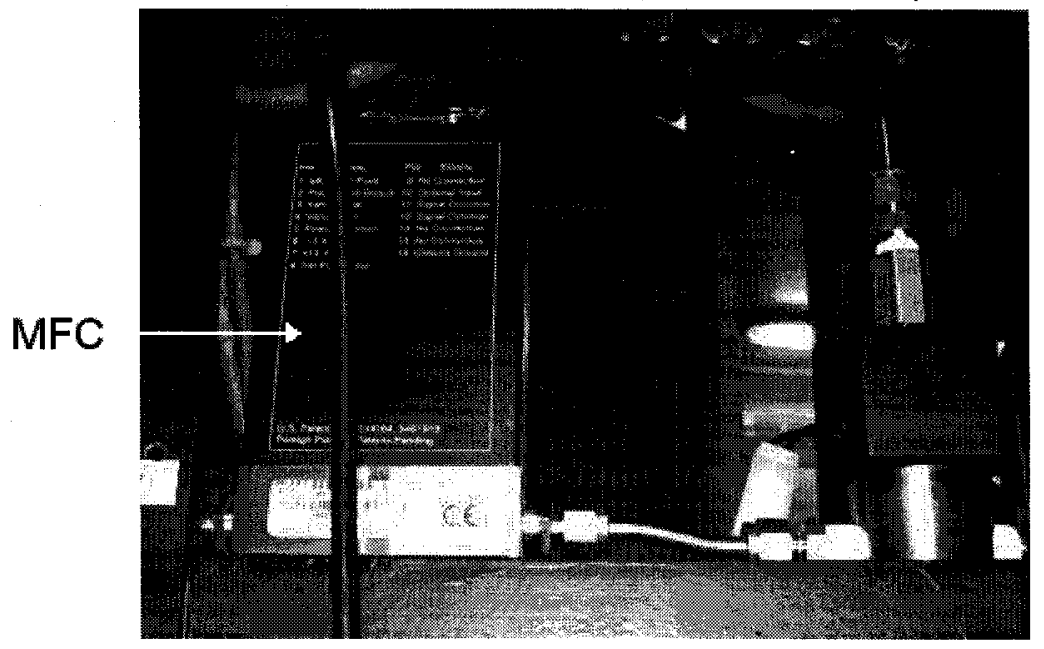

The dilute exhaust was pumped through one pipe to three separate lines (Figure 4.15). If the test was less than three phases, dummy cartridges were connected to the sample train instead of 2,4-DNPH cartridges. Once the test was completed, the cartridge caps were replaced and the cartridges were stored in their respective glass vials, under refrigeration, until staff were able to analyze them.

For each batch of cartridges, three blanks were prepared. One batch contains 33 cartridges, three of which were kept as batch blanks. These blanks were analyzed to determine the amount of each carbonyl species on the cartridge before sample collection so that concentration corrections to the samples could be made.

During a test, carbonyl compounds in the dilute exhaust reacted with 2,4-DNPH in a cartridge to form hydrazones, which were retained on the silica cartridge. Upon test completion, the sample was taken to the chemistry lab, where the hydrazones were dissolved and removed from the cartridge by elution with acetonitrile. The 
sample (eluate) was then analyzed by reverse phase high performance liquid chromatography (RP-HPLC) with UV detection.

Figure 4.15: ERMD unregulated emission sample train - carbonyl sampling

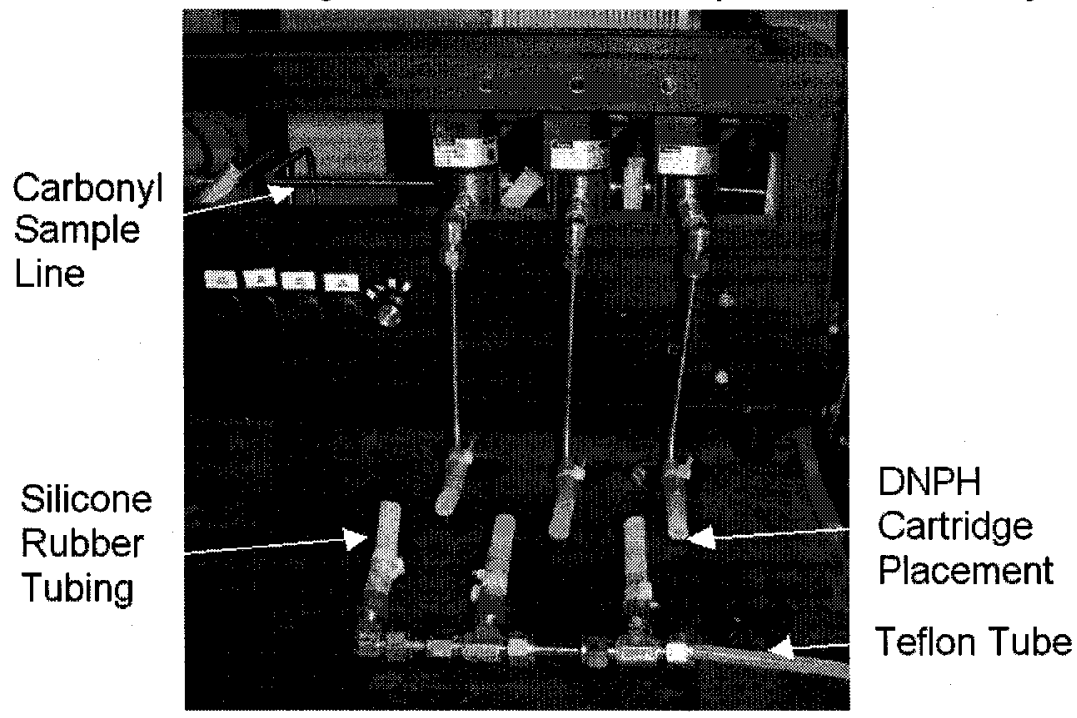

\subsubsection{Hybrid Battery}

One of the unique test procedures for HEVs (Section 2.6) is the estimation of the battery $S O C$, for the purpose of calculating the battery NEC. The $S O C$ was estimated using two methods: real-time current measurements (for the Escape Hybrid and Prius), and real-time percent $S O C$ measurements (for the Civic Hybrid and Insight). The current measurements were made with the use of an ammeter probe (see Figure 4.17(a)) and multimeter (see Figure 4.17(b)). The ammeter probe was manually connected to the battery and the positive and negative connections of the ammeter probe were plugged into the multimeter. The ammeter probe measured the current as a millivolt $(\mathrm{mV})$ reading, which was read by the multimeter. The conversion factor of the ammeter probe from $\mathrm{mV}$ to amps was $1 \mathrm{Amp}=1 \mathrm{mV}$. The frequency of these readings was $10 \mathrm{~Hz}$. These $\mathrm{mV}$ readings were sent to a software program called VLogger, which concurrently 
recorded the dynamometer speed. The calculations to estimate $\triangle S O C$ from the current measurements is described in Section 5.5, while the $N E C$ is calculated in Section 5.6.

Figure 4.16: AEMC Instruments MD510 Series Ammeter (a) and Wavetek Meterman Multimeter (b)

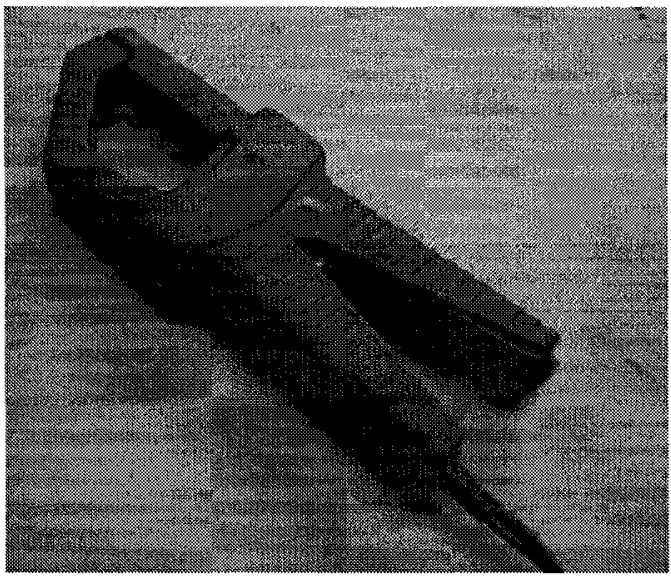

(a)

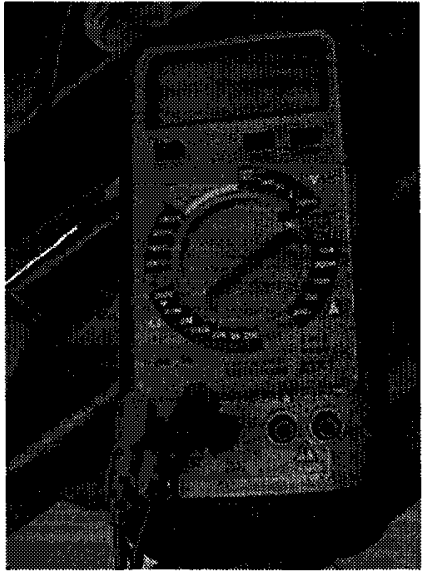

(b)

A different method was applied to the Civic Hybrid and the Insight, because their battery packs were not easily accessible. Modern vehicles are equipped with an OBD II system that is committed to notifying the driver of problems with the vehicle. As well as identifying and informing the driver about vehicle problems, the OBD II records several vehicle parameters at periodic time intervals of approximately 3.2 seconds. One of these parameters is the $S O C$, in percent. An OBD II SnapOn ${ }^{\circledR}$ diagnostics scanner was connected to the OBD II port, in the vehicle, prior to testing. The SnapOn ${ }^{\circledR}$ scanner relayed the recorded vehicle parameters, including the percent $S O C$, to the test cell computer, where it was stored as an ASCII file. The $\triangle S O C$ from these measurements was found as the difference between the final and initial $S O C$ measurements (see Section 5.5). 


\subsubsection{Test and Sample Validation}

The chassis dynamometer tests were validated according to the instructions in the CFR Title 40, Part 86.118 [50]. The vehicle speed was allowed to exceed the highest point on the trace by $2 \mathrm{mph}$ within one second of the trace time. The speed was also allowed to be $2 \mathrm{mph}$ less than the trace speed within one second of the trace time. If the speed exceeded this tolerance and on any occasion, lasted more than two seconds, the test was invalidated. If the following list of requirements were not met, a non-conformance report was issued for the test and the test was voided.

- Crank time $<60$ seconds

- $8<D F<110$

- $3000<$ Vol $_{\text {phase }}<6000$ SCF

- $20^{\circ} \mathrm{C}<$ Ambient Test Cell Temperature $<30^{\circ} \mathrm{C}$

- Root mean square error of speed for entire trace $<1$

In the above list, SCF is standard cubic feet. If the test was validated, based on the above conformance criteria, it was validated again, based on the sampled data. The $\mathrm{CO}_{2}, \mathrm{HC}, \mathrm{CO}$ and $\mathrm{NO}_{x}$ emission factors for the test, $\mathrm{CS}$ or $\mathrm{HS}$, were calculated (see Section 5.2) for each set of repeat tests done that day. The largest emission factor of each gas was divided by the lowest emission factor of that same gas. For each chemical, a maximum acceptable value was specified, above which more tests were required. This method was used as a measure of test repeatability. 


\section{Chapter 5}

\section{Data Analysis}

Data collection was mostly completed by automated systems. Because of the large amount of information for each test, the data produced by these automated systems were placed in four different files. Manually measured data was also recorded in these four files. Real-time dynamometer forces, speed, distance and acceleration measurements were all recorded in the Dynamometer File. Real-time gaseous emissions, current or SOC, dynamometer speed and time measurements were recorded in the Transient File. Drive cycle emissions of regulated, unregulated and GHG gases were recorded in the Integrated File. The $\triangle S O C$ and $N E C$ values, and carbonyl compound emissions were also included in the Integrated File.

In this chapter, the calculations, based on the above parameters, are presented. Many of these calculations are made using equations from the CFR Title 40, Part 86 [50]. Others are calculated from equations in literature [43,59], and some are calculated using energy equations. In the following sections, the calculations for the dilution factor, and $\mathrm{CO}, \mathrm{HC}, \mathrm{NO}_{x}$ and $\mathrm{CO}_{2}$ emission factors is provided. Fuel consumption, as well as, carbonyl compound and $\mathrm{N}_{2} \mathrm{O}$ emission factors, change in battery SOC, battery $N E C$, and battery related energies are also calculated. 
The procedure to calculate friction and augmented braking energies, engine-off time and number of engine restarts, and vehicle specific power are outlined. The uncertainties of some of the measured variables are available in the accompanying DVD. In this study, the uncertainty of results is represented by the standard deviation of an averaged value from three or more repeat tests.

\subsection{Dilution Factor}

The equation for the dilution factor $(D F)$ is provided by [50]. $D F$ is defined as the ratio of dilution air volume per exhaust volume. The use of dilution air was described in Section 4.6.1 as a means to maintain the volumetric flow rate of gas moving through the dilution tunnel. The $D F$ was determined by using the carbon balance at the mixing point of the dilution air and raw exhaust gas, shown below.

$$
C_{\text {raw }}\left(\frac{\text { mol carbon }}{\text { mol exhaust }}\right)(1 \text { mol exhaust })=C_{\text {dilute }}\left(\frac{\text { mol carbon }}{\text { mol dilute exhaust }}\right) \cdot D F(\text { mol dilute exhaust })
$$

Rearranging this carbon balance, the $D F$ was isolated and solved.

$$
D F=\frac{C_{\text {raw }}}{C_{\text {dilute }}}
$$

The ratio of the number of moles of carbon in dilute exhaust to the number of moles of carbon in raw exhaust $(D F)$, was determined by first solving for $C_{\text {raw }}$. By assuming that the $A / F$ ratio was stoichiometric, the number of carbon atoms in the raw exhaust was calculated by using the stoichiometric equation for the combustion of an oxygenated fuel (equation 2.1). Equation 5.2 assumed a fuel composition of $\mathrm{C}_{x} \mathrm{H}_{y} \mathrm{O}_{z}$, and summed the moles of carbon atoms in the products of combustion of equation 2.1 to find $C_{\text {raw }}$. The fuel composition of the two fuels used in this study 
are listed in Table 4.4.

$$
C_{r a w}=\frac{x}{x+y / 2+3.76(x+y / 4-z / 2)}
$$

The ratio of the number of carbon moles to the number of dilute exhaust moles $\left(C_{\text {dilute }}\right)$ was determined by using the measured concentrations of $\mathrm{CO}_{2}, \mathrm{HC}$ and $\mathrm{CO}$ at the sample lines, as is seen in equation 5.3. These are the concentrations of $\mathrm{CO}_{2}, \mathrm{HC}$ and $\mathrm{CO}$ in the dilute exhaust: $\left[\mathrm{CO}_{2}\right]_{d},[\mathrm{HC}]_{d}$ and $[\mathrm{CO}]_{d}$, respectively.

$$
C_{\text {dilute }}=\frac{\left[\mathrm{CO}_{2}\right]_{d}+0.0001\left([\mathrm{HC}]_{d}+[\mathrm{CO}]_{d}\right)}{100}
$$

The $D F$ could then be found as the ratio of $C_{\text {raw }}$ to $C_{\text {dilute }}$, as shown in equation 5.4.

$$
D F=\frac{100 \cdot \frac{x}{x+y / 2+3.76(x+y / 4-z / 2)}}{\left[\mathrm{CO}_{2}\right]_{d}+0.0001\left([\mathrm{HC}]_{d}+[\mathrm{CO}]_{d}\right)}
$$

After $D F$ was calculated, the emission factors of $\mathrm{CO}, \mathrm{CO}_{2}, \mathrm{HC}$ and $\mathrm{NO}_{x}$ could be calculated.

\subsection{Emission Factors of Carbon Dioxide, Carbon Monoxide, Hydrocarbon and Oxides of Nitrogen}

The concentrations of $\mathrm{CO}, \mathrm{NO}_{x}$ and $\mathrm{HC}$ were measured for each phase or test. Measurements of $\mathrm{CO}_{2}$ concentrations were also made as a means to calculate the fuel consumption and the dilution factor, and to determine the GHG emissions of each vehicle.

The emission factors were calculated from the dilute exhaust and ambient air concentrations measured by the gas analyzer bench. The gas analyzers generated curve-fit coefficients for $\mathrm{CO}, \mathrm{HC}, \mathrm{NO}_{x}$ and $\mathrm{CO}_{2}$. These coefficients are labelled as 
$C_{1_{g a s}}, C_{2_{g a s}}, C_{3_{g a s}}$ and $C_{4_{\text {gas }}}$. These coefficients were used to convert the ambient air and dilute exhaust meter readings $\left(M R_{a m b_{g a s}}\right.$ and $M R_{d_{g a s}}$, respectively) of the gases into ambient air and dilute exhaust concentrations ([gas $]_{a m b}$ and $[\text { gas }]_{d}$, respectively). The calculation of ambient air and dilute exhaust concentrations of a gas are shown in equations 5.5 and 5.6.

$$
\begin{aligned}
& {[g a s]_{a m b}(p p m)=C_{1_{g a s}}+C_{2_{g a s}} M R_{a m b_{g a s}}+C_{3_{g a s}} M R_{a m b_{g a s}}^{2}+C_{4_{g a s}} M R_{a m b_{g a s}}^{3}(5} \\
& {[g a s]_{d}(p p m)=C_{1_{g a s}}+C_{2_{g a s}} M R_{d_{g a s}}+C_{3_{g a s}} M R_{d_{g a s}}^{2}+C_{4_{g a s}} M R_{d_{g a s}}^{3}}
\end{aligned}
$$

The emission mass of a gas was determined using $D F$ (Section 5.1), the ambient air concentration of the gas, and the dilute exhaust concentration of a gas (see equation 5.7). However, if the ambient air concentration of the gas was more than its dilute exhaust concentration, the mass emission of the gas $\left([\mathrm{gas}]_{e m}\right)$ was set to zero, as shown below.

If $[\mathrm{gas}]_{\mathrm{amb}}>[\mathrm{gas}]_{d},[\mathrm{gas}]_{e m}=0 \mathrm{gram} / \mathrm{phase}$

If $[\text { gas }]_{d}>[g a s]_{a m b}$,

$$
[\text { gas }]_{e m}(g / \text { phase })=V o l_{\text {phase }} \cdot \rho_{\text {gas }} \cdot 10^{-6}\left([\text { gas }]_{d}-[\text { gas }]_{a m b}\left(1-\frac{1}{D F}\right)\right)
$$

The density of the gas, $\rho_{\text {gas }}$, is reported in gram $/ \mathrm{ft}^{3}$ and the volume of dilute exhaust flowing through the CVS, $V o l_{\text {phase }}$, is reported in $\mathrm{ft}^{3}$. In the case of $\mathrm{CO}_{2}$, the dilute exhaust and ambient air concentrations are a percent of the total exhaust and the conversion factor in equation 5.7 is 0.01 instead of $10^{-6}$. The emission factor of the gas, $[\mathrm{gas}]_{e f}$, was calculated by then dividing the emission mass by the distance travelled, distance, during the drive cycle (equation 5.8).

$$
[g a s]_{e f}(g / \text { mile })=\frac{[g a s]_{e m}(g / \text { phase })}{\text { distance }}
$$




\subsection{Fuel Consumption}

Fuel consumption is the measure of fuel, in volume, that is consumed for every unit of distance a vehicle travels. The fuel and exhaust contain carbon, and thus it is possible to use a carbon balance to determine the amount of fuel consumed during a driving cycle, given the specific gravity and chemical composition of the fuel, as well as the emissions that have carbon content. Equation 5.9, from [1], balances the fuel carbon content and the exhaust carbon content. The terms preceding the pollutant emission factors are in grams of carbon per gram of the corresponding gas to which it is multiplied. The pollutant emission factors are in grams of pollutant per mile.

$$
C W F \cdot[H C]_{e f}+0.273 \cdot\left[\mathrm{CO}_{2}\right]_{e f}+0.429[C O]_{e f}=\frac{C W F \cdot S G_{f u e l} \cdot 3785}{m p g}
$$

The value of 3785 has units of grams of water per gallon. $C W F$ is the fraction of carbon in the fuel, $S G_{\text {fuel }}$ is the specific gravity of the fuel and $\mathrm{mpg}$ is the fuel economy in miles per gallon. When the fuel economy is isolated, equation 5.10 follows.

$$
m p g=\frac{C W F \cdot S G_{\text {fuel }} \cdot 3785}{C W F \cdot[H C]_{e f}+0.273 \cdot\left[C \mathrm{C}_{2}\right]_{e f}+0.429[C O]_{e f}}
$$

Equation 5.10 is not, however, an accurate calculation of the energy consumed during a drive cycle test, because fuel energy content may vary, based on the fuel composition [1]. Thus, equation 5.10 was corrected using the net heating value (NHV) and specific gravity of the fuel. The regulatory fuel consumption equation, as stated by the CFR title 40 part 600 , section $113-93$, is shown in equation 5.11 [50]. The fuel consumption, $F C$, is in units of $L / 100 \mathrm{~km}$.

$$
F C=\frac{\frac{235.22}{5.174 \times 10^{7} \cdot C W F \cdot S G_{f u e l}}}{\left(C W F \cdot[H C]_{e f}+0.429 \cdot[C O]_{e f}+0.273 \cdot\left[C O_{2}\right]_{e f}\right) \cdot\left(0.6 \cdot S G_{f u e l} \cdot N H V+5417\right)}
$$




\subsection{Unregulated Emission Factors}

The unregulated emissions of interest in this study include selected carbonyl compounds, and $\mathrm{N}_{2} \mathrm{O}$. The calculations of these emissions factors are described in the following sections.

\subsubsection{Carbonyl Compounds}

The determination of emission factors for a carbonyl compound is similar to that for the regulated emissions in Section 5.2. The ambient air or dilute exhaust concentration of a carbonyl compound extract in the cartridge $\left([\text { carbonyl }]_{a m b_{e x}}\right.$ and $[\text { carbonyl }]_{d_{e x}}$, respectively), was used to find the concentration of the carbonyl compound in the ambient air or dilute exhaust $\left([\text { carbonyl }]_{a m b}\right.$ and $[\text { carbonyl }]_{d}$, respectively).

$$
\begin{aligned}
& {[\text { carbonyl }]_{a m b}(m g / L)=\frac{[\text { carbonyl }]_{a m b_{e x}} \cdot V_{e x} \cdot 0.001}{S L P M \cdot t i m e_{a m b}}} \\
& {[\text { carbonyl }]_{d}(m g / L)=\frac{[\text { carbonyl }]_{d_{e x}} \cdot V_{e x} \cdot 0.001}{S L P M \cdot t i m e_{\text {phase }}}}
\end{aligned}
$$

The volume of the extract, $V_{e x}$, has units of $\mathrm{mL}$, the value 0.001 has units of $\mathrm{mg} / \mu \mathrm{g}$, and the flow rate of dilute exhaust and ambient air flowing through each cartridge, $S L P M$, has units of $\mathrm{L} /$ minute. The duration of the phase or test is designated time $_{\text {phase }}$, while the duration for which ambient air was collected is time $e_{a m b}$. The carbonyl compound emission mass, $[\text { carbonyl }]_{e m}$, was calculated using $[\text { carbonyl }]_{d}$ and $[\text { carbonyl }]_{a m b}$ in equation 5.14. If the ambient air concentration of the carbonyl compound was higher than that of the dilute exhaust, the emission mass of the carbonyl compound was set to zero, as shown below.

If $\left[[\text { carbonyl }]_{d}-[\text { carbonyl }]_{a m b} \cdot\left(1-\frac{1}{D F}\right)\right] \times V o l_{\text {phase }} \cdot 28.316<0$, Then $[\text { carbonyl }]_{e m}=0$ 
Else,

$$
[\text { carbonyl }]_{e m}=\left[[\text { carbonyl }]_{d}-[\text { carbonyl }]_{a m b} \cdot\left(1-\frac{1}{D F}\right)\right] \times V o l_{\text {phase }} \cdot 28.316(5.1
$$

The units of $[\text { carbonyl }]_{e m}$ are $\mathrm{mg} / \mathrm{phase}$ or $\mathrm{mg} / \mathrm{test}$. The value 28.316 has units of $\mathrm{L} / \mathrm{ft}^{3}$. The emission factor of the carbonyl compound, $[\text { carbonyl }]_{e f}$, was calculated using equation 5.15 .

$$
[\text { carbonyl }]_{e f}(m g / \text { mile })=\frac{[\text { carbonyl }]_{e m}(g / \text { phase })}{\text { distance }}
$$

\subsubsection{Nitrous Oxide}

The emission factor of $\mathrm{N}_{2} \mathrm{O}$ was determined by relations similar to the above calculated emission factors. The concentrations of $\mathrm{N}_{2} \mathrm{O}$ in ambient air, $\left[\mathrm{N}_{2} \mathrm{O}\right]_{a m b}$, and dilute exhaust, $\left[\mathrm{N}_{2} \mathrm{O}\right]_{d}$, were used to find the emission mass, $\left[\mathrm{N}_{2} \mathrm{O}\right]_{e m}$, as shown in equation 5.16. Note that $\left[\mathrm{N}_{2} \mathrm{O}\right]_{a m b}$ and $\left[\mathrm{N}_{2} \mathrm{O}\right]_{d}$ are in units of ppb.

$$
\left[\mathrm{N}_{2} \mathrm{O}\right]_{e m}(\mathrm{~g} / \text { phase })=\operatorname{Vol}_{\text {phase }} \cdot 51.82 \cdot\left(\left[\mathrm{N}_{2} \mathrm{O}\right]_{d}-\left[\mathrm{N}_{2} \mathrm{O}\right]_{a m b} \cdot\left[1-\frac{1}{D F}\right]\right) \cdot 1.0^{-9}(5.1
$$

The value $10^{-9}$ converts ppb into parts of $\mathrm{N}_{2} \mathrm{O}$ per part of ideal gas, while 51.82 represents the density of $\mathrm{N}_{2} \mathrm{O}$ in $\mathrm{g} / \mathrm{ft}^{3}$. The emission factor of $\mathrm{N}_{2} \mathrm{O},\left[\mathrm{N}_{2} \mathrm{O}\right]_{e f}$, was then calculated (see equation 5.17).

$$
\left[\mathrm{N}_{2} \mathrm{O}\right]_{e f}(g / \text { mile })=\frac{\left[\mathrm{N}_{2} \mathrm{O}\right]_{\text {em }}(\mathrm{g} / \text { phase })}{\text { distance }}
$$

\subsection{Battery Change in State of Charge}

$\triangle S O C$ was calculated using one of two equations, depending on the battery parameter that was measured (SOC\% or current). Below, the method involving current is described, followed by the method using SOC\%. 
The equation to estimate $\triangle S O C$ from current measurements was provided by [43]. This method was applied to the Escape Hybrid and Prius tests. $\triangle S O C$ was calculated by averaging the real-time current measurements over the duration of the entire test, and multiplying it by the battery voltage and test time. Given that there are $n$ current measurements over the entire test and that each measurement was made at 0.1 second intervals, equation 5.18 calculates $n$.

$$
n=10 \cdot \text { time }_{\text {phase }}(s)
$$

The average current, $I_{a v e}$, was then calculated for the duration of the test, as shown in equation 5.19. $I_{i}$ is the current at time interval $i$, in amps.

$$
I_{\text {ave }}(A)=\frac{\sum_{i=1}^{n} I_{i}}{n}
$$

The product of the average current and the test duration yields $\triangle S O C$ (see equation 5.20).

$$
\triangle S O C(A h)=I_{\text {ave }} \cdot \text { time }_{\text {phase }}(s)
$$

If the had test was driven over a 4-phase drive cycle, then $\triangle S O C$ was found for each phase.

In the case of the Insight and Civic Hybrid, real-time SOC\% was extracted from OBD II measurements (see Section 4.6.5). The $\triangle S O C$ was then calculated using the difference between the initial $S O C, S O C_{\text {initial }}$, and the final $S O C, S O C_{f i n a l}$, multiplied by the battery capacity, as shown in equation 5.21 .

$$
\triangle S O C(A h)=\left(S O C_{\text {final }}(\%)-S O C_{\text {initial }}(\%)\right) \cdot \text { battery capacity }(A h)
$$




\subsection{Net Energy Change}

$N E C$ was calculated to standardize each HEV test (see Section 2.6). $N E C$ was calculated as a percent value of the $T C E$. The $T C E$ is the sum of the total fuel energy (TFE) and the contribution of $N E C$ to powering the vehicle, in kWh. TFE is calculated as a product of the fuel mass consumed, $m_{f u e l}$, and its $N H V, N H V_{g}$, which is in units of BTU/g. $m_{\text {fuel }}$ is the product of the fuel density, $\rho_{\text {fuel }}, \mathrm{FC}$ and distance (see equation 5.22).

$$
m_{\text {fuel }}(\mathrm{kg})=\rho_{\text {fuel }}(\mathrm{kg} / \mathrm{L}) \cdot \mathrm{FC}(\mathrm{L} / 100 \mathrm{~km}) \cdot\left[\frac{\text { distance }}{100}\right]
$$

TFE was then calculated, using conversion factors of $1000 \mathrm{~g} / \mathrm{kg}$ and 3412 kWh/BTU in equation 5.23 .

$$
\operatorname{TFE}(k W h)=m_{\text {fuel }} \cdot 1000 \cdot 3412 \cdot N H V_{g}
$$

$N E C$ was calculated from $\triangle S O C$ and $V_{N}$ (see equation 5.24).

$$
N E C(k W h)=V_{N} \cdot \Delta S O C
$$

$T C E$ was determined by the sum of $T F E$ and $N E C$. Note that the sign of $N E C$ in equation 5.25 is negative for a net energy gain throughout the cycle and positive for a net energy loss throughout the cycle.

$$
T C E(k W h)=T F E \pm N E C
$$

The percent $N E C$ was calculated as the ratio of $N E C$ over $T C E$ (see equation 5.26).

$$
N E C(\%)=\left|\frac{N E C(k W h)}{T C E(k W h)}\right| \times 100 \%
$$


No specific procedure has been recommended for determining the percent $N E C$ of 4-phase tests. In this study, the $N E C$ ( $\mathrm{kWh}$ ) were added from each phase, $i$, and divided by the sum of the TCE's for each phase (see equation 5.27).

$$
N E C(\%)=\left|\sum_{i=1}^{4} \frac{N E C_{i}(k W h)}{T C E_{i}(k W h)}\right|
$$

If the percent $N E C$ was greater than $5 \%$, the test was voided. If the percent $N E C$ was less than $5 \%$, but greater than $1 \%$, at least three repeat test data were used to linearly interpolate (or extrapolate) the zero $N E C$ value of the emission or FC. If the $N E C$ was less than $1 \%$, no correction was applied. Further details are described in Section 2.6.

\subsection{Energy Consumption and Recuperation}

Energy consumption and recuperation terms include the regenerative braking, ICE battery charging, battery discharging, friction and augmented braking energies, $T F E$, and the TCE. The equations used to calculate $T F E$ and $T C E$ have already been discussed in Section 5.6. Two other equations were used to find the battery related energies (regenerative braking, ICE battery charging and battery discharging) and the chassis dynamometer related energies (friction braking and augmented braking). The battery energy equation is discussed, followed by a description of the roller energy equation. Firstly, a description of the assumptions implied by using these equations is provided.

\subsubsection{Assumptions}

SOC and current measurements were originally collected to calculate $N E C$. The recommendations made by [43] state that $V_{N}$ is valid to use for $N E C$ calculations. Thus the voltage of the hybrid battery pack was not measured. In calculating 
the battery energies, $V_{N}$ was used to find the energy values between each measurement interval. It is recognized that by using $V_{N}$, and not real-time voltage measurements, the battery energy calculations are less accurate. Further, in chassis dynamometer tests, the vehicle wheels may slip on the rollers during an acceleration or deceleration. This wheel slippage may affect the regenerative braking energy recuperated, but instrumentation and procedures were not in place to account for this problem (see Section 2.6).

\subsubsection{Battery Energy Calculations}

The battery energies were calculated for the Escape Hybrid and Prius only, because the SOC\% measurement precision on the Insight and Civic Hybrid was too low. For instance, while the current was measured every 0.1 seconds and each reading had five significant figures, the $S O C \%$ was measured every 3.2 seconds and had two significant figures. While it is possible to convert SOC to current [60], such a calculation, in this case, would yield meaningless current values. The $S O C$ varied between 0 and $2 \%$ for each time interval, so only two non-zero current values were possible throughout the entire test data. The battery energies were found using a summation of real-time current measurements so a time interval of 3.2 seconds was too large for accurate integration estimates [43].

The energy relation used to find the regenerative braking, ICE battery charging and battery discharging energies ( $E_{\text {regen }}, E_{I C E c h a r g i n g}$, and $E_{\text {discharge }}$, respectively) is shown below, in equation 5.28 .

$$
E_{i}(W s)=V_{N} \cdot I_{i} \cdot\left(t_{i}-t_{i-1}\right)
$$

The length of time between each measurement is the difference between the present time interval, $t_{i}$, and the previous time interval, $t_{i-1}$. Equation 5.28 
calculates the battery energy, $E_{i}$, at the time interval $t_{i}$. Each of the three battery energies were defined using speed and current measurements. The following pseudo-code was developed to describe each energy term.

- Battery Discharge: IF the current is negative AND the speed is increasing or decreasing THEN the battery is supplying the wheels with energy.

- ICE Battery Charging: IF the speed is increasing AND the current is positive THEN the ICE is charging the battery pack.

- Regenerative Braking: IF the speed is decreasing AND the current is positive THEN braking energy is charging the battery pack.

Each type of energy is shown in Figure 5.1. ICE battery charging occurs while the speed is increasing. In this operation mode, current is being fed to the battery from the ICE; thus it is a positive current.

Figure 5.1: Battery Related Energies

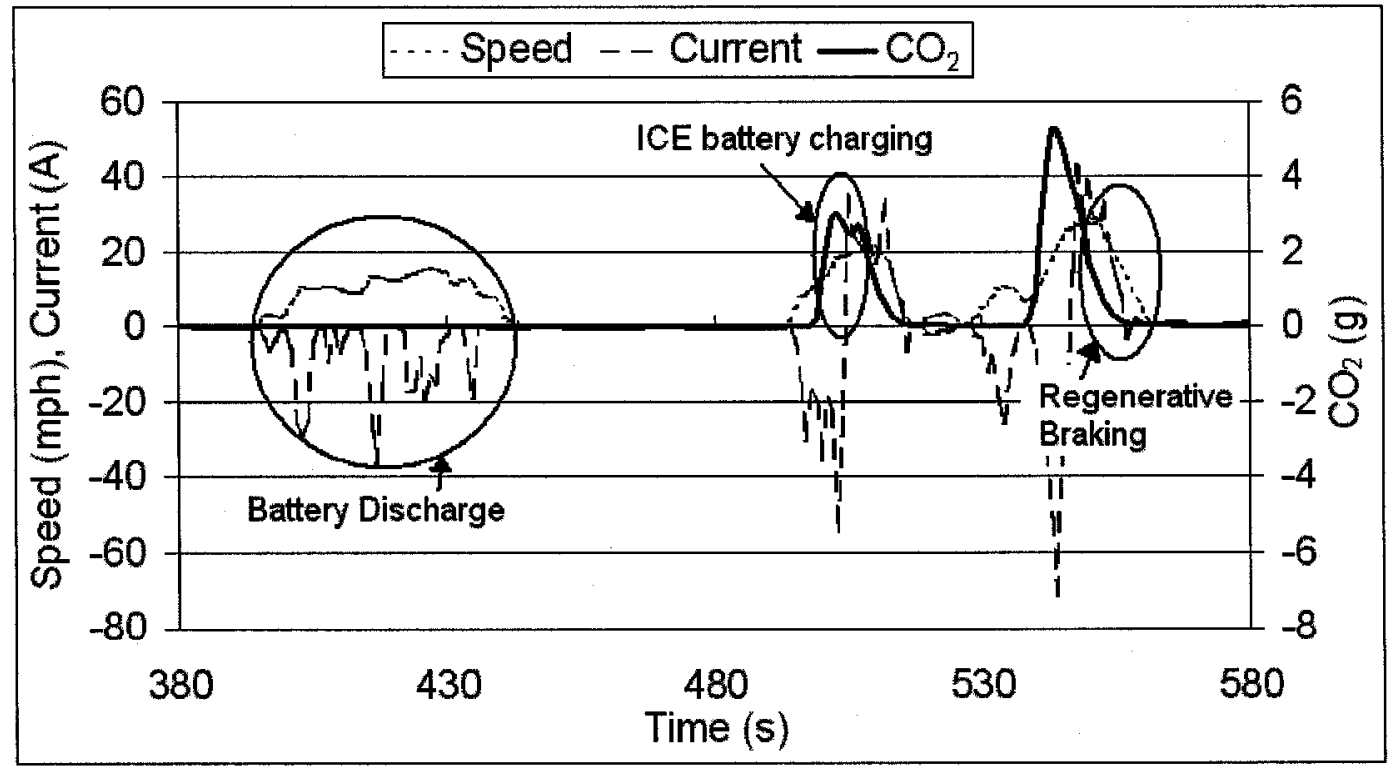

Battery discharge may occur at any point in a drive cycle, although more likely during an acceleration than a deceleration. At any time that the current was 
negative, the time interval was labelled as a battery discharge. Regenerative braking occurs during a deceleration sequence so the speed will decrease from one second to the next. As well, because regenerative braking feeds energy back to the battery, the battery current is positive.

To ensure that all of the current measurements were identified as regenerative braking, ICE battery charging or battery discharging modes, all $E_{i}$ values were summed and multiplied to $\mathrm{V}_{N}$ and $3600 \mathrm{sec} / \mathrm{hr}$ (see equation 5.29). This equation was used to compare the resulting $\triangle S O C$ with the $\triangle S O C$ found in equation 5.20 or 5.21. A difference in these values meant that some of the current measurement intervals were not defined as one of the energy modes.

$$
\Delta S O C(A h)=\frac{E_{I C E \text { charging }}+E_{\text {regen }}-E_{\text {discharge }}}{V_{N} \cdot 3600 \mathrm{sec} / \mathrm{hr}}
$$

\subsubsection{Chassis Dynamometer Roller Energy Calculations}

The friction and augmented braking energies ( $E_{\text {fric }}$ and $E_{a u g}$, respectively) were found by applying the principle of work and energy to the roller. The change in energy of the roller may be defined in rectilinear coordinates as the force at the roller surface multiplied by the distance it traversed. The force imposed on the roller surface (defined in Section 3.2.6 as $F_{\text {roll }}$ ) was identified as a vehicle braking force if it was less than zero. The augmented braking force was identified in a separate column of data. Speed and time measurements were also available. All of the above listed parameters were measured in real-time at 0.1 second intervals. Equation 5.30 calculates the change in energy for a 0.1 second interval for one of two braking modes $\left(E_{\text {mode }_{i}}\right)$, augmented braking or friction braking. The force $F_{\text {mode }_{i}}$ is the force at time interval $t_{i}$ for one of the two braking modes. The speed 
$V_{i}$, at time interval $t_{i}$, is in units of $\mathrm{m} / \mathrm{s}$.

$$
E_{\text {mode }_{i}}(W s)=F_{\text {mode }_{i}} \cdot V_{i} \cdot\left(t_{i}-t_{i-1}\right)
$$

\subsection{Engine-Off Time and Number of Engine Restarts}

The ICEs of HEVs may shut off during a test when the vehicle is at idle (all four HEVs) or when the vehicle is in motion and requires power (Escape Hybrid and Prius only). Modal speed and $\mathrm{CO}_{2}$ measurements were used to identify when the ICE of an HEV shut-off. $\mathrm{CO}_{2}$ was used as a means to identify the ICE as shut-off because it is directly related to fuel consumption (see Section 5.3). Thus, when $\mathrm{CO}_{2}$ emission rates decreased to zero, the ICE must have shut-off. Experimentally, however, this rule does not apply, because even after the ICE shuts off, $\mathrm{CO}_{2}$ emission rates are above zero. $\mathrm{CO}_{2}$ emission rates never reach zero because residual emissions of $\mathrm{CO}_{2}$ are adsorbed by the dilution tunnel walls and are randomly re-entrained into the flow. As well, ambient concentrations of $\mathrm{CO}_{2}$ may contribute to a higher dilute exhaust $\mathrm{CO}_{2}$ emission rate reading than expected. Thus, even when the vehicle speed is zero, the emission rate of $\mathrm{CO}_{2}$ is still decreasing. Figure 5.2 illustrates this effect. The ICE of the Prius is shut off for a portion of the speed-time trace circled in Figure 5.2, but the emission rate of $\mathrm{CO}_{2}$ is still above zero. 
Figure 5.2: Difference in speed decrease to $\mathrm{CO}_{2}$ emission rate decrease during a NYCC test of the Prius

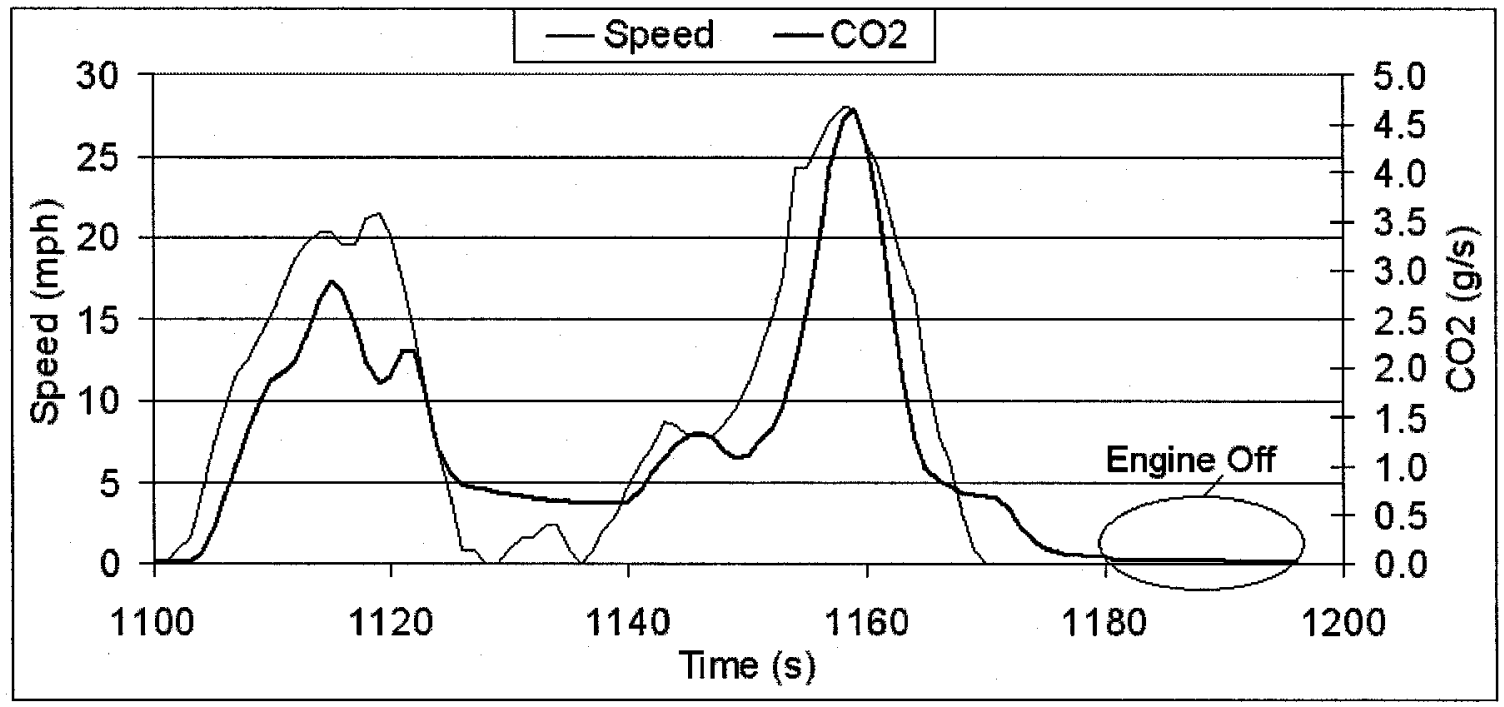

Figure 5.3 is an illustration of a typical $\mathrm{CO}_{2}$ decrease over time, observed in this study. This curve was developed by repeatedly observing declining curves of $\mathrm{CO}_{2}$ for various tests. The emission rate of $\mathrm{CO}_{2}$ drops rapidly and linearly after reaching a local maximum. This occurs as the ICE accelerator is released and the brakes are initiated, thus reducing the ICE load.

Figure 5.3: Schematic of a typical $\mathrm{CO}_{2}$ declination curve over time

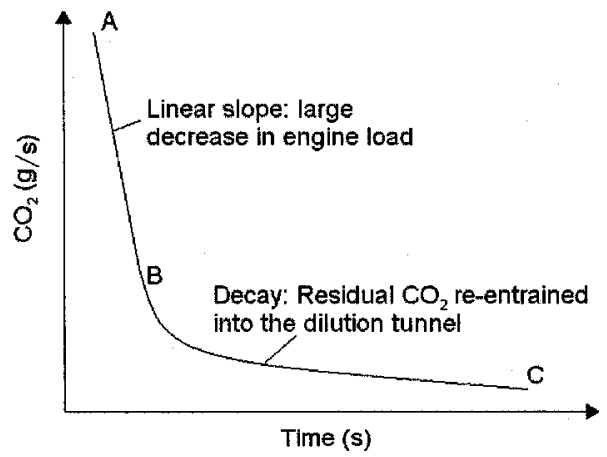

The decreasing emission rate then becomes a decay curve, indicating that the bulk of $\mathrm{CO}_{2}$ from the tailpipe has moved through the dilution tunnel and that only the $\mathrm{CO}_{2}$ residuals are left. In constructing this curve, the decay portion (point $\mathrm{B}$ 
on Figure 5.3) was found to occur at an emission rate between 0.2 and $1.2 \mathrm{~g} / \mathrm{s}$. In order to produce more conservative results, the indication of ICE shut off was defined as $\mathrm{CO}_{2} \leqslant 0.1 \mathrm{~g} / \mathrm{s}$.

The ICE off times were calculated by then identifying at what point along the speedtime trace the ICE restarted. The $\mathrm{CO}_{2}$ emission rate increase indicated at what time the ICE restarts. This increase was defined as a $\mathrm{CO}_{2} \geqslant 0.1 \mathrm{~g} / \mathrm{s}$ to be consistent with the indicating $\mathrm{CO}_{2}$ emission rate for ICE shut off.

\subsection{Vehicle Specific Power}

Vehicle specific power (VSP) was determined for every test for which real-time speed and emissions data were captured. VSP is a measure of the energy usage of a vehicle per unit mass. The VSP is determined using equation 5.31 [59].

$$
\begin{aligned}
V S P\left(\frac{k W}{\text { tonne }}\right)=V_{\text {mps }} \cdot & {\left[a_{\text {mps }} \cdot\left(1+\epsilon_{i}\right)+a_{g}(\text { grade })+9.81 .\right.} \\
& \left.\frac{A_{d y n o}+B_{d y n o} \cdot V_{k p h}+C_{d y n o} \cdot V_{k p h}^{2}}{m_{v}}\right]
\end{aligned}
$$

The dynamometer RLF coefficients $\left(A_{d y n o}, B_{d y n o}\right.$ and $\left.C_{d y n o}\right)$ were obtained from the dynamometer computer. At $-18^{\circ} \mathrm{C}$, the dynamometer coefficients were increased by $10 \%$ as per the standard procedures at ERMD. Modal vehicle speed was applied in units of $\mathrm{m} / \mathrm{s}\left(V_{m p s}\right)$, and $\mathrm{km} / \mathrm{hr}\left(V_{k p h}\right)$. The average acceleration of the roller surface $\left(a_{i}\right)$ replaced the average vehicle acceleration in equation 5.31 and was represented by $a_{m p s}$ to indicate units of $\mathrm{m} / \mathrm{s}^{2}$. The road inclination, grade, was zero and $m_{v}$ was obtained from the vehicle specification sheet. The mass fraction coefficient, $\epsilon_{i}$, may be either 0.015 or $0.1[48,59]$. In this study, $\epsilon_{i}$ was 
assigned the value of 0.015 , in accordance with the SAE practice [48]. The purpose of calculating the VSP was to synchronize the speed and emissions data, as explained in the following section.

\subsubsection{Modal Speed Data: Time Synchronization}

The CVS and chassis dynamometer measured and recorded emissions and speed in real-time. Thus, if the vehicle accelerated at a time, say 10 seconds into the test, the exhaust from that acceleration must have travelled out of the tailpipe, into the CVS and into the gas analyzer, where it spent time being measured. The real-time gas data was therefore calibrated so that the emission rates were matched to the time they were emitted. During this study, it was discovered that this calibration had not been properly completed for the tests conducted in Test Cell 1. This time misalignment was constant for all of the vehicles.

A procedure was developed to properly synchronize the time and emission measurements. $\mathrm{CO}_{2}$ emissions are directly related to fuel consumption. Also, VSP appears to be correlated to fuel consumption based on the results of a study conducted by the EPA [61]. Therefore, the VSP (a function of speed) was plotted with the emission rate of $\mathrm{CO}_{2}$ over the drive cycle so that the time difference between the speed and $\mathrm{CO}_{2}$ emission rate could be observed (see Figure 5.4). Given that $V S P$ and $\mathrm{CO}_{2}$ are correlated to fuel consumption, as $V S P$ increases, the $\mathrm{CO}_{2}$ emission rate should increase as well. This is not seen Figure 5.4.

When the time difference between the speed and emissions data was found (11 seconds), the speed data was time shifted. Figure 5.5 illustrates the effects of this speed and emission synchronization. The arrow in this figure indicates the direction 
that the emission rates were time shifted, relative to $\operatorname{VSP}$ (and thus speed).

Figure 5.4: Vehicle specific power and $\mathrm{CO}_{2}$ emission rate before the $V S P$ was time shifted



Figure 5.5: Vehicle specific power and $\mathrm{CO}_{2}$ emission rate after the speed was time shifted

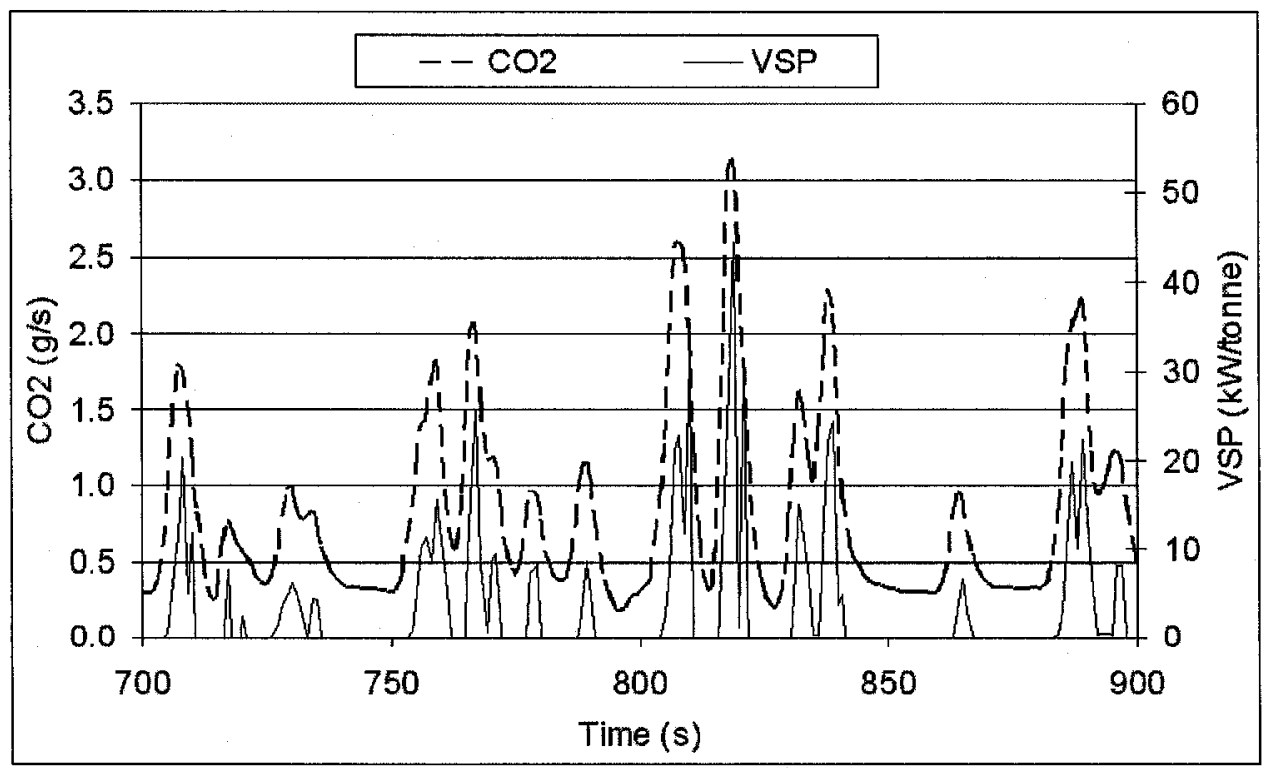

Only the SmartCar was used to determine this time misalignment, because the $V S P$ values of the HEVs included the ICE and battery power. Thus, VSP would 
no longer be directly related to fuel consumption. For the actual $V S P$ calculations, refer to the accompanying DVD under the folders Individual Test Files and Transient Files and file names Smart_NYCC3_28Feb06.xls and Smart_US063_02Mar06.xls. 


\section{Chapter 6}

\section{Results}

The results of this study are presented in this chapter, mostly in the form of summary graphs. All error bars in the graphs represent the standard deviation of multiple tests. The purpose of this chapter is threefold. Firstly, this chapter will investigate the correlation of battery energies to emission factors, ambient temperature, drive cycle and vehicle. The effect of augmented braking on regenerative braking is examined as well. Secondly, this chapter investigates gaseous emission factors of $\mathrm{CO}, \mathrm{NMOG}, \mathrm{NO}_{x}$, carbonyl compounds, $\mathrm{CO}_{2}, \mathrm{CH}_{4}$ and $\mathrm{N}_{2} \mathrm{O}$ during different driving patterns, for five vehicles, and at two temperatures. Thirdly, this chapter presents the influence of ICE off time and ICE restart count on the emission factors of $\mathrm{CO}, \mathrm{CO}_{2}, \mathrm{HC}$ and $\mathrm{NO}_{x}$. The chapter aims to document the results in summary form, leaving their discussion to the next chapter.

The chapter begins by presenting the battery and braking energies of the Escape Hybrid and Prius, for both operating temperatures and all transient cycles. Regenerative braking, ICE battery charging and battery discharging energies are quantified and compared at both operating temperatures, and between the Escape Hybrid and Prius. Augmented braking, friction braking and regenerative braking 
values are provided for the Escape Hybrid and Prius, as well.

Following the energy results, the emission factors of selected carbonyl compounds, $\mathrm{CO}, \mathrm{NO}_{x}, \mathrm{NMOG}, \mathrm{CO}_{2}, \mathrm{CH}_{4}$ and $\mathrm{N}_{2} \mathrm{O}$ are provided. These emission factors are compared to battery $N E C$, drive cycle and operating temperature.

Next, ICE off time and ICE restart counts are provided in summary tables. These two parameters are compared, and both are related to the real-time emissions of $\mathrm{CO}, \mathrm{CO}_{2}, \mathrm{HC}$ and $\mathrm{NO}_{x}$.

The availability of the results in the accompanying DVD is described in the last section of this chapter.

\subsection{Battery and Braking Energies}

In this section, battery activity and energy values are reported for the Prius and Escape Hybrid transient drive cycle tests. In this study, battery activity is defined as the amount of energy that flowed into and out of the battery throughout a test. Battery activity and energy values are also correlated to temperature, driving patterns and emission factors. Braking energies are also reported for the Prius and Escape Hybrid. These braking energies are then correlated to temperature, and driving patterns. The braking energies are also compared between the vehicles.

\subsubsection{Battery Activity}

Table 6.1 lists the average battery activities of all of the transient drive cycle tests of the Escape Hybrid and Prius tests at $-18^{\circ} \mathrm{C}$ and $20^{\circ} \mathrm{C}$. 
Table 6.1: Average battery activities of the Escape Hybrid and Prius transient drive cycle tests at $-18^{\circ} \mathrm{C}$ and $20^{\circ} \mathrm{C}$

\begin{tabular}{|l|c|c|c|c|c|c|}
\hline \multirow{2}{*}{ Cycle } & \multicolumn{5}{|c|}{ Battery Activity (kJ) } \\
\cline { 2 - 7 } & \multicolumn{3}{|c|}{ Escape Hybrid } & \multicolumn{3}{c|}{ Prius } \\
\cline { 2 - 7 } & $20^{\circ} \mathrm{C}$ & $-18^{\circ} \mathrm{C}$ & Decrease (\%) & $20^{\circ} \mathrm{C}$ & $-18^{\circ} \mathrm{C}$ & Decrease (\%) \\
\hline HWFET & 2237 & 2108 & 5.8 & 2404 & 712 & 70 \\
LA4CS & 4801 & 3262 & 32 & 3379 & 912 & 73 \\
LA4HS & 5241 & 4181 & 20 & 3252 & 794 & 76 \\
LA92CS & 5016 & 4479 & 11 & 2102 & 1558 & 26 \\
LA92HS & 4990 & 5106 & -2.3 & 2813 & 1746 & 38 \\
2XNYCC & 3735 & 2157 & 42 & 1627 & 507 & 69 \\
2xUS06 & 6838 & 3993 & 42 & 4794 & 2043 & 57 \\
\hline
\end{tabular}

Generally, the 2xNYCC and HWFET tests at both temperatures have the lowest battery activities. Except for the Escape Hybrid tests at $-18^{\circ} \mathrm{C}$, the $2 x U S 06$ tests at both temperatures have the highest battery activity.

The battery activity decreased between the $20^{\circ} \mathrm{C}$ and $-18^{\circ} \mathrm{C}$ tests, except for the Escape Hybrid LA92HS. The highest battery activity drop occurred during the 2xUS06 and 2XNYCC for the Escape Hybrid, and during the LA4CS and LA4HS for the Prius. The battery activity of the Prius decreased more than the Escape Hybrid between $20^{\circ} \mathrm{C}$ and $-18^{\circ} \mathrm{C}$ tests.

As discussed in Section 6.1.2, battery activity is not strongly linearly correlated to emission factors.

\subsubsection{Battery Energies}

Battery energies are shown for both HEVs and all transient cycles in Figures 6.1 to 6.4. Regenerative braking energy and ICE battery charging energy are positive values and battery discharge energy is a negative value. Battery discharge energy 
is shown as a positive value in graphs to facilitate comparison between the battery energies. Some of the energy bars in the following graphs have large error bars. Although the procedure to test vehicles on chassis dynamometers is rigidly set in order for repeatability, battery energy is not one of the parameters that these procedures attempt to make repeatable. Thus energy values can be very different from test to test.

Figure 6.1: Battery energy distribution for the Escape Hybrid at $-18^{\circ} \mathrm{C}$; averages of multiple tests

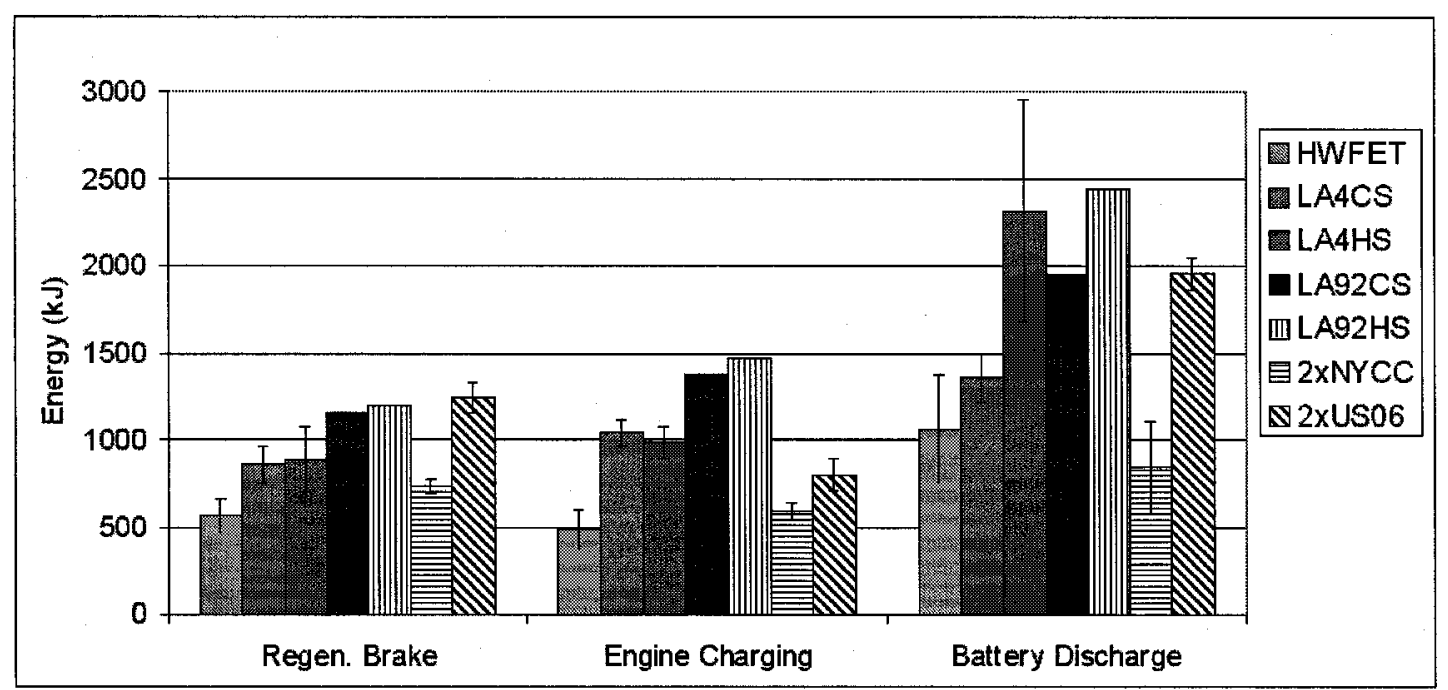


Figure 6.2: Battery energy distribution for the Escape Hybrid at $20^{\circ} \mathrm{C}$; averages of multiple tests

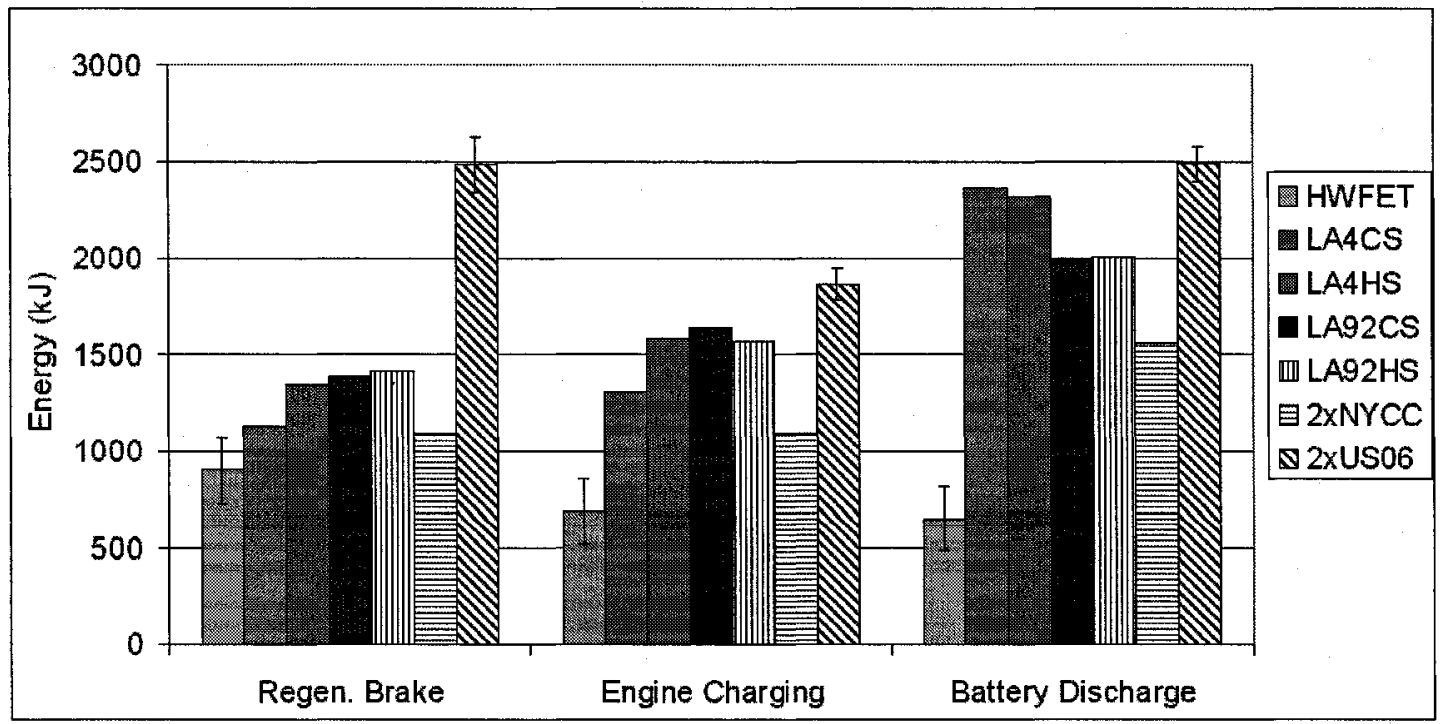

Figure 6.3: Battery energy distribution for the Prius at $-18^{\circ} \mathrm{C}$; averages of multiple tests

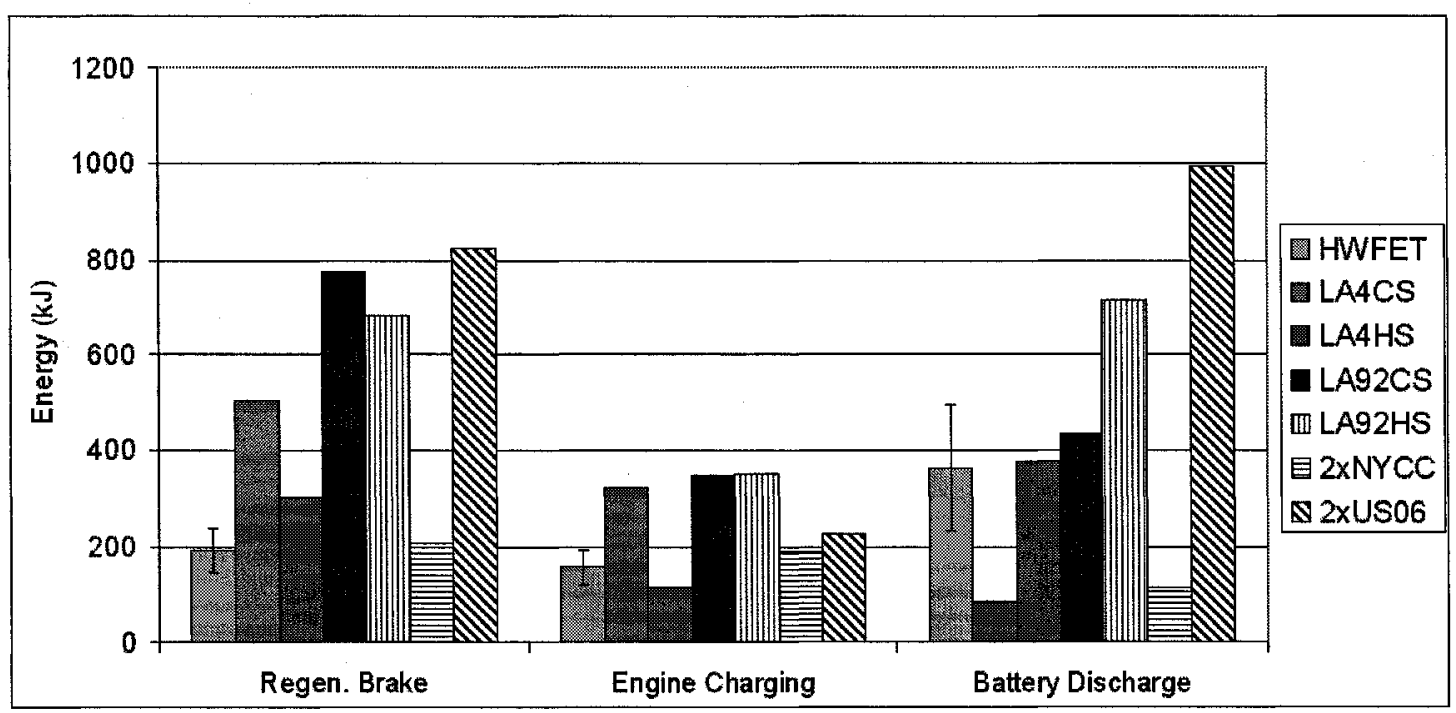

Regenerative braking energy is larger than ICE battery charging energy for the Prius tests, at both temperatures. The opposite is true for the Escape Hybrid. At both temperatures, battery discharge energy is the largest energy for the Escape Hybrid, but not for the Prius. 
Figure 6.4: Battery energy distribution for the Prius at $20^{\circ} \mathrm{C}$; averages of multiple tests

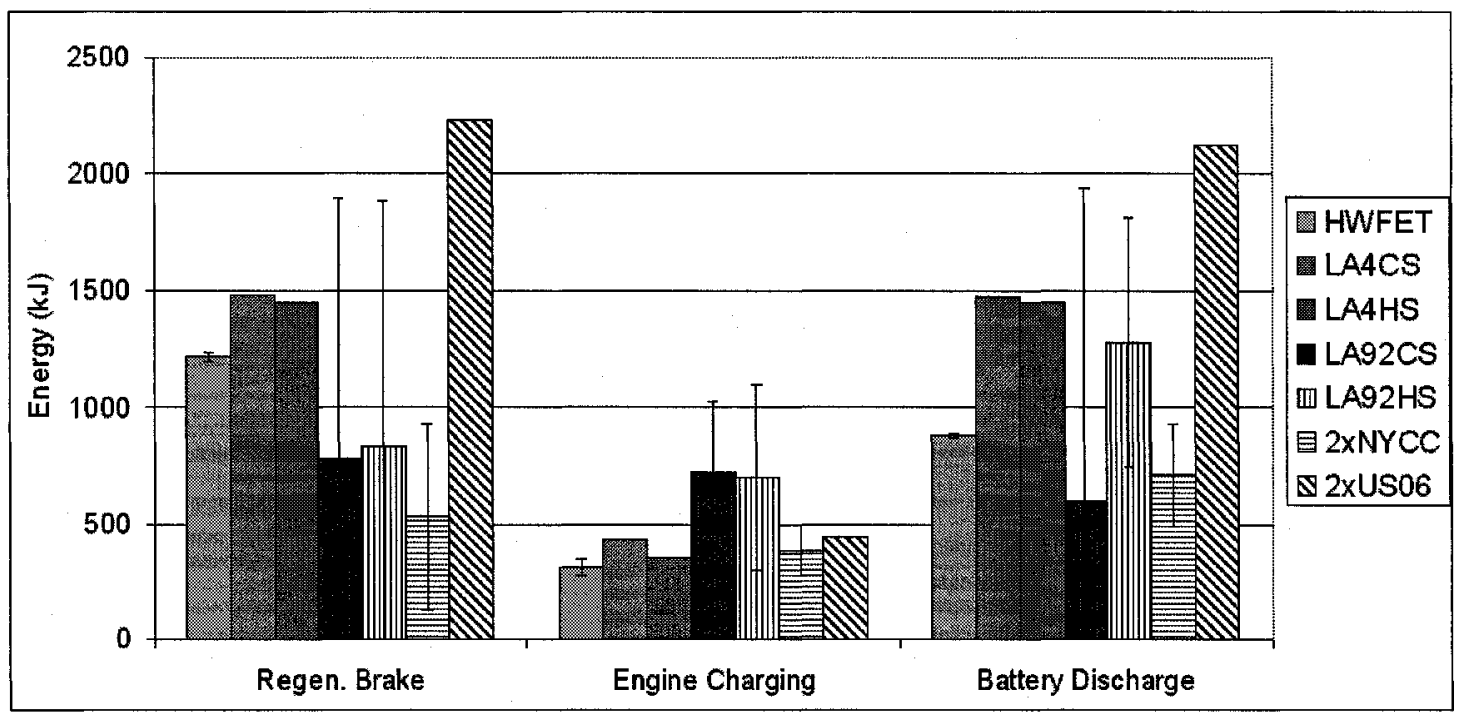

Figures 6.1 to 6.4 illustrate that the Prius and Escape Hybrid batteries are not as active during $-18^{\circ} \mathrm{C}$ tests as they are during $20^{\circ} \mathrm{C}$ tests, as observed in Section 6.1.1.

The 2xUS06 cycle regenerative braking energy values and battery discharge energy are the largest and second largest, respectively, for any test at both temperatures and for both HEVs. Regenerative braking, ICE battery charging and battery discharging energies are generally lowest during the HWFET and 2xNYCC tests, for both temperature and HEVs.

Correlations between gaseous emissions and regenerative braking, ICE battery charging and battery discharging energies were sought. Figure 6.5 is an example of the linear correlations, which are weak, if at all noticeable. The linear correlations in this example are consistent with the correlations for all the energies at both temperatures and for both HEVs. These correlations are also consistent to those observed between battery activity and emission factors. 
Figure 6.5: Average regenerative braking energy to total cycle energy ratios and average emission factors

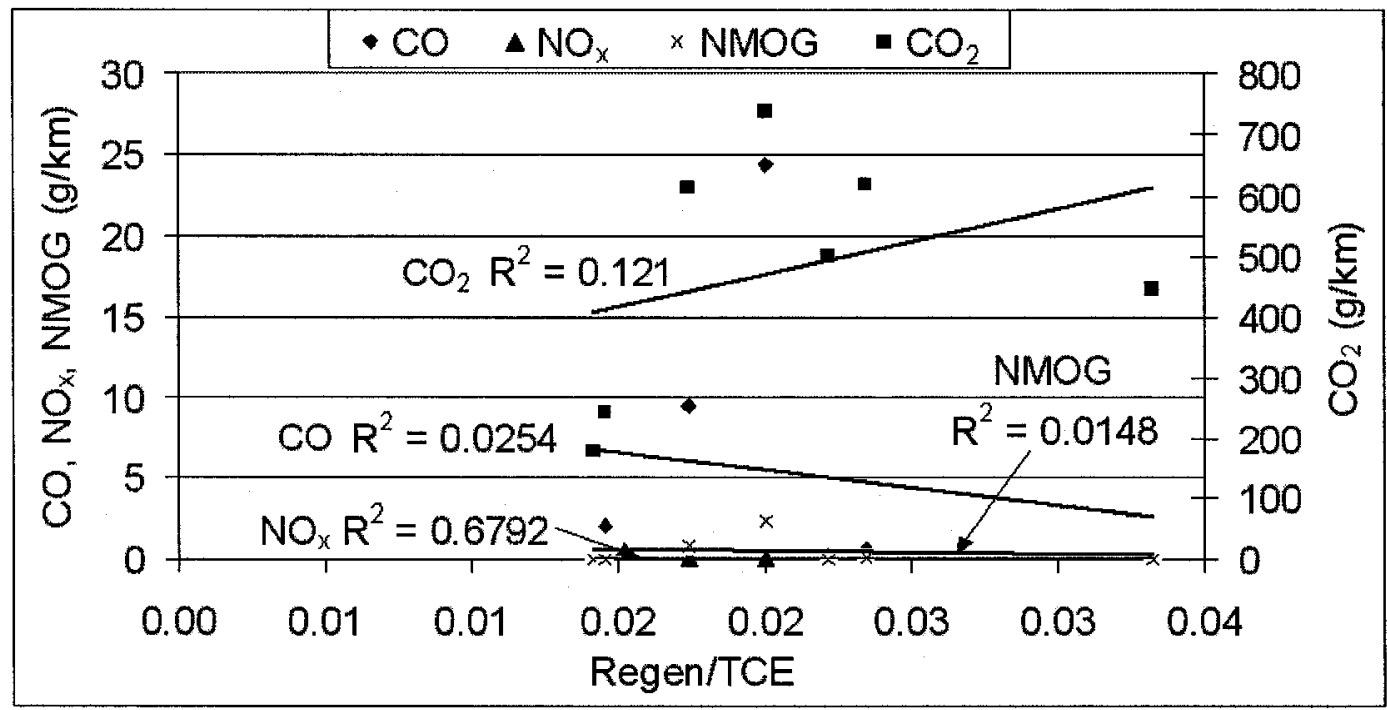

The energy ratios of regenerative braking, ICE battery charging, and battery discharging energy to $T C E$, are shown for both temperatures and HEVs in Figures 6.6 to 6.9 .

Figure 6.6: Average battery energies to average $T C E$ ratios for Escape Hybrid tests at $-18^{\circ} \mathrm{C}$

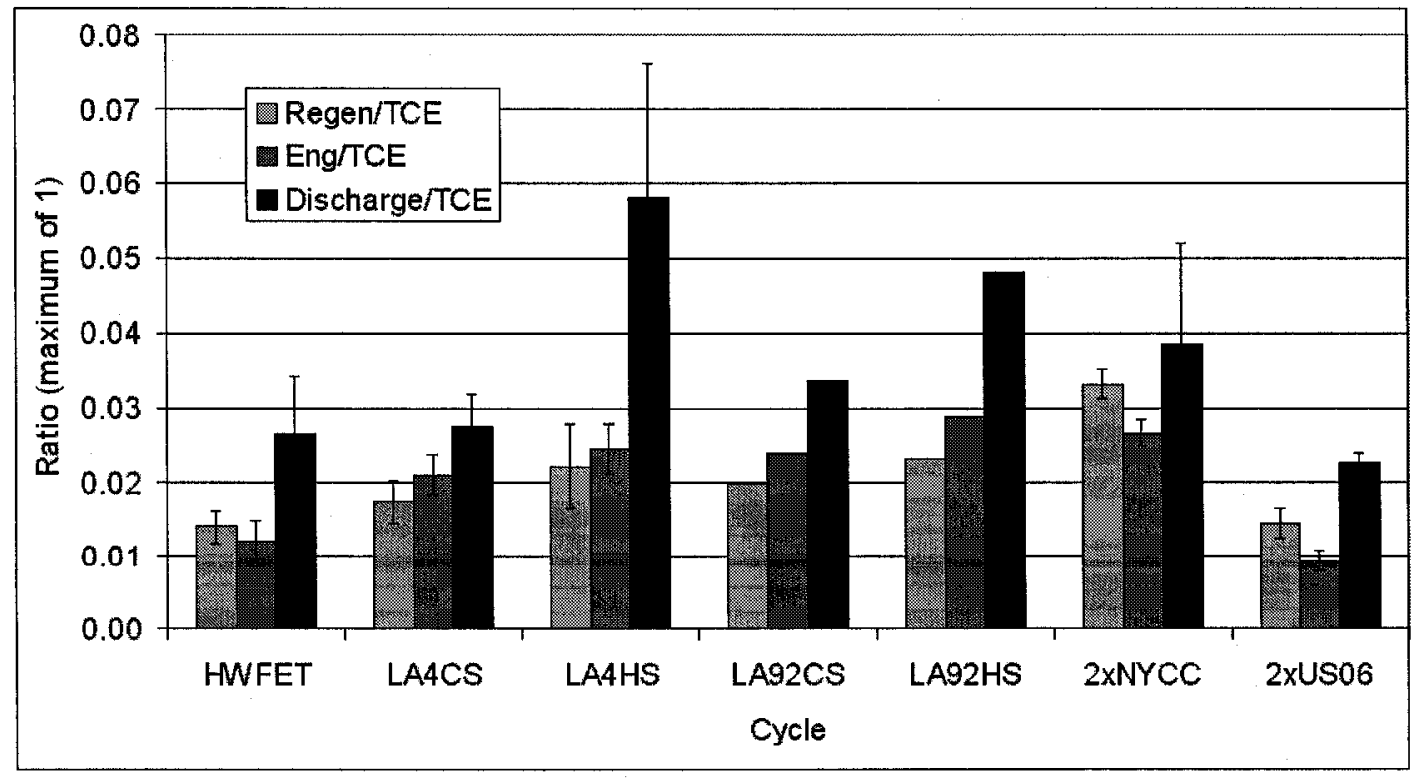


Figure 6.7: Average battery energies to average $T C E$ ratios for Escape Hybrid tests at $20^{\circ} \mathrm{C}$

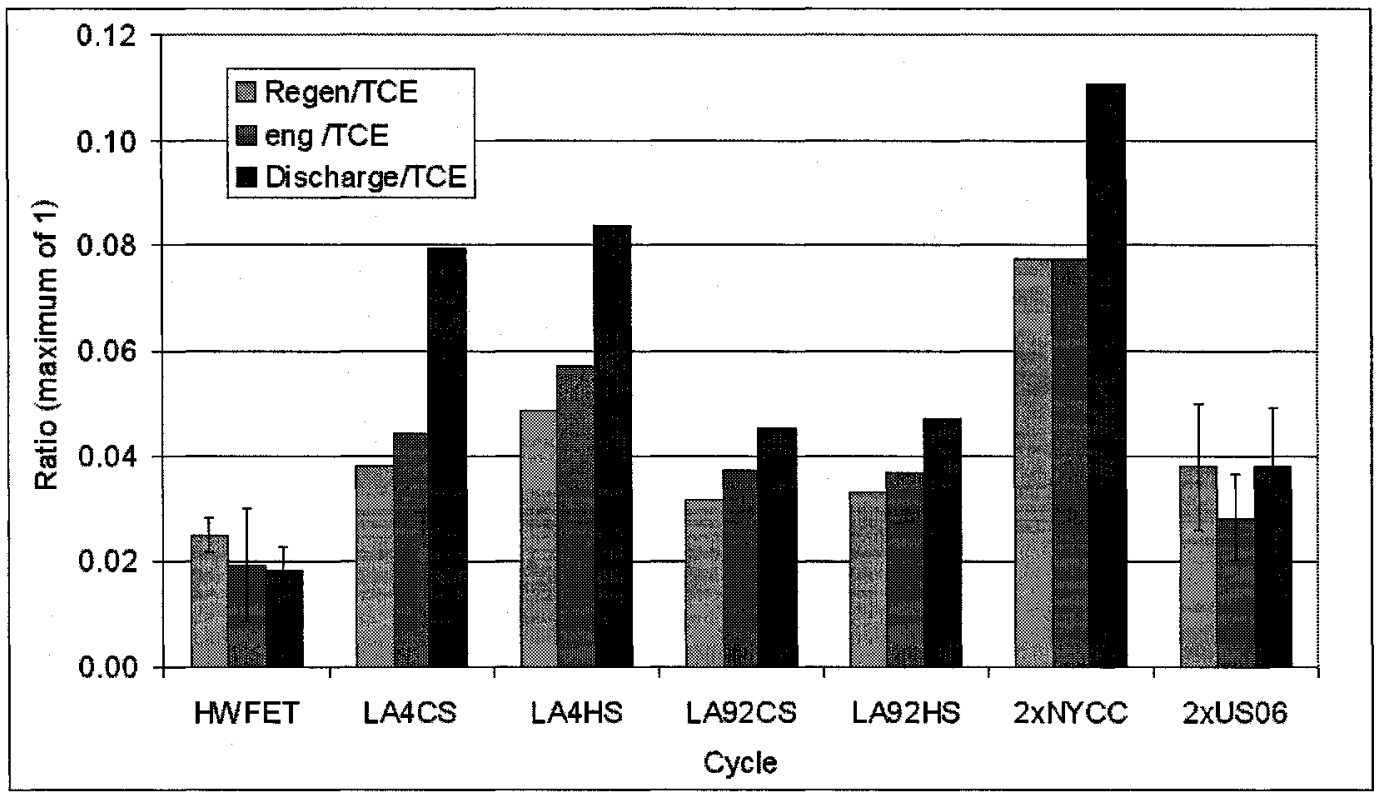

Figure 6.8: Average battery energies to average $T C E$ ratios for the Prius tests at $-18^{\circ} \mathrm{C}$



The energy fractions for both HEVs increase with increasing ambient temperature. In almost every Escape Hybrid test, the battery discharge energy constitutes the largest fraction of battery energy to TCE. In most of the Prius tests, the 
Figure 6.9: Average battery energies to average $T C E$ ratios for the Prius tests at $20^{\circ} \mathrm{C}$

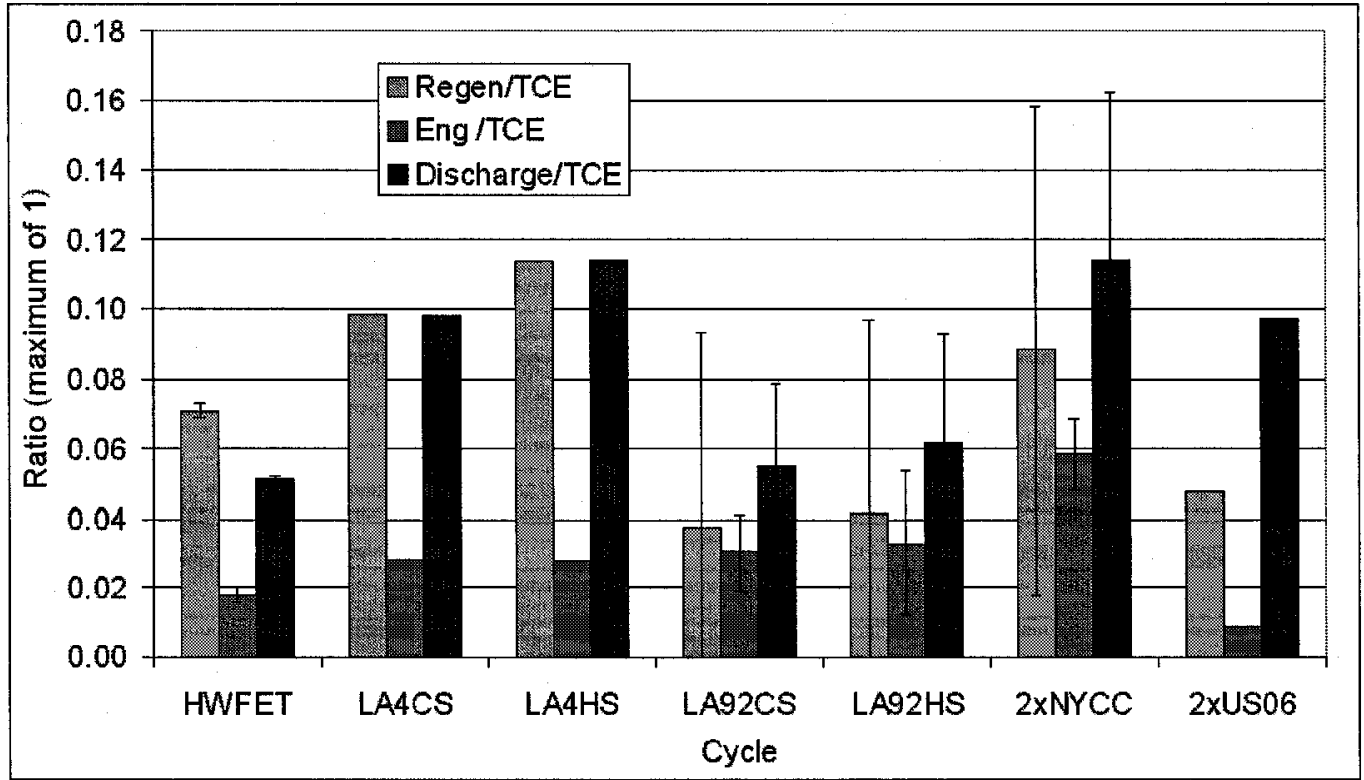

regenerative braking energy and battery discharge energy constitute the largest fractions of $T C E$.

The Escape Hybrid 2xNYCC tests at both temperatures have the most regenerative braking energy and ICE charging energy per TCE. The Prius LA92 tests at $-18^{\circ} \mathrm{C}$ have the lowest regenerative braking energy to $T C E$ ratio and the highest regenerative braking energy to $T C E$ ratio at $20^{\circ} \mathrm{C}$.

The Prius regenerative braking energies constitute a larger portion of the $T C E$ than those of the Escape Hybrid during $20^{\circ} \mathrm{C}$ tests and is comparable to the Escape Hybrid during $-18^{\circ} \mathrm{C}$ tests. 


\subsubsection{Vehicle Energy Comparisons}

The Prius and Escape Hybrid are compared in Figures 6.10 to 6.14. Figure 6.11 shows the regenerative braking energies of the Prius and Escape Hybrid for all of the $20^{\circ} \mathrm{C}$ transient cycle tests. All of the Prius average regenerative braking energies were calculated from tests that did not utilize augmented braking, except for the LA92CS and LA92HS. All of the Escape Hybrid tests conducted at $20^{\circ} \mathrm{C}$ were done so using augmented braking. The regenerative braking energy of the Prius is comparable to that of the Escape Hybrid at $20^{\circ} \mathrm{C}$. A third row was inserted in Figure 6.11, which represents the regenerative braking energy of the Escape Hybrid if augmented braking had not been employed. This value was calculated by multiplying the ratio of regenerative brake energy to total vehicle braking energy, to the total braking energy (TBE). TBE is the sum of vehicle and augmented braking. When the effect of augmented braking is removed, the Escape Hybrid regenerative braking energy values are larger than those of the Prius.

All of the tests conducted at $-18^{\circ} \mathrm{C}$ on the Escape Hybrid and Prius utilize augmented braking. The average regenerative braking energies for these two vehicles are comparable for the LA4CS, LA92CS and 2xUS06 drive cycles (see Figure 6.10). The Prius recuperated one fourth the regenerative braking energy that the Escape Hybrid recuperated during the 2xNYCC and one third of the energy for the HWFET.

The average ICE battery charging energies for the Escape Hybrid and Prius at $-18^{\circ} \mathrm{C}$ and $20^{\circ} \mathrm{C}$ are shown in Figures 6.12 and 6.13 , respectively. At both temperatures, the average ICE battery charging energies of the Escape Hybrid are up to six times larger than those of the Prius. The lowest average ICE battery 
charging energies are from tests conducted using the least aggressive drive cycles.

The battery discharge energy of the Escape Hybrid at $20^{\circ} \mathrm{C}$ (Figure 6.14) is larger than that at $-18^{\circ} \mathrm{C}$ (Figure 6.15 ), but the LA92 tests at $-18^{\circ} \mathrm{C}$ have comparable energies to those at $20^{\circ} \mathrm{C}$. The battery discharging energy of the Prius is less than that of the Escape Hybrid at $20^{\circ} \mathrm{C}$ and more pronouncedly so at $-18^{\circ} \mathrm{C}$.

Figure 6.10: Regenerative braking energies of the Prius and Escape Hybrid at $-18^{\circ} \mathrm{C}$; average of multiple tests

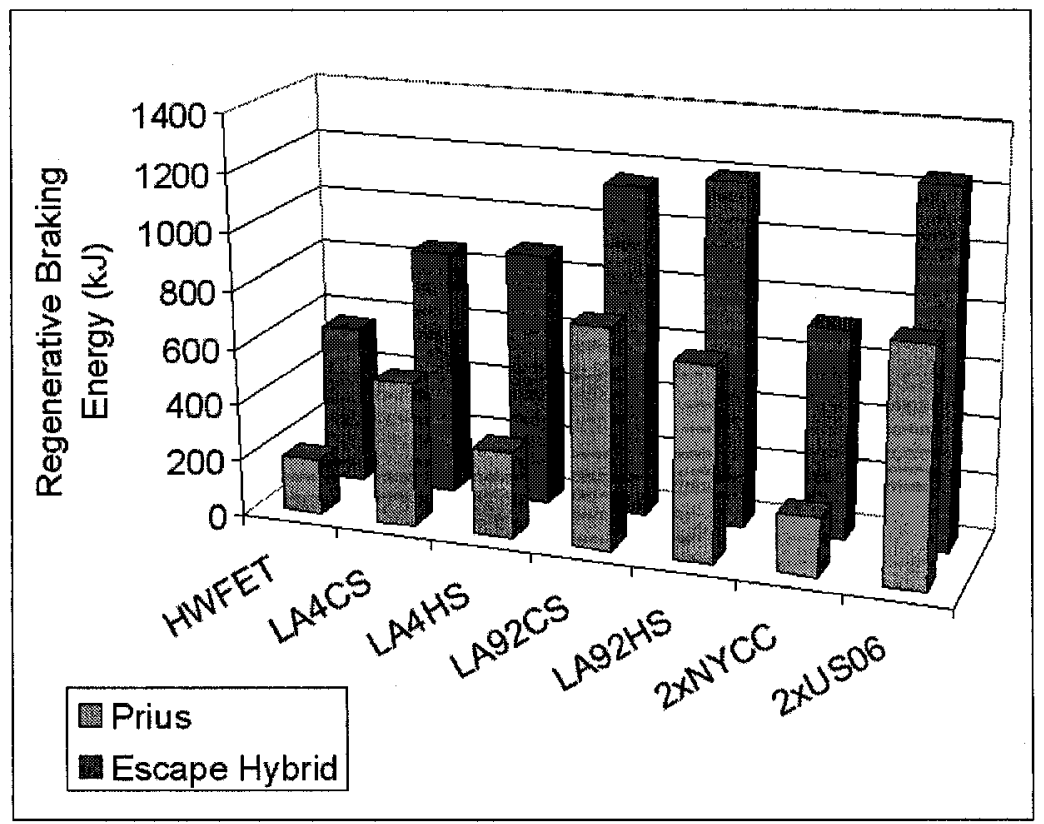


Figure 6.11: Regenerative braking energies of the Escape Hybrid, with and without (NO aug) augmented braking, and of the Prius at $20^{\circ} \mathrm{C}$; average of multiple tests

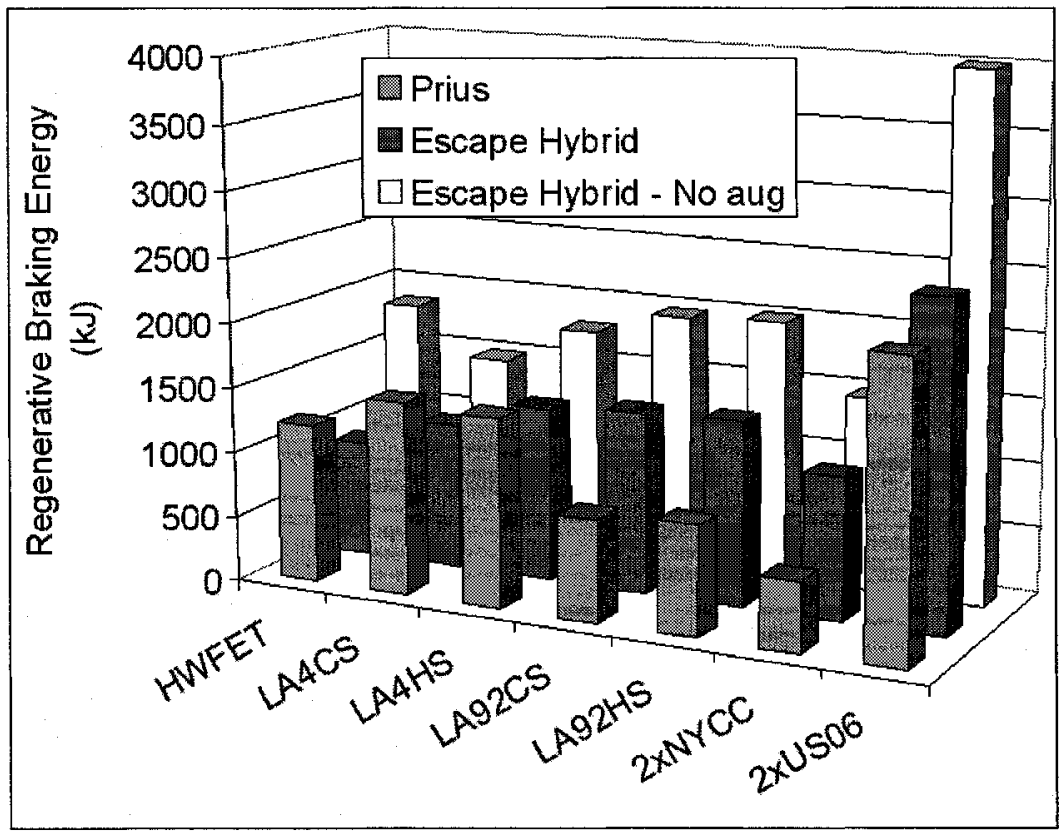

Figure 6.12: Internal combustion engine battery charging energy of the Prius and Escape Hybrid at $-18^{\circ} \mathrm{C}$; average of multiple tests

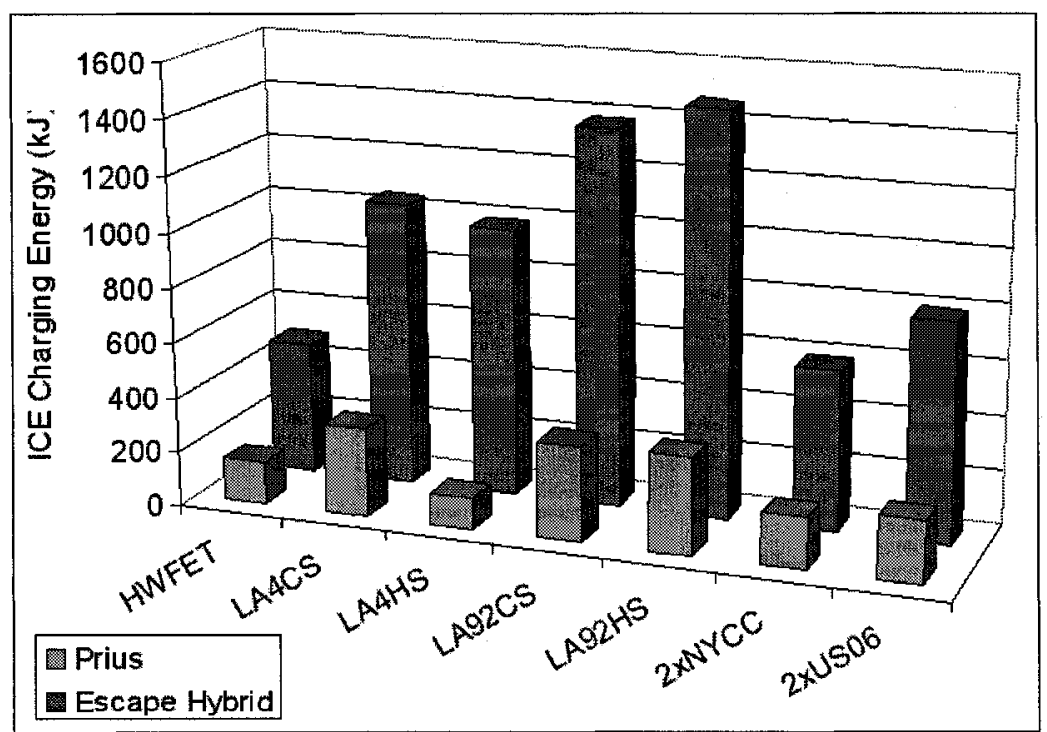


Figure 6.13: Internal combustion engine battery charging energy of the Prius and Escape Hybrid at $20^{\circ} \mathrm{C}$; average of multiple tests

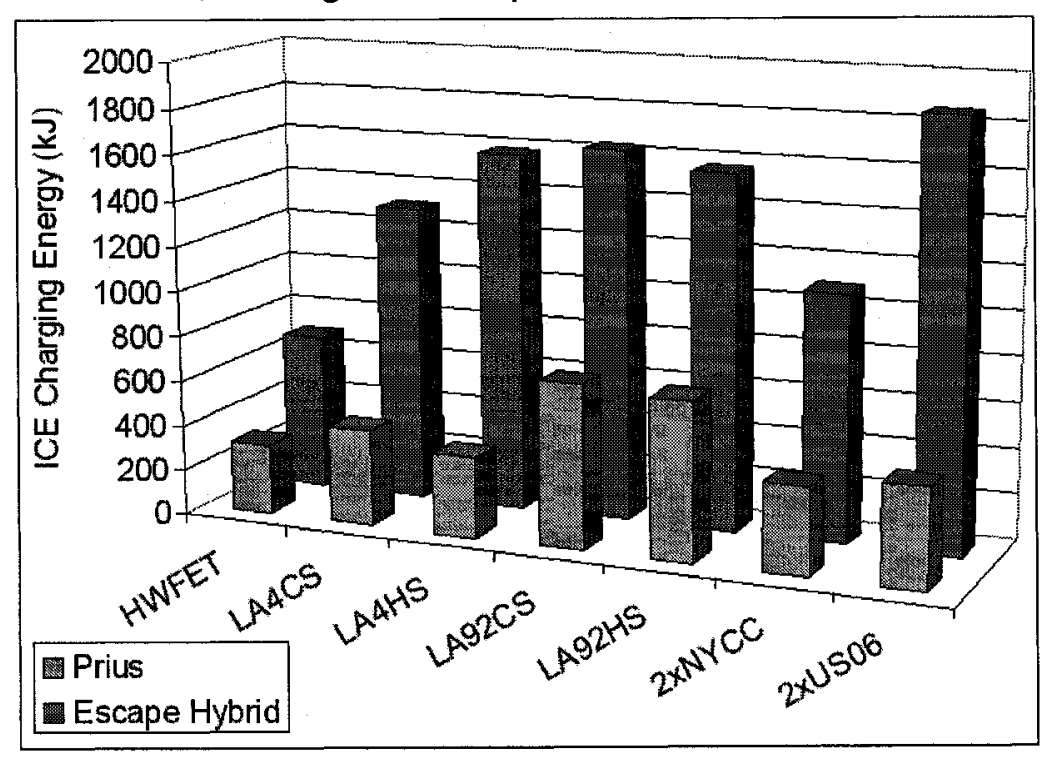

Figure 6.14: Battery discharging energy of the Prius and Escape Hybrid at $20^{\circ} \mathrm{C}$; average of multiple tests




Figure 6.15: Battery discharging energy of the Prius and Escape Hybrid at $-18^{\circ} \mathrm{C}$; average of multiple tests



\subsubsection{Braking Energies}

The Escape Hybrid and Prius friction, augmented and regenerative braking energies are presented in Tables 6.2 and 6.3, respectively. Most of the $20^{\circ} \mathrm{C}$ Prius tests do not employ augmented braking, as shown in Table 6.3. For tests at $-18^{\circ} \mathrm{C}$, the Escape Hybrid augmented braking energy was generally higher than that of the Prius.

In comparison to the available braking energy, both vehicles recuperated the most during $20^{\circ} \mathrm{C}$ tests on the HWFET, 2xUS06 and $2 \times N Y C C$ drive cycles, but not necessarily in that order.

At $20^{\circ} \mathrm{C}$, the Escape Hybrid recaptured up to $31 \%$ more braking energy per TBE than did the Prius. During $-18^{\circ} \mathrm{C}$ tests, the Escape Hybrid recuperated up to $12 \%$ more regenerative braking energy per TBE than did the Prius. 
Table 6.2: Escape Hybrid: Braking energy distribution between regenerative braking (reg), friction brakes and augmented braking (aug)

\begin{tabular}{|l|c|c|c|c|c|c|}
\hline \multirow{2}{*}{ Cycle } & \multicolumn{2}{|c|}{ Reg/TBE } & \multicolumn{2}{c|}{ Friction/TBE } & \multicolumn{2}{c|}{ Aug/TBE } \\
\cline { 2 - 7 } & $20^{\circ} \mathrm{C}$ & $-18^{\circ} \mathrm{C}$ & $20^{\circ} \mathrm{C}$ & $-18^{\circ} \mathrm{C}$ & $20^{\circ} \mathrm{C}$ & $-18^{\circ} \mathrm{C}$ \\
\hline HWFET & $0.46 \pm 0.06$ & $0.30 \pm 0.04$ & $0.49 \pm 0.02$ & $0.51 \pm 0.02$ & $0.51 \pm 0.02$ & $0.49 \pm 0.02$ \\
LA4CS & 0.30 & $0.24 \pm 0.04$ & 0.76 & $0.73 \pm 0.02$ & 0.24 & $0.27 \pm 0.02$ \\
LA4HS & 0.34 & $0.25 \pm 0.06$ & 0.75 & $0.73 \pm 0.02$ & 0.25 & $0.27 \pm 0.02$ \\
LA92CS & 0.30 & 0.26 & 0.70 & 0.68 & 0.30 & 0.32 \\
LA92HS & 0.29 & 0.27 & 0.71 & 0.68 & 0.29 & 0.32 \\
2xNYCC & 0.57 & $0.37 \pm 0.03$ & 0.73 & $0.71 \pm 0.01$ & 0.27 & $0.29 \pm 0.01$ \\
2xUS06 & $0.50 \pm 0.03$ & $0.26 \pm 0.02$ & $0.62 \pm 0.01$ & $0.60 \pm 0.00$ & $0.38 \pm 0.01$ & $0.40 \pm 0.00$ \\
\hline
\end{tabular}

The Prius regenerative brake energy fraction of TBE decreased more than the Escape Hybrid during $-18^{\circ} \mathrm{C}$ operation. All regenerative braking energy to TBE ratios decreased from $20^{\circ} \mathrm{C}$ to $-18^{\circ} \mathrm{C}$ operation, except for the Prius during the LA92CS.

Table 6.3: Prius: Braking energy distribution between regenerative braking (reg), friction brakes and augmented braking (aug)

\begin{tabular}{|l|c|c|c|c|c|c|}
\hline \multirow{2}{*}{ Cycle } & \multicolumn{2}{|c|}{ Reg/TBE } & \multicolumn{2}{c|}{ Friction/TBE } & \multicolumn{2}{c|}{ Aug/TBE } \\
\cline { 2 - 7 } & $20^{\circ} \mathrm{C}$ & $-18^{\circ} \mathrm{C}$ & $20^{\circ} \mathrm{C}$ & $-18^{\circ} \mathrm{C}$ & $20^{\circ} \mathrm{C}$ & $-18^{\circ} \mathrm{C}$ \\
\hline HWFET & $0.48 \pm 0.01$ & $0.08 \pm 0.02$ & $1.00 \pm 0.00$ & $0.74 \pm 0.02$ & $0.00 \pm 0.00$ & $0.26 \pm 0.02$ \\
LA4CS & 0.30 & 0.12 & 1.00 & 0.82 & 0.00 & 0.18 \\
LA4HS & 0.29 & 0.07 & 1.00 & 0.82 & 0.00 & 0.18 \\
LA92CS & $0.15 \pm 0.22$ & 0.16 & $0.93 \pm 0.13$ & 0.78 & $0.07 \pm 0.13$ & 0.22 \\
LA92HS & $0.16 \pm 0.20$ & 0.13 & $0.93 \pm 0.13$ & 0.78 & $0.07 \pm 0.13$ & 0.22 \\
2xNYCC & $0.26 \pm 0.20$ & 0.10 & $1.00 \pm 0.00$ & 0.80 & $0.00 \pm 0.00$ & 0.20 \\
2xUS06 & 0.40 & 0.16 & 1.00 & 0.71 & 0.00 & 0.29 \\
\hline
\end{tabular}

\subsection{Greenhouse Gas and Regulated Emissions}

$\mathrm{CO}_{2}, \mathrm{CO}, \mathrm{NO}_{x}, \mathrm{HC}, \mathrm{CH}_{4}$ and $\mathrm{N}_{2} \mathrm{O}$ emissions were measured for each test (or phase). From these measurements, the emission factors, or so-called integrated 
emissions, were calculated and are reported here, in units of $\mathrm{g} / \mathrm{km}$. NMOG was calculated as the addition of $\mathrm{HC}$, oxygenates, carbonyl compounds and the subtraction of $\mathrm{CH}_{4}$. For most tests, oxygenates and carbonyl compounds were not speciated and NMOG was essentially the equivalent of NMHC. Note that all of the following bar graphs use a logarithmic scale, except for the $\mathrm{CO}_{2}$ emission factor graphs. Also note that the standard deviations had to be altered in some cases, to facilitate graphing, but the original data is available on the accompanying DVD.

This section presents the results of the integrated emissions in relation to $N E C$, drive cycle and operating temperature.

\subsubsection{Battery Net Energy Change and Emissions}

An example of correcting emission factor and FC calculations for the $N E C$ contribution to $T C E$, as recommended by [43], is shown in Figure 6.16.

Figure 6.16: Example of the Prius $\mathrm{CO}_{2}$ emission factor correction for the 2xNYCC cycle at $-18^{\circ} \mathrm{C}$ based on $N E C$



To correct the emissions for the NEC contribution to TCE, the equation shown in Figure 6.16 would be interpolated at the $N E C=0$ point to find the corrected 
emission factor of $\mathrm{CO}_{2}$ from the Prius. This example shows that the range of $\mathrm{R}^{2}$ values for different tests varies from virtually 0 to approximately 0.9 . This range is consistent for all of the HEVs tested at both temperatures, although high $\mathrm{R}^{2}$ values were observed less frequently. In this example, the slopes of the trend lines for the 2xUS06 is slightly positive, the slope for the HWFET is virtually zero and the slope of the $2 x N Y C C$ is negative. In this case, $\mathrm{CO}_{2}$ varies with NEC for the $2 \times N Y C C$ test only, over a $2 \%$ NEC range.

The correlation between $\mathrm{CO}_{2}$ and $N E C$ for the Civic Hybrid is similar to that of the Prius (see Figure 6.17). However, in this case, the slopes of the trend lines for the HWFET and 2xNYCC tests are negative. The relationship between $\mathrm{CO}$, $\mathrm{NMOG}$ and $\mathrm{NO}_{x}$, and $N E C$ are comparable to those seen in Figure 6.17 (see accompanying DVD).

Although emission corrections were attempted for every test requiring one, in most instances, the corrected emissions did not make any sense. In this study, uncorrected emissions are reported for all tests.

Figure 6.17: Example of the Civic Hybrid $\mathrm{CO}_{2}$ emissions and $\mathrm{NEC}$ for the HWFET, $2 \times N Y C C$ and $2 \times U S 06$ drive cycles at $20^{\circ} \mathrm{C}$

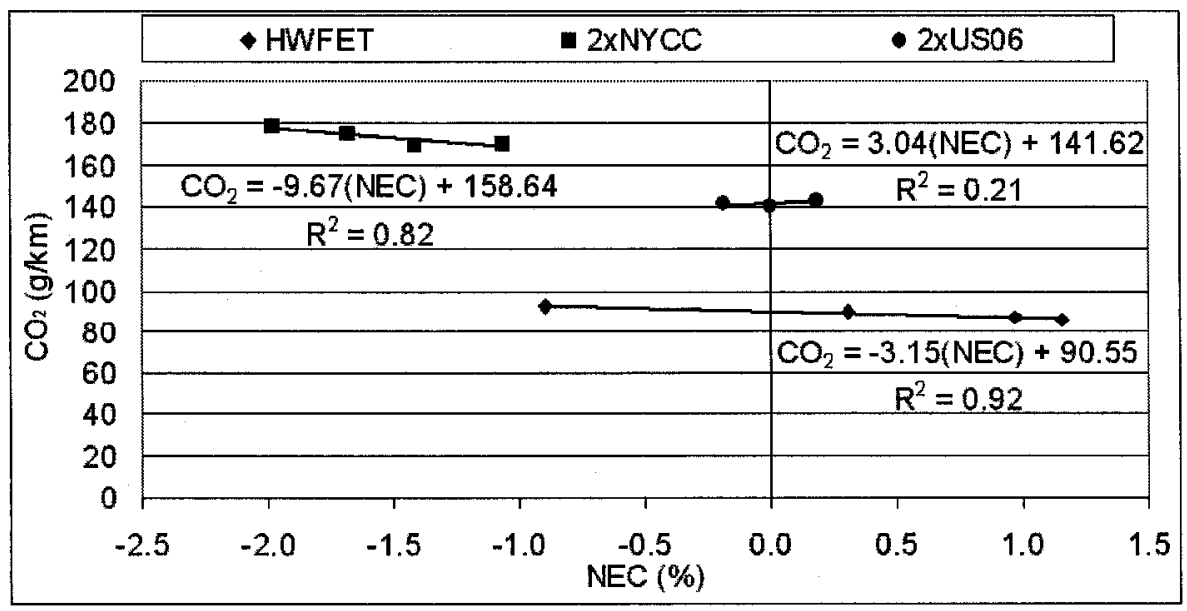


The $N E C$ for all tests ranged between 0 and $\pm 10 \%$. In one instance the $N E C$ was found to be $123 \%$, but this was attributed to a measurement error and the test was voided. One Prius 2xLA92 phase 3 test, Escape Hybrid 2xLA4 phase 3 test, Escape Hybrid 2xLA92 phase 1 test, Civic Hybrid 2xLA4 phase 4 test, and Civic Hybrid 2xLA92 phase 3 test exceeded $5 \% N E C$, but because the \% NEC for four-phase tests was found by summing the $N E C$ values from each phase, none of these instances resulted in a voided test. Table 6.4 provides the number of tests for each HEV and drive cycle that exceed $1 \% N E C$, but was below $5 \% N E C$.

A higher percentage of tests conducted at $20^{\circ} \mathrm{C}$ exceeded $1 \% N E C$ than those at $-18^{\circ} \mathrm{C}$. The SS40 tests resulted in the least frequent incidences of $N E C>1 \%$ during $20^{\circ} \mathrm{C}$ testing. For $20^{\circ} \mathrm{C}$ tests, the $2 x N Y C C$ and $2 x L A 4$ tests most frequently exceeded $1 \%$, while for the $-18^{\circ} \mathrm{C}$ tests, the steady state tests most frequently exceeded $1 \% N E C$.

Table 6.4: Tests with $N E C$ greater than $1 \%$ for the Prius, Escape Hybrid, Civic Hybrid and Insight at $20^{\circ} \mathrm{C}$ and $-18^{\circ} \mathrm{C}$

\begin{tabular}{|c|c|c|c|c|c|c|c|c|}
\hline & \multicolumn{7}{|c|}{ Number of Tests With $1 \%<N E C<5 \%$} & \multirow{2}{*}{$\begin{array}{l}\text { Percentage of Tests } \\
\text { With } 1 \%<N E C<5 \%\end{array}$} \\
\hline & $2 \times L A 4$ & $2 x L A 92$ & $2 \times N Y C C$ & HWFET & $2 \times U_{S 06}$ & $\$ \$ 40$ & $\$ S 80$ & \\
\hline $\begin{array}{l}\text { Prius } \\
20^{\circ} \mathrm{C} \\
-18^{\circ} \mathrm{C}\end{array}$ & $\begin{array}{l}0 \\
0\end{array}$ & $\begin{array}{l}0 \\
0\end{array}$ & $\begin{array}{l}2 \\
1\end{array}$ & $\begin{array}{l}2 \\
2\end{array}$ & $\begin{array}{l}2 \\
1\end{array}$ & $\begin{array}{l}0 \\
0\end{array}$ & $\begin{array}{l}1 \\
0\end{array}$ & $\begin{array}{l}44 \\
20\end{array}$ \\
\hline $\begin{array}{l}\text { Escape Hybrid } \\
20^{\circ} \mathrm{C} \\
-18^{\circ} \mathrm{C}\end{array}$ & $\begin{array}{l}1 \\
1\end{array}$ & $\begin{array}{l}2 \\
0\end{array}$ & $\begin{array}{l}2 \\
3\end{array}$ & $\begin{array}{l}3 \\
0\end{array}$ & $\begin{array}{l}4 \\
0\end{array}$ & $\begin{array}{l}0 \\
2\end{array}$ & $\begin{array}{l}0 \\
1\end{array}$ & $\begin{array}{l}75 \\
37\end{array}$ \\
\hline $\begin{array}{l}\text { Civic Hybrid } \\
20^{\circ} \mathrm{C} \\
-18^{\circ} \mathrm{C}\end{array}$ & $\begin{array}{l}2 \\
0\end{array}$ & $\begin{array}{l}0 \\
0\end{array}$ & $\begin{array}{l}4 \\
1\end{array}$ & $\begin{array}{l}1 \\
0\end{array}$ & $\begin{array}{l}0 \\
0\end{array}$ & $\begin{array}{l}0 \\
0\end{array}$ & $\begin{array}{l}0 \\
0\end{array}$ & $\begin{array}{c}32 \\
5\end{array}$ \\
\hline $\begin{array}{l}\text { Insight } \\
20^{\circ} \mathrm{C} \\
-18^{\circ} \mathrm{C}\end{array}$ & $\begin{array}{l}2 \\
0\end{array}$ & $\begin{array}{l}0 \\
0\end{array}$ & $\begin{array}{l}1 \\
0\end{array}$ & $\begin{array}{l}0 \\
0\end{array}$ & $\begin{array}{l}0 \\
0\end{array}$ & $\begin{array}{l}0 \\
1\end{array}$ & $\begin{array}{l}0 \\
1\end{array}$ & $\begin{array}{l}18 \\
13\end{array}$ \\
\hline \multicolumn{8}{|c|}{$20^{\circ} \mathrm{C}$} & \\
\hline Number of Tests & 9 & 12 & 14 & 14 & 13 & 6 & 4 & \\
\hline $\begin{array}{l}\text { Percentage of } \\
\text { Tests With } 1 \%< \\
N E C<5 \%\end{array}$ & 56 & 17 & 64 & 43 & 46 & 0 & 25 & \\
\hline \multicolumn{8}{|c|}{$-18^{\circ} \mathrm{C}$} & \\
\hline Number of Tests & 10 & 8 & 13 & 16 & 14 & 7 & 4 & \\
\hline $\begin{array}{l}\text { Percentage of } \\
\text { Tests With } 1 \%< \\
N E C<5 \%\end{array}$ & 10 & 0 & 38 & 13 & 7 & 43 & 50 & \\
\hline
\end{tabular}




\subsubsection{Effect of Drive Cycle and Operating Temperature on Gaseous Emissions}

The emissions of CO, NMOG and $\mathrm{NO}_{x}$ are shown for all the drive cycles and their phases for all five test vehicles, and at both temperatures in Figures 6.18 to 6.23. The emissions are reported on a logarithmic scale due to the large variation among vehicles and tests. Also shown on these figures are the SULEV limits mentioned in Section 2.1. Although not all of these vehicles are not certified to this standard, it has been used as the most demanding benchmark documented there.

$\mathrm{CO}$ emission factors are highest for the 2xUS06 and CS tests. The SmartCar emits the most $\mathrm{CO}$ for most cycles, but the Insight emits comparable or greater masses of $\mathrm{CO}$ during the third phase of the $2 \times L A 4$, the second, third and fourth phases of the $2 x L A 92$, the $2 x N Y C C$ and the $2 x U S 06$ at $20^{\circ} \mathrm{C}$ (see Figure 6.18 ). At $-18^{\circ} \mathrm{C}$, the Insight releases emissions of comparable magnitude to those from the SmartCar, only during the 2xUSO6 (see Figure 6.19). The Prius emits the least mass of $\mathrm{CO}$ for all tests and both operating temperatures, especially for the 2xUS06 and the CS tests. The Escape Hybrid also has very low emission factors, but during the CS and 2xUS06 tests, its emission factors increase to levels comparable to the SmartCar, Civic and Insight at both temperatures.

Operating temperature affects the $\mathrm{CO}$ emission factors more significantly for tests that include a CS. The emission factors during phase 1 of the $2 \times L A 4$ increase by approximately 4.5 to 38 times when changing from $20^{\circ} \mathrm{C}$ to $-18^{\circ} \mathrm{C}$ operation. The emission factors, during phase 1 of the $2 x L A 92$, increase by 5.8 to 48 times from $20^{\circ} \mathrm{C}$ to $-18^{\circ} \mathrm{C}$ operation. Operating temperature least affects tests that are driven over drive cycles with high average speeds or those including a warm-up (HWFET, 
SS40 and SS80). The average CO emission factors for the 2xUSO6 show variable patterns, from a decrease of $19 \%$ to an increase of $50 \%$ in going from $20^{\circ} \mathrm{C}$ to $-18^{\circ} \mathrm{C}$ operation. The average $\mathrm{CO}$ emission factors for the SS80 increase by up to three times from $20^{\circ} \mathrm{C}$ to $-18^{\circ} \mathrm{C}$ tests. The average $\mathrm{CO}$ emission factors of the Prius and SmartCar are most sensitive to temperature and the Insight is least sensitive to operating temperature.

Figure 6.18: $\mathrm{CO}$ emission factors averaged over multiple tests for the SmartCar, Prius, Escape Hybrid, Civic Hybrid and Insight at $20^{\circ} \mathrm{C}$

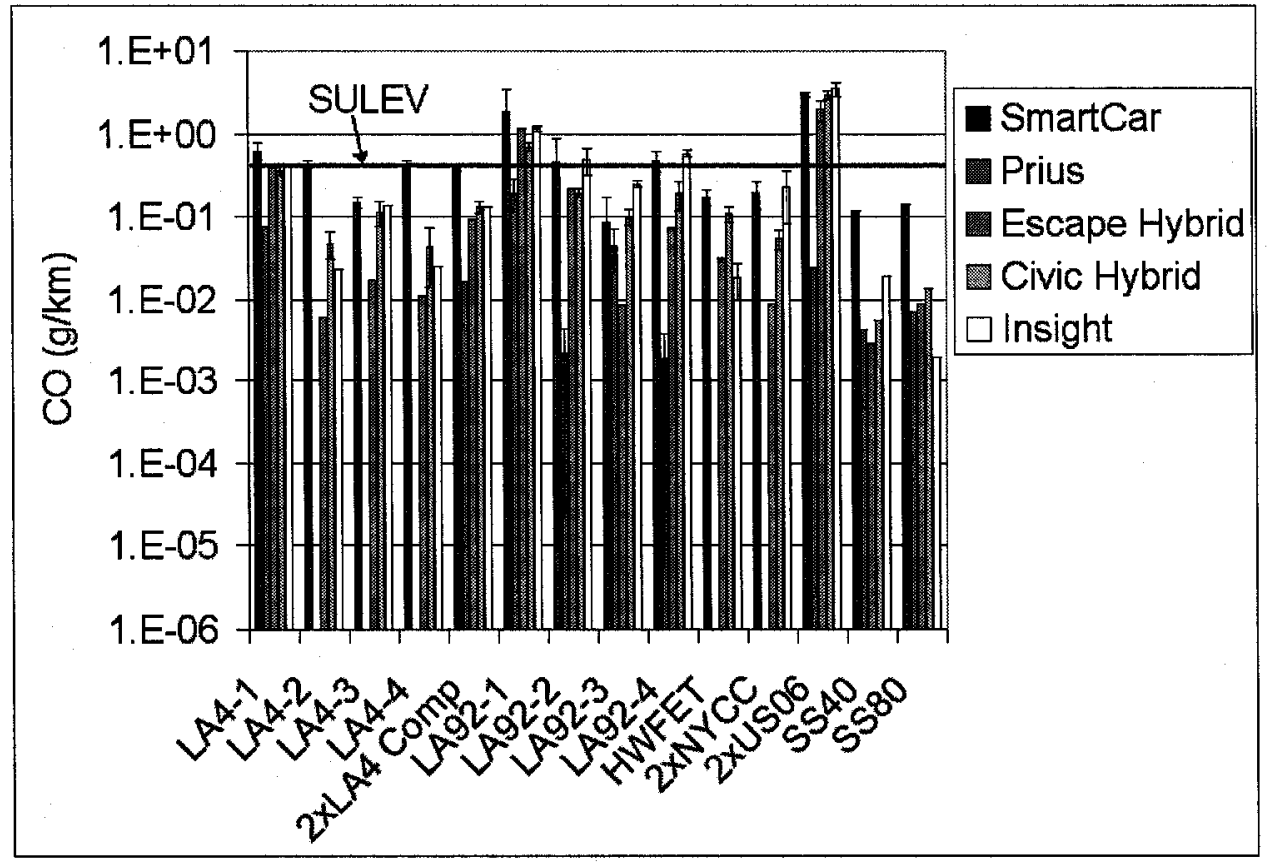


Figure 6.19: $\mathrm{CO}$ emission factors averaged over multiple tests for the SmartCar, Prius, Escape Hybrid, Civic Hybrid and Insight at $-18^{\circ} \mathrm{C}$

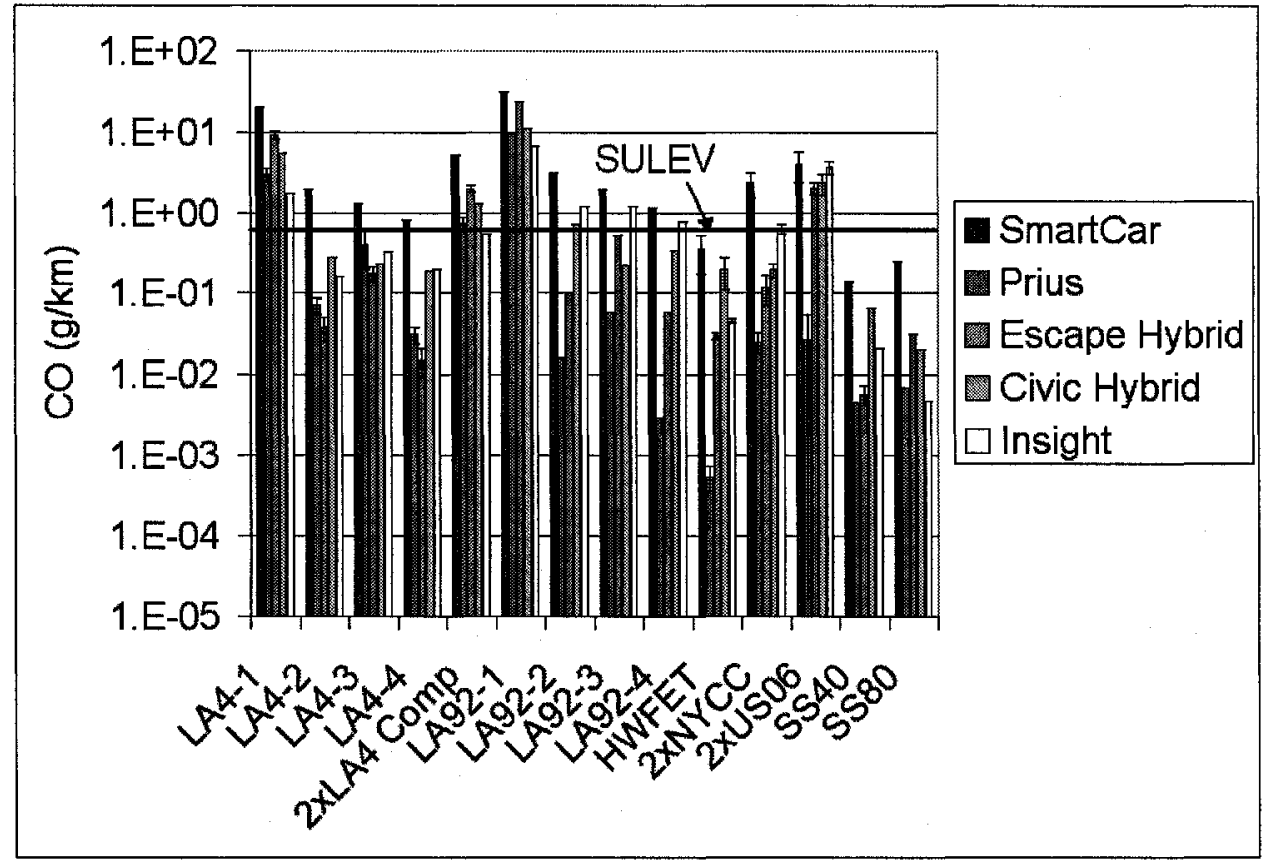

Figure 6.20: $\mathrm{NO}_{x}$ emission factors averaged over multiple tests for the SmartCar, Prius, Escape Hybrid, Civic Hybrid and Insight at $20^{\circ} \mathrm{C}$




Figure 6.21: $\mathrm{NO}_{x}$ emission factors averaged over multiple tests for the SmartCar, Prius, Escape Hybrid, Civic Hybrid and Insight at $-18^{\circ} \mathrm{C}$

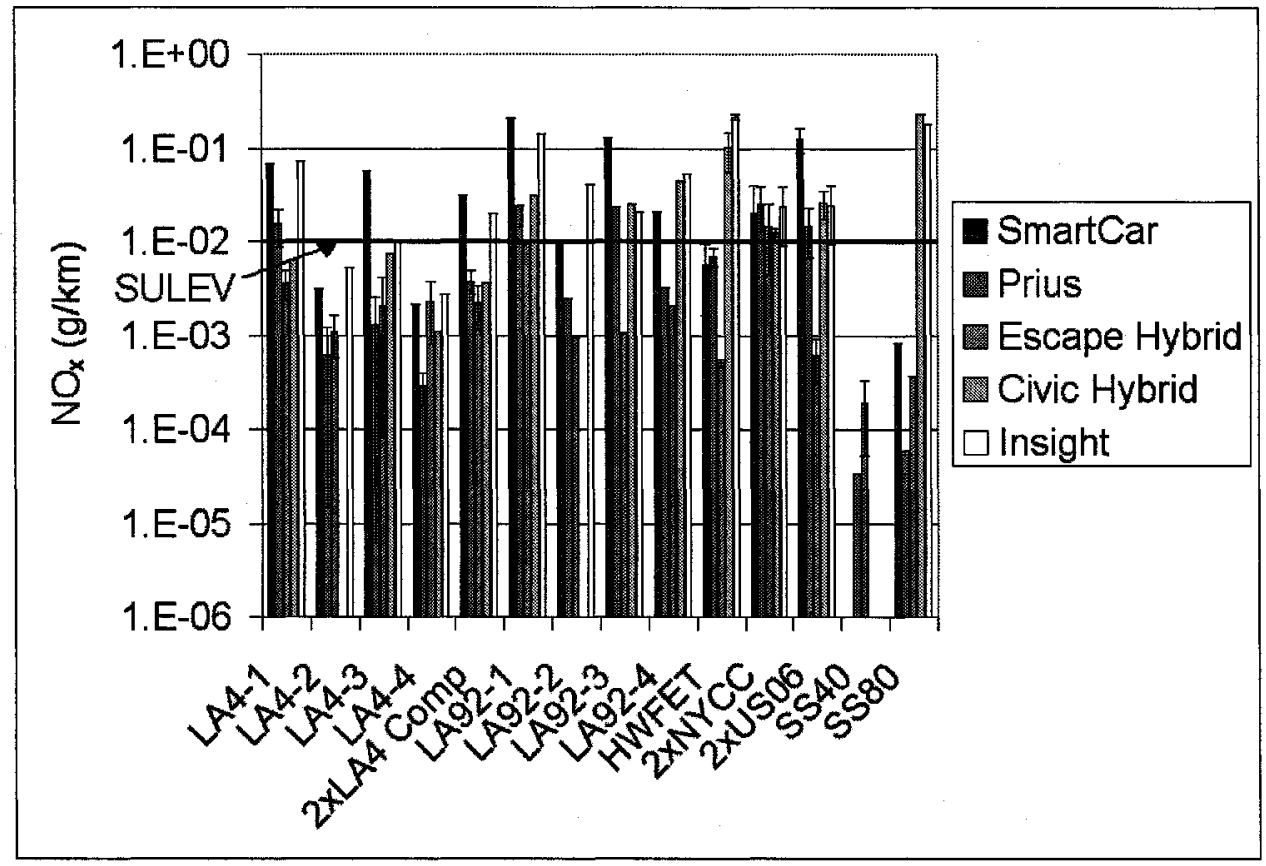

Figure 6.22: NMOG emission factors averaged over multiple tests for the SmartCar, Prius, Escape Hybrid, Civic Hybrid and Insight at $20^{\circ} \mathrm{C}$

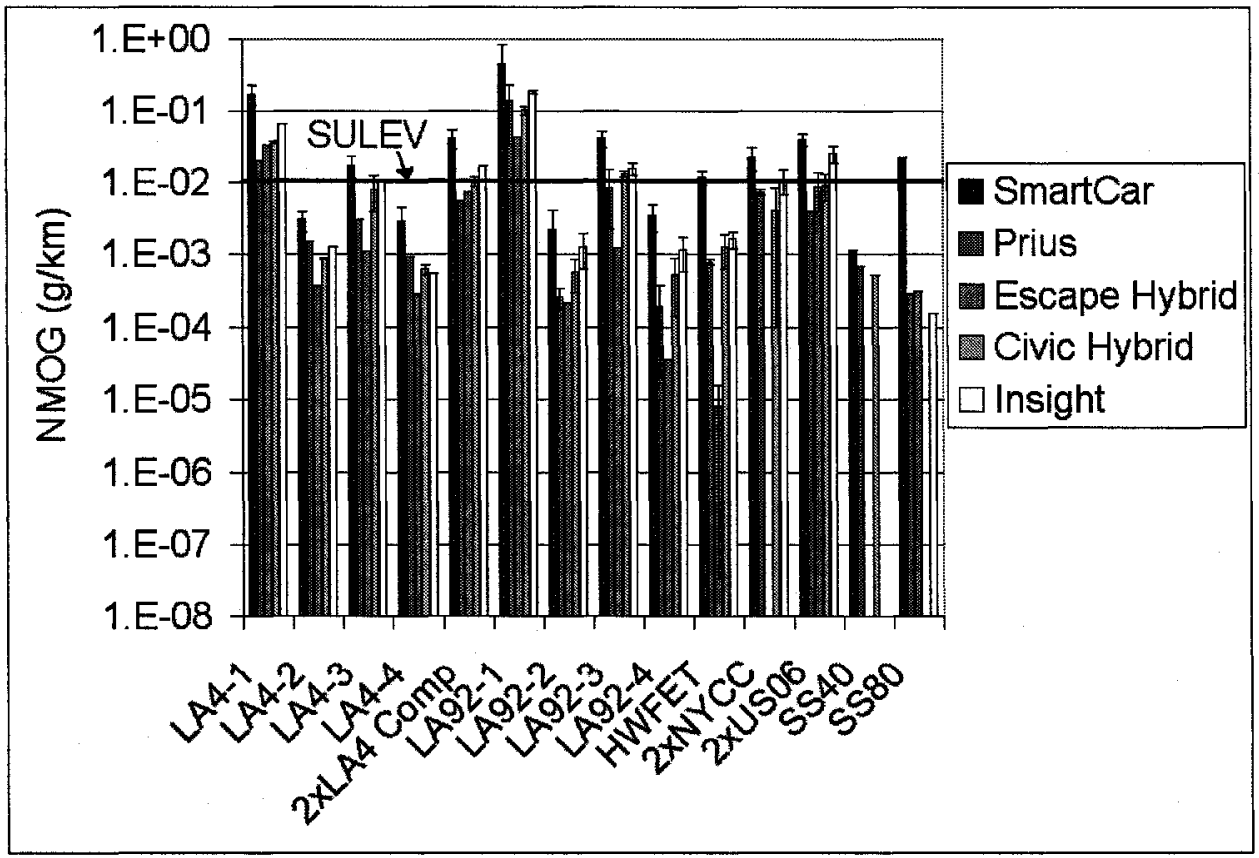


Figure 6.23: $\mathrm{NMOG}$ emission factors averaged over multiple tests for the SmartCar, Prius, Escape Hybrid, Civic Hybrid and Insight at $-18^{\circ} \mathrm{C}$

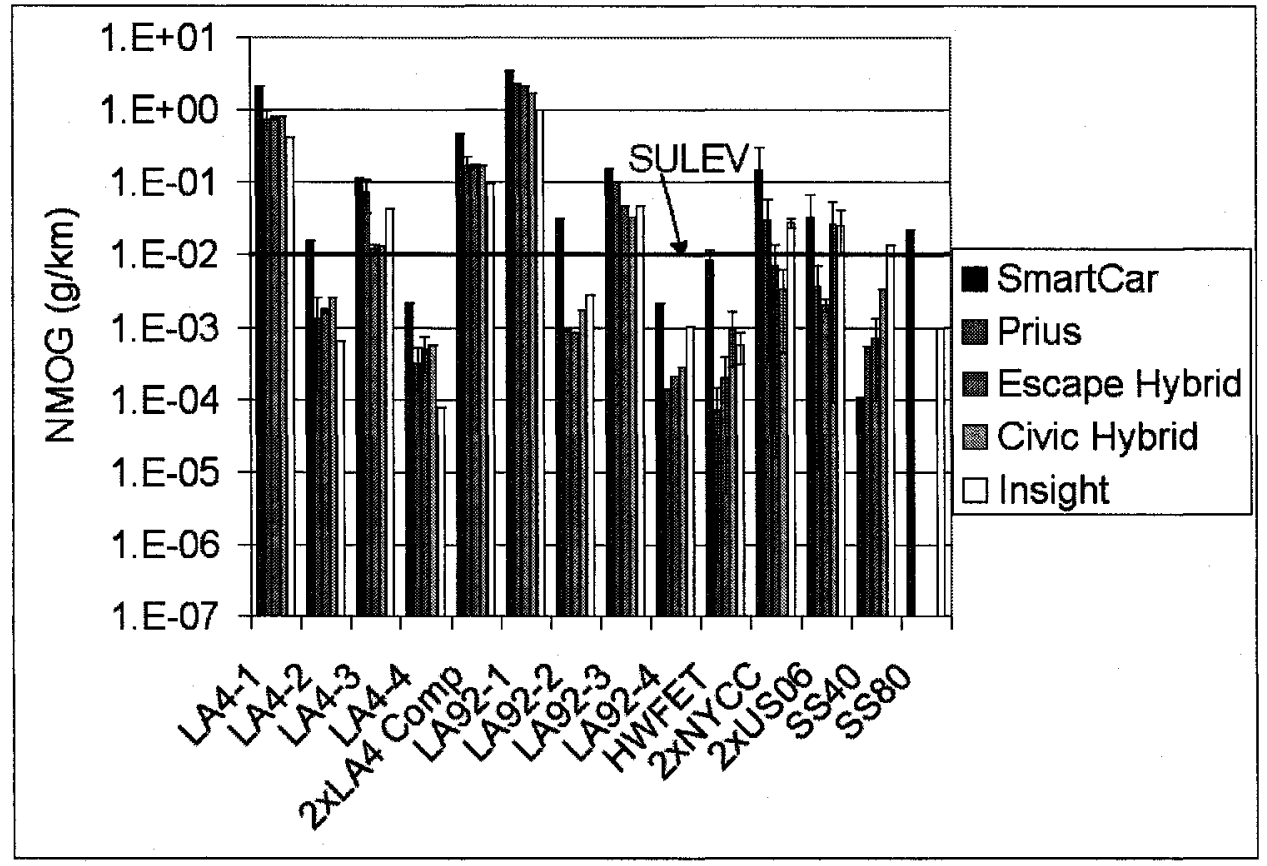

$\mathrm{NO}_{x}$ emission factors are highest for the SmartCar, Civic Hybrid and Insight for tests conducted at $20^{\circ} \mathrm{C}$ (see Figure 6.20), and the SmartCar and Insight for tests conducted at $-18^{\circ} \mathrm{C}$ (see Figure 6.21 ). The average $\mathrm{NO}_{x}$ emission factors of the SmartCar during $20^{\circ} \mathrm{C}$ tests are highest for the phases 1 and 3 of the $2 \times L A 4$ and $2 x L A 92$, and the $2 x N Y C C$ and $2 x$ US06 tests. At $-18^{\circ} \mathrm{C}$, the SmartCar $\mathrm{NO}_{x}$ emission factors are highest for the CS phases of the 2xLA4 and 2xLA92, as well as the $2 x U S 06$ cycle. At $-18^{\circ} \mathrm{C}$, the Insight released $\mathrm{NO}_{x}$ emission factors of comparable magnitude to the SmartCar, for the CS phases of the 2xLA4 and 2xLA92 tests. The Civic Hybrid and Insight $\mathrm{NO}_{x}$ emission factors are highest for the SS80 and HWFET tests, at both temperatures. The Escape Hybrid and Prius emitted the least $\mathrm{NO}_{x}$ emissions, respectively, at both operating temperatures. The Escape Hybrid $\mathrm{NO}_{x}$ emission factors are elevated for $-18^{\circ} \mathrm{C}$ CS phases, the $2 \times N Y C C$ and $2 x U S 06$ tests. 
Operating temperature affects the average $\mathrm{NO}_{x}$ emission factors of all vehicles and for all drive cycles. Tests at $-18^{\circ} \mathrm{C}$ decrease some vehicles' $\mathrm{NO}_{x}$ emission factors and increase others'. Table 6.5 shows $\mathrm{NO}_{x}$ emission factor fractions for all five vehicles over three phases of the $2 \times L A 4$ and $2 x L A 92$ and fractions of $-18^{\circ} \mathrm{C}$ emissions over $20^{\circ} \mathrm{C}$ emissions. The Civic Hybrid $\mathrm{NO}_{x}$ emission factors decrease for all three phases with decreasing temperature, while the Escape Hybrid $\mathrm{NO}_{x}$ emission factors increase from $20^{\circ} \mathrm{C}$ to $-18^{\circ} \mathrm{C}$ operation.

NMOG emission factors are pronouncedly higher for tests including a CS, particularly for phase 1 of the $2 \times L A 4$ and $2 \times L A 92$ at $20^{\circ} \mathrm{C}$. This pattern is more extreme at $-18^{\circ} \mathrm{C}$ operation. The average NMOG emission factors for all vehicles during the HWFET are very low for both $20^{\circ} \mathrm{C}$ and $-18^{\circ} \mathrm{C}$ tests as are the steady state test emission factors. For $20^{\circ} \mathrm{C}$ tests, the $2 \times N Y C C$ and $2 \times U S 06$ emission factors are lowest, respectively, and for $-18^{\circ} \mathrm{C}$ tests, the $2 x U S 06$ and $2 x N Y C C$ have the next lowest NMOG emission factors.

Table 6.5: $-18^{\circ} \mathrm{C} \mathrm{NO}_{x}$ emission factor fraction of $20^{\circ} \mathrm{C} \mathrm{NO}_{x}$ emission factor

\begin{tabular}{|l|l|l|l|}
\hline \multirow{2}{*}{ Vehicle } & \multicolumn{4}{|l|}{$-18^{\circ} \mathrm{C}$ over $20^{\circ} \mathrm{C} \mathrm{NO}$ Emission Factor (as fraction) } \\
\cline { 2 - 4 } & $2 \times L A 4-1$ & $2 \times L A 4-3$ & $2 x L A 92-1$ \\
\hline Insight & 1.79 & 0.21 & 2.97 \\
SmartCar & 0.71 & 0.34 & 2.61 \\
Civic Hybrid & 0.17 & 0.09 & 0.84 \\
Prius & 0.8 & 0.15 & 1.72 \\
Escape Hybrid & 3.19 & 1.65 & 4.72 \\
\hline
\end{tabular}

NMOG emission factors increase by 4 to 26 times for tests run on the 2xLA4 phase 1 between $20^{\circ} \mathrm{C}$ and $-18^{\circ} \mathrm{C}$, and 5.5 to 50 times for tests run on the $2 \times L A 92$ phase 1 cycle from $20^{\circ} \mathrm{C}$ and $-18^{\circ} \mathrm{C}$. The emission factor increase is not greater than 10 magnitudes for the HEVs on the 2xUS06, 2xNYCC, HWFET and SS tests between $20^{\circ} \mathrm{C}$ and $-18^{\circ} \mathrm{C}$. NMOG emission factors do not always increase between $20^{\circ} \mathrm{C}$ 
and $-18^{\circ} \mathrm{C}$ tests. All of the Civic Hybrid NMOG emission factors, for the $2 \times U S 06$, 2xNYCC, HWFET, and SS tests, decrease between $20^{\circ} \mathrm{C}$ and $-18^{\circ} \mathrm{C}$ while some of the Escape Hybrid, Insight and Prius NMOG emission factors increase.

The GHG emission factors for all five vehicles, all of the drive cycles and both operating temperatures are shown in Figures 6.24 to 6.29 .

Figure 6.24: $\mathrm{CO}_{2}$ emission factors averaged over multiple tests for the SmartCar, Prius, Escape Hybrid, Civic Hybrid and Insight at $20^{\circ} \mathrm{C}$

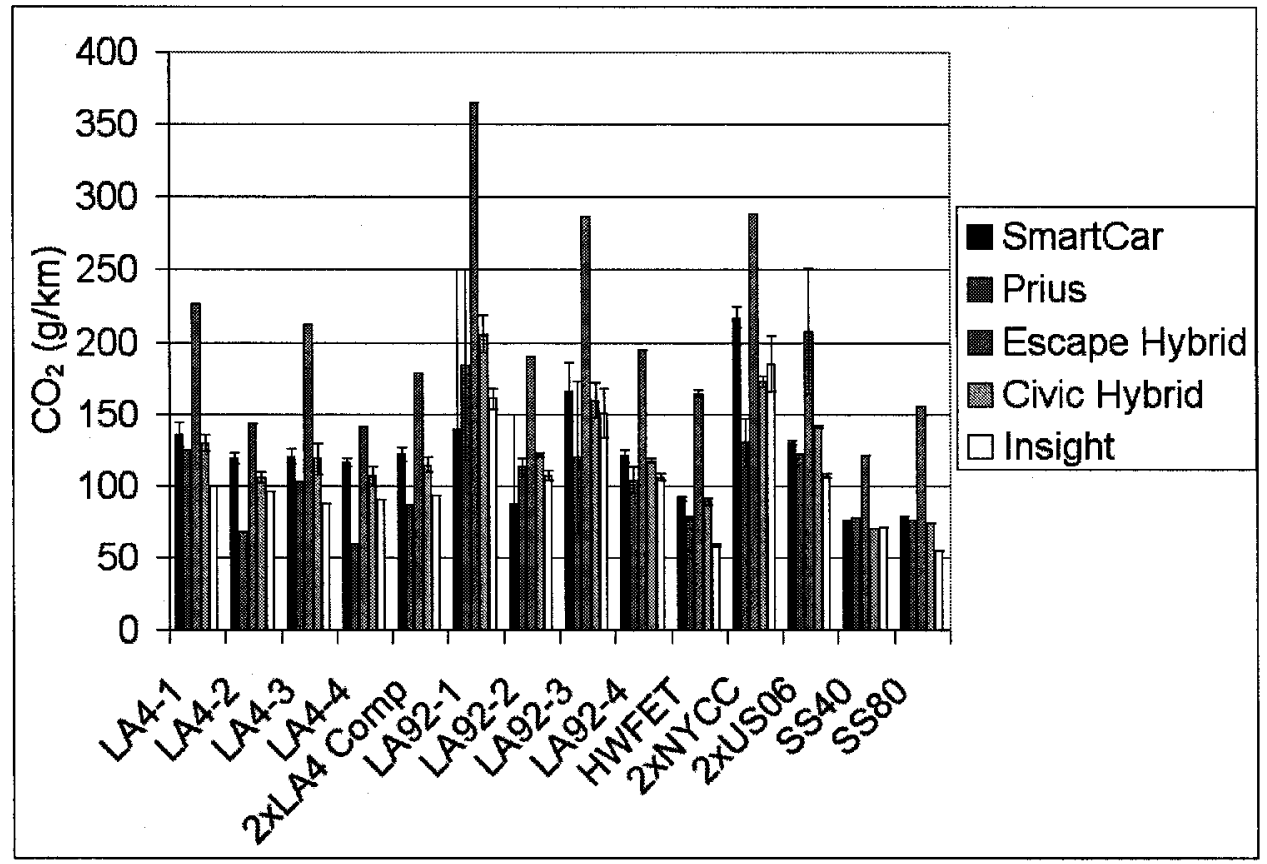


Figure 6.25: $\mathrm{CO}_{2}$ emission factors averaged over multiple tests for the SmartCar, Prius, Escape Hybrid, Civic Hybrid and Insight at $-18^{\circ} \mathrm{C}$

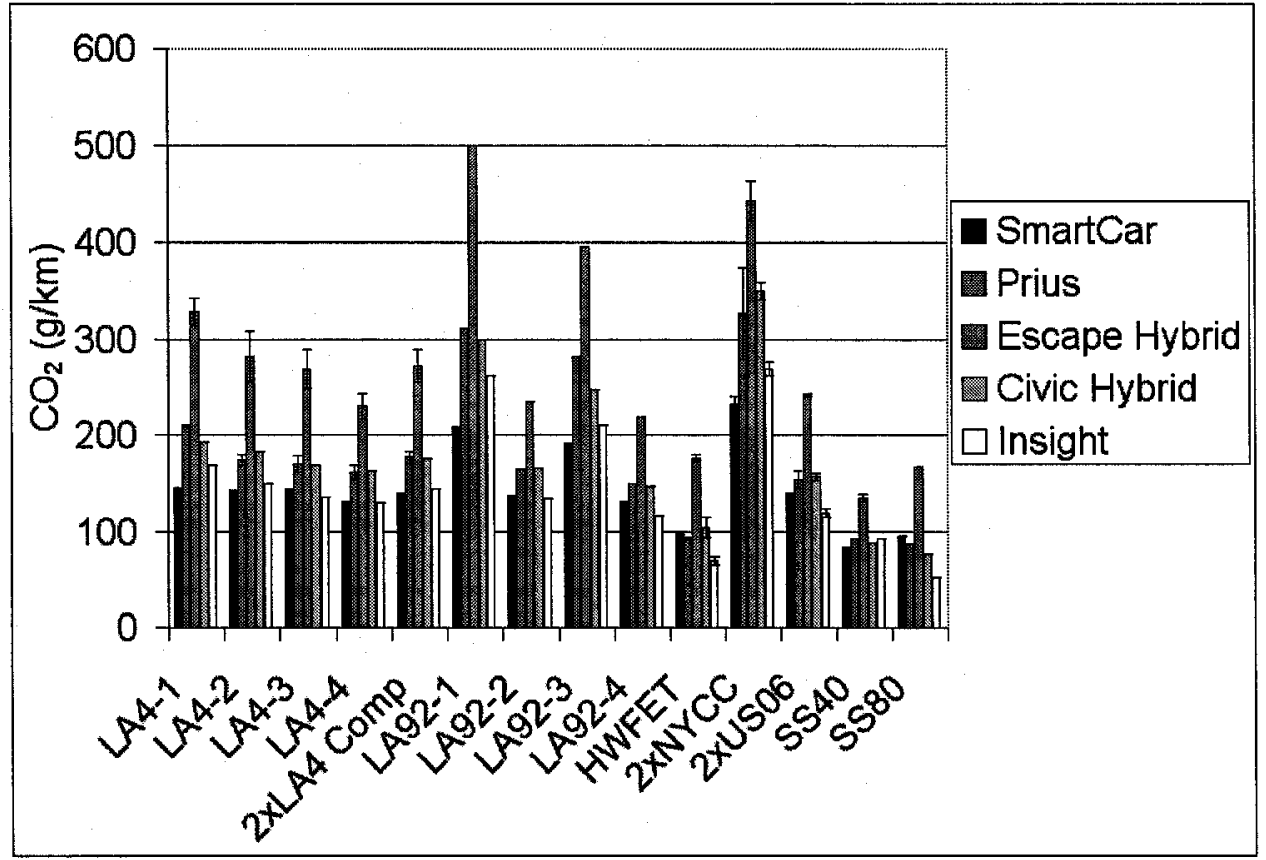

Figure 6.26: $\mathrm{CH}_{4}$ emission factors averaged over multiple tests for the SmartCar, Prius, Escape Hybrid, Civic Hybrid and Insight at $20^{\circ} \mathrm{C}$

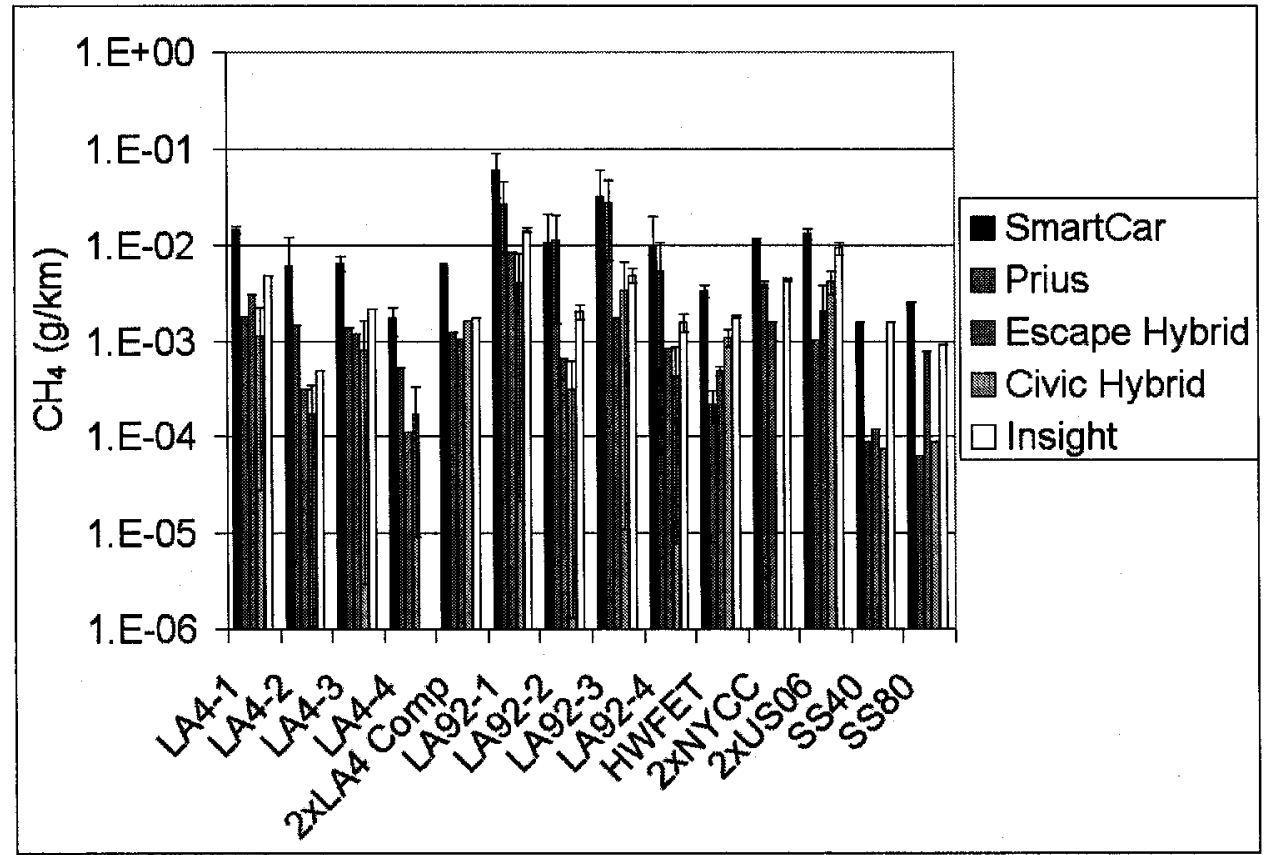


Figure 6.27: $\mathrm{CH}_{4}$ emission factors averaged over multiple tests for the SmartCar, Prius, Escape Hybrid, Civic Hybrid and Insight at $-18^{\circ} \mathrm{C}$

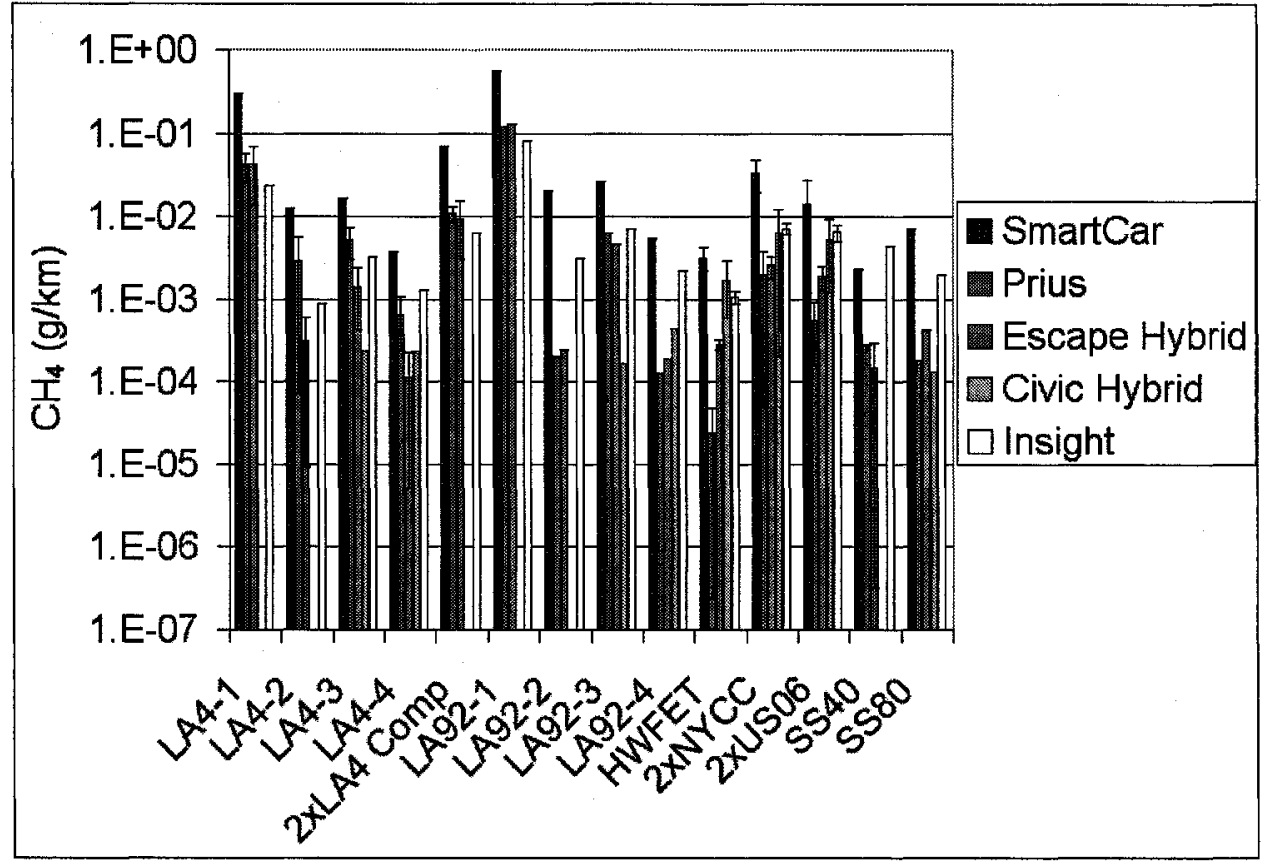

Figure 6.28: $\mathrm{N}_{2} \mathrm{O}$ emission factors averaged over multiple tests for the SmartCar, Prius, Escape Hybrid, Civic Hybrid and Insight at $20^{\circ} \mathrm{C}$

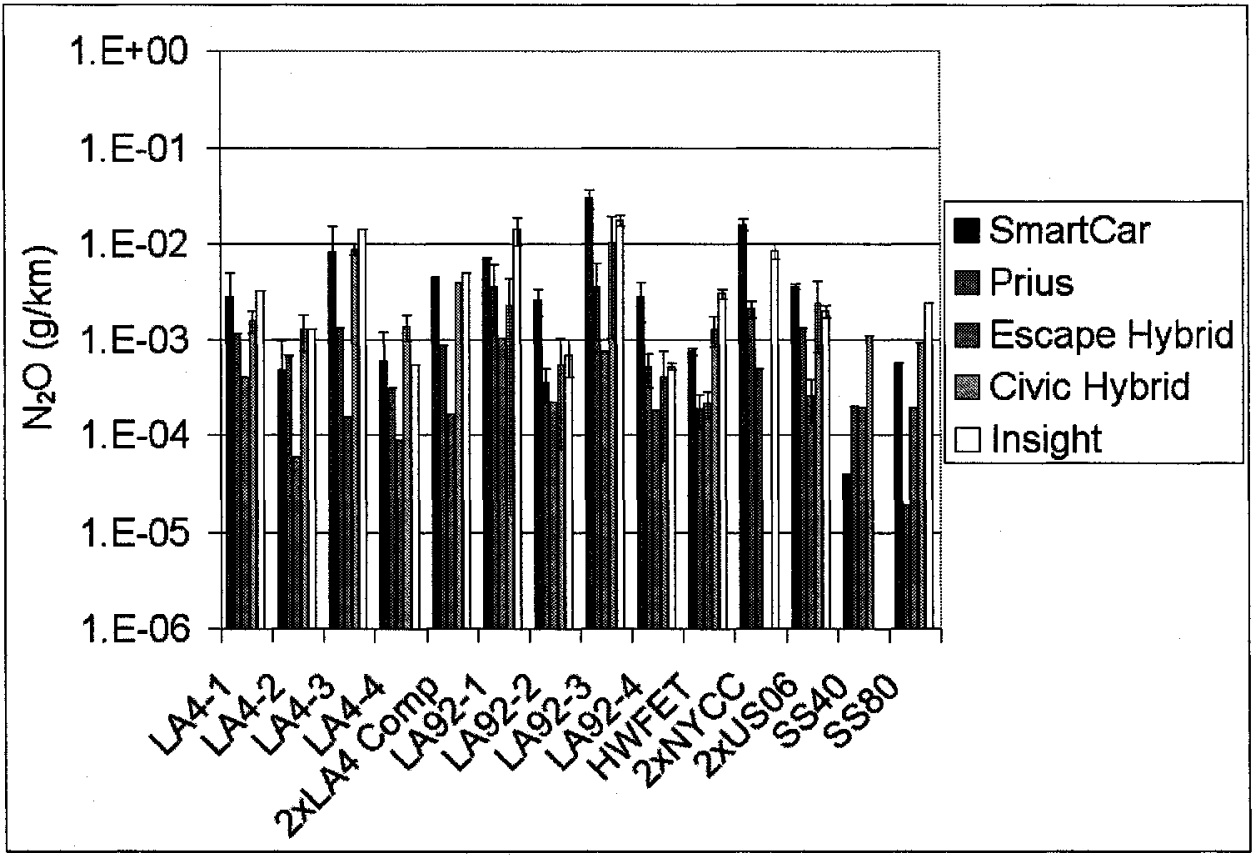


Figure 6.29: $\mathrm{N}_{2} \mathrm{O}$ emission factors averaged over multiple tests for the SmartCar, Prius, Escape Hybrid, Civic Hybrid and Insight at $-18^{\circ} \mathrm{C}$

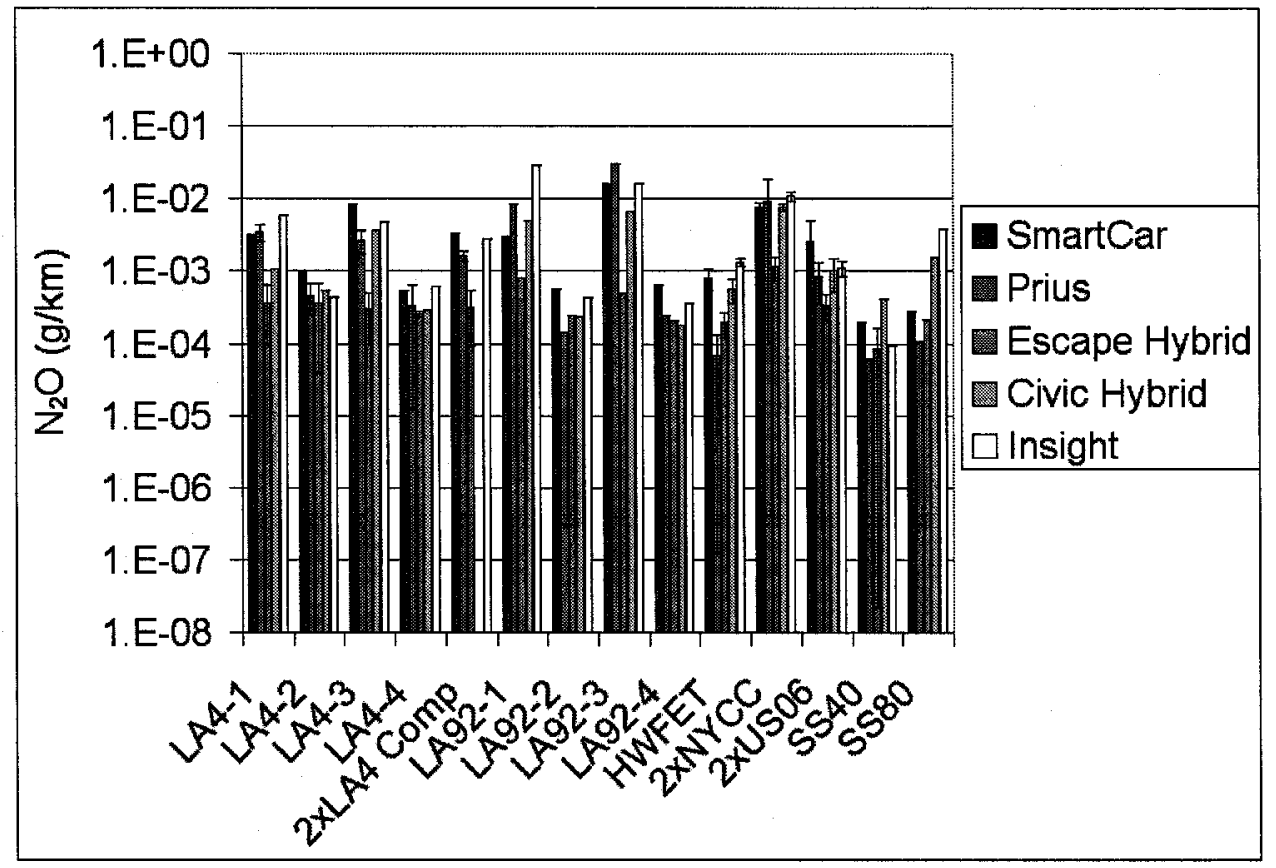

$\mathrm{CO}_{2}$ emission factors, for tests conducted at $20^{\circ} \mathrm{C}$, are highest for the $\mathrm{CS}$ phases of the $2 \times L A 4$ and $2 x L A 92$ tests, as well as the $2 \times N Y C C$ and $2 x U S 06$ tests. $\mathrm{CO}_{2}$ emission factors for tests conducted at $-18^{\circ} \mathrm{C}$ are highest for phase 1 of the $2 x L A 4$ (LA4-1), and phases 1 and 3 of the 2xLA92 (LA92-1 and LA92-3), as well as the 2xNYCC test. $\mathrm{CO}_{2}$ emission factors of the 2xLA4 generally decrease from phase 1 to phase 4 , for both temperatures. The HWFET and SS tests have the lowest $\mathrm{CO}_{2}$ emission factors of any drive cycle at both temperatures. The Escape Hybrid has the highest $\mathrm{CO}_{2}$ emission factor of any vehicle, for all tests, and at both temperatures. The SmartCar, Civic Hybrid, Prius and Insight generally have descending magnitudes of $\mathrm{CO}_{2}$ emission factors, respectively, for tests conducted at $20^{\circ} \mathrm{C}$. At $-18^{\circ} \mathrm{C}$, the order of descending $\mathrm{CO}_{2}$ emission factors is the Prius, Civic Hybrid, Insight and SmartCar.

$\mathrm{CO}_{2}$ emission factors increase most for the $2 \times \mathrm{NYCC}$, phases 2 and 4 from the 
$2 \times L A 4$, and phases 1 and 3 from the $2 \times L A 92$, between $20^{\circ} \mathrm{C}$ and $-18^{\circ} \mathrm{C}$. All $\mathrm{CO}_{2}$ emission factors increase from $20^{\circ} \mathrm{C}$ tests to $-18^{\circ} \mathrm{C}$ tests. The increase in $\mathrm{CO}_{2}$ emission factors from $20^{\circ} \mathrm{C}$ to $-18^{\circ} \mathrm{C}$ tests varies between one and three magnitudes of the $20^{\circ} \mathrm{C} \mathrm{CO}$ emission factor.

$\mathrm{CH}_{4}$ emission factors are highest for all of the 2xLA92 phases and the 2xUS06 cycle during $20^{\circ} \mathrm{C}$ tests. The $2 \times L A 4$ phase 1 test also has high $\mathrm{CH}_{4}$ emissions. During $-18^{\circ} \mathrm{C}$ tests, the $2 \times L A 92$ and $2 \times L A 4$ phase 1 emission factors are highest, followed by the $2 \times N Y C C \mathrm{CH}_{4}$ emission factors. The SmartCar has the highest emission factors for both temperatures and all tests. The SS and HWFET tests have the lowest $\mathrm{CH}_{4}$ emission factors for both temperatures. During $-18^{\circ} \mathrm{C}$ operation, $\mathrm{CH}_{4}$ emission factors from phases 2 and 4 of the $2 \times L A 92$ are low compared to the SS tests.

$\mathrm{CH}_{4}$ emission factors increase from $20^{\circ} \mathrm{C}$ to $-18^{\circ} \mathrm{C}$ operation, most notably for the 2xLA92 and 2xLA4 phase 1 tests. The HWFET $\mathrm{CH}_{4}$ emission factors decrease from $20^{\circ} \mathrm{C}$ to $-18^{\circ} \mathrm{C}$ tests, as do those for the $2 x L A 92$ phases 3 and 4 . The Civic Hybrid is the only vehicle whose $\mathrm{CH}_{4}$ emission factors increase very little for any of the drive cycles, from $20^{\circ} \mathrm{C}$ to $-18^{\circ} \mathrm{C}$ testing. The most significant increase in emissions occurs for the Prius, Escape Hybrid and SmartCar, but not necessarily in that order.

The third phase of the $2 \times L A 4$ (LA4-3) and the first and third phase of the $2 \times L A 92$, as well as the $2 \times N Y C C$, have the highest $\mathrm{N}_{2} \mathrm{O}$ emission factors during $20^{\circ} \mathrm{C}$ testing. This trend is repeated during $-18^{\circ} \mathrm{C}$ testing, except that the $2 \times L A 4$ phase 1 also produces high emission factors of $\mathrm{N}_{2} \mathrm{O}$. The Escape Hybrid, Prius, Civic Hybrid, Insight and SmartCar produce the lowest average $\mathrm{N}_{2} \mathrm{O}$ emission factors, 
respectively, during $20^{\circ} \mathrm{C}$ operation. During $-18^{\circ} \mathrm{C}$ operation, the Escape Hybrid, Civic Hybrid, Prius, SmartCar and Insight produce the lowest $\mathrm{N}_{2} \mathrm{O}$ emission factors, respectively.

Generally, average $\mathrm{N}_{2} \mathrm{O}$ emission factors decrease from $20^{\circ} \mathrm{C}$ to $-18^{\circ} \mathrm{C}$ operation. The exception is the $2 x N Y C C$ and SS80 for which emission factors increase by up to almost 5.6 magnitudes of the $20^{\circ} \mathrm{C} \mathrm{N} \mathrm{N}_{2} \mathrm{O}$ emission factor.

\subsection{Internal Combustion Engine Restarts, Engine- Off Time and Gaseous Emissions}

The time that HEV ICEs were off during each transient cycle was estimated by the method described in Section 5.8. From these estimations, the number of ICE restarts for each transient cycle was also estimated. Table 6.6 shows the average time that the ICE of each HEV was off during the given drive cycle at the operating temperature specified.

Table 6.6: Average ICE off times as a percentage of drive cycle duration for all transient drive cycles

\begin{tabular}{|c|c|c|c|c|c|c|c|c|}
\hline & \multirow{2}{*}{ Vehicle } & \multicolumn{7}{|c|}{ Average ICE off Time (\% of drive cycle) } \\
\hline & & LA4CS & LA4HS & LA92CS & LA92HS & HWFET & $2 x N Y C C$ & $2 \times \mathrm{USO}^{2}$ \\
\hline \multirow{4}{*}{$20^{\circ} \mathrm{C}$} & Prius & 50 & 51 & 36 & 41 & 6 & 61 & 11 \\
\hline & Escape & 17 & 20 & 21 & 22 & 0.3 & 46 & 5 \\
\hline & Civic & 15 & 15 & 10 & 12 & 0.4 & 26 & 6 \\
\hline & $\begin{array}{l}\text { Hybrid } \\
\text { Insight }\end{array}$ & 7 & 8 & 7 & 6 & 0.4 & 25 & 1 \\
\hline \multirow{4}{*}{$-18^{\circ} \mathrm{C}$} & Prius & 0.3 & 10 & 9 & 21 & 6 & 19 & 10 \\
\hline & Escape & 2 & 8 & 9 & 14 & 1 & 27 & 2 \\
\hline & Civic & 0.7 & 0.8 & 0.7 & 0.6 & 0.25 & 13 & 0.8 \\
\hline & $\begin{array}{l}\text { Hybrid } \\
\text { Insight }\end{array}$ & 0.6 & 1 & 1 & 1 & 0 & 2 & 2 \\
\hline
\end{tabular}


The ICE off time decreases from $20^{\circ} \mathrm{C}$ to $-18^{\circ} \mathrm{C}$ operation, except for the Escape Hybrid HWFET test and the Insight 2xUS06 test, which have very little ICE off time at either temperature. The Prius ICE off time decreases the most from $20^{\circ} \mathrm{C}$ to $18^{\circ} \mathrm{C}$ tests, by as much as $50 \%$. In descending order, the Insight, Civic Hybrid, and Escape Hybrid ICE off times decrease the least from $20^{\circ} \mathrm{C}$ to $-18^{\circ} \mathrm{C}$, respectively.

The average number of ICE restarts for each vehicle and transient drive cycle is shown in Table 6.7. The vehicle with the highest ICE off time, the Prius, also has the highest number of ICE restarts. The Insight, having the lowest ICE off time, also has the fewest number of ICE restarts. The relationship between ICE off time and number of ICE restarts is illustrated in Figure 6.30 . For both the $20^{\circ} \mathrm{C}$ and $-18^{\circ} \mathrm{C}$ tests, regardless of the HEV, as ICE off time increases ICE restart count increases.

Table 6.7: Average number of ICE restarts for all transient drive cycles

\begin{tabular}{|c|c|c|c|c|c|c|c|c|}
\hline & \multirow[b]{2}{*}{ Vehicle } & \multicolumn{7}{|c|}{ Average Number of ICE Restarts } \\
\hline & & LA4CS & LA4HS & LA92CS & LA92HS & HWFET & 2xNYCC & $2 x U S 06$ \\
\hline \multirow{4}{*}{$20^{\circ} \mathrm{C}$} & Prius & 24 & 25 & 24 & 27 & 3 & 30 & 10 \\
\hline & $\begin{array}{l}\text { Escape } \\
\text { Hybrid }\end{array}$ & 9 & 12 & 14 & 14 & 1 & 16 & 8 \\
\hline & $\begin{array}{l}\text { Civic } \\
\text { Hybrid }\end{array}$ & 16 & 16 & 12 & 14 & 0 & 18 & 11 \\
\hline & Insight & 10 & 13 & 8 & 8 & 0 & 13 & 2 \\
\hline \multirow{4}{*}{$-18^{\circ} \mathrm{C}$} & Prius & 0 & 7 & 7 & 16 & 3 & 10 & 10 \\
\hline & Escape & 3 & 7 & 10 & 10 & 1 & 6 & 6 \\
\hline & $\begin{array}{l}\text { Civic } \\
\text { Hybrid }\end{array}$ & 1 & 1 & 1 & 1 & 0 & 8 & 1 \\
\hline & Insight & 1 & 1 & 2 & 1 & 0 & 1 & 1 \\
\hline
\end{tabular}

The Prius average ICE off time and average gaseous emission factors $\left(\mathrm{CO}, \mathrm{CO}_{2}\right.$, $\mathrm{NO}_{x}$ and $\mathrm{HC}$ ) from each drive cycle are graphed together in Figure 6.31. All trend lines have positive slopes, indicating that as the ICE off time increases, the emission factors increase. The maximum $\mathrm{R}^{2}$ value is below 0.6 for these trends. 
This graph is representative of the trends seen for all the HEVs and the two operating temperatures.

Figure 6.30: Average ICE off time compared to average ICE restart count for all transient drive cycle tests at $20^{\circ} \mathrm{C}$

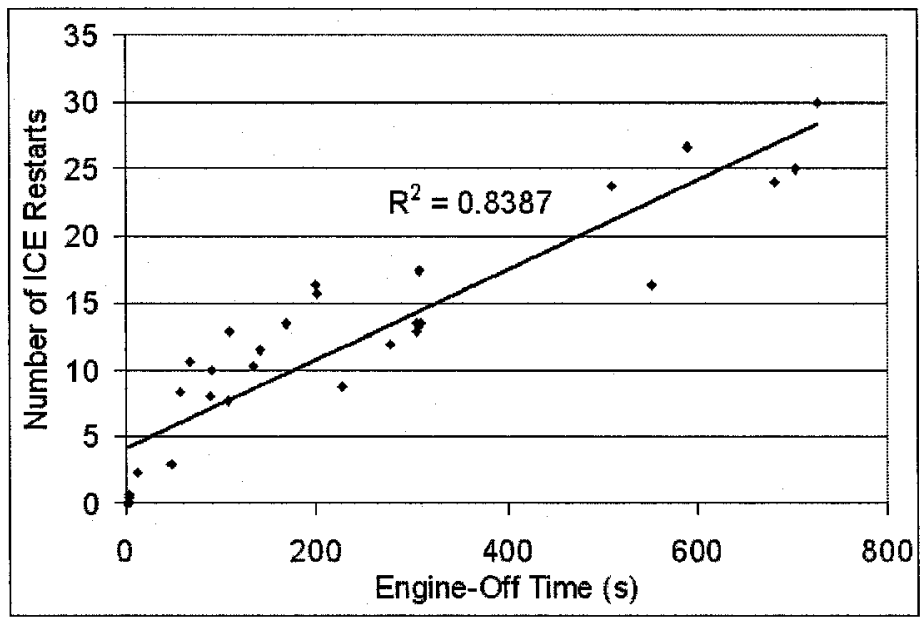

Figure 6.31: Prius emissions and ICE off times from all transient drive cycles at $20^{\circ} \mathrm{C}$

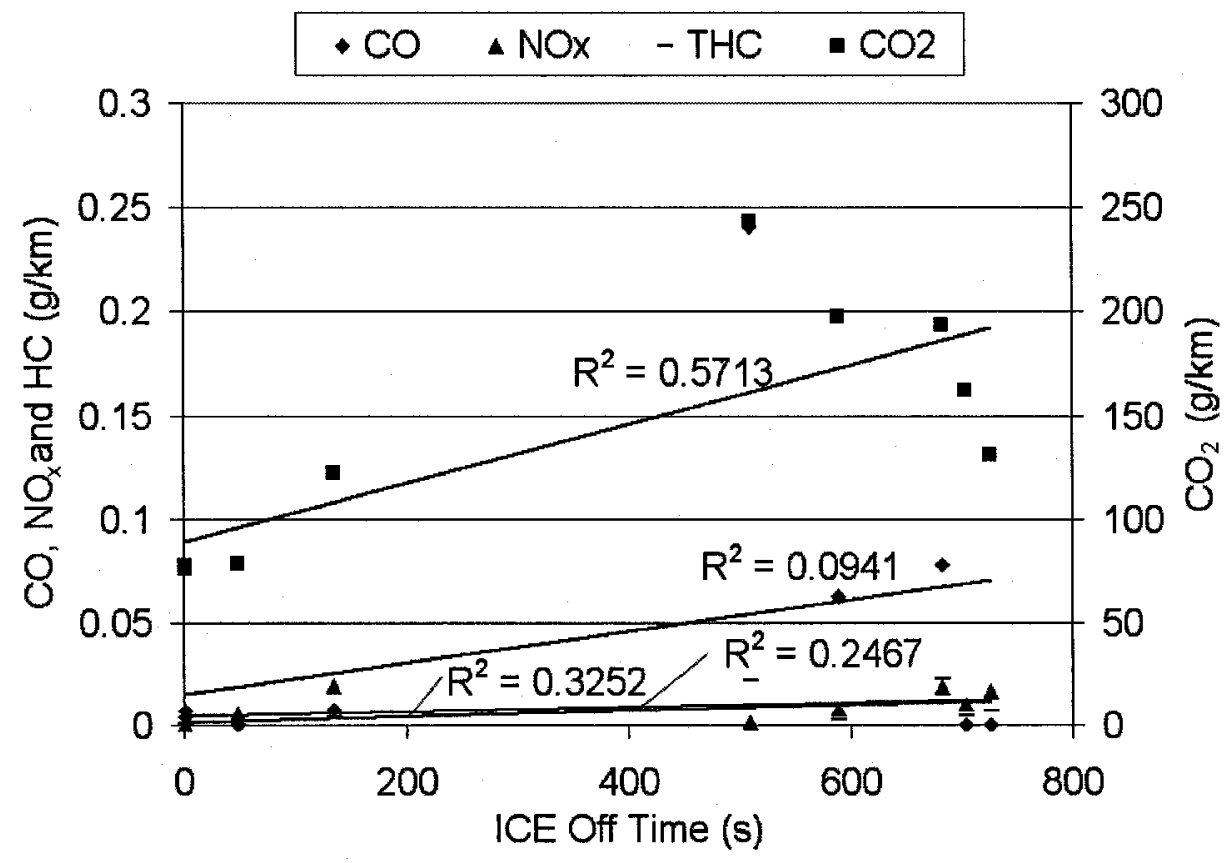


The $2 x N Y C C$ real-time emissions of two HEVs is compared to that of the SmartCar in Figures 6.32 to 6.35 . The $2 x N Y C C$ illustrates the differences between the two types of vehicles, because it is associated with the most number of ICE restarts. Figure 6.32 identifies the times at which an ICE restart occurs. These restart times are numbered in sequence along the $\mathrm{CO}_{2}$ and speed $\mathrm{x}$-axis. The emission rates of $\mathrm{NO}_{x}, \mathrm{CO}$ and $\mathrm{HC}$ occupy the bottom portion of the figure while the emission rate of $\mathrm{CO}_{2}$ and the vehicle speed occupy the top portion of the figure. At some instances along the graph $\mathrm{NO}_{x}, \mathrm{HC}$ or $\mathrm{CO}$ emission rate pikes occur at times when the ICE is off. These spikes are anomalies; single, relatively large values, otherwise surrounded by emission rates on the order of $10^{-4}$. The SmartCar real-time $\mathrm{CO}$, $\mathrm{HC}$ and $\mathrm{NO}_{x}$ emission rates are larger than those of the Prius (see Figure 6.33). The emission rates of $\mathrm{NO}_{x}$ and $\mathrm{CO}$ in Figure 6.32 are noticeably less than those in Figure 6.33.

Figure 6.32: Example of Prius real-time emissions during a $2 \times N Y C C$ at $20^{\circ} \mathrm{C}$ with ICE restart locations numbered in sequence



Further, at restart 1, $\mathrm{CO}$ approximates $0.0005 \mathrm{~g} / \mathrm{s}$, while the SmartCar $\mathrm{CO}$ and $\mathrm{NO}_{x}$ 
emission rates approach $0.01 \mathrm{~g} / \mathrm{s}$ at the same time. Also note that at the time during the cycle corresponding to restart 12 for the Prius, the SmartCar CO emission rate peaks at $0.01 \mathrm{~g} / \mathrm{s}$, while for the Prius $\mathrm{CO}$ emission rate peaks at $0.003 \mathrm{~g} / \mathrm{s}$. Also, at restart 16, the Prius emits under $0.001 \mathrm{~g} / \mathrm{s}$ of $\mathrm{NO}_{x}$ and virtually no $\mathrm{CO}$, while the SmartCar emits closer to $0.01 \mathrm{~g} / \mathrm{s}$ of $\mathrm{NO}_{x}$ and $0.01 \mathrm{~g} / \mathrm{s}$ of $\mathrm{CO}$ at the same point in the cycle. $\mathrm{CO}_{2}$ is emitted from both vehicles in comparable magnitudes. However, the SmartCar $\mathrm{CO}_{2}$ emission rates never decrease below approximately $0.3 \mathrm{~g} / \mathrm{s}$, while those of the Prius decrease to below $0.001 \mathrm{~g} / \mathrm{s}$. Further, at some of the restart points (i.e. 1, 9, 10,12,16,17, 1819 and 20), the emission rate of $\mathrm{CO}_{2}$ starts to increase approximately three seconds later than it does for the SmartCar.

Figure 6.33: Example of the real-time emissions of the SmartCar during a 2xNYCC at $20^{\circ} \mathrm{C}$

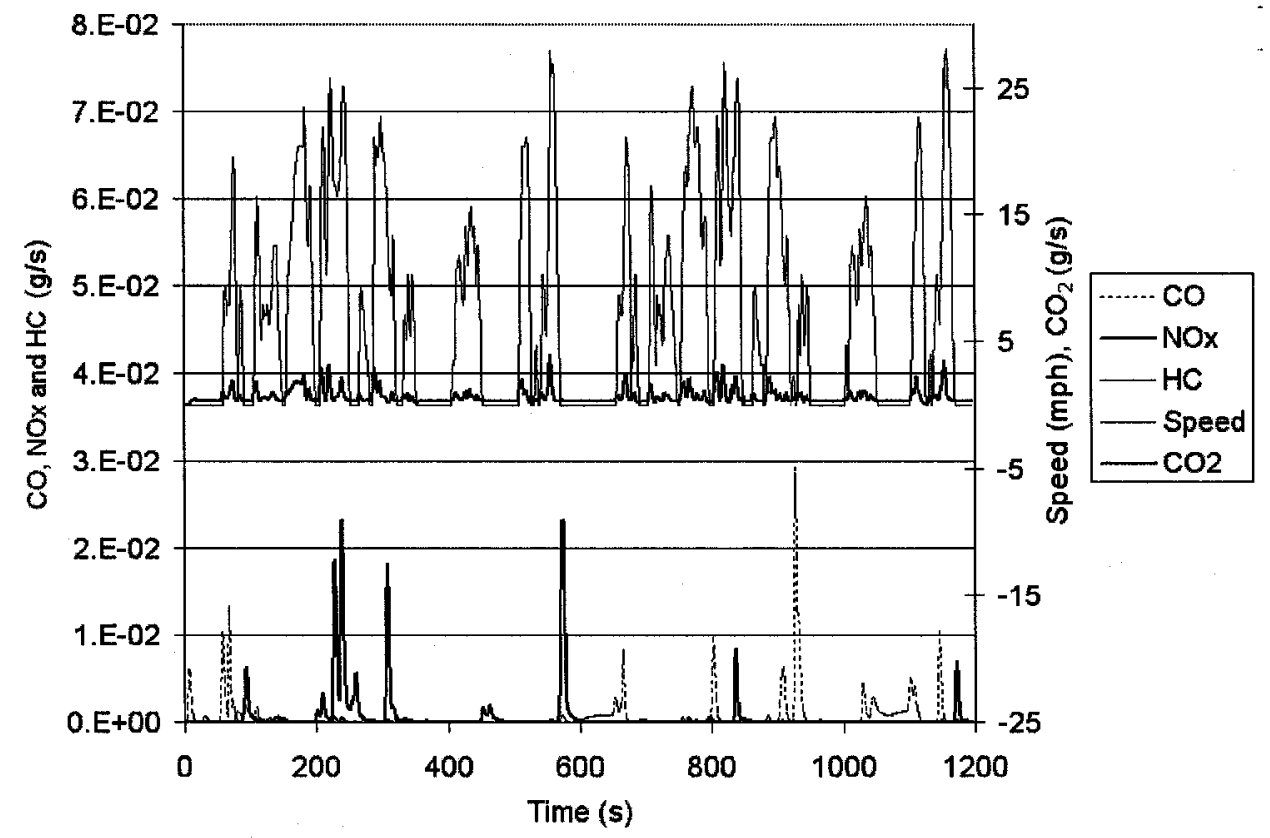

The Civic Hybrid real-time pollutant emission rates differ from the Prius. Figure 6.34 shows Civic Hybrid pollutant emission rates and vehicle speed for the first 400 seconds of a $2 \times N Y C C$. The remainder of the test is not shown because low graphing resolution skews the placement of emissions with respect to each other, 
and to speed. At restart $1, \mathrm{NO}_{x}$ emission rates peak at approximately $0.001 \mathrm{~g} / \mathrm{s}$ while at restart 2 , they peak at less than half that value. $\mathrm{CO}$ at restart 2 peaks at $0.0005 \mathrm{~g} / \mathrm{s}$. At restart 3 , the $\mathrm{CO}$ emission rate fluctuates below $0.001 \mathrm{~g} / \mathrm{s}$. The $\mathrm{CO}$ emission rate begins to increase at the time of ICE restart, but it appears in the figure as though they increase before ICE restart. This is a result of the graphing problem mentioned above. At restart 4, the $\mathrm{NO}_{x}$ emission rate rises to $0.001 \mathrm{~g} / \mathrm{s}$ and briefly fluctuates before decreasing. At restart $5, \mathrm{NO}_{x}$ emissions peak at less than $1.7 \times 10^{-4} \mathrm{~g} / \mathrm{s}$.

When compared to the Prius, the Civic Hybrid $\mathrm{NO}_{x}$ and $\mathrm{CO}$ emission factors for entire drive cycles are greater than those of the Prius (see Figures 6.18 to 6.21). At some points in Figure 6.34, the Civic Hybrid $\mathrm{NO}_{x}$ and $\mathrm{CO}$ emission rate curves are similar to those of the SmartCar (see Figure 6.35). However, the SmartCar emission rates are much larger than those of the Civic Hybrid. Figure 6.35 shows the first 400 seconds of the $2 \times N Y C C$ at $20^{\circ} \mathrm{C}$ for the SmartCar, to the same scale as Figure 6.34.The SmartCar $\mathrm{HC}$ emission rate is also much larger than that of the Civic Hybrid.

For the Prius and Civic Hybrid, the magnitude of the $\mathrm{NO}_{x}$ emission rate peak is highest for ICE restarts preceded by a short ICE off time (see points 4, 5, 11 and 16 in Figure 6.32 and points 1, 2 and 4 in Figure 6.34).

Figure 6.36 is the speed-time trace of the Civic Hybrid during a SS80 test at $18^{\circ} \mathrm{C}$. The ICE does not shut off during this drive cycle and the emission rates of $\mathrm{NO}_{x}$ and CO periodically peak. 
Figure 6.34: Example of Civic real-time emissions during the first 400 seconds of the $2 \times N Y C C$ at $20^{\circ} \mathrm{C}$ with ICE restart locations numbed in sequence

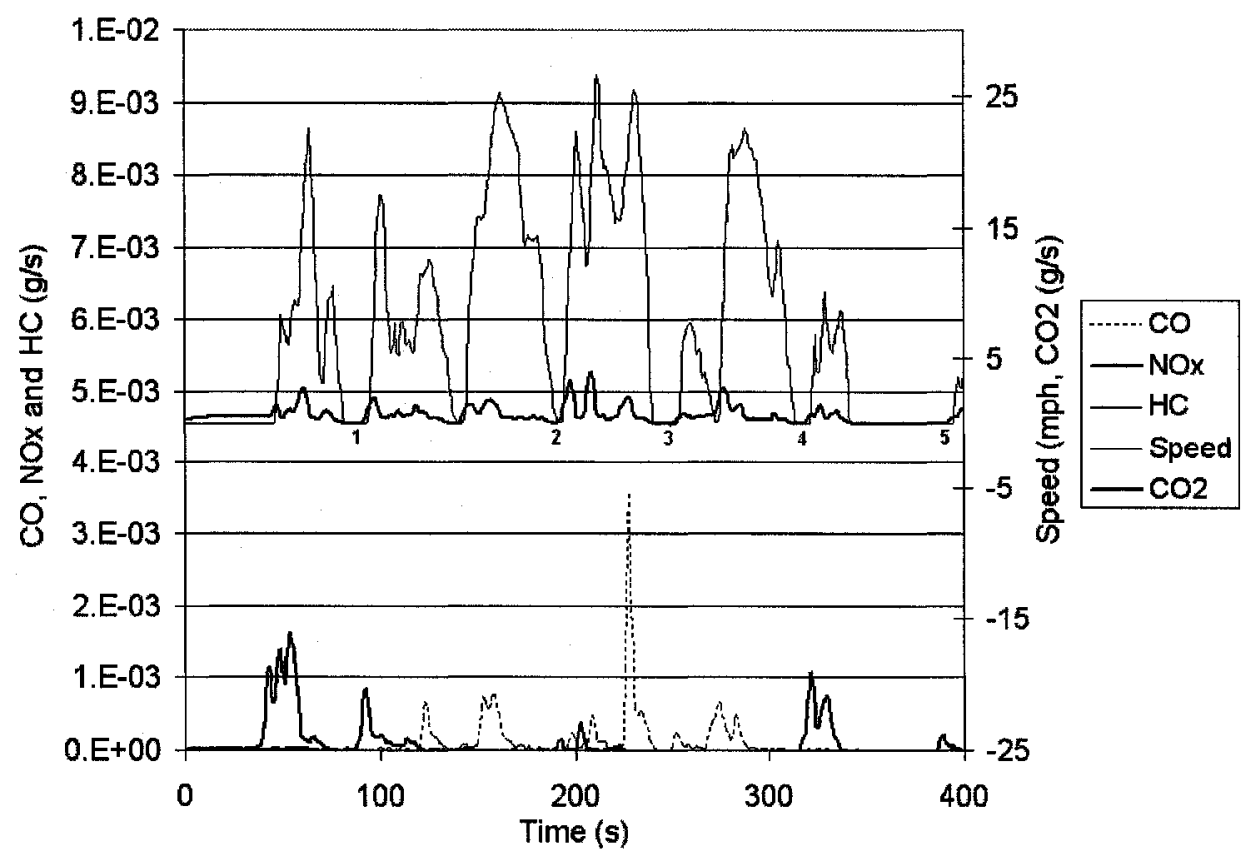

Figure 6.35: Example of SmartCar real-time emission rates during the first 400 seconds of the $2 \times N Y C C$ at $20^{\circ} \mathrm{C}$

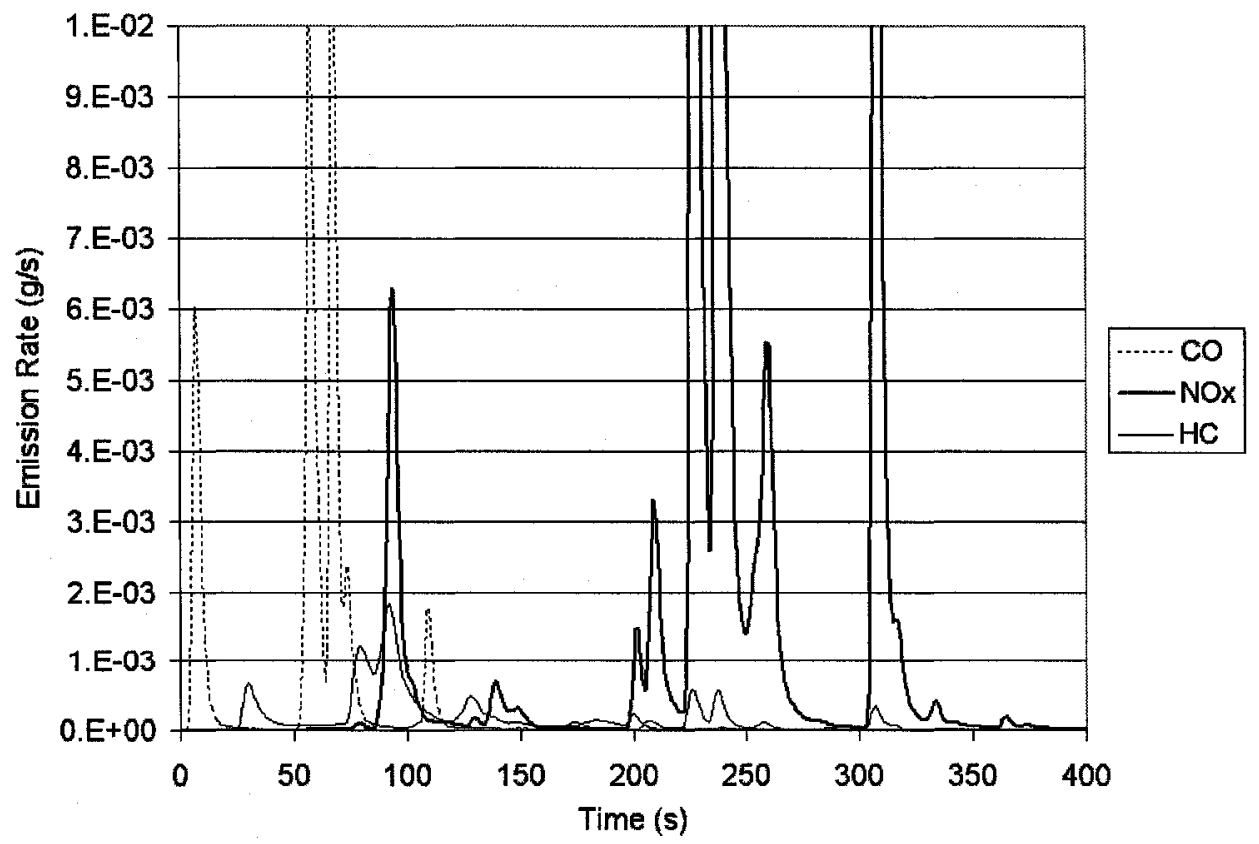


Figure 6.36: Example of Civic Hybrid real-time emission rates during the $S S 80$ at $-18^{\circ} \mathrm{C}$

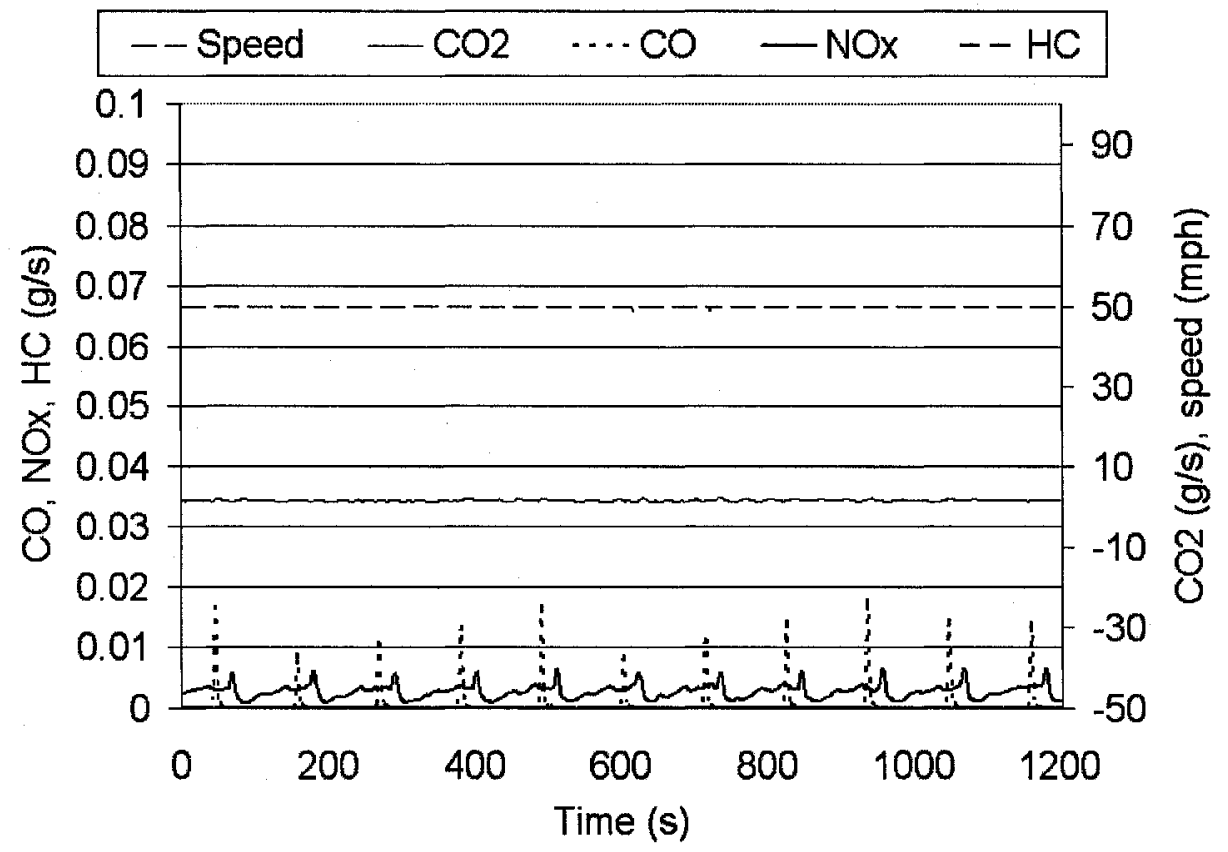

\subsection{Carbonyl Compound Emissions}

Carbonyl compounds were speciated for some of the 2xLA4 and 2xLA92 tests. LHC and NMOG were also speciated, but for too few tests to provide a basis for presentation or interpretation. When NMOG were speciated, carbonyl compound mass amounted to at most $8 \%$ of the mass of NMOG.

The emission factors of the carbonyl compounds are reported in $\mathrm{mg} / \mathrm{km}$ as a composite of the four phases of the $2 x L A 4$ or $2 x L A 92$. This composite emission factor is a weighted average, the equation for which is provided by CFR Title 40 , Part 86.144-90 [50]. Figures 6.37 to 6.40 show the average carbonyl compound emission factors for the 2xLA4 and 2xLA92 tests of the five vehicles tested. Carbonyl compound speciation was not completed for the Prius during the $20^{\circ} \mathrm{C}$ 
2xLA4 cycle, the Insight during the $-18^{\circ} \mathrm{C} 2 \times L A 4$ cycle, and the Prius and Insight during the $-18^{\circ} \mathrm{C} 2 \times L A 92$ cycle tests.

Figure 6.37: Carbonyl compound emission factors averaged over multiple tests for the $2 \times L A 4$ drive cycle at $20^{\circ} \mathrm{C}$

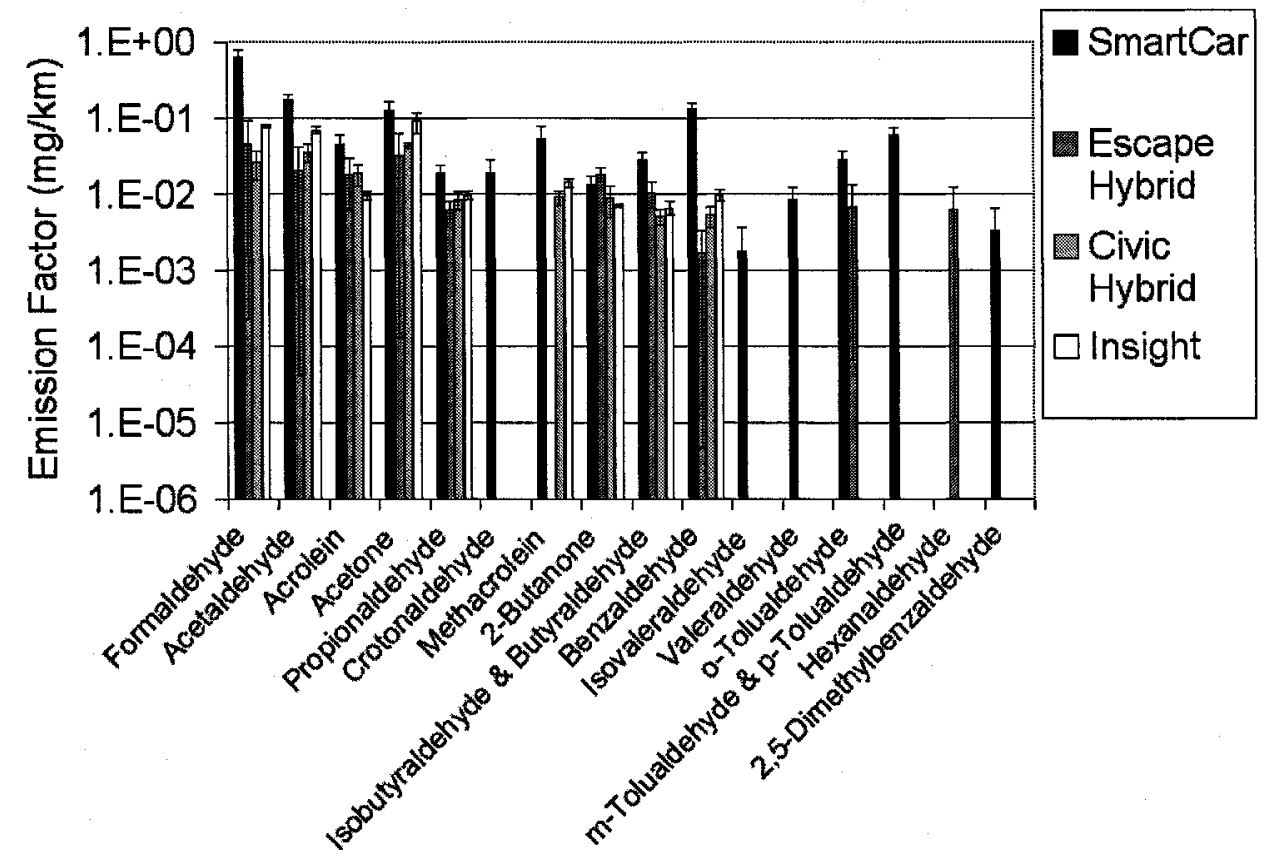

The carbonyl compounds with the highest emission factors include formaldehyde, acetaldehyde, acetone, and acrolein, for the $2 \times \mathrm{LA} 4$ cycle at $20^{\circ} \mathrm{C}$. At $-18^{\circ} \mathrm{C}$ the 2xLA4 carbonyl compound emission factors generally increase, especially for the SmartCar. At this temperature, formaldehyde, acetaldehyde, acetone, propionaldehyde and 2-butanone have the largest emission factors. In descending order, the SmartCar, Prius, Escape Hybrid and Civic Hybrid have the highest carbonyl compound emission factors during the $-18^{\circ} \mathrm{C} 2 x \mathrm{LA} 4$ tests, respectively. For the $20^{\circ} \mathrm{C} 2 \times L A 4$ test, in descending order, the SmartCar, Insight, Escape Hybrid and Civic Hybrid have the highest carbonyl compound emission factors.

The emission factors of the $2 x L A 92$ at both temperatures are smaller than those of the $2 x \mathrm{LA} 4$ cycles, respectively. During the $20^{\circ} \mathrm{C} 2 x \mathrm{LA} 92$ tests formaldehyde, 
Figure 6.38: Carbonyl compound emission factors averaged over multiple tests for the $2 x L A 4$ drive cycle at $-18^{\circ} \mathrm{C}$

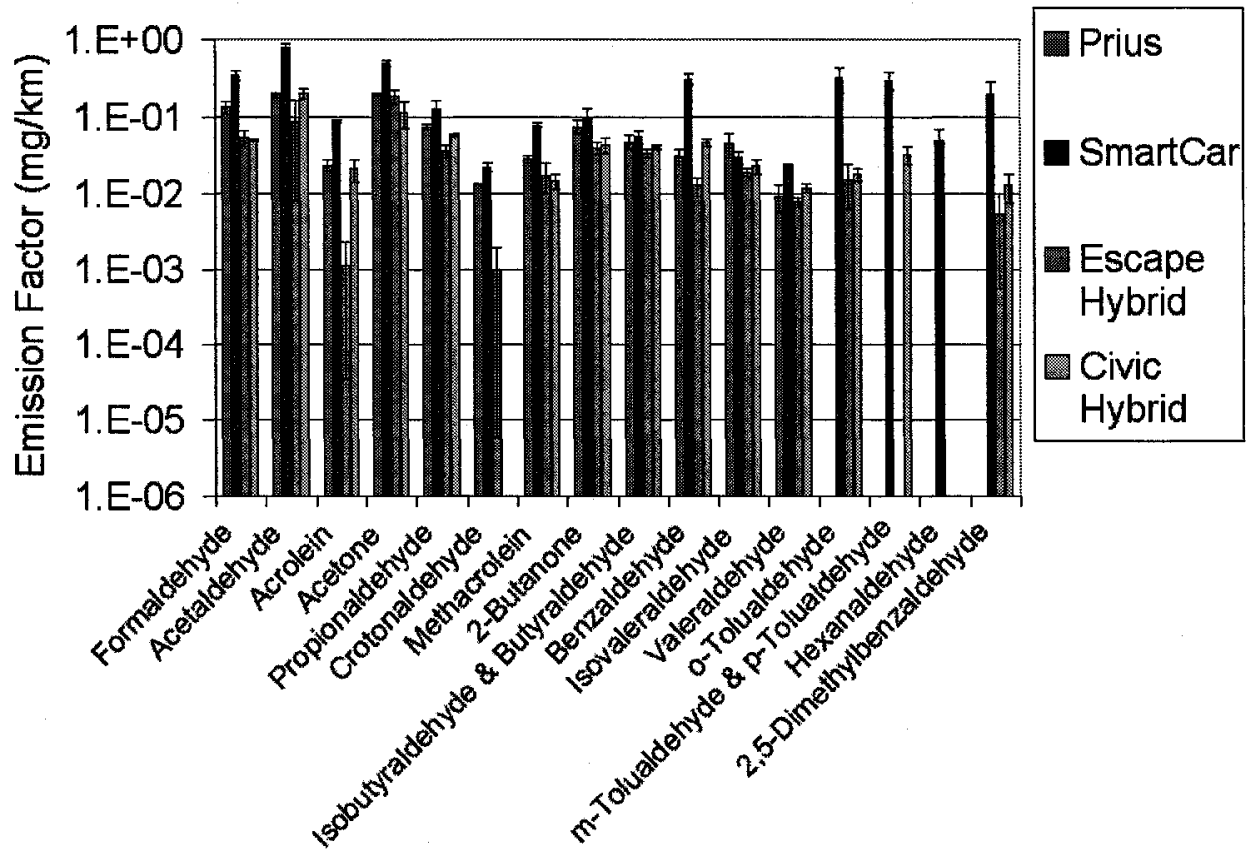

Figure 6.39: Carbonyl compound emission factors averaged over multiple tests for the $2 x \mathrm{LA} 92$ drive cycle at $20^{\circ} \mathrm{C}$

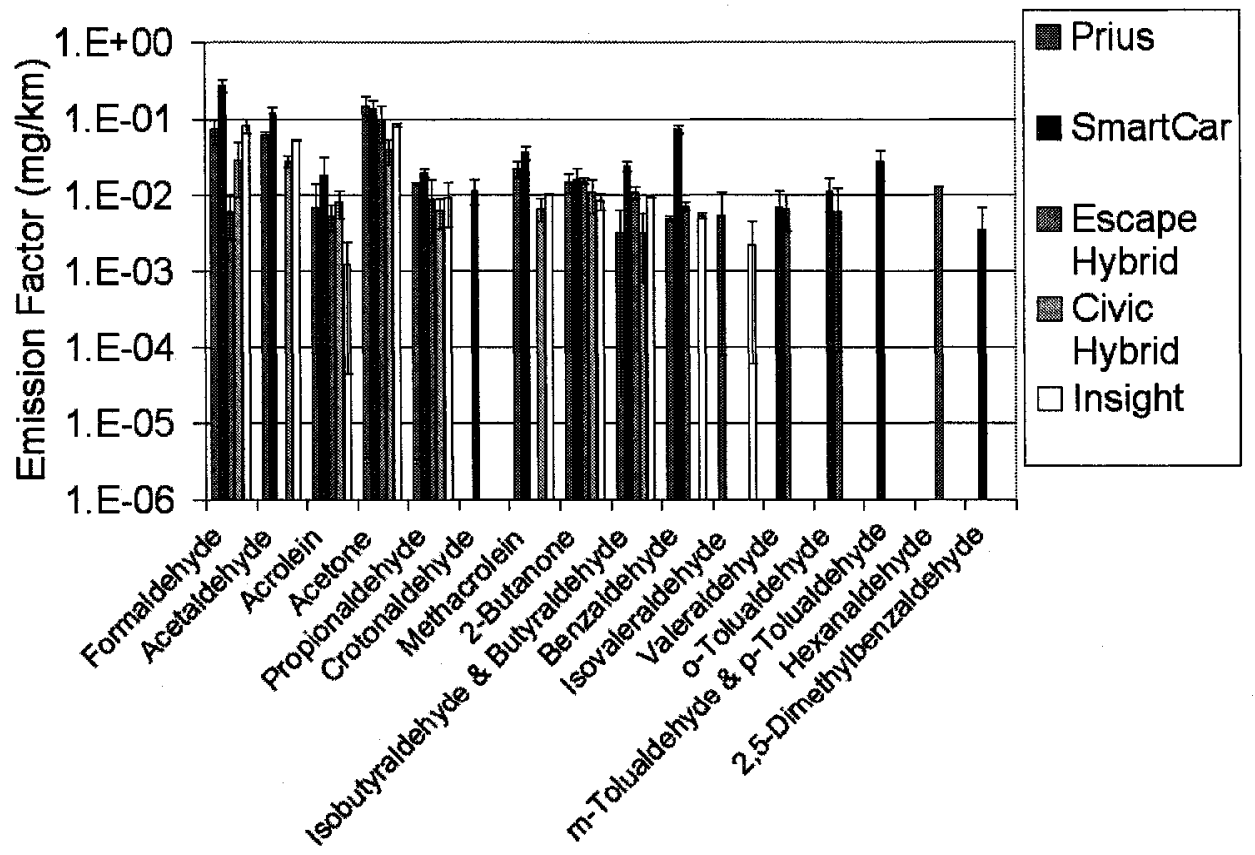


Figure 6.40: Carbonyl compound emission factors averaged over multiple tests for the $2 \times L A 92$ drive cycle at $-18^{\circ} \mathrm{C}$

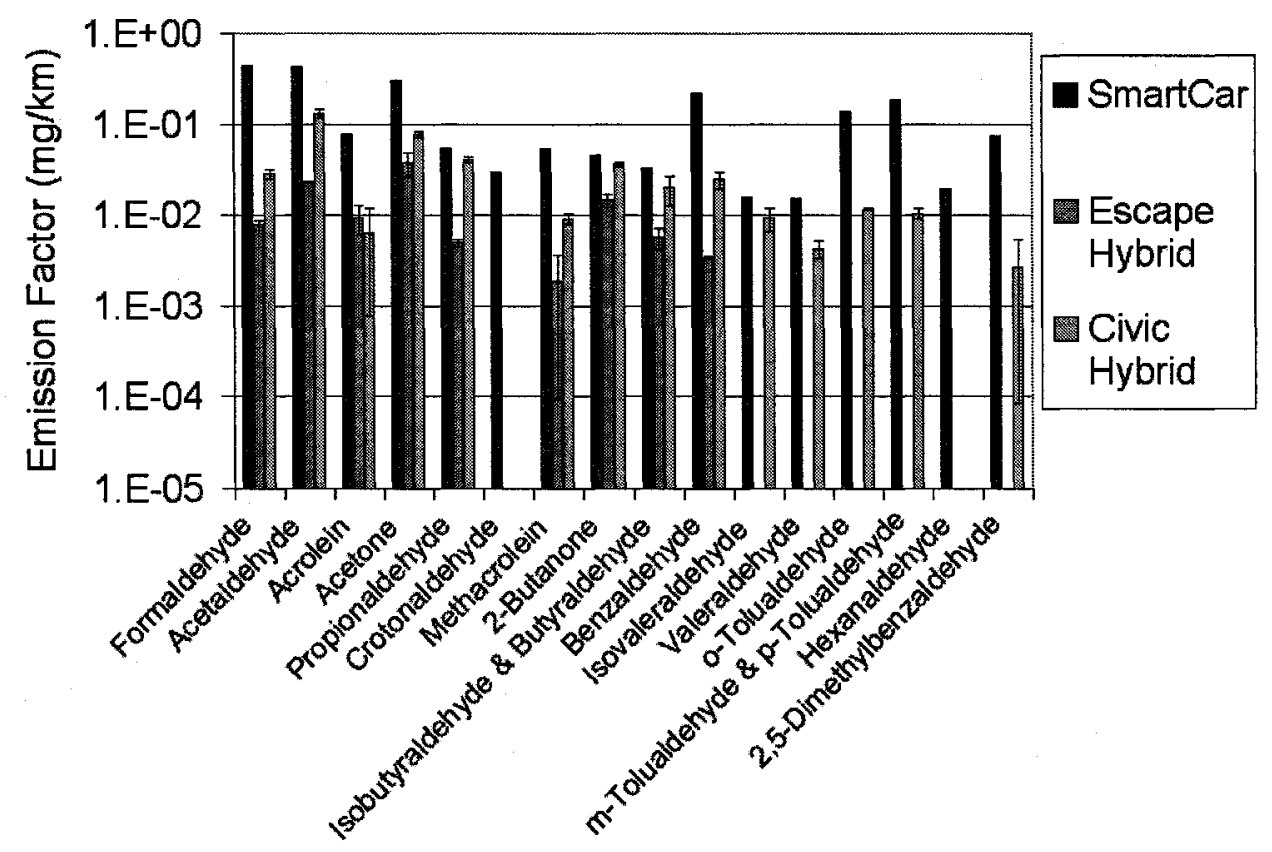

acetaldehyde and acetone have the largest emission factors of all the carbonyl compounds. For the $20^{\circ} \mathrm{C} 2 \times \mathrm{LA} 92$ tests, in descending order, the SmartCar, Prius, Insight, Civic Hybrid and Escape Hybrid have the highest carbonyl compound emission factors. For $-18^{\circ} \mathrm{C} 2 \times \mathrm{LA} 92$ tests, the SmartCar emission factors are very high compared to those of the HEVs. Formaldehyde, acetaldehyde, acetone and propionaldehyde have the largest emission factors for this cycle and temperature.

\subsection{Documentation of Data}

All of the results are included in the accompanying DVD. These results consist of three different types of data files: individual test files, summary files and Microsoft Excel macro codes. The individual test files include Integrated Files, Transient Files, Dynamometer Files and Energy Files. Integrated Files include cycle emission factors and $N E C$ calculations. Transient Files include real-time emission rates, 
and real-time current or SOC. Dynamometer Files contain real-time dynamometer forces, acceleration, speed and distance. Energy Files contain real-time battery and braking energy estimates.

The summary files in the accompanying DVD are the Integrated File Summary, Energy Summary and Engine-Off and Restart Count Summary. The Integrated File Summary contains individual test values, averages of emission factors and other calculations from the Integrated Files. The Energy Summary contains individual test energy values, energy averages and graphs. The Engine-Off and Restart Count Summary includes individual test ICE off times, ICE restart counts, and emission factors. It also contains averages of these parameters and graphs correlating them.

Two Microsoft Excel macro codes are also included. These macros are entitled Energy and Engine-Off Restart macros. The Energy macro was created to facilitate the production of Energy Files, while the Engine-Off and Restart macro was made to develop the Engine-Off and Restart Count Summary.

A table of contents and introduction is provided on the accompanying DVD to familiarize the reader with the location and context of the data. 


\section{Chapter 7}

\section{Discussion}

In this chapter, three themes are explored. First, battery and braking energies for each test are analyzed for the Escape Hybrid and Prius. The battery energies that are examined include regenerative braking, ICE battery charging and battery discharging energy. These energy values are compared to those in the literature (see Section 2.5.2). The battery energies are also compared to drive cycles to determine if any one of the three battery energies or battery activity are a function of driving patterns. The effect of cold temperature operation on battery energies and battery activity is determined and the effect of HEV energies on emission factors is investigated, as well. Finally, the battery energies between the Escape Hybrid and Prius are compared. Braking energy values are used to supplement discussions of the above investigations and to analyze the effects of augmented braking on regenerative braking energy.

The second theme explored in this chapter is gaseous emission factors from HEVs. The emission factors of $\mathrm{CO}, \mathrm{NO}_{x}, \mathrm{NMOG}, \mathrm{CO}_{2}, \mathrm{CH}_{4}$ and $\mathrm{N}_{2} \mathrm{O}$ from each HEV, and the SmartCar, are discussed in relation to driving patterns and CS effects. The effect of ambient temperature on these emission factors is also determined. 
The use of the battery SOC to standardize HEV test results is discussed. The emission factors of the HEVs are compared to those of the SmartCar and to those listed in Table 2.1 to determine if HEVs emit fewer gaseous emissions than conventional SI vehicles. This comparison is also made to determine if the required dynamometer tests (FTP and HWFET) for regulatory emissions compliance produce representative emission factors for the range of driving patterns used in this study. The emission factors of 16 carbonyl compounds from the 2xLA4 and 2xLA92 are compared between HEV models and the SmartCar. These carbonyl compound emission factors are also compared to those presented in Section 2.1.3. These comparisons are made to determine if HEVs emit fewer carbonyl compounds than conventional SI vehicles and if HEV carbonyl compound emission profiles are similar to those of conventional SI vehicles.

Lastly, the effect of ICE off time and the number of ICE restarts on the emission rates of $\mathrm{CO}, \mathrm{NO}_{x}, \mathrm{HC}$ and $\mathrm{CO}_{2}$ is examined. Four example tests are used to support this discussion, but 221 other files are available in the accompanying DVD under the folders, Individual Test Files and Transient Files, respectively.

\subsection{Battery and Braking Energies}

The following discussion is based on energy estimations. These energy values should not be considered real road values. This is because of three testing conditions: augmented braking, wheel slip and two-wheel dynamometer operation. Augmented braking, discussed in Section 7.1.5, reduces the potential energy that regenerative brakes may recover. Wheel slip is the event of the wheel and roller surface imposing such different forces on each other that the static friction force between the two is exceeded. If wheel slip occurs, friction braking energy will be 
overestimated and regenerative braking energy will be decreased. The effects of a FWD HEV being tested on a two-wheel chassis dynamometer have been shown to not affect the fuel economy of HEVs [39]. The effect of this testing apparatus on battery activity is not as well studied. By using only the front wheels to impose the braking force during a test, more regenerative braking energy is captured than would be possible if all four wheels were used to drive the HEV. Thus, the energies reported in this study may be considered as estimates of real road energy values.

The regenerative braking energy values presented in Section 2.5.2 were calculated by modelling electric vehicle operation. An electric vehicle relies solely on its battery for power to drive the wheels. Thus, its electric components are larger than those of an HEV, and it is expected that an electric vehicle will recuperate more regenerative braking energy than an HEV for a given drive cycle. The battery discharge and ICE battery charging energies are not reported in literature; however, it is expected that because the Escape Hybrid has a larger battery, it will discharge more energy per cycle than the Prius. Also, the Prius and Escape Hybrid ICE battery charging energies are expected to be approximately equal because, although the Escape Hybrid ICE is larger than the Prius ICE, the Escape Hybrid is heavier, and therefore requires the extra power provided by its ICE to power the vehicle. The regenerative braking energy of the Escape Hybrid is expected to be higher than that of the Prius, because the Escape Hybrid is a larger vehicle with a larger battery.

Drive cycles are characterized by their accelerations, decelerations, speeds, idling time and duration. An HEV driven over a drive cycle that has more deceleration time is likely to acquire more regenerative braking energy than it would from a cycle with a shorter cumulative deceleration time. Likewise, an HEV driven over 
drive cycle with many accelerations is expected to discharge the battery more than a cycle with fewer accelerations. A drive cycle that has moderate to high constant speeds is expected to have high ICE charging energies, because during these driving conditions, the ICE has excess energy and the battery does not participate in vehicle propulsion.

Battery discharging energy assists an HEV in meeting its power demand. Thus, it is expected that battery discharging energy decreases the fuel energy consumed, and therefore decreases the emissions of the HEV. ICE battery charging and regenerative braking energies are less related to assisting the HEV meet power demands; thus they are expected to not strongly correlate linearly to emissions. Battery activity includes all three of the battery energies and thus it is expected that its linear correlation to emissions will be weaker than that of discharging energy but stronger than ICE battery charging and regenerative braking energies.

At cold ambient temperatures, it is expected that total battery activity will be diminished. Prout and Jossen have related lower battery activity with low ambient temperatures $[62,63]$. This effect is expected to be similar for the NiMH batteries used in the HEVs of this study.

Chassis dynamometer augmented braking has been observed to not affect HEV fuel consumption, but the effect of this dynamometer operation on regenerative braking energy has not been published [39]. Because augmented braking directly reduces the potential energy for regenerative brakes to capture, it is expected that the use of augmented braking will result in a decrease in regenerative braking energy. 
Some of the expected trends listed above were not observed in the tests involving the Escape Hybrid and the Prius at $20^{\circ} \mathrm{C}$ and $-18^{\circ} \mathrm{C}$. The above issues are discussed in the following sections.

\subsubsection{Energy Values}

The regenerative braking energies reported in literature are shown in Table 2.5 for the NYCC, FTP, USO6 and HWFET. These values are for modelled electric vehicles. As a first approximation, the regenerative braking energy of the LA4 may be estimated by using that energy from the FTP cycle, multiplied by $2 / 3$ because the LA4 cycle has two out of the three cycles of the FTP. The regenerative energy values found in this study for the Escape Hybrid and Prius are both greater than, and less than, those presented in Table 2.5. Even between [42] and [41], the estimated regenerative braking energy recaptured during the FTP differs by $600 \mathrm{~kJ}$. The original expectation that these energy values would be larger than those found in this study, was incorrect. This may be because the modelled vehicles in [42] and [41] have smaller masses or, in the case of [42], less effective regenerative brakes than the actual HEVs tested in this study.

The Escape Hybrid recuperates more regenerative braking energy than the Prius at $-18^{\circ} \mathrm{C}$ and in some tests at $20^{\circ} \mathrm{C}$. This trend is expected because the Escape Hybrid has a larger mass than the Prius and therefore has more translational inertia that may be recovered. The reason why Prius regenerative braking energies are comparable to those of the Escape Hybrid at $20^{\circ} \mathrm{C}$ are explained in Section 7.1.5. Figures 6.6 to 6.9 illustrate that the Prius benefits more from regenerative braking than the Escape Hybrid. The ratio of regenerative braking energy to $T C E$ is an indicator of the overall effectiveness of the regenerative braking system for the 
HEV over a drive cycle. The Prius' regenerative braking energy to TCE ratio is higher than that of the Escape Hybrid as a partial result of its higher fuel economy, which is strongly related to vehicle mass [64]. Thus, both regenerative braking energy and TCE are proportional to the mass of an HEV. The effectiveness of an RBS, defined by regenerative braking energy divided by the $T C E$, is thus related to vehicle mass, but not necessarily linearly.

The Prius ICE battery charging energies are less than those of the Escape Hybrid. Also, the Prius ICE battery charging energies are less than the regenerative braking energies for every test. This is not true for the Escape Hybrid. For almost every drive cycle, and at both temperatures, ICE battery charging exceeds the regenerative braking energy. This trend may be explained by the larger ICE of the Escape Hybrid in comparison with that of the Prius. A larger ICE is able to accelerate a vehicle more quickly, but at constant loads the engine produces more excess power than a small ICE, that can be transferred to the battery. Thus, the original expectation that the two HEVs would have the same ICE charging energies was incorrect.

The Escape Hybrid has larger battery discharging energies than the Prius. This is expected because the Escape Hybrid has a larger battery and mass and thus more regenerative braking energy is captured and the larger engine may provide more ICE battery charging energy to the battery. These positive gains are discharged by the battery to maintain the SOC. For all of the $20^{\circ} \mathrm{C}$ tests, the Prius has a higher discharge energy to $T C E$ ratio than the Escape Hybrid (see Figures 6.9 and 6.7). This may be explained by the large regenerative braking energies for the Prius tests. Because the Prius is a charge sustaining HEV, it attempted to reduce the increase in SOC due to regenerative braking energy, by discharging the battery 
energy to power the wheels. If regenerative braking energy was less, then battery discharge energy would likewise be less (see Figure 6.8).

The $20^{\circ} \mathrm{C}$ tests of the Prius have higher battery activities than the Escape Hybrid. This may be explained by the discussion in the above paragraph about discharging energy. At $20^{\circ} \mathrm{C}$, augmented braking was not applied to the Prius tests, so its regenerative braking energy increased dramatically from $-18^{\circ} \mathrm{C}$ to $20^{\circ} \mathrm{C}$ (see Section 7.1.5). The Prius is a charge sustaining HEV, so it attempts to keep the battery $S O C$ within a small range. The large regenerative energy captured by the Prius during the $20^{\circ} \mathrm{C}$ tests was discharged to maintain the battery $S O C$ within a small range. When the Prius and Escape Hybrid are tested under the same conditions (i.e. both tested using augmented braking), the Escape Hybrid battery activity is much higher (see Table 6.1). This is expected because the Escape Hybrid has a larger battery, ICE and mass, so more energy is exchanged between the ICE, wheels and the battery.

\subsubsection{Drive Cycles and Battery Energies}

In Section 7.1 cumulative deceleration and acceleration time in a drive cycle was associated with large regenerative braking, and battery discharging energies, respectively. Table 7.1 lists the cumulative time in each transient cycle spent accelerating or decelerating.

It appears that the drive cycles that should produce the highest regenerative braking energies, in order, are: 2xUS06, LA92CS and LA92HS, LA4CS and LA4HS, 2XNYCC and HWFET. This is the case for the Escape Hybrid at both temperatures and the Prius at $-18^{\circ} \mathrm{C}$. During the Prius $20^{\circ} \mathrm{C} 2 \times L A 92$ test, augmented braking 
was employed, so regenerative braking energy was diminished. The regenerative braking energy of the Prius $20^{\circ} \mathrm{C} 2 \times N Y C C$ is less than that of the HWFET. This may be because one of the Prius $20^{\circ} \mathrm{C} 2 \times N Y C C$ tests had very low regenerative braking energy values (see PRIUS_NYCC1_12Aug05_ENERGY.xls in Energy File folder under Individual Test File folder in the accompanying DVD).

Table 7.1: Transient drive cycle cumulative acceleration and deceleration times

\begin{tabular}{|l|c|c|}
\hline \multirow{2}{*}{ Drive Cycle } & \multicolumn{2}{|c|}{ Cumulative Time (s) } \\
\cline { 2 - 3 } & Deceleration & Acceleration \\
\hline HWFET & 297 & 338 \\
LA4CS/LA4HS & 475 & 544 \\
LA92CS/LA92HS & 490 & 549 \\
2xNYCC & 406 & 404 \\
2xUS06 & 506 & 550 \\
\hline
\end{tabular}

From Table 7.1, the drive cycles that should produce the highest battery discharging energies are in the same order as for the highest acceleration times, listed above. However, this trend is not always observed. This may be because battery discharging energy is not only a function of accelerations, but also of idling time, low speeds and the battery SOC. Even if a drive cycle has many accelerations, long idling periods and long periods of low speeds, the battery will not contribute to powering the vehicle if its $S O C$ is low.

ICE battery recharging time was expected to be large for drive cycles that have moderate to high constant speeds. The HWFET drive cycle has these characteristics and yet it did not have the largest ICE battery charging energies. ICE battery charging is optimal when it is done under the above conditions; however, if the HEV computer recognizes that the battery $S O C$ is low, it may force the ICE to charge the battery during accelerations, low speeds or idling. The LA4 and LA92 are almost twice as long as the HWFET, and thus ICE battery charging 
is more likely to occur in the LA4 and LA92 in order to maintain SOC.

Longer drive cycles and drive cycles that are more aggressive (i.e. higher average speeds and accelerations) should have higher battery activity because a longer test provides more time for the battery to exchange energy with the ICE and wheels, and a more aggressive drive cycle induces the HEV battery to exchange energy with the ICE and wheels more often. The battery activities, shown in Table 6.1, are highest for the 2xUS06, LA92CS and LA92HS, and LA4CS and LA4HS cycles, not necessarily in that order. This coincides with the more aggressive and longer drive cycles engaging the battery more often.

\subsubsection{Battery Energies and Emissions}

Figure 6.5 illustrates the relationship between regenerative braking and emissions. In this figure, the regenerative braking energy is divided by $T C E$ to cancel out the effect of the drive cycle on the magnitude of regenerative braking energy. The linear correlations in Figure 6.5 are weak for all four emission factors. This trend was seen for both the Prius and the Escape Hybrid for all three battery energies and battery activity, and at both temperatures. The expectation that regenerative braking and ICE battery charging energies would not strongly linearly correlate to emission factors was correct. However, the expectation that battery discharging energy would be strongly linearly correlated to emission factors was incorrect. This must mean that battery discharge is not as large a factor in emissions from HEVs as previously expected. Such a conclusion is not intuitive when observing Figure 6.9 , where battery discharge energy accounts for up to $12 \%$ of the TCE. It may be that during the drive cycle, because of the large battery discharge, the Prius ICE charged the battery, at times when it did not have excess power, in order 
to maintain the battery $S O C$.

\subsubsection{Battery Activity and Operating Temperature}

Figures 6.1 to 6.4 show the three battery energies for all transient cycles during $20^{\circ} \mathrm{C}$ and $-18^{\circ} \mathrm{C}$ operation. From these graphs, the effect of cold ambient temperature on battery activity can be observed.

The Escape Hybrid battery energies in Figures 6.1 to 6.2 show that the three battery energies generally decrease from $20^{\circ} \mathrm{C}$ tests to $-18^{\circ} \mathrm{C}$ tests. For some of the tests, however, battery discharge energy increases during cold temperature operation. This unexpected result is associated with uncertainty in the average, because of the low number of tests for each drive cycle, vehicle and temperature. This anomaly is not seen for the Prius tests (see Figures 6.3 to 6.4). All of the Prius energies decrease more significantly than the Escape Hybrid energies from $20^{\circ} \mathrm{C}$ to $-18^{\circ} \mathrm{C}$ testing. This indicates that the Prius battery may be more sensitive to cold temperatures than the Escape Hybrid battery.

At cold temperatures, the hybrid battery's ability to discharge and charge are greatly reduced. This is because NiMH battery operation involves the diffusion of ions through a membrane towards electrodes where chemical reactions take place. Prout and Jossen have documented that diffusion through this membrane in a NiMH battery is decreased by temperature decrease, thus reducing overall battery activity [63].

At $-18^{\circ} \mathrm{C}$, the hybrid battery provides more power to the Escape Hybrid than does the Prius' battery. This behaviour is expected because the hybrid technology is 
similar and because the Escape Hybrid battery pack has a larger rated voltage. At $20^{\circ} \mathrm{C}$, however, the battery does not power the Escape Hybrid as much as the Prius does, relative to $T C E$. This may be because the $T C E$ is heavily dependent on TFE and the Escape Hybrid consumes more fuel as a function of the engine size and vehicle weight. As well, augmented braking was used on $-18^{\circ} \mathrm{C}$ and $20^{\circ} \mathrm{C}$ tests of the Escape Hybrid, and only on $-18^{\circ} \mathrm{C}$ tests of the Prius.

\subsubsection{Augmented Braking}

The effect of chassis dynamometer augmented braking on the regenerative braking energy recuperated by an HEV is not well characterized in literature. In this study, augmented braking was applied to all $-18^{\circ} \mathrm{C}$ tests, for all vehicles, and to all $20^{\circ} \mathrm{C}$ tests, for all vehicles but the Prius.

Figure 6.11 shows that the regenerative braking energy of the Prius is comparable to that of the Escape Hybrid at $20^{\circ} \mathrm{C}$. Also, Figures 6.1 and 6.2 show that the regenerative braking energy between $-18^{\circ} \mathrm{C}$ and $20^{\circ} \mathrm{C}$ tests increases by approximately $50 \%$ for the Escape Hybrid, and by at least $100 \%$ for the Prius, excluding the LA92 tests. These three trends are a result of the $20^{\circ} \mathrm{C}$ Prius tests not employing augmented braking. The Prius $20^{\circ} \mathrm{C}$ LA92CS and LA92HS tests employed augmented braking, which is why the regenerative braking energies for these drive cycles does not increase dramatically from $-18^{\circ} \mathrm{C}$ to $20^{\circ} \mathrm{C}$ tests.

Clearly, augmented braking affects the regenerative braking energy recaptured by HEVs. To observe this effect more directly, Figure 6.11 shows estimations of the regenerative braking energy that the Escape Hybrid would have recovered during $20^{\circ} \mathrm{C}$ tests, had augmented braking not been employed. This was accomplished by 
multiplying the fraction of average regenerative braking energy to average vehicle braking energy, by the TBE. This calculation excludes the effect of augmented braking by assuming that the TBE is solely vehicle braking energy. Table 6.2 shows the ratios of augmented, friction and regenerative braking to TBE. In the case of the $2 \times U S 06$ at $20^{\circ} \mathrm{C}$, if the $40 \%$ of TBE from augmented braking was instead from friction braking, the Escape Hybrid's regenerative brakes would have recovered $3990 \mathrm{~kJ}$ of energy instead of $2500 \mathrm{~kJ}$ (see Figure 6.11).

The Society of Automotive Engineers recommends that during HEV testing, the regenerative braking system should operate normally [43]. Based on the findings of this study, this is not possible with use of augmented braking on chassis dynamometers. It is therefore recommended that augmented braking not be used during testing of HEVs on chassis dynamometers. If augmented braking is not used, it is probable that regenerative braking energy will increase. Emissions are unlikely to be affected by the use of augmented braking because of the weak linear correlation between battery energies and emissions.

\subsection{Integrated Gaseous Emissions}

The integrated emission factors of $\mathrm{CO}, \mathrm{NO}_{x}$ and $\mathrm{NMOG}$, and $\mathrm{CO}_{2}, \mathrm{CH}_{4}$ and $\mathrm{N}_{2} \mathrm{O}$ from chassis dynamometer tests are used to develop vehicle emission factors for macro-scale emission models, such as MOBILE6, which can be used to develop emission inventories, and provide inputs to atmospheric modelling and human health effects assessments.

The relationship between drive cycle, ambient temperature and battery $N E C$, and emission factors is explored in this section. Also, Carbonyl compound emission 
factors are presented and compared to conventional SI vehicle emission factors.

\subsubsection{Drive Cycle and Emission Factors}

In this study, for both operating temperatures, it was found that $\mathrm{CO}$ and NMOG are emitted most during the LA4CS, LA92CS and 2xUS06 cycle. The emission factors of NMOG and CO for the LA4CS and LA92CS are much higher than those for the $2 x U S 06$ cycle at $-18^{\circ} \mathrm{C}$. These results are expected because HEVs rely heavily the operation of their TWC to reduce tailpipe emissions. During the first few minutes of phase 1, the ICE is not yet warm and the TWC has not reached operating temperatures. Also, at cold temperatures, in the first few minutes of a CS phase, fuel may not completely vapourize before being injected into the combustion chamber (see Section 2.1.2) and upon startup, the A/F ratio is initially rich. Thus, the combination of the above three conditions dramatically increases the NMOG and $\mathrm{CO}$ emissions of a HEV, relative to other cycles where the HEV has been warmed up before a test begins. Aggressive cycles, such as the US06, demand high power output from the vehicle so the HEV has difficulty maintaining stoichiometric A/F ratio. Gaseous emissions tend to be high for this type of cycle.

At both temperatures, $\mathrm{NO}_{x}$ emission factors are a minimum for the Insight and Civic Hybrid driven over the 2xLA4 and 2xLA92 CS phases, 2xNYCC and 2xUS06 drive cycles. Emissions of $\mathrm{NO}_{x}$ are created during high temperature combustion, which occurs for complete combustion. During CS, complete combustion is not as likely to occur as during the steady state tests. Conversely, during CS, the TWC does not effectively reduce $\mathrm{NO}_{x}$ into $\mathrm{N}_{2}$. The Civic Hybrid and Insight use lean-burning ICE's that not only increase the completeness of combustion, but also introduce more nitrogen and oxygen to the flame. However, these vehicles are equipped 
with $\mathrm{NO}_{x}$ adsorption catalysts to reduce $\mathrm{NO}_{x}$ tailpipe emissions. During a drive cycle test with high flame temperatures and oxygen content, this $\mathrm{NO}_{x}$ adsorption catalyst may not be able to adsorb all of the $\mathrm{NO}_{x}$ created, and the excess $\mathrm{NO}_{x}$ passes through the catalyst without being reduced. During a CS, lean burn may not be achieved, and compounded with low flame temperature, $\mathrm{NO}_{x}$ formation will not be substantial.

At both temperatures, the SmartCar, Escape Hybrid and Prius emit high $\mathrm{NO}_{x}$ emissions during the LA4CS, LA92CS, 2xUS06 and 2XNYCC drive cycles, relative to their emissions during other cycles. The effect of a non-operating catalyst during CS contributes to the LA4CS and LA92CS emission factors. The discussion in Section 7.3 suggests that drive cycles associated long HEV ICE off time, such as the $2 \times N Y C C$, have higher gaseous emission rates than cycles with short ICE off time. Vehicles driven over the US06 consume more fuel because the drive cycle involves many large accelerations and high speeds. High fuel consumption results in a high volume of exhaust, including $\mathrm{NO}_{x}$. At high exhaust volumes, there is too much exhaust moving too quickly for it all to react in the TWC, and thus some of this exhaust, including $\mathrm{NO}_{x}$, escapes without reacting.

At both temperatures, $\mathrm{CO}_{2}$ emission factors are highest for the LA4CS, LA92CS, and the 2xNYCC. At cold temperatures or when a vehicle has not warmed up, the initial A/F ratio is enriched and fuel may not be completely vapourized when it enters the combustion chamber. This results in the combustion not being efficient and more fuel being required to drive the vehicle. Drive cycles that involve low speeds and long idling times will consume fuel, and produce $\mathrm{CO}_{2}$, without travelling far. For the above two reasons, this is why $2 \times L A 4$ and $2 \times L A 92$ CS phases and the $2 \times N Y C C$ have the highest $\mathrm{CO}_{2}$ emission factors, in $\mathrm{g} / \mathrm{km}$. The US06 is a very 
energy intensive drive cycle, but it has a short idling time and very fast speeds so in the same length of time as the NYCC it covers 12 kilometers more than the NYCC.

$\mathrm{CH}_{4}$ emission factors are strongly correlated to those of NMOG because NMOG emissions are mostly from $\mathrm{HCs}$, and $\mathrm{CH}_{4}$ forms under the same conditions as $\mathrm{HC}$.

$\mathrm{N}_{2} \mathrm{O}$ emissions are not a product of combustion, but instead form in the TWC. At both temperatures, $\mathrm{N}_{2} \mathrm{O}$ emission factors are highest for the $2 \times \mathrm{LA} 4$ and $2 \times \mathrm{LA9} 2$ CS phases and the $2 \times N Y C C . \mathrm{NO}_{x}$ emission factors are highest for the $2 \times \mathrm{LA} 4$ and $2 \times L A 92 \mathrm{CS}$ phases and the $2 \times N Y C C$ as well. $\mathrm{N}_{2} \mathrm{O}$ is formed in the TWC as $\mathrm{NO}_{x}$ is being reduced to $\mathrm{N}_{2}$ and $\mathrm{O}_{2}$; thus the emissions of $\mathrm{N}_{2} \mathrm{O}$ are correlated to those of $\mathrm{NO}_{x}$. As explained above for $\mathrm{CO}_{2}$, the NYCC only covers $1.9 \mathrm{~km}$ in 600 seconds, so emissions reported per kilometer for this cycle appear more than if reported per cycle time.

\subsubsection{Ambient Temperature and Emission Factors}

Emission factors of NMOG, $\mathrm{CO}, \mathrm{CO}_{2}$ and $\mathrm{CH}_{4}$ are expected to increase with decreasing ambient temperatures. NMOG and $\mathrm{CH}_{4}$ are formed because of incomplete combustion. At low ambient temperatures, the fuel may be too cold to vapourize in the combustion chamber, resulting in partial combustion and low flame temperatures (see Section 2.1.2). CO forms when oxygen is not available, under fuel rich conditions. The inefficient fuel combustion described above requires that more fuel be used to power the vehicle, and thus more $\mathrm{CO}_{2}$ and $\mathrm{CO}$ will be emitted. $\mathrm{NO}_{x}$ forms under conditions of lean A/F ratio and high flame temperatures. At cold temperatures, these conditions are not met, so the emission factors of $\mathrm{NO}_{x}$ are expected to be lower. $\mathrm{N}_{2} \mathrm{O}$ is formed during the reduction of $\mathrm{NO}_{x}$, so its emissions 
are also expected to decrease during cold temperature operation. All of these gaseous emissions, except for $\mathrm{CO}_{2}$, will be affected by the temperature of the TWC. These effects are described below, in each of the discussions of temperature and emission factors for NMOG, $\mathrm{CO}, \mathrm{CO}_{2}$ and $\mathrm{CH}_{4}, \mathrm{NO}_{x}$ and $\mathrm{N}_{2} \mathrm{O}$.

$\mathrm{NO}_{x}$ emission factors decreased from $20^{\circ} \mathrm{C}$ operation to $-18^{\circ} \mathrm{C}$ operation, for most drive cycles and vehicles (see Figures 6.20 and 6.21). For most tests, the Escape Hybrid $\mathrm{NO}_{x}$ emission factors increased from $20^{\circ} \mathrm{C}$ to $-18^{\circ} \mathrm{C}$ operation. This increase in $\mathrm{NO}_{x}$ emission factor is unexpected. At $-18^{\circ} \mathrm{C}$, the Escape Hybrid's TWC may not have warmed up as quickly as the other vehicles' TWCs, allowing $\mathrm{NO}_{x}$ emissions to pass through without being reduced. Conversely, the Escape Hybrid ICE may have warmed up more quickly and achieved stoichiometric $A / F$ ratio faster than the other vehicles. The Escape Hybrid has the largest ICE of all the test vehicles and it therefore emits a higher volume of exhaust than the other vehicles. A combination of the above conditions likely contributed to the Escape Hybrid $\mathrm{NO}_{x}$ emission factors increasing from $20^{\circ} \mathrm{C}$ to $-18^{\circ} \mathrm{C}$ operation.

CO Emission factors increased significantly from $20^{\circ} \mathrm{C}$ tests to $-18^{\circ} \mathrm{C}$ tests, as shown in Figures 6.18 and 6.19. During LA4CS and LA92CS tests, the A/F ratio is initially rich and the TWC is initially non-operational. These conditions induce the formation of $\mathrm{CO}$ in the engine, and its release from the tailpipe without being oxidized. The A/F ratio is rich during part of the $2 \mathrm{xUS06}$ drive cycle because of its aggressive accelerations. This fuel rich $A / F$ mixture and the inefficient combustion, caused by low ambient temperatures, results in high $\mathrm{CO}$ emissions. The $\mathrm{CO}$ emission factors from the HWFET, 2xNYCC and SS tests, for all of the HEVs and the SmartCar are relatively low. This may be attributed to the fewer hard accelerations in these drive cycles. These drive cycles are also run as HS tests; 
therefore the ICE and TWC have already warmed up.

NMOG emission factors increase from $20^{\circ} \mathrm{C}$ operation to $-18^{\circ} \mathrm{C}$ operation for all tests, except the HWFET and for some vehicles, the SS tests (see Figures 6.22 and 6.23). Cold operating temperature decreases ICE efficiency and thus more NMOG will be formed, especially during CS when the vehicle engine and fuel are at ambient temperature and the TWC is non-operational. The HWFET and SS tests have very low emission factors at both $20^{\circ} \mathrm{C}$ and $-18^{\circ} \mathrm{C}$. The standard deviations (when available) for these tests are often greater than the emission factor. Thus, this trend of NMOG emission factors decreasing from $20^{\circ} \mathrm{C}$ to $-18^{\circ} \mathrm{C}$ for the HWFET and SS tests, may be a consequence of uncertainty. Nonetheless, drive cycles for which the ICE has already been warmed are least affected by $-18^{\circ} \mathrm{C}$ operation.

The $\mathrm{CO}_{2}$ emission factor is directly related to fuel consumption, and to a lesser degree the TWC. The $\mathrm{CO}_{2}$ emission factors presented in Figures 6.24 and 6.25 are therefore indicative of the fuel economy of each vehicle over each test. Not surprisingly, $\mathrm{CO}_{2}$ emission factors increase from $20^{\circ} \mathrm{C}$ to $-18^{\circ} \mathrm{C}$. This increase in $\mathrm{CO}_{2}$ emission factors is because the ICE efficiency decreases during cold temperatures, so more fuel is required to power the vehicle. Drive cycles requiring high power, or CS phases, consume more fuel and thus the $\mathrm{CO}_{2}$ emissions are higher for these drive cycles. The Escape Hybrid is the largest vehicle and thus consumes the most fuel over every cycle at both temperatures.

$\mathrm{CH}_{4}$ is a hydrocarbon emission and is a relatively chemically benign molecule compared to other $\mathrm{HC}$; therefore, it is not included in the NMOG emission factor. It is therefore expected that its emission profiles follow the same trends as the NMOG. $\mathrm{CH}_{4}$ emission factors do follow the same trends as NMOG emission 
factors, except during some of the $20^{\circ} \mathrm{C}$ tests, such as the $2 x L A 92$ phases 2 and 4 (see Figures 6.26 and 6.27 ). The emission factors from these two phases have very large standard deviations, which may explain why they do not follow the same trend as NMOG.

$\mathrm{N}_{2} \mathrm{O}$ emission factors, as described in Section 2.1.5, are formed in the TWC during $\mathrm{NO}_{x}$ reduction reactions. Thus, $\mathrm{N}_{2} \mathrm{O}$ emission factors should follow the same trends as $\mathrm{NO}_{x}$ for each drive cycle. During cold temperatures, less $\mathrm{NO}_{x}$ was formed and consequently, less $\mathrm{N}_{2} \mathrm{O}$ should form. This trend was generally observed (see Figures 6.28 and 6.29). Older catalytic converters have been shown to increase $\mathrm{N}_{2} \mathrm{O}$ emissions in vehicles compared to those equipped with newer TWCs [29]. This pattern is observed in this study. The most recent vehicle models, in descending order, are the Escape Hybrid, Prius, Civic Hybrid, SmartCar and Insight. The $\mathrm{N}_{2} \mathrm{O}$ emissions observed during $20^{\circ} \mathrm{C}$ operation are lowest in the same descending order listed above. During $-18^{\circ} \mathrm{C}$ operation this pattern is again observed except that the Civic Hybrid emits less $\mathrm{N}_{2} \mathrm{O}$ than the Prius.

\subsubsection{Battery Net Energy Change and Emission Factors}

The SAE recommendations for HEV testing requires that the emission factors be adjusted if the $N E C$ is above $1 \%$ and below $5 \%$. Between 5 to $75 \%$ of the tests conducted on each HEV required emission factor adjustments (see Table 6.4). This emission factor adjustment requires that emissions and $N E C$ values from at least three repeat tests are measured so that a $N E C$ and emission factor plot can be made. Ideally, the linear correlation between these plotted points is $R^{2} \geq 0.8$.

Figures 6.16 and 6.17 show that some of the drive cycles have $R^{2} \geq 0.8$. 
For most tests of the four HEVs, $R^{2}$ was below 0.8 . This may be observed in the accompanying DVD under the folder Summaries and the file Integrated File Summary. For some tests in Figures 6.16 and 6.17, all of the data points on the $N E C$ and emission factor graphs are on one side of the $y$-axis, necessitating extrapolation in order to find the zero $N E C$ emission factor. This practice is accepted, but not highly regarded by the SAE recommendations [43].

The negative slopes of some of the trend lines in Figures 6.16 and 6.17 indicate that as the battery contribution to vehicle energy increases (i.e. decreasing or negative $N E C$ ), the emission factor will increase. This trend is not expected, because as the battery contributes more energy to the $T C E$, fuel consumption should decrease, and thus emission factors should decrease. This implies that if the $N E C$ contribution to powering the vehicle is high, other factors in testing must increase the emission factors. For example, during one 2xNYCC test, the battery may completely power the HEV during idling (negative $N E C$ ) and contribute very little for accelerations or at low speeds. During a second 2XNYCC test, the battery may not power the HEV at all during idling, but mildly assist during accelerations (slightly negative $N E C$ ). The emission factor of the second 2xNYCC test is likely to be less because accelerations produce more emissions than does idling.

In some cases, different emissions factors were observed for the same NEC, producing a vertical trend line on the emission factor and NEC plot. Obtaining the emission factors that correspond to zero NEC, in this case, is an impossible task.

The zero $N E C$ emission factor for many tests is often a nonsensical value. For instance, the zero $N E C$ emission factor may be negative, grossly large or virtually zero. From the discussion above, even when three repeat tests are conducted, 
they do not necessarily lead to a linear, meaningful relationship between $N E C$ and emission factors.

Tests conducted at $20^{\circ} \mathrm{C}$ have more instances of $N E C>1 \%$ than tests conducted at $-18^{\circ} \mathrm{C}$. This finding may be attributed to the decreased battery activity at $-18^{\circ} \mathrm{C}$ (see Section 7.1.4). Cold temperature decreases battery activity and so the vehicle computer is better able to maintain the battery $S O C$ at its initial level, from the beginning to the end of the test. Also, during $-18^{\circ} \mathrm{C}$ tests, the HEV consumed more fuel so the $T C E$ increased, which in turn decreased the percent $N E C$ (see Section 5.6).

$N E C$ exceeded $1 \%$ most frequently during the transient drive cycles, except for the 2xLA92. Transient drive cycles engage the hybrid battery more than steady state tests because the electric motor functions best during accelerations, low speeds and idling. The low frequency of $N E C>1 \%$ during the $2 x L A 92$ tests may be attributed to the long test time of this drive cycle. The $2 \times$ LA92 is 49 minutes long, $7 \%$ longer than the 2xLA4 and 59\% longer than the 2xUS06 and $2 \times N Y C C$ drive cycles. This extra time may allow the HEV to maintain the HEV's initial SOC at the beginning of the test. The SS 80 cycle had one incidence of $N E C>1 \%$ out of the four tests at $20^{\circ} \mathrm{C}$. During the $-18^{\circ} \mathrm{C}$ tests the steady state tests have the largest percentage of tests exceeding $1 \% N E C$. A vehicle travelling at a constant speed does not use all of the power created by the engine. The excess power is routed to the battery and the $S O C$ increases. If the battery has been previously discharged during another drive cycle, the HEV computer may not stop the battery from recharging, even if it means not maintaining the initial SOC.

The SAE recommended practice for testing HEVs and adjusting emission factors 
based on a linear correlation to NEC does not work for the HEVs and test cycles used in this study. If the $N E C$ correction method is not used, another means of test repeatability is required. One alternative is to have no means of controlling the battery energy and simply conduct multiple repeat tests to ensure repeatability. The battery $S O C$ would not be starting at the same value from test to test, nor would the $N E C$ contribution be the same from test to test; thus adding extraneous variables to the experiment. Another possibility is the use of the battery draining hybrid procedure, where the battery is preset to a specific $S O C$ value before each test. This would standardize each test, but not account for the contribution of $N E C$ to $T C E$. It would also require multiple tests to ensure repeatability; thus it is not an ideal solution, but does control $S O C$ from test to test.

\subsubsection{Carbonyl Compound Emission Factors}

Table 7.2 lists the number of tests for each vehicle, cycle and temperature for which carbonyl compound speciation was completed. Formaldehyde, acetaldehyde, acetone, propionaldehyde and 2-butanone have the largest emission factors of the carbonyl compounds speciated for the five vehicles tested over the 2xLA4 and 2xLA92 drive cycles. The first three of these carbonyl compounds have the highest emission factors out of the carbonyl compounds speciated for [13-15]. The carbonyl compound emission factors increase from $20^{\circ} \mathrm{C}$ to $-18^{\circ} \mathrm{C}$ tests for both the 2xLA4 and 2xLA92 cycles. The same factors that contribute to $\mathrm{HC}$ emissions contribute to the formation of carbonyl compounds (Section 2.1.1). The SmartCar, having been designed for different emission standards (Section 4.2), emits more carbonyl compounds than the HEVs. The HEV emission technology is a likely factor in their substantially lower carbonyl emissions. The Prius and Insight emit more carbonyl compounds than the Escape Hybrid and Civic Hybrid during both 
the $2 \times L A 4$ and $2 \times L A 92$.

The profile of carbonyl compound emissions is very similar to that of other lightduty vehicles [13-15]. Carbonyl compound emissions increase with decreasing operating temperature and are typically lower than the SmartCar carbonyl emissions. This is expected because HEVs, like conventional SI vehicles, employ an ICE.

Table 7.2: Number of tests conducted that included carbonyl speciation

\begin{tabular}{|c|l|l|l|}
\hline \multirow{2}{*}{ Temperature } & Vehicle & Number of Tests with Speciated Carbonyl Compounds \\
\cline { 2 - 4 } $20^{\circ} \mathrm{C}$ & 2xLA4 & 2xLA92 \\
\hline \multirow{5}{*}{$-18^{\circ} \mathrm{C}$} & Prius & 0 & 2 \\
& Escape Hybrid & 2 & 2 \\
& Civic Hybrid & 2 & 3 \\
& Insight & 2 & 2 \\
& SmartCar & 3 & 3 \\
\hline \multirow{3}{*}{} & Prius & 2 & 0 \\
& Escape Hybrid & 3 & 2 \\
& Civic Hybrid & 2 & 2 \\
& Insight & 0 & 0 \\
& SmartCar & 2 & 1 \\
\hline
\end{tabular}

\subsection{Effect of Engine Off Time and Number of Engine Restarts on Gaseous Emission Rates}

One of the benefits of an HEV over a conventional SI vehicle is that the ICE of an HEV can shut off while the vehicle is at idle, or at a slow speed. This feature of an HEV is believed to reduce emissions because while the ICE is off, no pollutants are being emitted. While this is true, this study has found that longer ICE off time can be correlated to higher pollutant emission rates due to the emission rates associated 
with ICE restarts.

Figures 6.32, 6.34 and 6.33 show the emissions during the NYCC for the Prius, Civic Hybrid and SmartCar, respectively. The differences in the SmartCar's lowest $\mathrm{CO}_{2}$ emission rate compared to those of the Prius and the Civic Hybrid illustrate that the SmartCar ICE never shuts off during the 2xNYCC, while the ICEs of the Civic Hybrid and the Prius do shut off. The Prius ICE shuts off while the vehicle is moving (restart point 17 on Figure 6.32) and when vehicle speed is zero, while the Civic Hybrid ICE shuts off only while the HEV is at idle. As stated in Section 5.8, the ICE of the HEV is off when the emission rate of $\mathrm{CO}_{2}$ is below $0.1 \mathrm{~g} / \mathrm{s}$. For the Civic Hybrid and the Insight, a further restriction is that the vehicle speed must be zero. The ICE is assumed to restart once the $\mathrm{CO}_{2}$ emission rate increases to above $0.1 \mathrm{~g} / \mathrm{s}$. No sensitivity analysis was conducted for this $\mathrm{CO}_{2}$ emission rate to observe the effects of smaller or larger emission rates defining the ICE off, but such an analysis would provide more confidence in these results.

During a drive cycle, if the ICE shuts off for a period of time, the overall emission rate is expected to decrease because no pollutants will be emitted from the ICE. However, based on Figure 6.31 this does not occur. Instead, emission factors increase as the ICE off time increases. The ICE off time is linearly correlated to the number of ICE restarts in Figure 6.30. By observing the real-time emission rates emitted by an HEV during a drive cycle, at the points where ICE restart occurs, it is clear why emission factors increase as engine-off time increases. At the ICE restart points along the graph of the Prius and Civic Hybrid 2xNYCC tests (Figures 6.32 and 6.34) small peaks in $\mathrm{NO}_{x}, \mathrm{CO}$, and less often $\mathrm{HC}$, occur. These peaks in emission rates occur because the ICE has restarted, and the A/F ratio is initially rich during startup. At every instance of ICE restart, at least one of the gaseous 
pollutant emission rates peak, even if only slightly.

The $\mathrm{CO}$ and $\mathrm{NO}_{x}$ emission rate peaks at the ICE restart locations on the speedtime traces are, in every instance, less than the peaks on the SmartCar real-time emission rate plot at the same points. The SmartCar has an ICE of comparable size to the HEVs tested in this study. The lower emission factors of the HEVs may be attributed to the various emission technologies that the HEVs are equipped with. The Civic Hybrid and Insight employ an idle-stop feature which allows the electric motor, powered by the battery, to crank the ICE up to at least $400 \mathrm{rpm}$ before ignition, thus decreasing the initial load on the ICE and reducing restart emissions. This feature may be applied on the Prius and Escape Hybrid, but detailed information on these vehicles was not available at the time of this study. The Prius and Civic Hybrid employ different cold temperature engine start features that reduce pollutant emissions.

As ICE off time increases, the number of ICE restarts will increase, and consequently the gaseous pollutant emission factors will increase. Despite the effects of ICE restart, however, the $\mathrm{HC}, \mathrm{NO}_{x}$ and $\mathrm{CO}$ emission rates of the HEVs are much smaller than those of the SmartCar.

It appears from Figures 6.32 and 6.34 that if the ICE did not shut off, the pollutant emission rates would decrease significantly. However, this is not necessarily the case, as Figure 6.36 exemplifies. Here, periodic peaks in $\mathrm{NO}_{x}$ and $\mathrm{CO}$ occur that contribute to an overall larger emission factor. This may be a result of the $\mathrm{NO}_{x}$ adsorption reaction catalyst in the Civic Hybrid becoming saturated with $\mathrm{NO}_{x}$ and thus allowing it to pass by the TWC without being reduced. In turn, this may affect CO emission rates (see Section 2.2). During the SS80 drive cycle, the ICE does 
not turn off and restart, and yet the emission rates of $\mathrm{CO}$ and $\mathrm{NO}_{x}$ are comparable to those of the SmartCar on the 2xNYCC.

It is evident that although ICE off time is associated with higher emission rates of $\mathrm{CO}, \mathrm{NO}_{x}$ and $\mathrm{HC}$, this trend is for specific driving conditions. This subject may be further researched to derive a relation between ICE off time and emission rates for HEVs for all ICE off times, including zero. Such research would require real-time information from the HEV on its operation mode, and control over how long an ICE shuts off for during a drive cycle. The results of such research could be used to design micro models that predict HEV emission rates from known ICE off times. 


\section{Chapter 8}

\section{Conclusions and Recommendations}

This study explored gasoline-electric hybrid vehicle energy consumption and recuperation patterns, vehicle engine operation, and gaseous emissions. Four hybrid vehicles, the 2005 Ford Escape Hybrid, 2004 Toyota Prius, 2003 Honda Civic, and the 2000 Honda Insight, as well as one conventional spark-ignition vehicle, the SmartCar, were tested on an chassis dynamometer. Integrated emission factors of $\mathrm{CO}, \mathrm{NO}_{x}, \mathrm{NMOG}, \mathrm{CO}_{2}, \mathrm{CH}_{4}$ and $\mathrm{N}_{2} \mathrm{O}$, and real-time emission rates of $\mathrm{CO}, \mathrm{NO}_{x}, \mathrm{CO}_{2}$ and $\mathrm{HC}$ were measured over the 2xLA4, 2xLA92, 2xNYCC, $2 x U S 06, H W F E T, S S 40$ and SS 80 drive cycles at both $20^{\circ} \mathrm{C}$ and $-18^{\circ} \mathrm{C}$. Carbonyl compounds were speciated over two of the transient drive cycles. All tests were conducted at the Emissions Research and Measurement Division of the Environmental Technology Center, a part of Environment Canada. The tests were conducted using the procedures outlined in the United States Environmental Protection Agency's Code of Federal Regulations [50].

The objectives of this study were to quantify the above emission factors under a range of driving conditions for different HEVs, quantify the total cycle, braking and battery energies, and to describe the impact of the engine operation during a 
drive cycle. The following are the conclusions and recommendations of this study.

\section{Conclusions}

Energy

1. Battery activity is highly dependent on operating temperature. As the ambient temperature decreases, battery activity decreases. Consequently the constituents of battery activity, regenerative braking, ICE battery charging and battery discharging energy, decrease with cold temperatures as well.

2. The hybrid battery pack may provide as much as $11 \%$ of the total cycle energy during a chassis dynamometer test. Regenerative braking energy may be as high as $11 \%$ of the total cycle energy and ICE battery recharging energy reaches $8 \%$ during $20^{\circ} \mathrm{C}$ tests. These energy contributions are associated with increasing the fuel economy of hybrid vehicles.

3. A weak linear correlation was found between the battery energies and gaseous emission factors. This implies that the battery does not contribute enough energy to the vehicle during a drive cycle such that noticable and consistent emission rates decrease.

4. As much as $50 \%$ of braking energy was recovered by the regenerative brakes during testing. Estimates made using computer modelling techniques by other studies predicted $50 \%$ recovery at all times.

\section{Emission Factors}

1. $\mathrm{CO}_{2}$ emissions are less for hybrid vehicles than conventional $\mathrm{SI}$ vehicles, owing to the high fuel economy of these vehicles. 
2. Cold temperature operation increases $C O$ and NMOG emissions, and decreases $\mathrm{NO}_{x}$ emissions. This behaviour is similar for conventional $\mathrm{SI}$ vehicles and may be explained by the increased engine inefficiency during cold temperatures.

3. Cold start and aggressive cycles produce more $\mathrm{CO}, \mathrm{NMOG}, \mathrm{CO}_{2}$ and $\mathrm{CH}_{4}$ emissions because the engine cannot function as effectively at cold temperatures or under very transient power loads. $\mathrm{NO}_{x}$ and $\mathrm{N}_{2} \mathrm{O}$ emissions were a minimum for these cycles because $\mathrm{NO}_{x}$ emission factors are related to engine efficiency and $\mathrm{N}_{2} \mathrm{O}$ emissions are dependent on those of $\mathrm{NO}_{x}$.

\section{Engine-off Time and Engine Restart Count}

1. The number of engine restarts directly influences the gaseous regulated emission factors because of the enriched $A / F$ ratio during ignition. These peak emission rates and test emission factors can be substantially less than those of conventional SI vehicles.

2. Longer engine off times can indirectly produce higher pollutant emissions because of the linear correlation between engine off time and the number of engine restarts during a cycle.

\section{Testing Procedures}

1. The SAE recommended emissions correction for hybrid vehicles was unsuccessful for the tests in this study because the battery net energy change does not strongly correlate to gaseous emissions. Thus, linear interpolation of the zero NEC emissions is not possible. Transient driving operations and short test times may contribute to this effect.

2. Chassis dynamometer augmented braking reduces the regenerative braking energy captured by hybrid vehicles. Therefore, specific procedures for testing 
hybrid vehicles should include the disengagement of augmented braking. Gaseous emissions are not affected by augmented braking because regenerative braking energy does not influence emissions as strongly as other factors, such as fuel consumption.

\section{Recommendations}

\section{Testing Procedures}

1. Hybrid vehicle testing recommendations should explicitly state that the augmented braking function on chassis dynamometers be disengaged while testing hybrid vehicles. Further research should be completed to evaluate the fuel economy, emissions and energy differences between tests conducted using augmented braking and tests conducted without augmented braking. It is expected that although regenerative braking energy may decrease with the use of augmented braking, emissions will not, because regenerative braking is not strongly linearly correlated to emissions.

2. In order to standardize the battery condition before each test, an alternative method to the SAE recommendations should be applied. Conducting more than three tests to find a strong linear correlation between emissions and $N E C$, when, for instance, one is required, is a costly procedure. An alternative testing method is pre-test battery discharging or recharging to a standard $S O C$.

3. Testing that is being done to quantify energy or qualify operational mode should directly collect real-time current and voltage at 0.005 second intervals to ensure a low integration error for energy calculations, and apply OBD SnapOn Scanners to identify the hybrid operational mode. 
Research

1. The influence of engine restarts on emissions may be further explored by controlling the frequency of the engine shutting off. This may be accomplished by pre-setting the $S O C$ to limit battery energy discharge. Thus, the number of extraneous variables during testing may be reduced to determine the true effect of engine restarts on gaseous emissions. The relationship between engine off time and emission rates is complex. It is expected that such research will find that for zero engine off time, there is no correlation between emissions and engine off time.

2. The relationship between hybrid vehicle specific power and emission rates may be analyzed to compare against this same relationship for conventional SI vehicles. This would give a perspective on the use of VSP as a basis for estimations of gaseous emissions in emission models. It is expected that because hybrid vehicles employ a power source that does not produce emissions, $V S P$ is not a good indicator of emission rates.

3. The energy recuperation and consumption patterns of mild hybrid vehicles may be analyzed and compared to those of full hybrid vehicles. Because the energy flow in a hybrid vehicle is highly dependent on the braking strategy employed and the structure of the control algorithm, it is difficult to predict the relationship between these two types of hybrid vehicles. 


\section{Bibliography}

[1] M. Christenson, "The effect of driving conditions and ambient temperature on particulate matter emission rates and size distributions from light duty gasoline-electric hybrid vehicles," Master's thesis, Carleton University, Canada, 2007.

[2] T. M. Chen, J. Gokhale, S. Shofer, and W. G. Kuschner, "Outdoor air pollution: Nitrogen dioxide, sulfur dioxide, and carbon monoxide health effects," Am. J. Med. Sci., vol. 333, no. 4, pp. 249-256, Apr. 2007.

[3] P. Kongtip, W. Thongsuk, W. Yoosook, and S. Chantanakul, "Health effects of metropolitan traffic-related air pollutants on street vendors," Atmos. Environ., vol. 40, no. 37, pp. 7138-7145, Dec. 2006.

[4] (2008, May 15) Health Effects Notebook for Hazardous Air Pollutants. United States Government. [May 15, 2008]. [Online]. Available: http://www.epa.gov/ttn/atw/hlthef/hapindex.html

[5] (Oct. 10, 2007) Test Car List Data. U.S. Environmental Protection Agency. [Apr. 18, 2008]. [Online]. Available: http://www.epa.gov/otaq/tcldata.htm

[6] (2006, Dec.) Emission standards. Ecopoint Inc. [April 18, 2008]. [Online]. Available: http://www.dieselnet.com/standards/ 
[7] R. Stone, Introduction to Internal Combustion Engines. Warrendale: Society of Automotive Engineers, Inc., 1999, pp. 172-173, 175-176, 203-204, 209210.

[8] "Stoichiometric, thermodynamic and kinetic considerations in pollutant formation," Class notes for ENVE5102, Department of Civil and Environmental Engineering, Carleton University at Ottawa, Winter 2007.

[9] N. De Nevers, Air Pollution Control Engineering. New York: McGraw-Hill Higher Education, 2000, pp. 440, 456-457, 477, 484.

[10] S. Hochgreb, "Combustion-Related Emissions in SI Engines," in Handbook of Air Pollution from Internal Combustion Engines, E. Sher, Ed. San Diego: Academic Press, 1998, pp. 125, 139, 141, 145, 148.

[11] N. Sawyer, P. L. McCarty, and G. F. Parkin, Chemistry for Environmental Engineering. Montreal: McGraw-Hill Inc., 1994, pp. 204, 206-207.

[12] Y. Zvirin, M. Gutman, and L. Tartakovsky, "Fuel Effects on Emissions," in Handbook of Air Pollution from Internal Combustion Engines, E. Sher, Ed. San Diego: Academic Press, 1998, p. 559.

[13] J. J. Schauer, M. J. Kleeman, G. R. Cass, and B. R. T. Simoneit, "Measurement of emissions from air pollution sources. 5. C1 - C32 organic compounds from gasoline-powered motor vehicles," Environ. Sci. Technol., vol. 36, no. 6, pp. 1169-1180, 2002, [Jan. 19, 2008]. [Online]. Available: http://dx.doi.org.proxy.library.carleton.ca/10.1021/es0108077

[14] D. Grosjean, E. Grosjean, and A. W. Gertler, "On-road emissions of carbonyls from light-duty and heavy-duty vehicles," Environ. Sci. Technol., 
vol. 35, no. 1, pp. 45-53, 2001, [Nov. 9, 2007]. [Online]. Available: http://dx.doi.org.proxy.library.carleton.ca/10.1021/es001326a

[15] A. Kristensson, C. Johansson, R. Westerholm, E. Swietlicki, L. Gidhagen, U. Wideqvist, and V. Vesely, "Real-world traffic emission factors of gases and particles measured in a road tunnel in Stockholm, Sweden," Atmos. Environ., vol. 38, no. 5, pp. 657-673, Feb. 2004.

[16] L. Graham, "Chemical characterization of emissions from advanced technology light-duty vehicles," Atmos. Environ., vol. 39, no. 13, pp. 23852398, 2005.

[17] Greenhouse Gas Division, "National inventory report, 1990-2005: Greenhouse gas sources and sinks in Canada," Environment Canada, Quebec, Canada, Tech. Rep. Cat. no.: En81-4/2005E, 2007, [April 18, 2008]. [Online]. Available: http://www.ec.gc.ca/pdb/ghg/inventory_e.cfm

[18] P. Forster, V. Ramaswamy, P. Artaxo, T. Berntsen, R. Betts, D. Fahey, J. Haywood, J. Lean, D. Lowe, G. Myhre, J. Nganga, R. Prinn, G. Raga, M. Schulz, and R. Van Dorland, "Changes in atmospheric constituents and in radiative forcing," in Climate Change 2007: The Physical Science Basis. Contribution of Working Group I to the Fourth Assessment Report of the Intergovernmental Panel on Climate Change, S. Solomon, D. Qin, M. Manning, Z. Chen, M. Marquis, K. Averyt, M. Tignor, and H. Miller, Eds. Cambridge: Cambridge University Press, 2007, p. 212.

[19] L. B. Lave and H. L. MacLean, "An environmental-economic evaluation of hybrid electric vehicles: Toyota's Prius vs. its conventional internal combustion engine Corolla," Transport. Res. D-Tr. E, vol. 7, 
no. 2, pp. 155-162, 2002, [Nov. 9, 2007]. [Online]. Available: http://dx.doi.org.proxy.library.carleton.ca/10.1016/S1361-9209(01)00014-1

[20] T. E. Lipman and M. A. Delucchi, "Emissions of nitrous oxide and methane from conventional and alternative fuel motor vehicles," Climatic Change, vol. 53, no. 4, pp. 477-516, 2002.

[21] A. Takigawa, A. Matsunami, and N. Arai, "Methane emission from automobile equipped with three-way catalytic converter while driving," Energy, vol. 30, no. 2-4, pp. 461-473, 2005.

[22] J. Warnatz, U. Maas, and R. W. Dibble, Combustion Physical and Chemical Fundamentals, Modeling and Simulation, Experiments, Pollutant Formation. New York: Springer-Verlag, 2006, p. 265.

[23] H. L. Karlsson, "Ammonia, nitrous oxide and hydrogen cyanide emissions from five passenger vehicles," Sci. Total Environ., vol. 334-335, pp. 125-132, 2004, [Nov. 9, 2007]. [Online]. Available: http://dx.doi.org.proxy.library.carleton.ca/10.1016/j.scitotenv.2004.04.061

[24] H. Hirano, T. Yamada, K. I. Tanaka, J. Siera, P. Cobden, and B. E. Nieuwenhuys, "Mechanisms of the various nitric oxide reduction reactions on a platinum-rhodium (100) alloy single crystal surface," Surf Sci, vol. 262, no. 1-2, pp. 97-112, 1992. [Online]. Available: http://dx.doi.org.proxy.library.carleton.ca/10.1016/0039-6028(92)90463-G

[25] T. Huai, T. D. Durbin, J. W. Miller, and J. M. Norbeck, "Estimates of the emission rates of nitrous oxide from light-duty vehicles using different chassis dynamometer test cycles," Atmos. Environ., vol. 38, no. 38, pp. 6621-6629, 2004. 
[26] E. Behrentz, R. Ling, P. Rieger, and A. M. Winer, "Measurements of nitrous oxide emissions from light-duty motor vehicles: A pilot study," Atmos. Environ., vol. 38, no. 26, pp. 4291-4303, 2004.

[27] M. Takei, H. Matsuda, Y. Itaya, S. Deguchi, K. Nakano, K. Nagahashi, M. Yoshino, J. Shibata, and M. Hasatani, "NO reduction and the formation of nitrogen compounds over a metal-supported three-way catalyst," Fuel, vol. 77, no. 9-10, pp. 1027-1031, July 1998.

[28] B. K. Cho, B. H. Shank, and J. E. Bailey, "Kinetics of NO reduction by CO over supported rhodium catalysts: Isotopic cycling experiments," J. Catal., vol. 115, no. 2, pp. 486-499, 1989.

[29] G. De Soete, "Nitrous oxide from combustion and industry: Chemistry, emissions and control," Rev. I. Fr. Petrol., vol. 48, no. 4, pp. 413-451, 1993.

[30] K. H. Becker, J. C. Lorzer, R. Kurtenbach, P. Wiesen, T. E. Jensen, and T. J. Wallington, "Nitrous oxide (N2O) emissions from vehicles." Environ. Sci. Technol., vol. 33, no. 22, pp. 4134-4139, 1999.

[31] T. Beer, T. Grant, H. Watson, and D. Olaru, "Life-cycle emissions analysis of fuels for light vehicles," Australian Government, Victoria, Australia, Tech. Rep. HA93A-C837/1/F5.2E, May 2004, [April 18, 2008]. [Online]. Available: http://www.environment.gov.au/settlements/transport/publications/ lightvehicles.html

[32] K. Aoki, S. Kuroda, S. Kajiwara, H. Sato, and Y. Yamamoto, "Development of integrated motor assist hybrid system: Development of the 'Insight', a personal hybrid coupe," SAE Technical Paper Series, no. 2000-01-2216, 2000. 
[33] J. Miller, "Hybrid electric vehicles," in Handbook of Automotive Power Electronics And Motor Drives, A. Emadi, Ed. Boca Raton: Taylor \& Francis, 2005, p. 30.

[34] J. R. Cogdell, Foundations of Electric Power. Upper Saddle River: Prentice Hall, Inc., 1999, p. 306.

[35] J. M. Miller. (2004) Propulsion Systems for Hybrid Vehicles. [April 18, 2008]. [Online]. Available: $\mathrm{http}: / / \mathrm{www} \cdot$ books24x7.com/login.asp?ic=0

[36] M. Ehsani. (2005) Modern Electric, Hybrid Electric, and Fuel Cell Vehicles: Fundamentals, Theory, and Design. [April 18, 2008]. [Online]. Available: http://engnetbase.com/

[37] C. C. Chan, "The state of the art of electric and hybrid vehicles," P. IEEE, vol. 90, no. 2, pp. 247-275, 2002, [Nov. 9, 2007]. [Online]. Available: http://dx.doi.org.proxy.library.carleton.ca/10.1109/5.989873

[38] Y. Gao, M. Ehsani, and J. M. Miller, "Hybrid electric vehicle: Overview and state of the art," in Proceedings of the IEEE International Symposium on Industrial Electronics, vol. 1, June 20-23, 2005, pp. 307-322.

[39] M. Duoba, T. Bohn, and H. Lohse-Busch, "Investigating possible fuel economy bias due to regenerative braking in testing HEVs on 2WD and 4WD chassis dynamometers," SAE Technical Paper Series, no. 2005-01-0685, 2005.

[40] F. Wicks and K. Donnelly, "Modeling regenerative braking and storage for vehicles," in IECEC-97 Proceedings of the Thirty-Second Intersociety Energy Conversion Engineering Conference (Cat. No.97CH6203), vol. 3, July 27 Aug. 1, 1997, pp. 2030-2035. 
[41] L. Jeongwoo and D. J. Nelson, "Rotating inertia impact on propulsion and regenerative braking for electric motor driven vehicles," in 2005 IEEE Vehicle Power and Propulsion Conference, VPPC, Sep. 7-9, 2005, pp. 308-314, [Nov. 9, 2007]. [Online]. Available: http://dx.doi.org.proxy.library.carleton.ca/10.1109/VPPC.2005.1554575

[42] Y. Gao, L. Chen, and M. Ehsani, "Investigation of the effectiveness of regenerative braking for EV and HEV ," SAE Technical Paper Series, no. 199901-2910, 1999.

[43] Society of Automotive Engineers, "Surface vehicle recommended practice Recommended practice for measuring fuel economy and emissions of hybridelectric and conventional heavy-duty vehicles," SAE International, no. J2711, 2002.

[44] Society of Automotive Engineers, "Surface vehicle recommended practice Recommended practice for measuring the exhaust emissions, fuel economy, electrical energy consumption, and all-electric range of hybrid-electric vehicles," SAE International, no. J1711, 1995.

[45] FreedomCAR \& Vehicle Technologies Program, "Annual progress report for advanced vehicle technology analysis and evaluation activities," U.S. Department of Energy, District of Columbia, United States of America, Tech. Rep., 2003, [April 18, 2008]. [Online]. Available: http://www1.eere.energy.gov/vehiclesandfuels/resources/printable_versions/ fcvt_reports.html

[46] A. Takamura, M. Ono, and S. Ohigashi, "Chassis dynamometer provided with control device simulating road load," SAE Preprints, no. 800324, pp. 14-29, 1980. 
[47] MAHA Maschinenbau Haldenwang GmbH \& Co. KG., "Chassis dynamometer LPS 3000 for trucks standard operating instructions and user's manual," MAHA GMBH \& CO. KG., Haldenwang, Germany, Tech. Rep. D1 0524BA1-GB01, 2005, [April 18, 2008]. [Online]. Available: http://www.maha.de/datenbank/support/ba/books/gb/0524B01G.pdf

[48] Society of Automotive Engineers, "Surface vehicle recommended practice - Road load measurement and dynamometer simulation using coastdown techniques," SAE International, no. J1263, 1996.

[49] Society of Automotive Engineers, "Surface vehicle recommended practice Chassis dynamometer simulation of road load using coastdown techniques," SAE International, no. J2264, 1995.

[50] Code of Federal Regulations Title 40, Protection of the Environment, U.S. Environmental Protection Agency Std., Mar. 6, 2008, [April 18, 2008]. [Online]. Available: http://www.epa.gov/lawsregs/search/40cfr.html

[51] T. C. Austin, F. J. DiGenova, T. R. Carlson, R. W. Joy, K. A. Gianolini, and J. M. Lee, "Characterization of driving patterns and emissions from light-duty vehicles in California," California Air resource board, California, United States of America, Contract No. A932-185, Nov. 1993, [April 18, 2008]. [Online]. Available: http://www.arb.ca.gov/research/abstracts/a932-185.htm

[52] H. Ogawa, M. Matsuki, and T. Eguchi, "Development of a power train for the hybrid automobile - The Civic Hybrid," SAE Technical Paper Series, no. 200301-0083, 2003.

[53] K. Muta, Y. Tokieda, and J. Tokieda, "Development of new-generation hybrid system THS II - Drastic improvement of power performance and fuel economy," SAE Technical Paper Series, no. 2004-01-0064, 2004. 
[54] H. L. Husted, "A comparative study of the production applications of hybrid electric powertrains," SAE Technical Paper Series, no. 2003-01-2307, 2003.

[55] P. Valdes-Dapena. (2007, Sep. 25) Toyota Prius just keeps on going. Cable News Network. [April 18, 2008]. [Online]. Available: http://money.cnn.com/2007/09/24/autos/prius_keeps_going/index.htm

[56] P. Valdes - Dapena. (2004, August 4) Green groups: Ford still worst on fuel. Cable News Network. [April 18, 2008]. [Online]. Available: http://money.cnn.com/2004/08/04/pf/autos/ran_vs_ford/index.htm

[57] L. Graham, M. Christenson, and A. Loiselle, "The effect of driving conditions and ambient temperature on light duty gasoline-electric hybrid vehicles (2): Fuel consumption and gaseous pollutant emission rates," SAE Technical Paper Series, no. 2007-01-2137, 2007.

[58] (2006) CAI. California Analytical Instruments. [April 18, 2008]. [Online]. Available: http://www.gasanalyzers.com

[59] T. Huai, T. D. Durbin, T. Younglove, G. Scora, M. Barth, and J. M. Norbeck, "Vehicle specific power approach to estimating onroad $\mathrm{NH}_{3}$ emissions from light-duty vehicles," Environ. Sci. Technol., vol. 39, no. 24, pp. 9595-9600, 2005, [Nov. 15, 2007]. [Online]. Available: http://dx.doi.org.proxy.library.carleton.ca/10.1021/es050120c; http://dx.doi.org.proxy.library.carleton.ca/10.1021/es050120c

[60] J. Van Mierlo, P. Van den Bossche, and G. Maggetto, "Models of energy sources for EV and HEV: Fuel cells, batteries, ultracapacitors, flywheels and engine-generators," J. Power Sources, vol. 128, no. 1, pp. 76-89, March, 2004. 
[61] E. Nam, "Proof of concept for the physical emission rate estimator (PERE) to be used in MOVES," U.S. Environmental Protection Agency, Disctrict of Columbia, United States of America, Tech. Rep. EPA420-R-03-005, Feb. 2003, [April 18, 2008]. [Online]. Available: http://www.epa.gov/otaq/ngm.htm

[62] L. Prout, "Aspects of lead/acid battery technology 10. cold-start performance," J. Power Sources, vol. 51, no. 3, pp. 463-487, 1994, [Feb. 12, 2008]. [Online]. Available: http://dx.doi.org.proxy.library.carleton.ca/10.1016/03787753(94)80114-2

[63] A. Jossen, "Fundamentals of battery dynamics," J. Power Sources, vol. 154, no. 2, pp. 530-538, Mar. 2006, [July 18, 2007]. [Online]. Available: http://dx.doi.org.proxy.library.carleton.ca/10.1016/j.jpowsour.2005.10.041

[64] B. W. Ang, T. F. Fwa, and C. K. Poh, "Statistical study on automobile fuel consumption," Energy, vol. 16, no. 8, pp. 1067-1077, 1991. 